
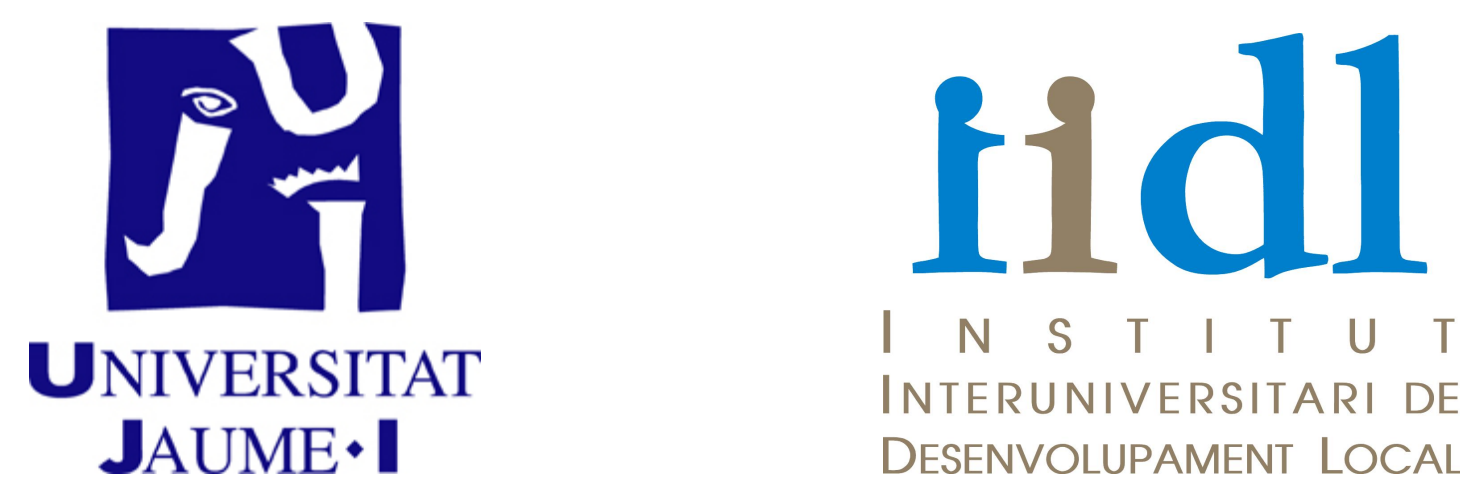

$\begin{array}{lllllll}N & S & T & I & T & U & T\end{array}$

INTERUNIVERSITARI DE DESENVOLUPAMENT LOCAL

\title{
"EL SECTOR AGRÍCOLA MEXICANO Y EL TRATADO DE LIBRE COMERCIO DE AMÉRICA DEL NORTE"
}

\author{
TESIS \\ PARA OBTENER EL GRADO DE \\ DOCTORA EN COOPERACIÓN AL DESARROLLO \\ POR
}

GUADALUPE YAMIN ROCHA

DIRECTOR: JAVIER ORDOÑEZ MONFORT

Castellón de la plana, España, octubre de 2015. 
A mis padres, José y Guadalupe, por darme la maravillosa oportunidad de estudiar y por enseñarme a amar a mi patria, México. 


\section{ÍNDICE}

Lista de cuadros y gráficos

Introducción.

\section{Población y territorio}

1.1 Aspectos geográficos

1.2 Población

1.3 Trabajo

1.4 Producto Interno Bruto

1.6 Características de los consumidores

\section{Integración económica generada por el Tratado de Libre} Comercio de América del Norte

2.1 Teoría de la integración económica

2.2 Proceso de liberalización económica de México.

2.3 La negociación entre los países firmantes del TLCAN.

2.4 Sector agrícola en el TLCAN

\section{Sector agrícola en México.}

3.1 Conceptos económicos generales

\subsubsection{Commodity}

3.1.2 Volatilidad de precios

3.1.3 Índices Nacionales de Precios

3.1.4 Ciclos productivos y modalidades de producción

3.2 Grupos de productos ofertados

3.2.1 Maíz.

3.2.2 Hortalizas.

3.2.3 Frutas.

3.3 Comercio exterior de productos ofertados

3.3.1 Maíz grano.

3.3.2 Hortalizas.

3.3.3 Frutas. 
3.3.4 Flores.

3.3.5 Trigo.

3.3.6 Frijol.

3.3.7 Oleaginosas

3.3.8 Sorgo

3.4 Precios internacionales de cultivos seleccionados

3.5 Balanza comercial

4. Desempeño agrícola en el Estado de México.

4.1 Antecedentes históricos de los ordenamientos jurídicos en materia de agricultura en el Estado de México.

4.2 Actividad del sector agrícola en el Estado de México por ciclo productivo y sus rendimientos

4.2.1 Primavera-Verano

a) Superficie sembrada

b) Superficie siniestrada

c) Volúmenes cosechados

d) Rendimientos

4.2.2. Otoño-Invierno
a) Superficie sembrada
b) Superficie siniestrada
C) Volúmenes cosechados
d) Rendimientos

4.2.3. Perennes
a) Superficie sembrada
b) Volúmenes cosechados
c) Rendimientos

4.3. Principales cultivos comercializados por el Estado de México con el mundo.

5. Valor de la producción agrícola del Estado de México

5.1. Valor de producción por municipio.

5.2. Valor de producción por cultivo

5.3. Comportamiento histórico de los precios pagados al productor de los principales cultivos agrícolas en el Estado de México. 
5.3.1. Precios de los principales cereales

5.3.2. Precios de los principales cultivos de plantas y flores......

5.3.3. Precios de los principales cultivos de hortalizas.

5.3.4. Precios de los principales cultivos forrajeros

5.3.5. Precios de los principales cultivos frutales

5.3.6. Precios de los principales cultivos por ciclo y modalidad productiva.

5.4. Comparativo de los ciclos productivos y sus rendimientos

\section{Cambios estructurales en los precios para los commodities} seleccionados.

6.1. Pruebas estacionarias y de raíz unitaria.

6.2. Contraste de raíz unitaria con cambios estructurales

6.3. Conclusiones

\section{Conclusiones}

Apéndice estadístico.

Notas

Bibliografía.

Glosario 


\section{LISTA DE CUADROS Y GRÁFICOS}

\section{CUADROS}

2.1 Niveles de integración económica

2.2 Asimetrías entre México, Estado Unidos y Canadá

2.3 Proceso de liberalización de productos alimentarios seleccionados en el marco del TLCAN (1989-2008)

3.1 Componentes de los commodities del sector primario

3.2 Características del INP

3.3 PIB anual según sectores económicos 1989-2011

3.4 Maíz grano: comparativo de la superficie sembrada del ciclo O-I, 1980-2010

3.5 Maíz grano: comparativo del valor de la producción del ciclo O-I, 1980-2010

3.6 Maíz grano: comparativo de la superficie sembrada del ciclo P-V, 1980-2010

3.7 Maíz grano: comparativo del valor de la producción del ciclo P-V, 1980-2010

3.8 Maíz grano: rendimiento promedio anual (tons./ha), 1980-2010

3.9 Exportaciones de frutas de México

3.10 Estadísticas mundiales de oleaginosas

3.11 Estadísticas mundiales de sorgo

3.12 Comportamiento del maíz grano en México 1980-2010

3.13 Comportamiento del sorgo grano en México 1980-2010

4.1 Superficie sembrada (has), ciclo P-V de temporal

4.2 Superficie sembrada (has), ciclo P-V de riego

4.3 Superficie sembrada promedio anual (has), ciclo P-V de riego

4.4 Superficie siniestrada (has), ciclo P-V de riego

4.5 Volumen de producción (ton), ciclo P-V de temporal

4.6 Volumen de producción (ton), ciclo P-V de riego

4.7 Rendimientos (tons/has), ciclo P-V de temporal (var \%)

4.8 Rendimientos (tons/has), ciclo P-V de riego (var \%)

4.9 Superficie sembrada (has), ciclo O-I de riego 
4.10 Superficie sembrada (has), ciclo O-I de temporal

4.11 Volumen de producción (ton), ciclo O-I de riego

4.12 Volumen de producción (ton), ciclo O-I de temporal

4.13 Rendimientos (tons/has), ciclo O-I riego (var \%)

4.14 Superficie cosechada (has), ciclo perennes de temporal

4.15 Superficie cosechada (has), ciclo perennes de riego

4.16 Volumen de producción (ton), ciclo perennes de riego

4.17 Volumen de producción (ton), ciclo perennes de temporal

4.18 Rendimientos (tons/has), ciclo perennes de riego (var \%)

4.19 Rendimientos (tons/has), ciclo perennes de temporal (var \%)

4.20 Comercio exterior de productos agropecuarios y pequeros por entidad federativa al 2011

4.21 Comercio exterior agrícola del Estado de México al 2011 (mdp)

5.1 Valor de producción (mdp) de los ciclos productivos en el Estado de México

5.2 Principales variables por municipios productores en el Estado de México para maíz grano (2003 y 2010)

5.3 Principales variables por municipios productores en el Estado de México para crisantemo (2003 y 2010)

5.4 Principales variables por municipios productores en el Estado de México para pasto (2003 y 2010)

5.5 Principales variables por municipios productores en el Estado de México para papa (2003 y 2010)

5.6 Variación porcentual anual de los Índices de Precios al Productor para cereales en el Estado de México (2000-2010)

5.7 Variación porcentual anual de los Índices de Precios al Productor para plantas y flores en el Estado de México (2000-2010)

5.8 Variación porcentual anual de los Índices de Precios al Productor para hortalizas en el Estado de México (2000-2010)

5.9 Variación porcentual anual de los Índices de Precios al Productor para forrajes en el Estado de México (2000-2010)

5.10 Variación porcentual anual de los Índices de Precios al Productor para frutas en el Estado de México (2000-2010) 
5.11 Volumen de producción (\%) por ciclo productivo en el Estado de México 1980-2010

5.12 Valor de producción (pesos) por ciclo productivo en el Estado de México 1980-2010

5.13 Volumen de producción (toneladas) de maíz grano por ciclo productivo en el Estado de México

5.14 Volumen de producción (toneladas) de maíz forrajero por ciclo productivo en el Estado de México

5.15 Superficie siniestrada (hectáreas) por ciclo productivo en el Estado de México

6.1 Periodo analizado por commodity

6.2 Prueba $A D F^{G L S}$ de raíz unitaria para precios de commodities seleccionados

6.3 Prueba KPSS de estacionariedad para precios de commodities seleccionados

6.4 Prueba Perron-NG de raíz unitaria para precios de commodities seleccionados

6.5 Prueba Perron-Rodríguez de raíz unitaria con cambio en tendencia para precios de commodities seleccionados

6.6 Prueba Lumsdaine-Papell de raíz unitaria y dos cambios estructurales para precios de commodities seleccionados

6.7 Prueba Lee-Strazicich de raíz unitaria y dos cambios estructurales para precios de commodities seleccionados

7.1 Estructura de las unidades de producción rural 1991 y 2007

8.1 Cultivos de seguimiento mensual

8.2 Calendario agrícola

\section{GRÁFICOS}

1.1 División municipal y colindancias del Estado de México

1.2 Climas del Estado de México

1.3 Distribución de la temperatura en el Estado de México 
1.4 Distribución de la precipitación en el Estado de México

1.5 Hidrografía del Estado de México

1.6 Uso potencial agrícola del Estado de México

1.7 Población urbana y rural de México

1.8 Principales indicadores demográficos del Estado de México

1.9 Población total por grupo quinquenal de edad según sexo del Estado de México en 2010

1.10 Población total por grupo quinquenal de edad según sexo del Estado de México en 2010

1.11 Ocupación y tasa de participación en el sector primario de la población del Estado de México en 1990

1.12 Ocupación y tasa de participación en el sector primario de la población del Estado de México en 2000

1.13 Ocupación y tasa de participación en el sector primario de la población del Estado de México en 2010

1.14 Población ocupada por sector de actividad económica según sexo al primer trimestre de 2010

1.15 Distribución porcentual del producto interno bruto en valores básicos por entidad federativa

1.16 Producto interno bruto por sector de actividad económica del Estado de México. Serie anual de 2003 al 2011

2.1 Competitividad de los sectores agroalimentarios de México y EEUU en la región del TLCAN (1961-2001)

2.2 Presupuesto real para el desarrollo rural de México, 1990-2002 (millones de pesos de 2011)

2.3 Estimación de los apoyos a la agricultura en Estados Unidos, Canadá y México, 1986-2001 (\% del valor de la producción)

3.1 Superficie sembrada en México por grupo de productos

3.2 Volumen de Producción en México por grupo de productos

3.3 Maíz grano otoño-invierno de riego

3.4 Maíz grano otoño-invierno de temporal

3.5 Maíz grano primavera-verano de temporal

3.6 Maíz grano primavera-verano de riego

3.7 Producción de hortalizas 2006-2010

3.8 Volumen de las exportaciones e importaciones de maíz de 1992-2011

3.9 Valor de las exportaciones e importaciones de maíz de 1992-2011 
3.10 Valor de las exportaciones de hortalizas de 1993-2011

3.11 Valor de las exportaciones de frutas de 1993-2011

3.12 Superficie sembrada de ornamentos en México

3.13 Exportaciones de flores mexicanas

3.14 Volumen de las exportaciones e importaciones de trigo de 1992-2011

3.15 Valor de las exportaciones e importaciones de trigo de 1992-2011

3.16 Volumen de las exportaciones e importaciones de frijol 1992-2011

3.17 Valor de las exportaciones e importaciones de frijol 1992-2009

3.18 Superficie de maíz grano en México

3.19 Superficie de sorgo grano en México

3.20 Volumen de las exportaciones e importaciones de sorgo 1992-2011

3.21 Valor de las exportaciones e importaciones de sorgo 1992-2011

3.22 Precio internacional del maíz amarillo y blanco

3.23 Precio internacional del trigo

3.24 Precio internacional del frijol

3.25 Precio internacional de la soya

3.26 Balanza comercial de México 1993-2011

3.27 Balanza agropecuaria, pesquera y agroindustrial de México

4.1 Superficie promedio anual sembrada de 2000 a 2010 (\%), ciclo P-V de temporal

4.2 Superficie promedio anual sembrada de 2000 a 2010 (\%), ciclo P-V de riego

4.3 Superficie promedio anual siniestrada de 2000 a 2010 (\%), ciclo P-V de temporal

4.4 Superficie promedio anual siniestrada de 2000 a 2010 (\%), ciclo $\mathrm{P}-\mathrm{V}$ de riego

4.5 Volumen de producción promedio anual de 2000 a 2010 (\%), ciclo P-V de temporal

4.6 Volumen de producción promedio anual de 2000 a 2010 (\%), ciclo P-V de riego

4.7 Superficie promedio anual sembrada de 2000 a 2010 (\%), ciclo O-I de riego

4.8 Superficie promedio anual siniestrada (has), ciclo O-I de temporal 
4.9 Superficie promedio anual siniestrada (has), ciclo O-I de riego

4.10 Volumen de producción promedio anual de 2000 a 2010 (\%), ciclo O-I de riego

4.11 Volumen de producción promedio anual de 2000 a 2010 (\%), ciclo O-I de temporal

4.12 Superficie promedio anual cosechada de 2000 a 2010 (\%), ciclo perennes de temporal

4.13 Superficie promedio anual cosechada de 2000 a 2010 (\%), ciclo perennes de riego

4.14 Volumen de producción promedio anual de 2000 a 2010 (\%), ciclo perennes de riego

5.1 Valor de producción promedio anual por cultivo en el Estado de México 2003-2010 (mdp)

5.2 Valor de producción promedio anual por municipio en el Estado de México 2003-2010 (mdp)

5.3 Participación porcentual por municipio en el valor total de la producción del Estado de México 2003-2010 (mdp)

5.4 Promedio anual del valor de producción por cultivo 2003-2010 (mdp) para el municipio de Villa Guerrero

5.5 Promedio anual del valor de producción por cultivo 2003-2010 (mdp) para el municipio de Coatepec Harinas

5.6 Promedio anual del valor de producción por cultivo 2003-2010 (mdp) para el municipio de Tenancingo

5.7 Promedio anual del valor de producción por cultivo 2003-2010 (mdp) para el municipio de Jocotitlán

5.8 Promedio anual del valor de producción por cultivo 2003-2010 (mdp) para el municipio de Tlatlaya

5.9 Promedio anual del valor de producción por cultivo 2003-2010 (mdp) para el municipio de Tlatlaya

5.10 Superficie promedio anual sembrada en el Estado de México 2003- 2010 (miles de hectáreas)

5.11 Participación porcentual en la superficie sembrada total del Estado de México por 2003- 2010 (miles de hectáreas)

5.12 Variación porcentual anual de los Índices de Precios al Productor para los principales cultivos del Estado de México (1981-2010)

5.13 Variación porcentual anual de los Índices de Precios al Productor para cereales a nivel nacional y en el Estado de México (1981-2010) 
5.14 Variación porcentual anual de los Índices de Precios al Productor para hortalizas a nivel nacional y en el Estado de México (1981-2010)

5.16 Precio medio rural promedio anual 2000-2010 por ciclo productivo en el Estado de México (pesos/toneladas)

5.17 Volumen de producción agrícola (\%) por ciclo productivo en el Estado de México 1980-1990

5.18 Volumen de producción agrícola (\%) por ciclo productivo en el Estado de México 1990-2000

5.19 Volumen de producción agrícola (\%) por ciclo productivo en el Estado de México 2000-2010

5.20 Valor de producción agrícola (pesos) promedio por ciclo productivo en el Estado de México 1980-1990

5.21 Valor de producción agrícola (pesos) promedio por ciclo productivo en el Estado de México 1990-2000

5.22 Valor de producción agrícola (pesos) promedio por ciclo productivo en el Estado de México 2000-2010

5.23 Volumen de producción (toneladas y \%) de maíz grano por ciclo productivo en el Estado de México 1980-1990

5.24 Volumen de producción (toneladas y \%) de maíz grano por ciclo productivo en el Estado de México 1990-2000

5.25 Volumen de producción (toneladas y \%) de maíz grano por ciclo productivo en el Estado de México 2000-2010

5.26 Volumen de producción (toneladas y \%) de maíz forrajero por ciclo productivo en el Estado de México 1980-1990

5.27 Volumen de producción (toneladas y \%) de maíz forrajero por ciclo productivo en el Estado de México 1990-2000

5.28 Volumen de producción (toneladas y \%) de maíz forrajero por ciclo productivo en el Estado de México 2000-2010

5.29 Superficie siniestrada (hectáreas) por ciclo productivo en el Estado de México 1980-1990

5.30 Superficie siniestrada (hectáreas) por ciclo productivo en el Estado de México 1990-2000

5.31 Superficie siniestrada (hectáreas) por ciclo productivo en el Estado de México 2000-2010

6.1 Precios de commodities seleccionados en México 


\section{INTRODUCCIÓN}

La agricultura ha sido, desde sus orígenes hasta nuestros días, la principal actividad del hombre. Actividad que le genera el alimento necesario para subsistir. Esta noble actividad ahora se enfrenta a factores como las consecuencias negativas en la salud de los alimentos transgénicos y de la carne animal contaminada por la ingesta que éstos tienen de sustancias tóxicas para el hombre. Adicionalmente, es afectada por variables como las sequías, los desastres naturales, los conflictos bélicos, la aparición de nuevos consumidores, el aumento en la demanda de ciertas materias primas para la producción de agrocombustibles, así como el uso de elementos especulativos como son los futuros en las bolsas de valores.

Los alimentos han perdido su valor de alimentar y han adquirido valor en función de los beneficios económicos que sean capaces de generar. En otras palabras, su valor se mide en términos monetarios por el impacto que tiene este sector productivo en el Producto Interno Bruto (PIB), la balanza comercial, entre otras variables. Este mundo económicamente globalizado tiene que dar cuenta sobre aquellos que no tienen una capacidad de consumo básica y por qué. Debe explicar además por qué hay países que, a pesar de contar con los recursos naturales suficientes, no tienen la capacidad de producir los alimentos que su población demanda.

Sin embargo, la agricultura puede ser observada también desde los impactos benéficos que genera en la sociedad. En este sentido, influye directamente sobre las industrias de insumos y transformación, el transporte, los servicios y el comercio. Adicionalmente, por ser la base de la alimentación, genera empleos y divisas, promueve la paz en el medio rural; si se realiza desde el respeto también protege al medio ambiente y a la biodiversidad. Sin olvidar que es parte fundamental de nuestra identidad nacional (Gómez Cruz, Manuel Ángel y Rita Schwentesius 2004: 51).

Desde la segunda mitad de la década de los setenta, la agricultura y la sociedad rural de nuestro país enfrentan una crisis estructural. Es posible observar pues, la pérdida de crecimiento, la baja contribución al PIB nacional, 
la disminución de la productividad, el deterioro de los términos de intercambio intersectorial, la incapacidad de satisfacer las necesidades del mercado interno, la insuficiente diversificación de las agro exportaciones, la descapitalización de los productores, el bajo valor agregado de la producción agropecuaria, la pérdida de ingresos y la depauperación acelerada de los campesinos, el creciente deterioro de los niveles de alimentación de grandes sectores de la población rural y urbana, el desempleo y subempleo rural, la migración hacia las ciudades y a los Estados Unidos, la afectación grave en la renovabilidad de los agro recursos, la pérdida de la cohesión social en el campo y la expansión del cultivo de estupefacientes.

México ha perdido su capacidad productiva. Las décadas han dejado en el olvido un campo proveedor de suficientes alimentos para su población. Si analizamos la situación desde dentro, tropezamos con un sin número de políticas públicas de corto plazo, cada una con objetivos distintos, cada una reflejo de los estilos de los gobernantes en turno.

La liberalización de la economía es un fenómeno mundial que se consolidó en la década de los años ochenta. México no resultó exento a este proceso y en 1994 entra en vigor su acuerdo comercial con Estados Unidos y Canadá, el Tratado de Libre Comercio de América del Norte (TLCAN). Este instrumento fue, y sigue siendo, duramente criticado, pues se consideraba que México no compartía condiciones económicas para intercambiar, sin aranceles, productos con dos países más desarrollados.

Dentro de los sectores económicos que se consideraron los más vulnerables, se mencionaba a la agricultura. Pero únicamente el tiempo comprobaría o refutaría la afirmación de que el campo mexicano no tenía oportunidad alguna de competir con los socios comerciales del TLCAN.

Desde su firma, se han generado numerosos estudios e investigaciones que pretenden analizar qué impactos tuvo la firma de este acuerdo comercial sobre el campo mexicano. También se ha estudiado tanto la pertinencia de este acuerdo comercial como sus fallas. Estos estudios han sido generales, es decir, han tomado en cuenta la totalidad de la geografía nacional y la producción de bienes agropecuarios. Y también específicos, se ha estudiado de 
manera particular el caso del maíz, por ejemplo, o del frijol, tanto a nivel nacional como en algunos estados de la federación. Sin embargo, entre la literatura consultada, está ausente el estudio del impacto del Tratado en los precios de los productos agrícolas y su comparación con los volúmenes de producción. La hipótesis de la presente investigación es que el proceso de implementación del TLCAN en México impactó al alza el precio de ciertos commodities en México. Es decir, que la desgravación comercial que se genera a partir de su firma nos ayuda a explicar el comportamiento de los precios de los alimentos en México. Para ello, el objetivo general de la presente investigación es:

- $\quad$ Analizar el impacto del TLCAN en el precio de ciertos commodities en el Estado de México.

Y los objetivos específicos son:

- Analizar qué commodities se producen en mayor volumen en México y en el Estado de México.

- $\quad$ Estudiar qué ciclos productivos tienen mayores rendimientos.

- Analizar qué modalidades de producción tienen mayores rendimientos.

- Estudiar si los precios de los commodities que se producen en mayor volumen en México y el Estado de México son impactados por el proceso de desgravación comercial generado por la firma del TLCAN.

Para llevar a buen puerto esta investigación, y debido a que será presentada en una universidad extranjera, comenzaremos por bosquejar las principales características de la población en el Estado de México, para que el lector cuente con los elementos esenciales para la comprensión del tema. Resulta importante conocer algunos de estos datos para comprender la importancia que tiene la agricultura en esta entidad federativa.

Como lo hemos comentado, el TLCAN fue el resultado de una política de liberalización comercial mexicana. Esta política comenzó casi treinta años antes de la firma del acuerdo en mención, lapso de tiempo en el que se generaron 
otros tratados comerciales y en el que México se posicionó, a nivel América Latina, como país modelo en cuestiones económicas. En el capítulo segundo abordaremos, de manera concisa, los antecedentes comerciales y el contenido de este acuerdo comercial. El contenido arrojará la calendarización de desregulación por producto comercial, misma que nos permitirá realizar una comparación con los índices de precios de los alimentos en México. De igual forma, se estudiarán aspectos teóricos de los procesos de integración económica para entender qué tipo de acuerdo comercial estamos estudiando.

Una vez que conocemos el marco legal del tratado en comento, daremos paso a analizar el sector agrícola en México. Para ello, en el primer apartado se introducirán conceptos económicos generales como commodity, volatilidad de precios, Índices Nacionales de Precios, ciclos productivos y modalidades de producción. Aquí se especificará por qué será utilizado el término commodity en lugar de producto agrícola y por qué los precios que serán utilizados para analizar los volúmenes de producción serán los del Índice de Precios al Productor y no los del Índice de Precios al Consumidor. Se identificarán también los commodities a analizar, su producción anual y cómo participan de la balanza comercial del país.

En el capítulo cuarto se estudiará el desempeño agrícola en el Estado de México. Primeramente se mencionarán los ordenamientos jurídicos en materia de agricultura del Estado de México para tener un referente legal. En segundo lugar, se estudiará la actividad del sector agrícola por ciclo productivo, indicando sus rendimientos. Este apartado nos permitirá analizar qué ciclo productivo y bajo qué modalidad de producción se genera un volumen de producción mayor. Por último, se estudiará cuáles son los principales cultivos que se comercializan por el Estado de México.

El capítulo quinto corresponderá al análisis del valor de la producción agrícola en la entidad federativa en estudio. Se estudiarán qué valor tiene la producción por municipio y por cultivo, para posteriormente analizar el comportamiento histórico de los precios pagados al productor de los principales cultivos del estado. Concluiremos este capítulo realizando un comparativo entre los ciclos productivos y sus rendimientos. 
Para los capítulos tercero, cuarto y quinto el tipo de metodología empleada será no experimental cuantitativa, aquella que se realiza sin manipular variables deliberadamente. Consiste en la observación del fenómeno tal como se da en su contexto natural, para después analizarlo. Se recomienda la investigación no experimental en los casos en que las variables no pueden o no deben ser manipuladas. En cuanto al enfoque no experimental, resulta el adecuado cuando necesitamos evaluar una situación, comunidad, evento, fenómeno o contexto en un punto del tiempo.

A diferencia de los anteriores, en el capítulo sexto se empleará el método econométrico para analizar el comportamiento de los precios de los commodities indicados en el capitulo tercero, que son: avena forrajera, cebada, frijol, maíz grano, papa, pasto, sorgo y trigo. Específicamente, se aplicarán contrastes de raíz unitaria y estacionariedad a la hipótesis a fin de estudiar cambios estructurales en el precio de los commodities. De cada uno de ellos. Concretamente, en este capitulo se comprobará o refutará la hipótesis de la presente investigación haciendo uso de la econometría.

En las conclusiones, además de dar cumplimiento a los planteamientos de cada capítulo, se enumerarán un serie de recomendaciones generales que sirvan para analizar las políticas públicas agrícolas existentes o bien, para la elaboración de políticas que permitan mejorar los rendimientos agrícolas de México. 


\section{CAPITULO 1 \\ POBLACIÓN Y TERRITORIO}

En México la variedad de la oferta de productos agroalimentarios tiene como origen la vocación productiva de sus 32 entidades federativas. En cada una se mezcla una complejidad de relaciones culturales, sociales, políticas y económicas, que al mismo tiempo convergen en la producción de los alimentos que se consumen, no sólo en el país, sino más allá de sus fronteras.

Para llevar a buen puerto esta investigación, y debido a que será presentada en una universidad extranjera, se bosquejarán las principales características de la población en el Estado de México, para que el lector cuente con los elementos esenciales para la comprensión del tema. Resulta importante conocer quiénes son los protagonistas, cuáles son las características del terreno que da alimentos, cuáles son las potencialidades y áreas de oportunidad para comprender la importancia que tiene la agricultura en esta entidad federativa.

Por tanto, corresponde a este capítulo iniciar con la caracterización del territorio y población del Estado de México con el fin de determinar los elementos esenciales sobre los cuáles se va configurando su vocación productiva, sus fortalezas, debilidades y oportunidades. Cabe señalar que la información de este capitulo se tomó del Anuario estadístico y geográfico del Estado de México 2013 del Instituto Nacional de Estadística y Geografía (INEGI).

\subsection{Aspectos geográficos}

El Estado de México tiene una extensión de 22 mil 357 kilómetros cuadrados, lo que representa $1.1 \%$ de la superficie del país. El territorio mexiquense se encuentra en las provincias fisiográficas denominadas Sierra Madre del Sur y Eje Neovolcánico. La entidad colinda con el Distrito Federal y con los estados de Querétaro, Hidalgo, Tlaxcala, Puebla, Morelos, Guerrero y 
Michoacán. Adicionalmente, se divide políticamente en 120 municipios, siendo Toluca su capital. (Ver gráfico 1.1 División municipal y colindancias del Estado de México)

En la mayor parte del Estado de México (61.82\%) el clima es templado subhúmedo, en el $10.90 \%$ semifrío subhúmedo con lluvias en verano, en el $10.36 \%$ semicálido subhúmedo con lluvias en verano, en el $10.32 \%$ cálido subhúmedo con lluvias en verano y en algunas otras zonas con porcentajes menores es semiseco templado y frío. (ver Gráfico 1.2 Climas en el Estado de México)

La temperatura media anual es de 14 grados centígrados; las más bajas se presentan durante los dos primeros meses del año promediando $10.7^{\circ} \mathrm{C}$ y las más altas en abril y mayo con un promedio de $16.4^{\circ} \mathrm{C}$. (ver Gráfico 1.3 Distribución de la temperatura en el Estado de México)

En el Estado de México llueve durante el verano y la precipitación total oscila entre los 591.7 y los 1,225.2 mm. La precipitación del año más seco promedia $540.92 \mathrm{~mm}$ y la precipitación del año más lluvioso alcanza los 1,476 mm. (Ver Gráfico 1.4 Distribución de la precipitación en el Estado de México)

De las 26 corrientes de agua de la entidad, las principales son: Lerma, Aguiagua, Salitre, Temascaltepec-La Comunidad y Tilastoc. Cuenta también con 10 cuerpos de agua (lagos) destacando Nabor Carrillo, Zumpango, Antonio Alzate, Danxhó y Guadalupe. Adicionalmente, tiene 10 presas para el almacenamiento de agua, siendo las de mayor capacidad de almacenaje: Valle de Bravo, Villa Victoria, Huapango y Tepetitlán. (Ver Gráfico 1.5 Hidrografía del Estado de México)

Respecto al uso potencial agrícola de la entidad, encontramos que el $33.84 \%$ de la de la superficie se destina a la agricultura mecanizada continua, el $33.79 \%$ a la agricultura manual continua, el $11.65 \%$ para la agricultura manual estacional y el $7.28 \%$ para la de tracción animal continua. Resulta interesante mencionar que el $12.66 \%$ de la superficie total no es apta para la agricultura. (Ver Gráfico 1.6 Uso potencial agrícola del Estado de México) 


\section{Gráfico 1.1 División municipal y colindancias del Estado de México}

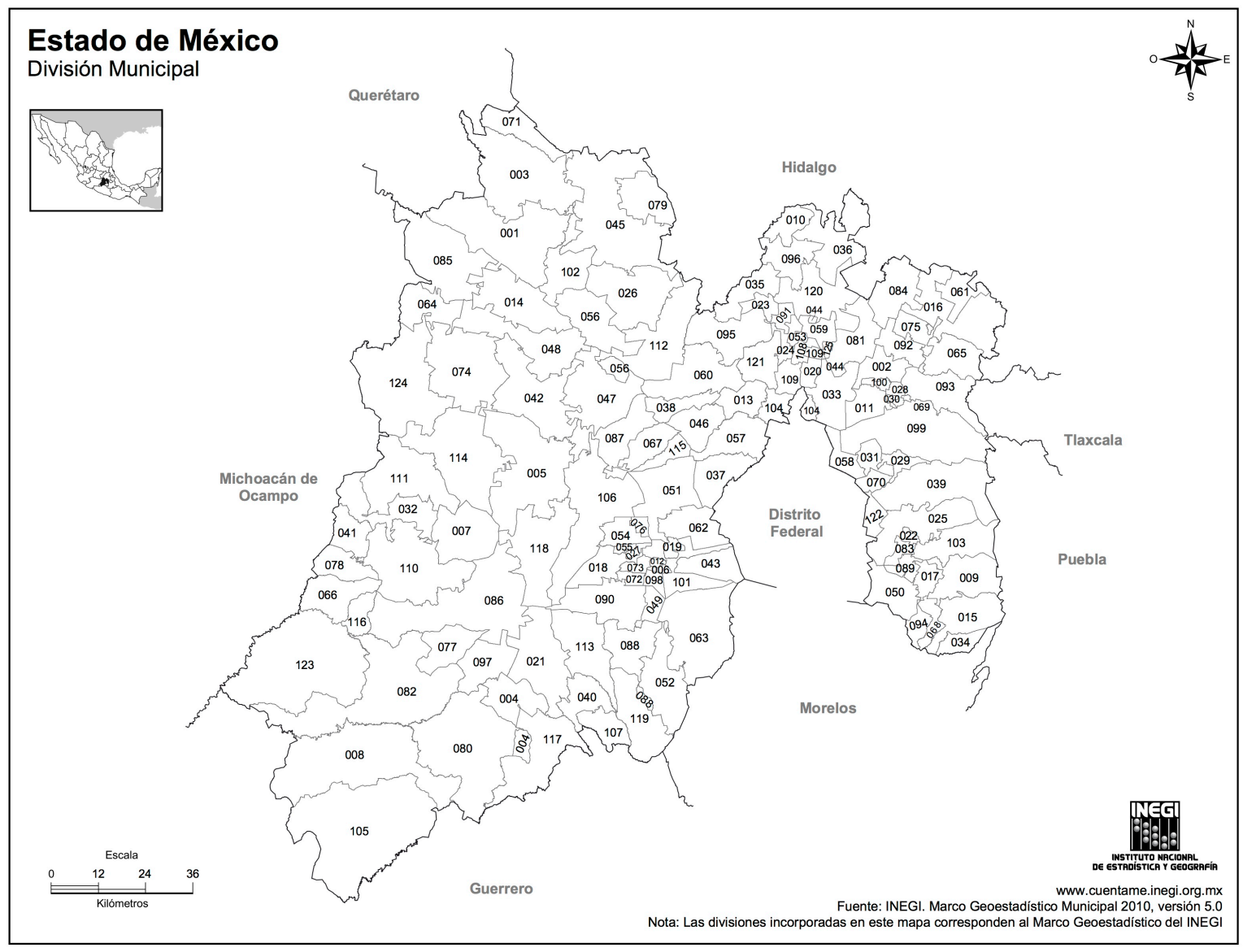

Fuente: INEGI. 


\section{Gráfico 1.2 Climas del Estado de México}

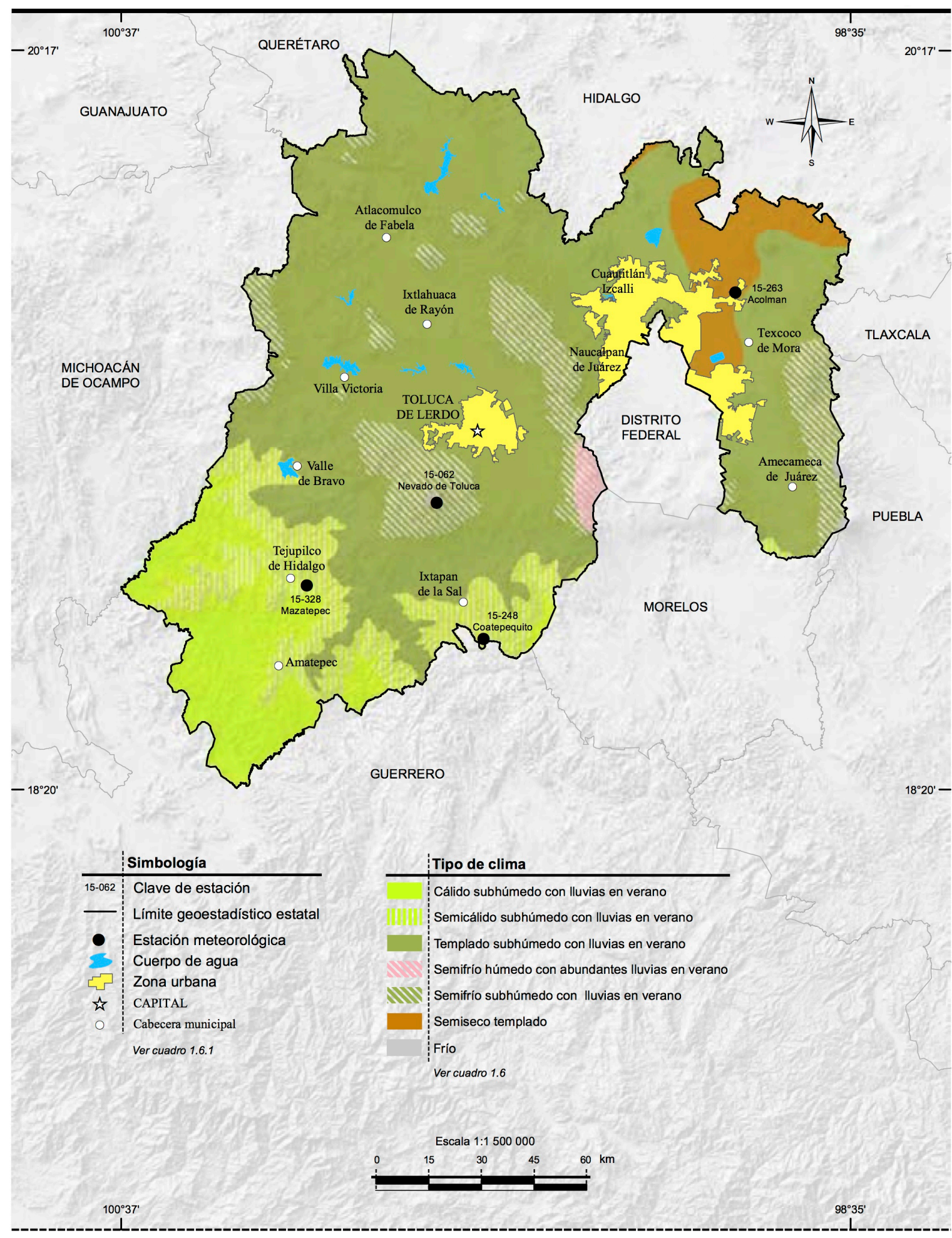

Fuente: INEGI 2013: 40. 
Gráfico 1.3 Distribución de la temperatura en el Estado de México

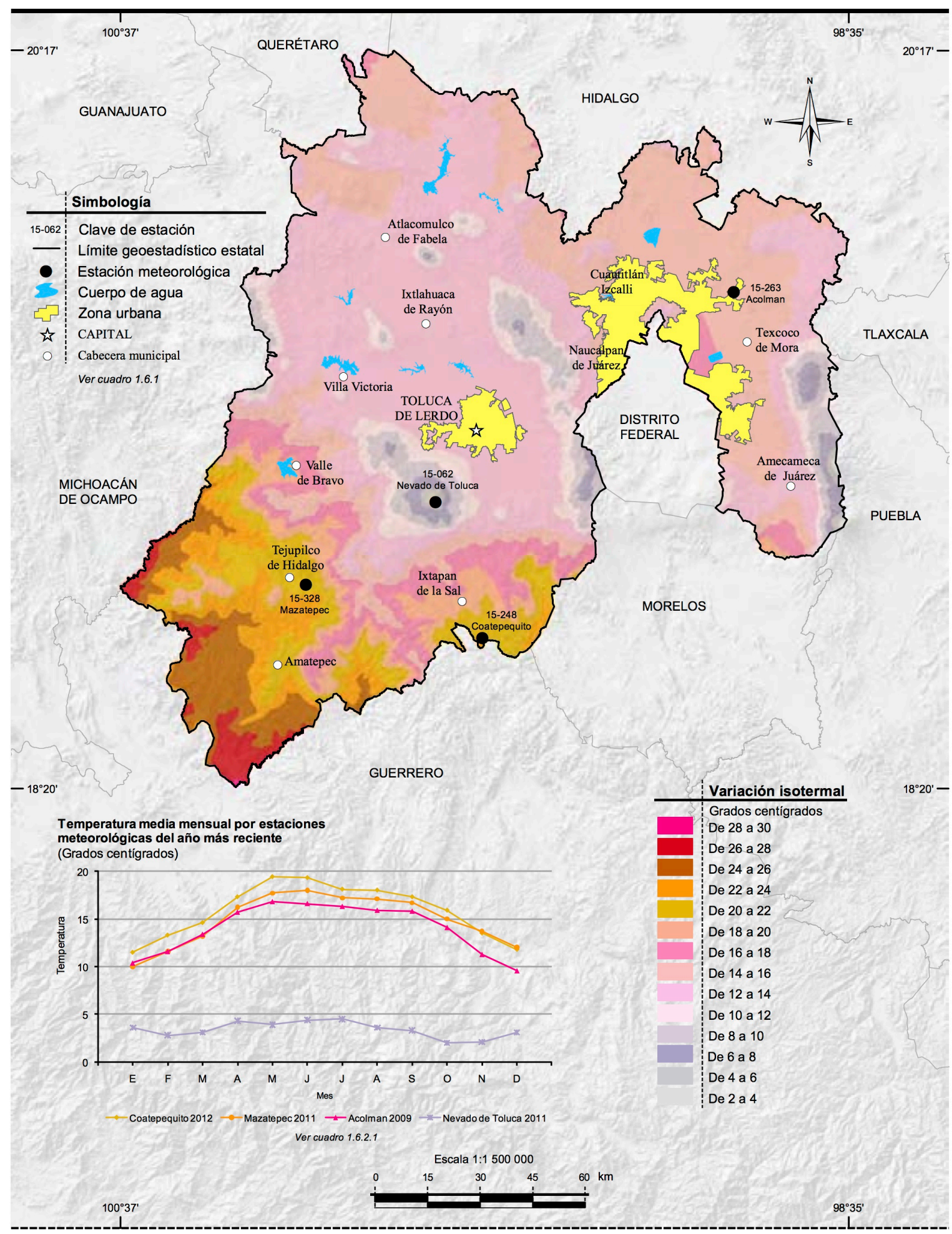

Fuente: INEGI 2013: 41. 


\section{Gráfico 1.4 Distribución de la precipitación en el Estado de México}

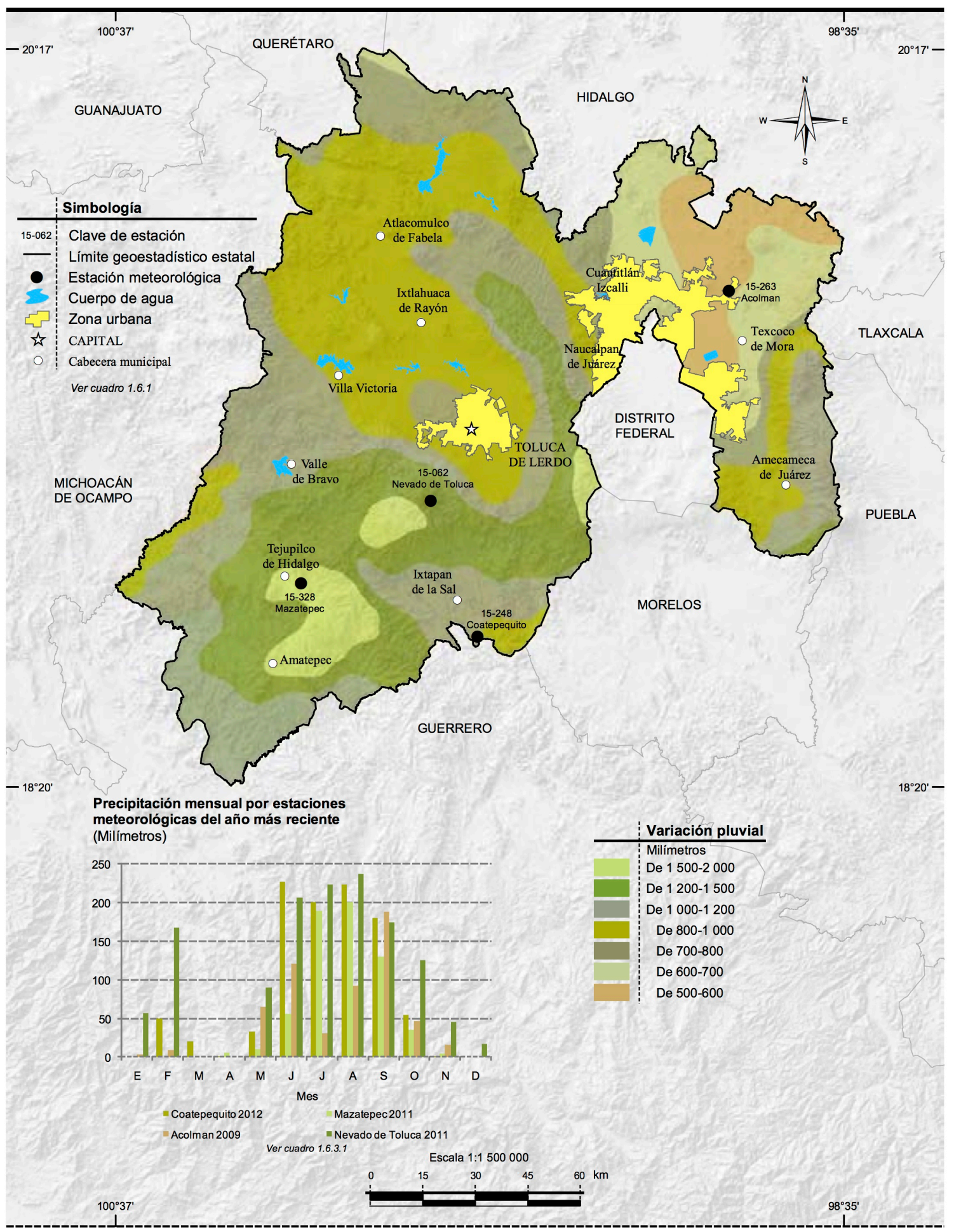

Fuente: INEGI 2013: 42. 


\section{Gráfico 1.5 Hidrografía del Estado de México}

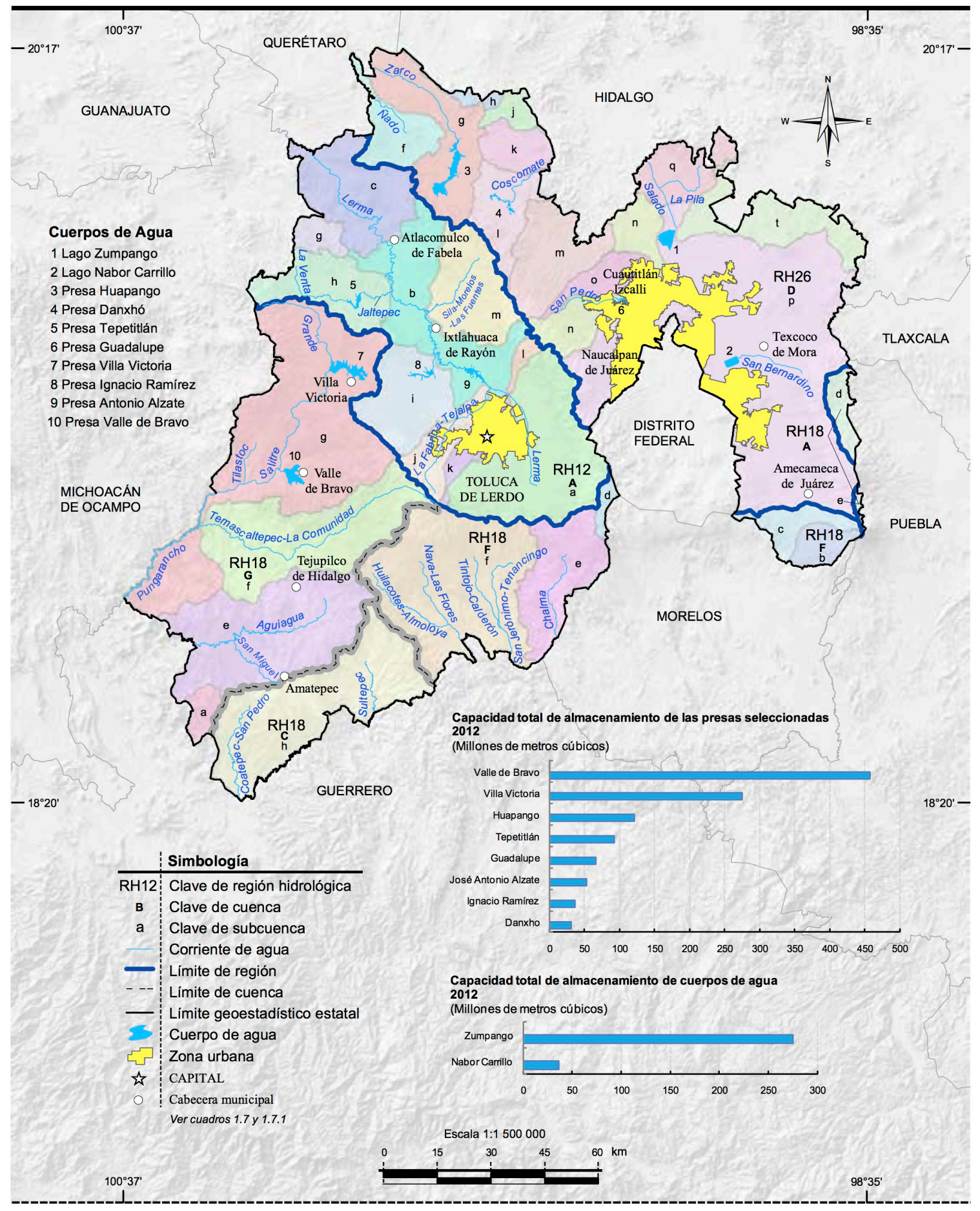

Fuente: INEGI 2013: 43. 


\section{Gráfico 1.6 Uso potencial agrícola del Estado de México}

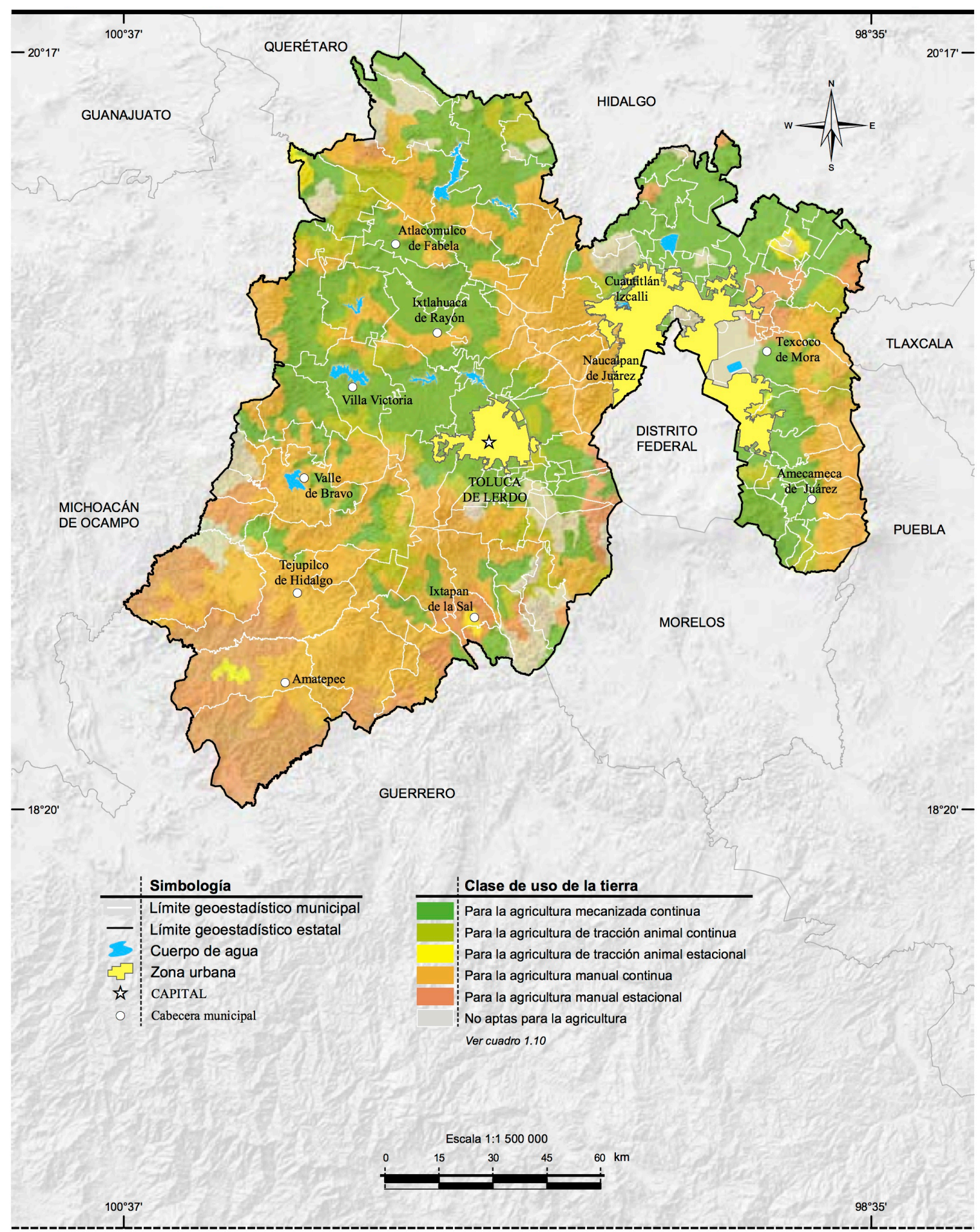

Fuente: INEGI 2013: 47. 


\subsection{Población}

En 2010 México reportó un total de 108396211 habitantes, con una tasa de crecimiento del $0.8 \%$. En el mismo año, el Estado de México reportó $15,571,679$ habitantes, que constituye el $14.35 \%$ de la población total nacional, posicionándose así como la entidad más poblada del país. En 2012 hay 16,106,485 mexiquenses. De 2010 a 2012 la tasa de crecimiento a caído de $1.7 \%$ a $1.6 \%$, mientras que la esperanza de vida ha aumentado de 74.5 a 74.7 años. En el Estado de México viven más personas que en Finlandia, Grecia y Cuba.

La población mexiquense se concentra en la zona metropolitana de la Ciudad de México; tan sólo en el municipio de Ecatepec de Morelos vive más gente que en los nueve estados menos poblados de la República. En todo el país, $23.5 \%$ de la población habita en localidades rurales, en el Estado de México 13 por ciento.

\section{Gráfico 1.7 Población urbana y rural de México}

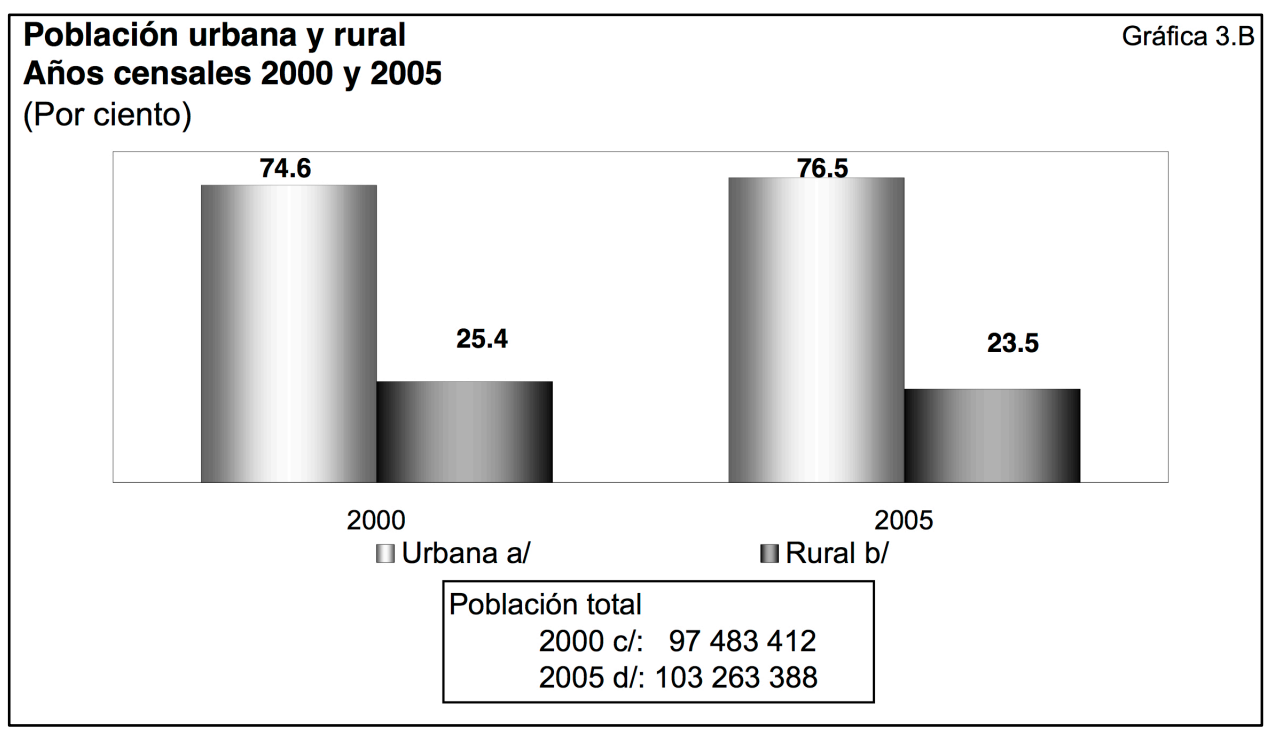

Fuente: INEGI 2010: 42.

A lo largo del siglo pasado la población del estado tuvo importantes cambios: entre 1900 y el año 2000 la población mexiquense se multiplicó 14 veces, lo que significa que pasó de 934 mil a 13.1 millones de habitantes. Sin embargo, en el transcurso del periodo señalado los incrementos poblacionales 
se presentaron con diferente intensidad. La población de principios del siglo pasado tardó 60 años en duplicarse. Posteriormente, como resultado de la alta natalidad y de una sensible baja de la mortalidad, la población de 1960 (1.9 millones) se duplicó en tan sólo diez años.

Los 3.8 millones de habitantes contabilizados censalmente en 1970, tardaron cerca de 30 años en triplicar el tamaño de su población, comportamiento que obedece en gran parte al descenso ininterrumpido de la fecundidad observado desde mediados de la década. En términos del ritmo de crecimiento, esto significa que mientras en los años sesenta la población creció a una tasa promedio anual de $7.6 \%$, durante la última década lo hizo al $2.9 \%$ (3.2\% en el quinquenio $1990-1995$ y $2.6 \%$ en el segundo). De 9.8 millones de habitantes que había en 1990, la población ascendió a 11.7 millones en 1995 y para el año 2000 a 13.1 millones. En 2005, los residentes del Estado de México alcanzaron 14.7 millones de personas. El último censo levantado en 2010, indica que hay 15.5 millones, de los cuales 7.5 millones son hombres y 7.9 millones son mujeres.

\section{Gráfico 1.8 Principales indicadores demográficos del Estado de México}

\begin{tabular}{|c|c|c|c|}
\hline Indicador & 2010 & 2011 & 2012 \\
\hline Población a mitad del año & 15571679 & 15845558 & 16106485 \\
\hline Hombres & 7594028 & 7735706 & 7864368 \\
\hline Mujeres & 7977652 & 8109852 & 8242117 \\
\hline \multicolumn{4}{|l|}{$\begin{array}{l}\text { Tasas de crecimiento } \\
\text { (Porcentaje) }\end{array}$} \\
\hline Total & 1.7 & 1.7 & 1.6 \\
\hline Natural & 1.5 & 1.5 & 1.4 \\
\hline Social & 0.2 & 0.2 & 0.2 \\
\hline $\begin{array}{l}\text { Tasa bruta de natalidad } \\
\text { (Nacimientos por cada } 1000 \\
\text { habitantes) }\end{array}$ & 19.6 & 19.3 & 19.0 \\
\hline $\begin{array}{l}\text { Tasa bruta de mortalidad } \\
\text { (Defunciones por cada } 1000 \\
\text { habitantes) }\end{array}$ & 4.7 & 4.8 & 4.9 \\
\hline $\begin{array}{l}\text { Tasa global de fecundidad } \\
\text { (Hijos nacidos vivos por mujer) }\end{array}$ & 2.2 & 2.2 & 2.2 \\
\hline \multicolumn{4}{|l|}{$\begin{array}{l}\text { Esperanza de vida } \\
\text { (Años) }\end{array}$} \\
\hline Total & 74.5 & 74.6 & 74.7 \\
\hline Hombres & 71.9 & 72.0 & 72.1 \\
\hline Mujeres & 77.2 & 77.3 & 77.4 \\
\hline
\end{tabular}

Fuente: INEGI 2013: 99. 
La pirámide de población del Estado de México presenta un comportamiento distinto al del país en su conjunto, mientras que la base de la pirámide nacional se ha venido reduciendo, la del Estado de México ha crecido. Esto puede explicarse por factores como el proceso de urbanización, la saturación del espacio habitacional en el Distrito Federal y el desarrollo inmobiliario en el Estado de México, principalmente de viviendas de interés social. No obstante hay municipios que han frenado el crecimiento acelerado que tuvieron entre 1985 y 1995 . Tal ese le caso de Nezahualcóyotl.

Lo composición demográfica en la entidad ha representado una fuerte presión para administrar y dotar de nuevos recursos e infraestructura al estado, pero también lo ha colocado con una ventaja con respecto al resto de las entidades: cuenta con la mayor fuerza de trabajo del país.

\section{Gráfico 1.9 Población total por grupo quinquenal de edad según sexo del Estado de México en 2010}

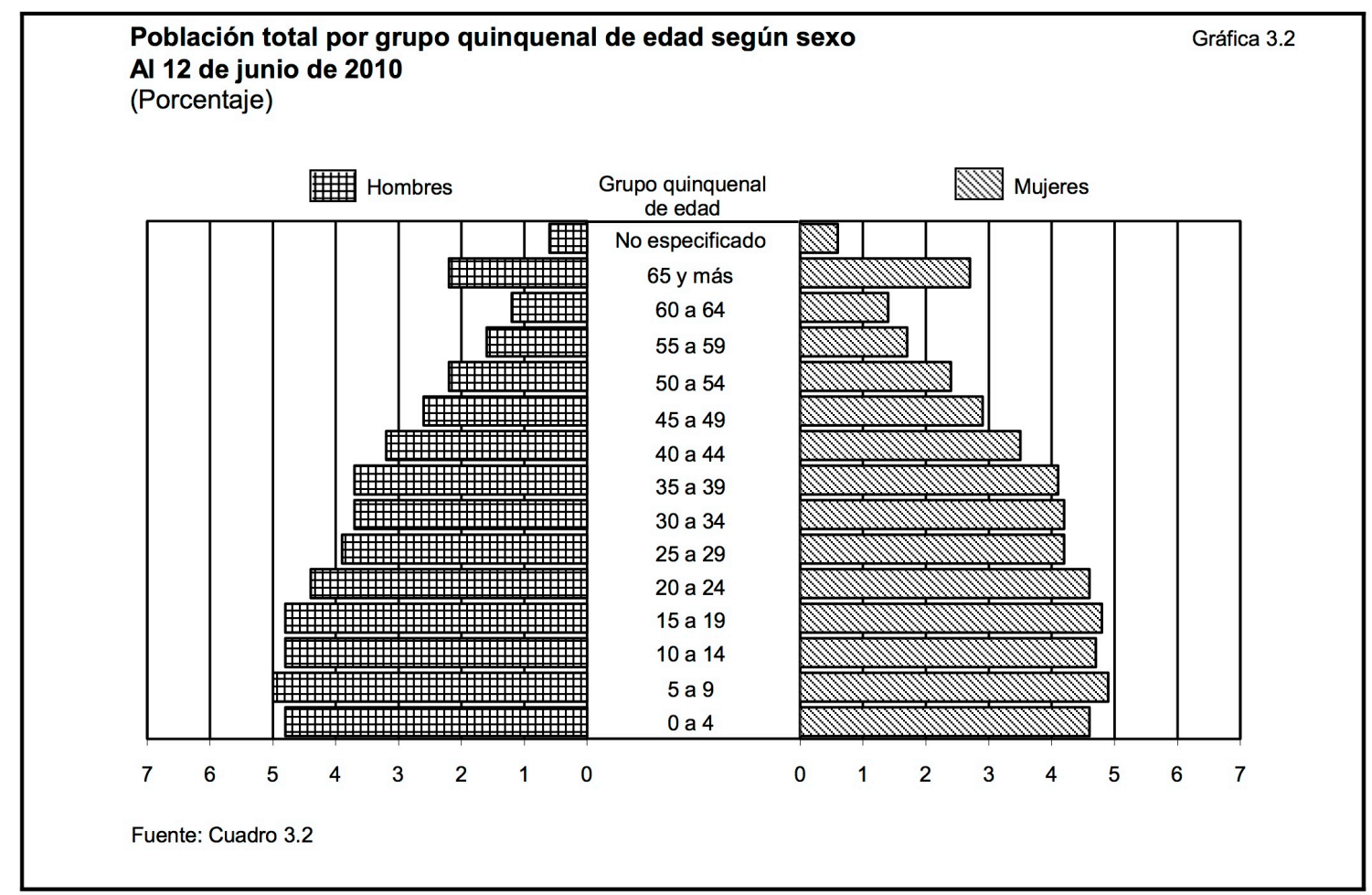

Fuente: INEGI 2013:102. 


\section{Gráfico 1.10 Población total por grupo quinquenal de edad según sexo del Estado de México en 2010}

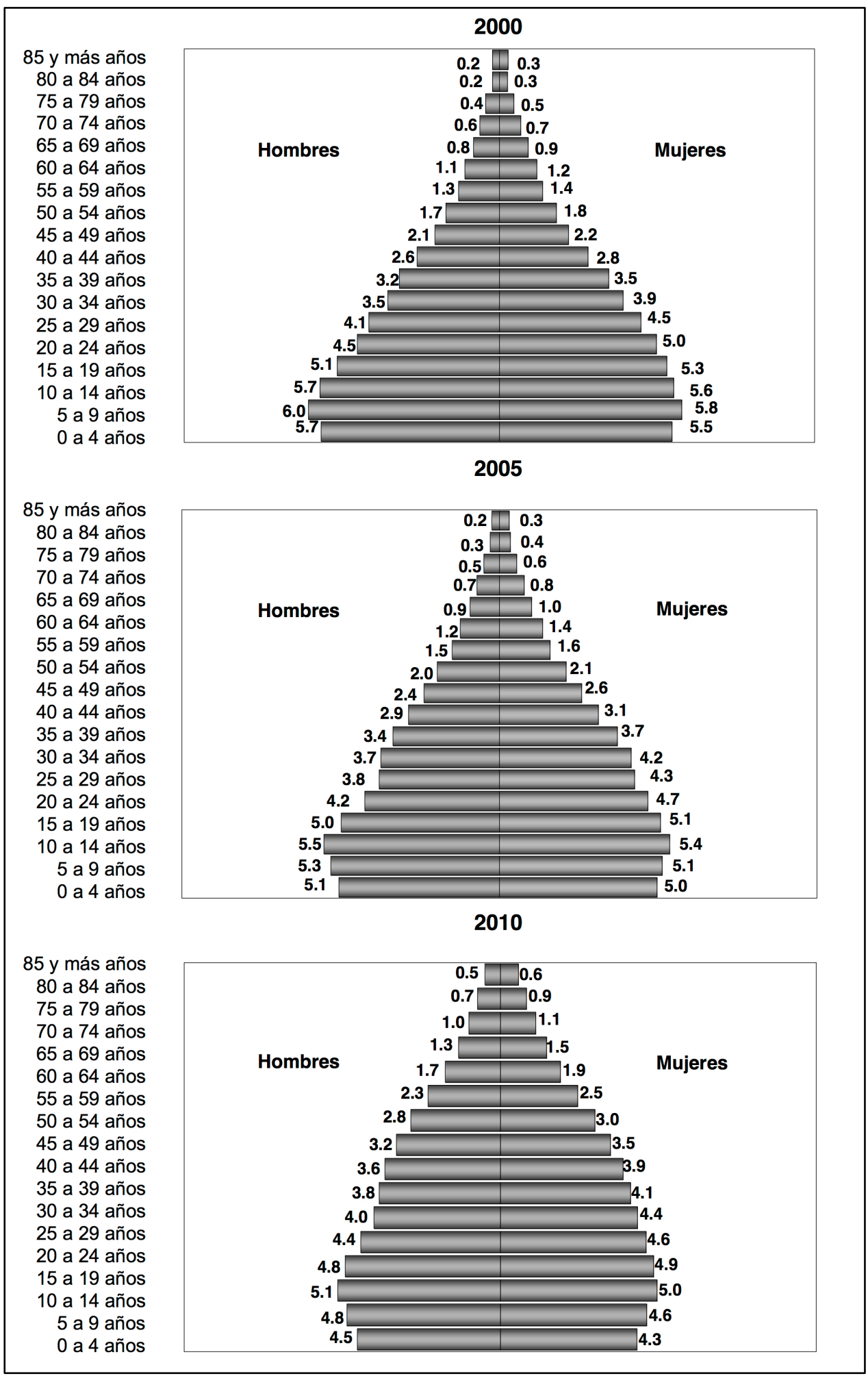

Fuente: INEGI 2010: 40. 


\subsection{Trabajo}

En 1990 más de 248 mil personas se dedicaban al sector primario del Estado de México, la principal actividad en la que se empleaban era en la agricultura: 88 de cada 100 ocupados se dedicaban a labores agrícolas, seis a de cada 100 a la ganadería y el resto a otras actividades.

\section{Gráfico 1.11 Ocupación y tasa de participación en el sector primario de la población del Estado de México en 1990}

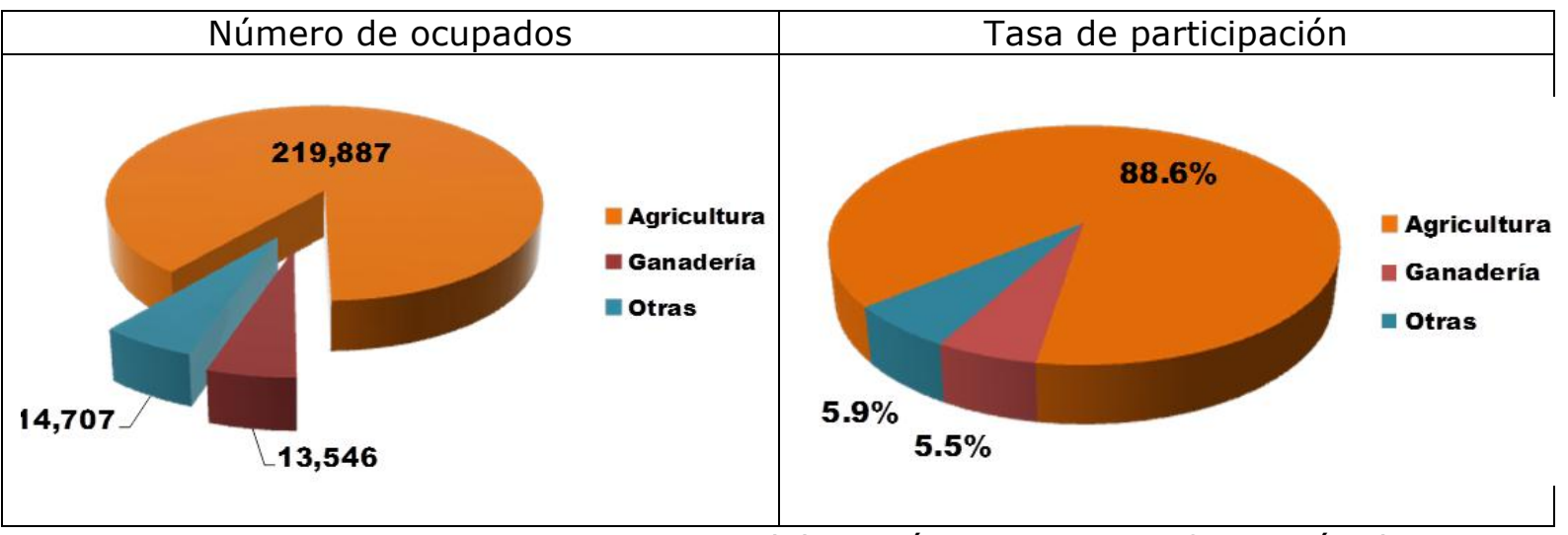

Fuente: elaboración propia con información de INEGI.

Diez años después, en el 2000, la ocupación del sector primario había perdido más de 15 mil personas. La actividad que más empleos disminuyó fue la agricultura; en términos relativos dejaron la actividad $8.2 \%$ de los que se dedicaban a ella en 1990.

No obstante, la ganadería cobró importancia al pasar de 13,546 trabajadores a 27,756 , lo que significó un incremento porcentual de $75 \%$, es decir, 11,49 personas más en comparación con 1990. Así, la tasa de participación de la agricultura de la entidad descendió 1.7 puntos porcentuales, en tanto que la ganadería ganó 5.6 puntos. 


\section{Gráfico 1.12 Ocupación y tasa de participación en el sector primario de la población del Estado de México en 2000}

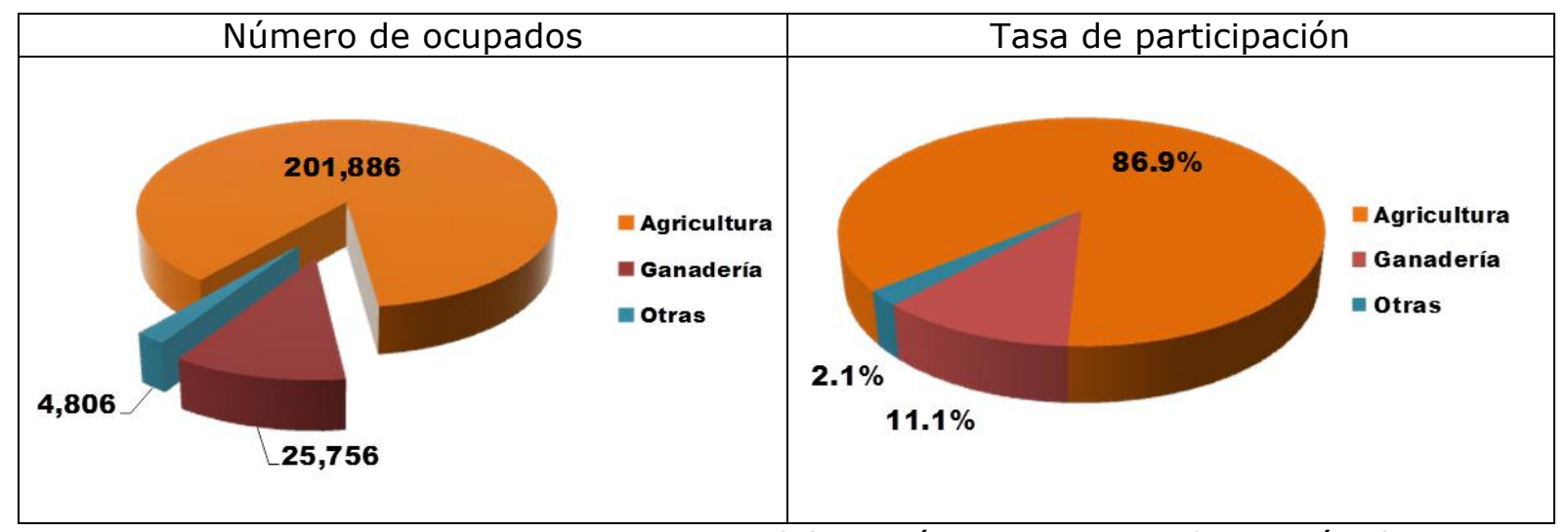

Fuente: elaboración propia con información de INEGI.

Para 2010 se presentó una revalorización de la actividad, de tal suerte que la población ocupada en el sector primario aumento $21.4 \%$ con respecto a 1990, es decir, 53 mil personas más; y 29.5\% en comparación con el año 2000, lo cual significó un incremento de 18 mil personas.

La agricultura, respecto de 1990, atrajo 45,256 personas, esto es un crecimiento de $20.6 \%$, pero con relación a 2000 significó un aumento de $31.3 \%$, es decir, 63,257 personas más que las empleadas en el subsector diez años antes.

La ganadería, por su parte, crece en más del doble (105\%) con respecto a 1990, al pasar de 14,707 ocupados a 30,214 en 2010. En comparación con 2000 el incremento no deja de ser importante $17.3 \%$, es decir, más de cuatro mil personas adicionales.

En el Estado de México, de las personas ocupadas en el sector primario $88 \%$ son varones. En promedio, quien encabeza las actividades productivas agropecuarias en el Estado de México es un hombre de 52 años, quien casi concluyó la primaria -5.1 años escolares, prácticamente igual al promedio que presentan los productores del sector en el país-, y trabaja alrededor de 37 horas a la semana. A nivel nacional el porcentaje es similar, siendo $x \%$ de varones los que trabajan en actividades del sector primario, contra un $X$ de mujeres. 


\section{Gráfico 1.13 Ocupación y tasa de participación en el sector primario de la población del Estado de México en 2010}

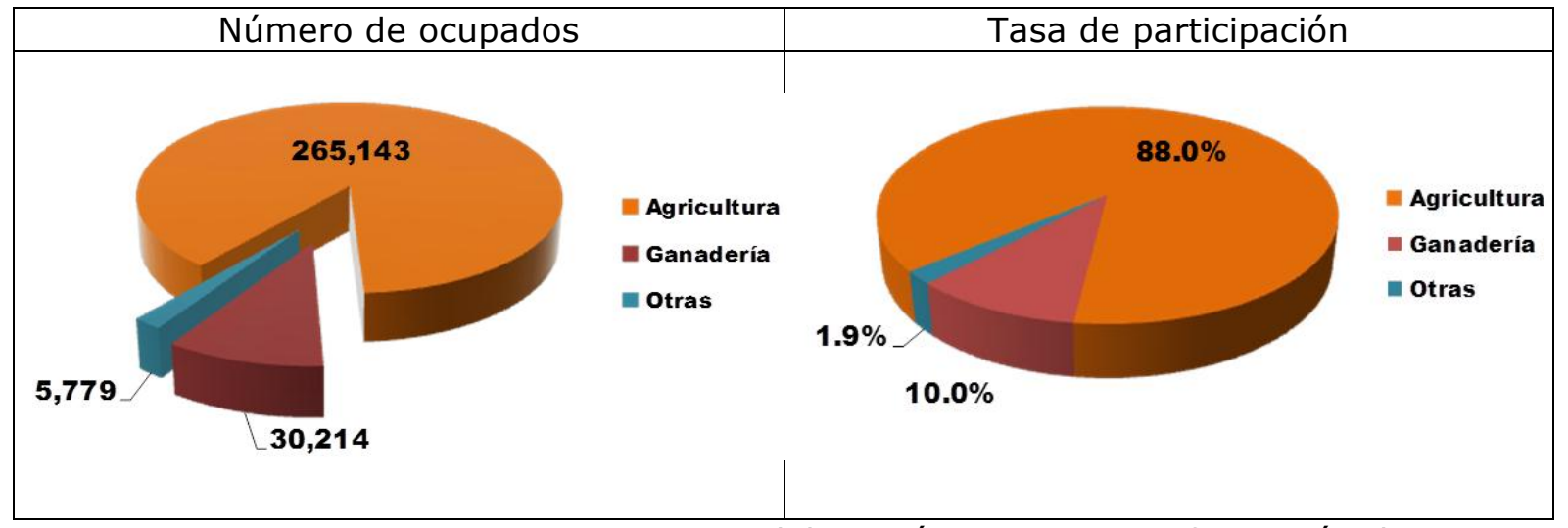

Fuente: elaboración propia con información de INEGI.

Gráfico 1.14 Población ocupada por sector de actividad económica según sexo al primer trimestre de $\mathbf{2 0 1 0}$

\begin{tabular}{|lrrr|}
\hline Sector de actividad & Total & Hombres & Mujeres \\
\hline Total & $\mathbf{4 3 6 3 3 7 5 9}$ & $\mathbf{2 7} \mathbf{2 1 4} \mathbf{0 1 3}$ & $\mathbf{1 6 4 1 9 7 4 6}$ \\
Primario a/ & 5594767 & 5037130 & 557637 \\
Secundario b/ & 10619359 & 7983393 & 2635966 \\
Terciario c/ & 27131200 & 14003045 & 13128155 \\
No especificado & 288433 & 190445 & 97988 \\
\hline a/ Comprende: agricultura, ganadería, silvicultura, caza y pesca. & \\
b/ Comprende: industria extractiva y de la electricidad; industria manufacturera y construcción. \\
c/ Comprende: comercio; restaurantes y servicios de alojamiento; transportes, comunicaciones, correo \\
y almacenamiento; servicios profesionales, financieros y corporativos; servicios sociales; servicios di- \\
versos; y gobierno y organismos internacionales. \\
Fuente: INEGl. Encuesta Nacional de Ocupación y Empleo. Indicadores Estratégicos de Ocupación y \\
Empleo. En: www.inegi.org.mx (12 de julio de 2010).
\end{tabular}

Fuente: INEGI 2010: 79.

\subsection{Producto Interno Bruto}

El Producto Interno Bruto (PIB) en valores básicos ${ }^{1}$ (millones de pesos a precios de 2003) de México en 2010 fue de 8,481,446.8. El Estado de México representa el 9.4\%, ubicándose tan solo por debajo del Distrito Federal que tiene una aportación del 18\%. Le siguen Nuevo León con $7.9 \%$ y Jalisco con $6.7 \%$. 


\section{Gráfico 1.15 Distribución porcentual del producto interno bruto en valores básicos por entidad federativa}

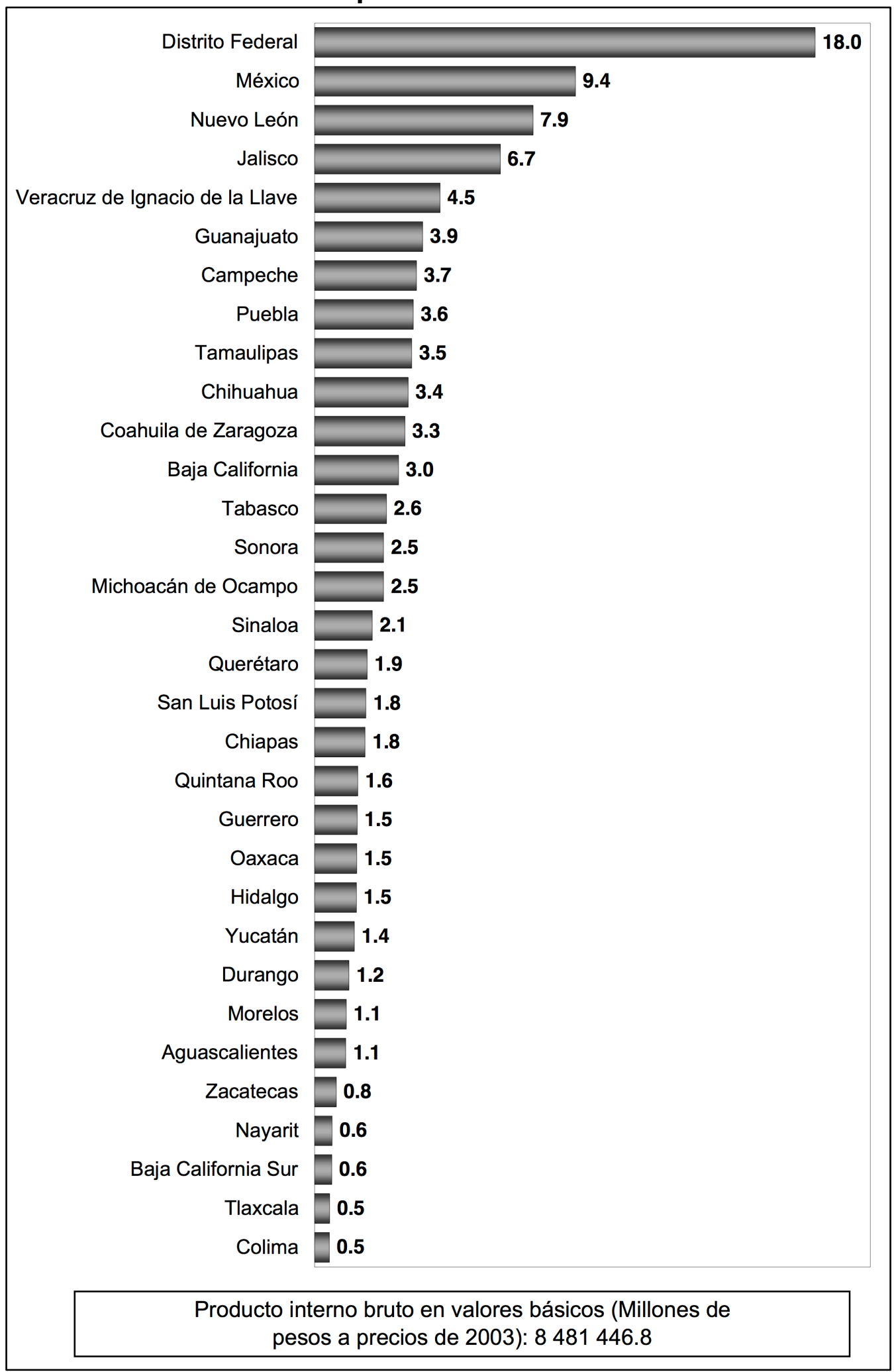

Fuente: INEGI 2010: 112. 
En 2011, el PIB del Estado de México fue de 1,134,967 millones de pesos a precios de 2008. De éste, 13,346 millones fueron aportados por el sector agropecuario. Cabe destacar que la aportación de este sector en 2003 y en 2007 fue de poco más de 17,000 mdp, observándose una disminución en la participación del sector. Resulta interesante mencionar que dos de los sectores que han presentado un aumento de 2003 a 2007 son las industrias manufactureras y el comercio. Las primeras tuvieron un aumento de los 231,261 millones de pesos a los 262,662 millones. El comercio, por su parte, pasó de los 144,905 millones de pesos a los 206,088 millones.

\section{Gráfico 1.16 Producto interno bruto por sector de actividad económica del} Estado de México. Serie anual de 2003 al 2011

\begin{tabular}{|c|c|c|c|c|c|c|c|c|c|}
\hline \multicolumn{10}{|l|}{ (Millones de pesos a precios de 2008) } \\
\hline Sector & 2003 & 2004 & 2005 & 2006 & 2007 & 2008 & 2009 & $2010 \mathrm{Pl}$ & $2011 \mathrm{P} /$ \\
\hline Total & 873441 & 906505 & 946445 & 997129 & 1041075 & 1058285 & 1018003 & 1094927 & 1134967 \\
\hline $\begin{array}{l}\text { Agricultura, cría y explotación de animales, } \\
\text { aprovechamiento forestal, pesca y caza }\end{array}$ & 17051 & 16600 & 15340 & 16830 & 17714 & 17078 & 14945 & 15886 & 13346 \\
\hline Minería & 1832 & 1917 & 1980 & 1909 & 2046 & 1910 & 1986 & 2297 & 2165 \\
\hline $\begin{array}{l}\text { Generación, transmisión y distribución de } \\
\text { energía eléctrica, suministro de agua y } \\
\text { de gas por ductos al consumidor final }\end{array}$ & 11168 & 11596 & 13321 & 14398 & 16588 & 17138 & 19693 & 19510 & 20490 \\
\hline Construcción & 61784 & 67560 & 72666 & 74200 & 79982 & 80747 & 78569 & 102436 & 95368 \\
\hline Industrias manufactureras & 231261 & 237807 & 245948 & 253651 & 256869 & 255748 & 233733 & 251772 & 262662 \\
\hline Comercio & 144905 & 152666 & 161495 & 174073 & 185950 & 188326 & 169142 & 186135 & 206088 \\
\hline $\begin{array}{l}\text { Transportes, correos } \\
\text { y almacenamiento }\end{array}$ & 41035 & 42450 & 44779 & 49569 & 51591 & 49818 & 46353 & 50634 & 52571 \\
\hline Información en medios masivos & 12843 & 15773 & 18809 & 20662 & 23517 & 24114 & 24534 & 24011 & 25732 \\
\hline Servicios financieros y de seguros & 10851 & 12719 & 13681 & 16059 & 18344 & 22787 & 25243 & 28282 & 31324 \\
\hline $\begin{array}{l}\text { Servicios inmobiliarios y de alquiler } \\
\text { de bienes muebles e intangibles }\end{array}$ & 175692 & 180904 & 185763 & 193047 & 200120 & 207479 & 213026 & 220529 & 226227 \\
\hline $\begin{array}{l}\text { Servicios profesionales, científicos } \\
\text { y técnicos }\end{array}$ & 10001 & 10115 & 9986 & 10864 & 11341 & 12109 & 12084 & 11927 & 12593 \\
\hline Corporativos & 1429 & 1439 & 1482 & 1560 & 1597 & 1644 & 1519 & 1553 & 1652 \\
\hline $\begin{array}{l}\text { Servicios de apoyo a los negocios } \\
\text { y manejo de desechos y servicios } \\
\text { de remediación }\end{array}$ & 15805 & 16537 & 17094 & 18388 & 19529 & 20872 & 18990 & 19640 & 21255 \\
\hline Servicios educativos & 42885 & 43678 & 45481 & 46999 & 47306 & 47457 & 47232 & 47994 & 49224 \\
\hline $\begin{array}{l}\text { Servicios de salud y de asistencia } \\
\text { social }\end{array}$ & 18492 & 18245 & 19517 & 20712 & 20976 & 21491 & 22942 & 23721 & 24245 \\
\hline $\begin{array}{l}\text { Servicios de esparcimiento culturales } \\
\text { y deportivos, y otros servicios } \\
\text { recreativos }\end{array}$ & 2955 & 3019 & 3014 & 3212 & 3388 & 3433 & 3313 & 3559 & 3534 \\
\hline $\begin{array}{l}\text { Servicios de alojamiento temporal } \\
\text { y de preparación de alimentos } \\
\text { y bebidas }\end{array}$ & 12023 & 11837 & 11738 & 13403 & 15023 & 15002 & 13025 & 12207 & 13133 \\
\hline $\begin{array}{l}\text { Otros servicios excepto actividades } \\
\text { gubernamentales }\end{array}$ & 23767 & 23434 & 25373 & 27681 & 27676 & 28275 & 29078 & 29600 & 30754 \\
\hline $\begin{array}{l}\text { Actividades legislativas, gubernamentales, } \\
\text { de impartición de justicia y de organismos } \\
\text { internacionales y extraterritoriales }\end{array}$ & 37661 & 38211 & 38980 & 39914 & 41518 & 42855 & 42596 & 43235 & 42605 \\
\hline
\end{tabular}

Fuente: INEGI 2013: 536. 


\subsection{Características de los consumidores}

Según la Encuesta Nacional de Ingresos y Gastos de los hogares (ENIGH) del INEGI, en México los hogares de ingreso más alto conforman el $11 \%$ de la población y concentran el 37\% del ingreso total del país. Los hogares del estrato de ingreso más bajo conforman $8 \%$ de la población y concentran únicamente $2 \%$ del ingreso total.

Esta concentración provoca que las familias de más bajos ingresos destinen, proporcionalmente, una mayor parte de sus recursos monetarios en alimentos, generando una polarización en el gasto.

De conformidad con la ENIGH, el decil de hogares con ingreso más bajo destina $52 \%$ de su ingreso total en la compra de alimentos, mientras que dicho indicador para el decil con el ingreso más alto es del $23 \%$.

El decil de población con ingresos más altos gasta $4.1 \%$ veces más dinero en alimentos que el decil de población con ingresos más bajos.

Esa diferencia es mayor en algunos tipos de alimentos, por ejemplo, en el caso de carnes es de 4.3 veces, leche y derivados 4.4 , pescados y mariscos 5.6, frutas 7.3 y, el resto de los rubros (principalmente alimentos y bebidas consumidas fuera del hogar y alimentos y bebidas alcohólicas y no alcohólicas) 8.7 veces.

Al analizar la composición del gasto en alimentos por decil, la participación de los cereales en el gasto en alimentos es mayor entre menor es el estrato de ingreso, para el caso de la carne dicho indicador es uniforme en todos los estratos, mientras que el resto de los alimentos (principalmente alimentos y bebidas consumidas fuera del hogar y alimentos y bebidas alcohólicas y no alcohólicas) dicho gasto es mayor conforme aumenta el ingreso.

Una característica de los consumidores mexicanos es la falta de educación para el consumo, en especial en la compra de alimentos, ya que sus decisiones de compra están basadas, básicamente, en el precio del producto, mientras que el adecuado etiquetado de los alimentos, que debe contener información sobre la calidad, cualidades nutricionales, pesos y medidas, sanidad e 
inocuidad, entre otras, generalmente no son tomadas en cuenta al momento de la compra. Lo anterior se profundiza con el limitado uso de estándares de calidad a lo largo de la cadena de suministro.

A la limitada educación para el consumo, se agrega también la limitada educación en la alimentación. Generalmente la población mexicana no valora la calidad alimentaria pues no utiliza ni se encuentra del todo disponible la información que oriente sus decisiones de compra. Como resultado, la mala alimentación conlleva a problemas de salud como el sobrepeso y la obesidad.

La Secretaria de Salud indica que en los últimos treinta años, la obesidad y el sobrepeso en México se han triplicado, por lo que actualmente cerca del $70 \%$ de la población adulta tiene una masa corporal inadecuada (39.5\% de los hombres y mujeres tienen sobrepeso y $31.7 \%$ obesidad).

Según información de la Secretaria de Salud, actualmente México ocupa el segundo lugar en prevalencia mundial de obesidad, después de los Estados Unidos de América. Esta situación representa, además de un grave problema de salud pública, una elevada carga fiscal, pues la atención y tratamiento de enfermedades derivadas del sobrepeso y la obesidad implican costos significativos para el sistema de salud pública, para la sustentabilidad del régimen de pensiones y para la estabilidad económica y social de la población, especialmente de los sectores más pobres. 


\section{CAPITULO 2}

\section{INTEGRACIÓN ECONÓMICA GENERADA POR EL TRATADO DE LIBRE COMERCIO DE AMÉRICA DEL NORTE}

Hasta el momento, hemos bosquejado las características tanto de la población como del territorio de la entidad federativa que es objeto de estudio de la presente tesis: el Estado de México. Para analizar las características del sector agrícola mexiquense y el posible impacto de las medidas contenidas en el TLCAN, debemos conocer no sólo el contenido de este acuerdo comercial, sino también el proceso de liberalización comercial que se inició en México en la década de 1980. En otras palabras, estamos sugiriendo que la problemática que afecta al sector agrícola no se explica únicamente por el TLCAN, sino posiblemente por la política macroeconómica y sectorial instrumentada desde una década antes de la firma de este tratado.

Para tales fines, este capítulo estará dividido en tres partes. En un primer momento, se harán apuntes referentes a la integración económica regional desde un punto de vista teórico. En la segunda parte, se explicará en qué consistieron las primeras reformas liberales y en qué momento se dieron en México. Finalmente, se describirá el proceso de negociación que se generó entre los países firmantes del TLCAN y el contenido específico de éste en material agrícola.

\subsection{Teoría de la integración económica}

En términos económicos, la globalización puede ser definida como el aumento de las transacciones internacionales en el mercado de bienes, servicios, capital y trabajo, que se combina con la expansión e incremento de las actividades tanto de los actores del mercado internacional como de las instituciones que se superponen a las fronteras nacionales (Jager y Jepma 2011: 180).

La primera oleada de globalización económica inició en 1880 con el proceso de industrialización de aquella época. Esta primera "era" terminó 
abruptamente con el estallido de la Gran Guerra y el colapso del sistema Patrón Oro ${ }^{1}$ en la década de 1920. La segunda oleada, que estamos viviendo actualmente, se identifica después de la Segunda Guerra Mundial con la firma del Acuerdo General sobre Aranceles Aduaneros y Comercio (GATT por sus siglas en inglés) ${ }^{2}$ en 1948, que tenía como objetivo principal organizar el comercio internacional a través de tres funciones:

- Resolver diferencias comerciales entre países.

- Definir las condiciones relativas a la política comercial de las partes implicadas.

- Promover la reducción arancelaria.

El GATT consistía, principalmente, en un texto que establecía lineamientos para el comercio de bienes entre los países firmantes. No fue un acuerdo ratificado por los parlamentos nacionales de sus miembros y no tuvo nunca la intención de crear una organización como tal. Décadas más tarde, y cuando el comercio internacional tocó al sector de la propiedad intelectual (ideas, inventos y diseños) nacen el Acuerdo sobre los Aspectos de los Derechos de Propiedad Intelectual relacionados con el Comercio (TRIPS por sus siglas en inglés) en 1994 y Acuerdo General sobre el Comercio de Servicios (GATS por sus siglas en inglés) en 1995. Así, el GATT, el TRIPS y el GATS, fueron integrados para crear la Organización Mundial del Comercio (OMC) en 1995.

La OMC, a diferencia del GATT, cuenta con un sistema para resolver controversias y sus decisiones no pueden ser bloqueadas debido a que sus miembros ratificaron los acuerdos en sus parlamentos. Algunos de los principios sobre los que se base la OMC son:

1. Cláusula de la Nación más Favorecida (MFN por sus siglas en inglés): implica que si dos países acuerdan reducir aranceles respecto de un bien o servicio particular (sin establecer una Zona de Libre Comercio o una Unión Aduanera, estos conceptos serán explicados en páginas siguientes), los aranceles que impongan a terceros que pertenezcan a la OMC no pueden ser más elevados. Esto significa que si un país reduce los aranceles de un bien o 
servicio particular respecto de otro país, esa reducción arancelaria aplicará a todos los países miembros de la OMC.

2. Cláusula de Tratamiento Nacional (en inglés National Treatment): implica que los productos importados deben ser tratados de la misma manera que el equivalente de dichos productos en el mercado interno del país importador.

A partir de este momento, resulta posible observar que la eliminación de las barreras arancelarias y el acelerado desarrollo de las tecnologías de la información, así como la intención de algunos países de beneficiarse en mayor medida del comercio internacional, contribuyeron a que la economía mundial experimentara un aumento sustancial de integración económica. Esto sucedió, en mayor medida, con los acuerdos de comercio regional como son los casos de la Unión Europea (EU por sus siglas en inglés), el Mercado Común del Sur (MERCOSUR), la Asociación de Naciones del Sudeste Asiático (ASEAN por sus siglas en inglés), el Mercado Común de África Oriental y Austral (COMESA por sus siglas en inglés) y el TLCAN, objeto de estudio de esta tesis.

La teoría clásica de la integración económica es el resultado de las contribuciones de Viner (1950), Tinbergen (1954) y Balassa (1961). Tinbergen hace una distinción entre integración económica positiva e integración económica negativa. La primera se refiere a la transferencia de instituciones comunes o a la armonización de las políticas macroeconómicas de los países involucrados. La segunda hace referencia a la eliminación de las barreras arancelarias, principalmente.

Balassa, por su parte, clasifica 5 niveles de integración partiendo del más superficial, las áreas de libre comercio, al más profundo, integración económica completa. A continuación se detalla esta clasificación (Jager y Jepma 2011: 186):

1. Zona de Libre Comercio (FTA por sus siglas en inglés): los aranceles y las cuotas son eliminados entre los miembros pero mantienen el derecho de fijar aranceles o cuotas en relación con otros países. 
2. Unión Aduanera: no existe discriminación entre los miembros en cuanto a los mercados de productos y la Unión aplica aranceles externos comunes a otros países.

3. Mercado Común: al igual que la Unión Aduanera, no existe discriminación entre los miembros en cuanto a los mercados de productos y la Unión aplica aranceles externos comunes a otros países. A estas condiciones se agrega el libre tránsito de capitales y servicios.

4. Unión Económica: un Mercado Común que implementa cierto grado de uniformidad respecto de sus políticas económicas.

5. Integración Económica Completa: amalgama las políticas monetaria, fiscal y social, donde las decisiones son tomadas por una autoridad supranacional y se prevé un estado unitario central.

Estos cinco niveles de integración económica pueden resumirse en el siguiente cuadro:

Cuadro 2.1. Niveles de integración económica

\begin{tabular}{|c|c|c|c|c|c|}
\cline { 2 - 5 } \multicolumn{1}{c|}{} & $\begin{array}{c}\text { Eliminación } \\
\text { de } \\
\text { aranceles } \\
\text { y similares }\end{array}$ & $\begin{array}{c}\text { Arancel } \\
\text { exterior } \\
\text { común }\end{array}$ & $\begin{array}{c}\text { Libertad de } \\
\text { movimientos } \\
\text { de capital } \\
\text { y trabajo }\end{array}$ & $\begin{array}{c}\text { Instituciones } \\
\text { Económicas } \\
\text { comunes }\end{array}$ & $\begin{array}{c}\text { Instituciones } \\
\text { políticas } \\
\text { comunes }\end{array}$ \\
\hline $\begin{array}{c}\text { Zona de libre } \\
\text { comercio }\end{array}$ & $\mathrm{X}$ & $\mathrm{X}$ & & & \\
\hline Unión aduanera & $\mathrm{X}$ & $\mathrm{X}$ & $\mathrm{X}$ & & \\
\hline Mercado común & $\mathrm{X}$ & $\mathrm{X}$ & $\mathrm{X}$ & & \\
\hline Unión económica & $\mathrm{X}$ & $\mathrm{X}$ & $\mathrm{X}$ & $\mathrm{X}$ & \\
\hline Unión política & $\mathrm{X}$ & $\mathrm{X}$ & $\mathrm{X}$ & $\mathrm{X}$ & $\mathrm{X}$ \\
\hline
\end{tabular}

Fuente: Muñoz de Bustillo y Bonete 2009: 45.

Ahora bien, ¿la integración económica se genera entre países con condiciones de desarrollo similares o no? En este sentido, Lawrence (1996) distingue entre integración profunda e integración superficial. Según este autor, la integración profunda no necesariamente es más eficiente, pero permite la implementación de elementos que potencializan la eficiencia económica de los países involucrados. 
Para ejemplificar los niveles de integración analicemos lo siguiente. El TLCAN establece el libre comercio entre EEUU, Canadá y México, creando un área de libre comercio donde no hay obligación de que, por ejemplo, EEUU y México tengan el mismo arancel sobre textiles procedentes de China. Por su parte, la UE es una unión aduanera total donde todos los países aplican el mismo tipo arancelario a cada bien importado, sin importar por qué aduana entre el bien. Pero, a pesar de que México y Estados Unidos tienen libre comercio, los bienes que intercambian deben seguir pasando por una inspección de aduanas para asegurar que los bienes no sean mercancías producidas por terceros países. Observamos entonces, que los acuerdos de libre comercio imponen un carga burocrática importante, que puede ser un obstáculo significativo al comercio. (Krugman y Obstfeld 2008: 249)

Existen Acuerdos de Intercambio Comercial (RTAs por sus siglas en inglés) tanto entre países desarrollados como entre países en desarrollo, debido a que comparten características institucionales y monetarias. Es común que países con condiciones similares puedan integrarse con mayor facilidad y con menores costos de transición que aquellos que no comparten estas condiciones. No obstante, existen algunos RTAs entre países desarrollados y en desarrollo. Los estudios empíricos de teoría económica, teoría del desarrollo y economía política sugieren que para poder realizar esta integración, deberá ser de tipo profunda más que de tipo superficial (Jager y Jepma 2011: 187).

A pesar del impacto de la internacionalización, las condiciones domésticas e internacionales de mercado se mantienen separadas. Sobre todo por el peso específico de la identidad económica nacional, esto es, los gobiernos nacionales siguen teniendo, en cierta medida, soberanía para implementar políticas económicas propias. La economía internacional se convierte entonces, en un campo de batalla en el que las fuerzas de los mercados internacionalizados compiten con las políticas nacionales y las prácticas de las empresas individuales.

En general, las ventajas del libre comercio son más claras a mayores niveles de integración económica. Para Jacob Viner (1950) el cambio en las condiciones de comercio que están asociadas a la puesta en marcha de 
acuerdos de integración entre dos o más países genera dos tipos de efectos sobre el comercio exterior:

1. Desviación de comercio: al abaratarse el costo de las importaciones de los países pertenecientes al acuerdo, con respecto de terceros países, se penalizará el comercio con estos últimos a favor del comercio con los países de la zona integrada.

2. Efecto de creación de comercio: la integración provocará la sustitución de productos nacionales con precios más elevados por importaciones de otros países miembros, que resultan ser más baratas después de la eliminación de los aranceles.

El autor concluye que "...un proceso de integración será tanto más beneficioso cuanto mayor sea el efecto de creación de comercio y menor el efecto de desviación" (Muñoz de Bustillo y Bunete 2009: 47).

Además de potenciar el comercio, los acuerdos de integración regional, al aumentar el tamaño del mercado de las empresas de los países miembros, facilitarán la obtención de economías de escala. No obstante, para las empresas individuales o para sectores específicos de la economía esto puede presentarse de manera inversa, debido al aumento de la competencia. La participación de un país en un proceso de integración económica puede generar descontento entre su clase empresarial, pues la sitúa en una posición complicada obligándola a eliminar prácticas no eficientes dentro de la empresa, generando así un cambio-modernización de la cultura empresarial (Muñoz de Bustillo y Bonete 2009: 48).

Cabe señalar también, que la integración económica genera la pertenencia de un país a un bloque comercial y puede aumentar su credibilidad respecto de su política económica. Adicionalmente, le otorga a los países miembros un poder de negociación mayor en ciertos foros internacionales. Pero estas ventajas pueden convertirse en desventajas fácil y rápidamente. Ejemplo de ello es la prohibición impuesta por Rusia a la importación de alimentos procedentes de EEUU, la UE, Australia, Canadá y Noruega válida por un año desde el 7 de agosto de 2014. Esta prohibición se da como respuesta 
del gobierno ruso ante las sanciones que le fueron impuestas por EEUU y la UE derivadas del conflicto que mantiene este país con Ucrania. ${ }^{3}$ En este caso observamos cómo el hecho de pertenecer a un bloque comercial puede afectar la economía nacional de sus países miembros, pues en el caso de la UE se deriva de la postura política respecto del conflicto entre Ucrania, un país con el que se firmó en 21 de marzo de 2014 un acuerdo de asociación, y un país externo, Rusia.

Junto con las ventajas que se mencionan respecto de la integración económica, también pueden mencionarse los efectos negativos que estos acuerdos tienen sobre los países firmantes. Primero, la eliminación de las barreras comerciales generará un cambio en la composición sectorial de los integrantes. Es decir, la especialización generará el hundimiento de algunos sectores y el crecimiento de otros. "Por otra parte, si los sectores que utilizan distinta combinación de factores en su producción están localizados... en distintas áreas geográficas del país, la integración no sólo perjudicará a algunos colectivos y beneficiará a otros, sino que simultáneamente perjudicará a algunas regiones y beneficiará a otras" (Muñoz de Bustillo y Bonete 2009: $50)$.

Muchos observadores ven a la globalización y a la integración económica como motores del crecimiento económico que son irreversibles y que no se detienen. Sin embargo, y como lo veremos a continuación, es posible que surjan nuevas olas de proteccionismo como un esfuerzo de los países por asegurar el crecimiento de estos sectores en un contexto de integración económica.

En la década de 1970, las barreras arancelarias fueron sustituidas, en la mayoría de los casos, por barreras no arancelarias (BNA) ${ }^{4}$ que consisten en todo tipo de medidas a excepción de los aranceles de importación. En algunos casos, estas medidas proteccionistas son implementadas a partir de una decisión política explicita. Sin embargo, en otros casos las prácticas proteccionistas se basan en decisiones de las burocracias y agencias ejecutivas. A este tipo de proteccionismo se le llama protección administrada (en inglés Administered Protection). 
Existen formas de protección administrada, permitidas por la OMC, que pueden ser adoptadas por los gobiernos para proteger sus sectores económicos de daños derivados del comercio internacional, como son (Jager y Jepma 2011: 159-166):

1. Medidas de Salvaguardia. Muchos países suelen introducir cláusulas de escape a sus leyes comerciales. Estas medidas de urgencia se aplican cuando el aumento de las importaciones de determinados productos causan o amenazan con causar daño grave a la rama de producción nacional del país importador. Sus características son: que deberán ser temporales, se aplicarán en régimen de MFN, se liberalizarán progresivamente mientras estén en vigor, y el país que las imponga deberá dar una compensación a los Miembros cuyo comercio se vea afectado. (OMC 1994b)

2. Medidas Antidumping. El dumping es la venta de productos en el mercado internacional a un precio inferior al que se vendería en su propio mercado nacional. Esta práctica provoca que los productores del país no puedan competir en precio, y en ocasiones en calidad, con los productores extranjeros y quiebren. Las medidas antidumping consisten en la imposición de aranceles a los productos que, después de una investigación, se ha comprobado que están siendo objeto de dumping que están dañando la economía nacional. (OMC 1994)

3. Medidas Compensatorias. Si un país exportador subsidia las importaciones, pueden imponerse aranceles a dichas importaciones para compensar el valor de los subsidios con el fin de proteger la industria nacional que está siendo dañada por las importaciones. (OMC 1994c)

Como se comentó, estas nuevas formas de proteccionismo surgen con la finalidad de proteger ciertos sectores de la economía. Se ha observado que la el sector más protegido es la agricultura. Esto sucede, por ejemplo, con la Política Agrícola Común de la Unión Europea (PAC). Su proteccionismo va 
dirigido, por un lado, al mercado interno a través de subsidios a la producción, precios de garantía y suplementos de ingresos. Por otro lado, al comercio internacional a través de aranceles a la importación y subsidios a la exportación. Estas medidas pretenden lograr que los precios, que resultan ser más elevados en la EU, no sean minados por importaciones más baratas.

Esto genera que la PAC sea extremadamente cara, pues cada año la EU le destina el $46 \%$ de su presupuesto total. El Departamento de Negocios, Innovación y Habilidades del gobierno británico estima que los precios artificialmente altos promovidos por esta política agrícola suman aproximadamente 9 libras a lo que una familia gasta en alimentos a la semana. Además, implica que los ingresos derivados de una vaca lechera de la EU son mayores que aquellos de la mitad de la población humana del mundo. (Jager y Jepma 2011: 102)

Otro de los efectos de la PAC es que tiende a alentar la sobreproducción. El mercado de la EU no puede absorber el totalidad de su producción agrícola y entonces vende el superávit a países en desarrollo a precios muy bajos. Esto distorsiona la economía de estos países, pues sus productores son incapaces de competir con los productos altamente subsidiados de la Unión Europea.

\subsection{Proceso de liberalización económica de México}

En 1940 se da un punto de inflexión en el desarrollo nacional. Se abandona el proyecto Cardenista que basaba el desarrollo del país en el sector agropecuario y se consolida el proyecto industrializador liderado por el Estado. Dentro de esta nueva estrategia se subordinó el sector agrícola a las necesidades del crecimiento del sector industrial. El agro mexicano entra a jugar un doble papel: como proveedor de alimentos a los consumidores urbanos y materias primas baratas a la industria; y, proporcionando al país divisas indispensables para sufragar la importación de los insumos y bienes de capital que necesitaba la industria y que no podía financiar por sí misma. "Las políticas instrumentadas en este marco crearon el modelo de desarrollo dual del sector agropecuario mexicano, en el cual coexisten dos sectores altamente 
diferenciados: uno de gran escala y alta productividad, beneficiado por muchos de los estímulos otorgados a la industria sustitutiva (arroz, algodón, sorgo), y otro de baja productividad e ingresos, orientado al mercado interno compuesto por campesinos pequeños y minifundistas como los productores de maíz..." (Puyana y Romero 2004: 19-20).

La principal característica de la economía mexicana durante el modelo de sustitución de importaciones fue la concentración del manejo de los instrumentos para conseguir crecimiento económico. En este sentido, "el papel activo que adoptó el sector público durante el periodo de sustitución de importaciones hizo que la política fiscal fuera el instrumento más importante tanto por el lado del gasto como por el de los ingresos" (Clavijo 2000: 16). Al suministro de bienes públcos básicos el gobierno mexicano añadió la provisión directa de otros bienes considerados como estratégicos, es decir, aquellos con características de monopolios naturales.

La política de sustitución de importaciones redujo notablemente la presión de la competencia en la economía y el alcance de los incrementos en la productividad a través de la importación de tecnología. De esta manera, la sustitución de importaciones redujo la competitividad de los exportadores y condujo a una disminución de la participacón de las exportaciones en el PIB de largo plazo.

Durante este modelo económico se experimentó un elevado crecimiento económico, con una estabilidad de precios y del tipo de cambio y con un importante avance social. Por otro lado, también se gestaron una serie de problemas estructurales que posteriormente pretendieron ser solucionados mediante la liberalización de la economía. El enfoque de exclusiva producción para el mercado interno se agotó a comienzos de la década de los setenta del siglo pasado. Pretender sustituir todos los bienes intermedios y los bienes de capital parece haber sido una política errónea, pues era un camino que lejos de evitar importaciones iba a demandar muchas más en el mediano y largo plazo. Como Leopoldo Solís afirmara hace algunos años, "en el tipo de desarrollo hacia adentro tarde o temprano hace falta expandir la disponibilidad de divisas que permita sostener el proceso de desarrollo. La sustitución, en el mejor de 
los casos, concede un alivio temporal que es imperativo moderar para que el proceso no resulte de tal manera ineficiente, que impida más tarde competir en el campo internacional u obtener las divisas indispensables para sostner el proceso de crecimiento. Es decir, se necesita tener un plan para aumentar las exportaciones" [...] Aunado a ello, la crisis del sector agropecuario, la falta de una reforma fiscal y el consecuente estancamiento del sector exportador que no pudo contrarrestar las importaciones crecientes, dieron lugar a una serie de déficits fiscales y de cuenta corriente de la balanza de pagos que se volvieron crónicos, y establecieron retos importantes" (Cárdenas 2003: 84-85).

Uno de los principales objetivos de la política agrícola en el modelo de sustitución de importaciones fue mejorar la capacidad productiva para lograr la autosuficiencia alimentaria y apoyar así el desarrollo industrial. Esta política agraria funcionó a partir de los subsidios, los cuales compensaban los deteriorados términos de intercambio del campo en relación con otros sectores productivos. "La inversión pública en investigación, extensión, asistencia técnica, capacitación, controles sanitarios, apoyos directos a la producción, comercialización y transformación y los subsidios a través del sistema de crédito, de los precios subvencionados y del gasto público en fomento eran la base del desarrollo agrícola, acompañado de la protección a la producción nacional para el mercado interno" (Cámara de Diputados 2000: 31-32).

Aunque la integración regional y la diversificación comercial se iniciaron desde antes, no fue sino hasta 1961 que México se adhirió a un acuerdo regional: la Asociación Latinoamericana de Libre Comercio (ALALC), la cual en 1980 se transformó en la Asociación Latinoamericana de Integración (ALADI).

En los años ochenta del siglo XX se inician una serie de reformas estructurales en materia económica con las que se pretendió combatir el desempleo, la pobreza y la baja productividad a través del logro de tasas de crecimiento elevadas y sostenidas. En este sentido, la apertura comercial induciría cambios en la ubicación de factores productivos y promovería exportaciones en los bienes en los que México fuera más eficiente que sus socios comerciales. Se suponía, por tanto, que la nueva estructura y el mayor dinamismo de la economía mexicana serían los generadores de una mayor 
productividad, elevados ingresos y disminución de la tasa de desempleo. Con las medidas anteriores, el nuevo objetivo de la política económica era pasar de una economía protegida y orientada al mercado interno, hacia una economía abierta mayormente orientada al mercado mundial.

A nivel internacional el crecimiento del sistema capitalista está determinado por el aumento en el nivel de ganancias de los productores de bienes y servicios, el cual debe buscar extenderse a todos los mercados del planeta, siempre y cuando se cuente con los niveles competitivos que eviten riesgos de pérdidas y quiebras. Los grandes países capitalistas saben muy bien que además de buscar contar con ventajas competitivas y comparativas a nivel internacional, su búsqueda de nuevos mercados también implica el dirigirse a economías con ciertas condiciones de estabilidad económica, política y social. La búsqueda de medidas de estabilización para lograr mejores condiciones de intercambio comercial en un contexto de firmas de tratados entre países tuvo su mayor auge en la década de los ochentas.

La nueva política de estabilización planteada por México a lo largo de la década en comento estuvo claramente determinada por las necesidades de incorporarse a las políticas neoliberales en un contexto de mayor apertura comercial internacional. Dicha política inició el 15 de diciembre de 1987 con tres elementos centrales: la concertación social como marco de la política económica, el establecimiento de "anclas" monetarias múltiples para el control del lado de la oferta y una política de demanda global orientada a evitar un eventual colapso de las "anclas" establecidas. Formalmente se trata de un mecanismo por el cual el gobierno se compromete a compartir la responsabilidad de la política económica con los representantes de los sectores empresarial, obrero y campesino, estableciendo acuerdos sobre precios públicos y privados de bienes, servicios, niveles salariales, políticas fiscal, crediticia y cambiaria, grado de apertura comercial y cualquier otro aspecto relevante sobre un horizonte temporal definido (LASA 1992: 162). Dichos mecanismos son conocidos comúnmente como "Planes de choque" y en México iniciaron con la firma del Pacto de Solidaridad Económica (PSE) en 1988. 
Las principales medidas iniciales acordadas en el PSE fueron (LASA 1992: 165-170):

1. Control de precios.

- Se elevaron los salarios mínimos y contractuales en un $15 \%$ a partir del 16 de diciembre de 1987 y se dispuso un aumento adicional de $20 \%$ en los salarios mínimos a partir del 1 de enero. Esta medida representa el inicio de un control predeterminado en el aumento a los salarios, aceptado por las principales representaciones patronales.

- Ajuste de precios y tarifas del sector público y congelamiento de los mismos hasta el final de la concertación a fines de febrero de 1988. A partir de marzo se ajustarían de acuerdo con la inflación proyectada. Resulta evidente la búsqueda del control de precios.

- La Comisión de Seguimiento y Evaluación del Pacto buscó mantener fijos los precios de los bienes y servicios controlados.

- Los precios de artículos de la canasta básica se corregirían en diciembre y se mantendrían sin cambios hasta fines de febrero. Se consideró la necesidad de ajustarlos de acuerdo con la evolución de los precios y tarifas del sector público, los salarios y los precios de garantía de los productos agropecuarios.

- Los precios de garantía se ajustarían de acuerdo con el calendario agrícola a fin de que mantuvieran el valor real promedio de 1987.

- Se aumentó el tipo de cambio controlado en 22\% (el libre había sido ya aumentado desde octubre) y se afirmaba que la evolución de este precio debía contribuir a moderar las presiones inflacionarias y a mantener competitivas las exportaciones del país. 
2. Política comercial.

- La tasa arancelaria máxima se redujo de 40 a $20 \%$, con lo que el promedio arancelario pasó de 22.8 a $11.8 \%$ y se anuló el impuesto adicional a la importación, que significaba un gravamen del $5 \%$ sobre las importaciones.

3. Política fiscal.

- El gobierno se comprometió a lograr un superávit primario de 8.3\% del PIB, para lo cual habría una reducción adicional del gasto público no financiero y se reforzaría el combate a la elusión y evasión fiscal. Sin embargo, a pesar de la desincorporación de empresas y organismos del sector público, el superávit primario fue de $6 \%$ del PIB, como consecuencia principalmente de una disminución del precio del petróleo.

4. Política monetaria y crediticia.

- En materia monetaria y crediticia, se permitiría que la tasa de interés se ajustara con la flexibilidad y se aplicarían restricciones crediticias en la banca comercial y la de desarrollo. Esto último se concretó mediante una disposición por la cual el sistema bancario debía reducir su cartera de créditos al sector privado a partir de enero de 1988 hasta llegar a 90\% del nivel promedio alcanzado por esa cartera en diciembre del año anterior. Puesto que el tipo de cambio real se mantuvo prácticamente constante durante todo 1988, la tasa de interés real en dólares fue muy alta durante todo el año, aunque con una marcada tendencia a la baja en el primer semestre y cierta estabilidad en el segundo.

- Tres de los cuatro precios relativos claves se movieron decididamente a la baja en 1988: 17.3\% para el tipo de cambio real; $4.7 \%$ para los precios controlados; y $12.4 \%$ para el salario real. Aunque el índice de precios relativos de los bienes de las empresas públicas no disminuyó, lo cierto es que prácticamente se mantuvo sin cambio al aumentar en $0.2 \%$. 
En consecuencia, puede decirse que la políticas de ajuste llamadas de la "Segunda generación", implementadas en la segunda mitad de los ochenta y de inspiración liberal (contracción del Estado, apertura de las fronteras), pudieron lograr cierto éxito, pues pusieron fin a los procesos hiperinflacionarios y permitieron en cierta medida la reanudación del crecimiento (Salama y Valier 1992:131).

Se esperaba que a partir de los últimos años del decenio de los ochenta y hasta principios de los noventa, el Estado se alejara de las políticas de seguridad alimentaria de decenios anteriores, con lo que se desmantelarían los mecanismos de apoyo estatal que incluían el otorgamiento de créditos con tasas de interés más bajas que las del mercado, la comercialización de productos agrícolas y la venta de insumos a precios subsidiados, además de reducir los servicios de investigación y extensión rural.

México redujo las operaciones del BANRURAL, el banco estatal de crédito al campo; eliminó el monopolio de la Compañía Nacional de Subsistencias Populares (CONASUPO) respecto de la comercialización de alimentos básicos, con excepción del maíz y el frijol. Los controles de precios de alimentos básicos e insumos agroindustriales se relajaron, aunque en forma más lenta en los casos del frijol y el maíz, los dos principales elementos de la dieta del mexicano.

Una de las políticas con mayor consecuencia fue la reforma en 1992 del artículo 27 de la constitución ${ }^{5}$, que contribuyó a la liberación de los mercados al eliminar la mayoría de las prohibiciones respecto de la transferencia y tenencia de la tierra, sobre todo ejidal. El ejido es un tipo de propiedad comunal de la tierra que se estableció después de la revolución de 1910, casi $70 \%$ de los campesinos mexicanos son ejidatarios o comuneros.

A principios del decenio de los noventa, para compensar la contracción de los mecanismos de apoyo estatal el gobierno federal puso en marcha un programa sectorial de subsidio directo por hectárea: el Procampo, aún en operación. 
México siguió concertando acuerdos subregionales hasta 1991, cuando firma el Acuerdo de Complementación Económica con Chile, que establece un arancel cero para el comercio a partir de 1996. La diversificación comercial se convirtió en la razón de ser de la política comercial externa, y el gran reto fue la vinculación con la región del Pacífico. En mayo de 1989, México ingresó al Consejo Económico de la Cuenca del Pacífico (PBEC); en mayo de 1991 se incorporó al Consejo de Cooperación Económica del Pacífico (PECC), y en noviembre de 1993 al Foro de Cooperación Económica Asia-Pacífico (APEC) (González García 1998: 96).

Antes de iniciarse las negociaciones del TLCAN se instrumentaron las siguientes reformas: desaparición de la Compañía Nacional de Subsistencias Populares (Conasupo) y la liquidación o privatización de otras empresas públicas agropecuarias o de alimentación; la eliminación de los precios de garantía y de los subsidios a los insumos agropecuarios; la reestructuración del sistema de crédito oficial; la reforma al artículo 27 Constitucional y la privatización de los derechos de propiedad de la tierra en el sector social (reforma ejidal), y la liberalización del comercio tras el GATT en la UR. Además, desde 1989 se han creado el Órgano Desconcentrado de Atención al Sector (Aserca) y programas como Procampo y Alianza para el Campo.

El 17 de diciembre de 1992 México firma el Tratado de Libre Comercio de América del Norte (TLCAN) con Estados Unidos y Canadá; que entró en vigor el 10 de enero de 1994; año que sería de suma importancia para la política económica mexicana, debido a la suscripción de dos acuerdos económicos más. En el mes de junio se signa el acuerdo del Grupo de los Tres con Venezuela y Colombia, mismo que entra en vigor el 1 de enero de 1995 . El mismo año pacta con Costa Rica un acuerdo de libre comercio, que entró en vigor en 1995 (González García 1998: 296). Como se observa, la política de apertura comercial de México se impulsó tres décadas antes de firmar el TLCAN. La diversificación de los mercados y la producción a partir de las ventajas competitivas fueron algunas de las razones por las que muchos países de América Latina buscaron socios comerciales. 
Al momento de negociar el TLCAN el sector agropecuario mexicano estaba, como lo está hoy en día, profundamente escindido por un dualismo sectorial. Esto implica que ciertos segmentos de la agricultura, la ganadería, la pesca y la silvicultura mexicanas producían con niveles de productividad muy bajos con respecto a sus socios comerciales y en relación a la productividad que representaba el resto de la economía mexicana. "Esta dualidad emerge, por una parte, de la fragmentación de la propiedad de la tierra y, por la otra... del sesgo de ciertos instrumentos de política sectorial que favorecieron la agricultura mecanizable de gran extensión, orientada a las exportaciones y a producir insumos industriales" (Puyana y Romero 2004: 22). Estas condiciones nos indican que para la mayor parte de los pequeños productores el tamaño de sus predios era demasiado reducido y no les permitía dedicación exclusiva a actividades agropecuarias. Como indican Alicia Puyana y José Romero: "A mayor fragmentación y concentración de la propiedad, más restringida la respuesta" (Puyana y Romero 2004: 64).

\subsection{La negociación entre los países firmantes del TLCAN}

A lo largo de la década de los noventa del siglo XX, a la par de la entrada en vigor del TCLAN ocurrieron diversos acontecimientos que impactaron al sector agrícola:

"Entre ellos destacan la crisis ocurrida entre 1994 y 1995, la depreciación y posterior apreciación del peso mexicano; la insuficiente inversión en infraestructura; los no siempre eficientes programas de apoyo instrumentados por el gobierno mexicano; la caída de los precios internacionales de los productos agrícolas; la insuficiencia del crédito; las disparidades en las condiciones de producción y comercialización de lo distintos tipos de productores; el ineficiente funcionamiento de los mercados domésticos agropecuarios; la fragmentación de la tenencia de la tierra; rezagos estructurales en el 
desarrollo de mercados regionales; graves fenómenos naturales" (Puyana y Romero 2004: 9-10).

Estos factores confluyeron cuando el sector agropecuario mexicano, afectado por una baja competitividad, se abría a la competencia con Estados Unidos y Canadá, economías sumamente competitivas, como lo muestra la siguiente gráfica:

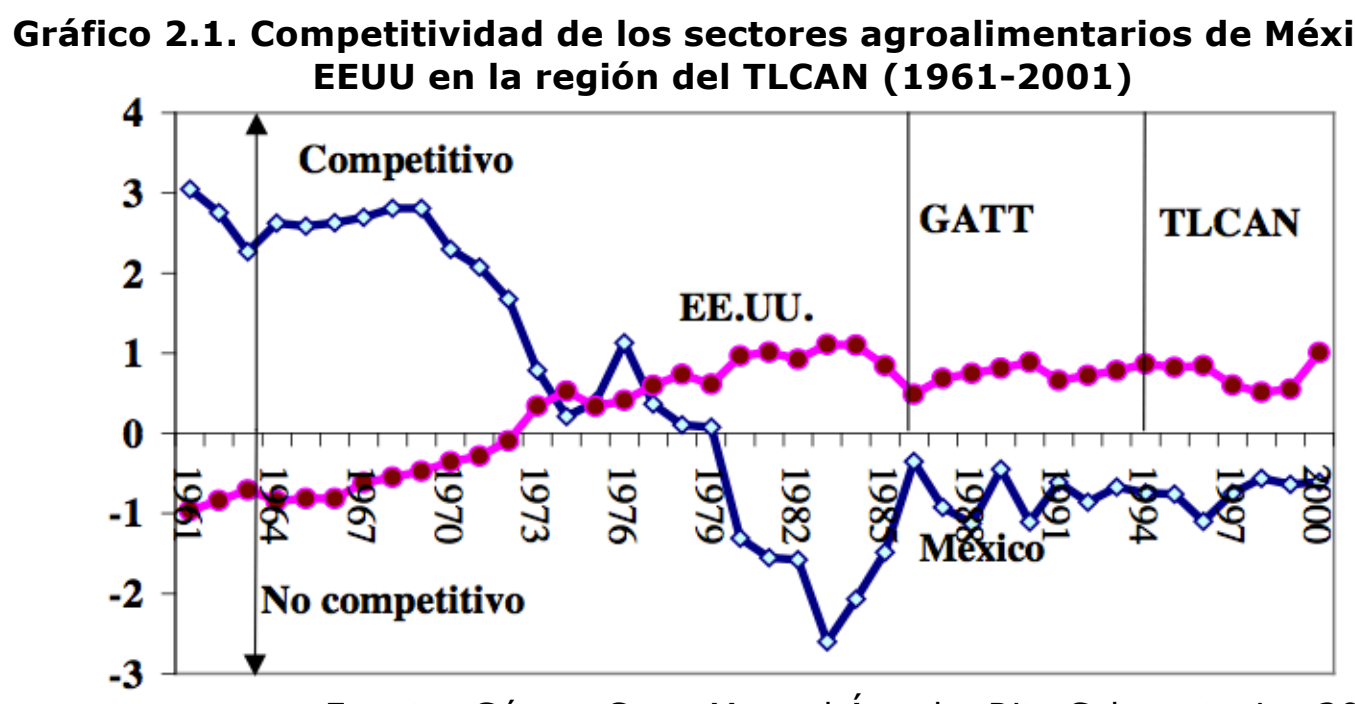

Fuente: Gómez Cruz, Manuel Ángel y Rita Schwentesius 2004: 59.

En este sentido, el TLCAN debe entenderse como el resultado de un proceso de negociaciones en el que los tres países firmantes buscaron obtener los mayores beneficios económicos posibles. Si no conocemos cómo se dio este proceso de gestación del acuerdo que intentamos analizar en el presente capítulo, difícilmente podremos analizar el impacto que ha tenido sobre el sector agrícola mexicano. Por tal motivo, a continuación detallamos brevemente el proceso de negociaciones que existió entre México, EEUU y Canadá.

Las negociaciones sobre el TLCAN se iniciaron en junio de 1991 entre los tres países interesados. Tan sólo un par de años después, el 17 de noviembre de 1993, el Congreso de los EEUU lo aprobó, una vez que las cuestiones polémicas relacionadas con el medio ambiente y asuntos laborales fueran 
abordadas en los Acuerdos Paralelos. Su entrada en vigor data del 1 de enero de 1994.

EI TLCAN además de ser producto de las negociaciones entre los países firmantes reúne tres acuerdos comerciales distintos:

"El de Estados Unidos y Canadá, que funciona teniendo como base el Acuerdo de Libre Comercio firmado por estos países en 1989; el de México y Estados Unidos, que empezó a discutirse en 1990; y, finalmente, el de México y Canadá, al incorporarse este país a las negociaciones de México y Estados Unidos en 1991. La redacción del texto final y la firma del mismo por los tres países el 1 de junio de 1993, estuvo a cargo de las administraciones Bush en Estados Unidos, Salinas en México y Mulroney en Canadá...". (Cámara de Diputados 2000: 3)

No se puede ignorar la gran disparidad que existe entre las economías de los países firmantes. "En la agricultura las asimetrías son aún mayores. La productividad de la agricultura mexicana en el periodo de las negociaciones era casi nueve veces menor que la estadounidense" (Puyana y Romero 2004: 41). Las asimetrías en este sector son de carácter económico, tecnológicas y de factores de producción.

El territorio mexicano equivale al 20 por ciento del tamaño de EEUU. Dos terceras partes de México son áridas y semiáridas. Comparada con los 187.9 millones de hectáreas de EEUU, México únicamente cuenta con 23.1 millones de hectáreas de superficie cultivable; es decir, en México la tierra cultivable por persona es en promedio de 0.283 hectáreas, comparado con las 0.769 de Estados Unidos. Alrededor del $10 \%$ de la tierra cultivable en Estados Unidos es de riego, comparada con el $20 \%$ de México. La disponibilidad de agua en México depende básicamente de la lluvia, pues la mayor parte de la cantidad de agua necesaria para el riego proviene de los almacenamientos superficiales.

En 1990 la población de México era alrededor de un tercio de la de EEUU, en promedio diez años más joven y con expectativas de vida de 67 años, en comparación con la esperanza de vida en Estados Unidos de 73 años. 
Aunado a lo anterior, México está densamente poblado, pues aproximadamente un tercio de la población vive y trabaja en las áreas rurales.

Respecto de la economia de ambos países existían diferencias reales y significativas:

"La economía de Estados Unidos es mucho más fuerte que la economía mexicana, con un producto interno bruto (PIB), cerca de veinte veces el de México... Las exportaciones e importaciones de Estados Unidos aportan entre el 7 y 9 por ciento al PIB total, mientras que en México aportan entre 15 y 16 por ciento. El sector agropecuario mexicano aporta al PIB alrededor del 7 por ciento, mientras en Estados Unidos su contribución es menor al 3 por ciento" (Cámara de Diputados 2000: 4-5).

Esta situación impacta directamente en los montos que cada gobierno destina al desarrollo rural.

Gráfico 2.2. Presupuesto real para el desarrollo rural de México, 1990-2002 (millones de pesos de 2011)

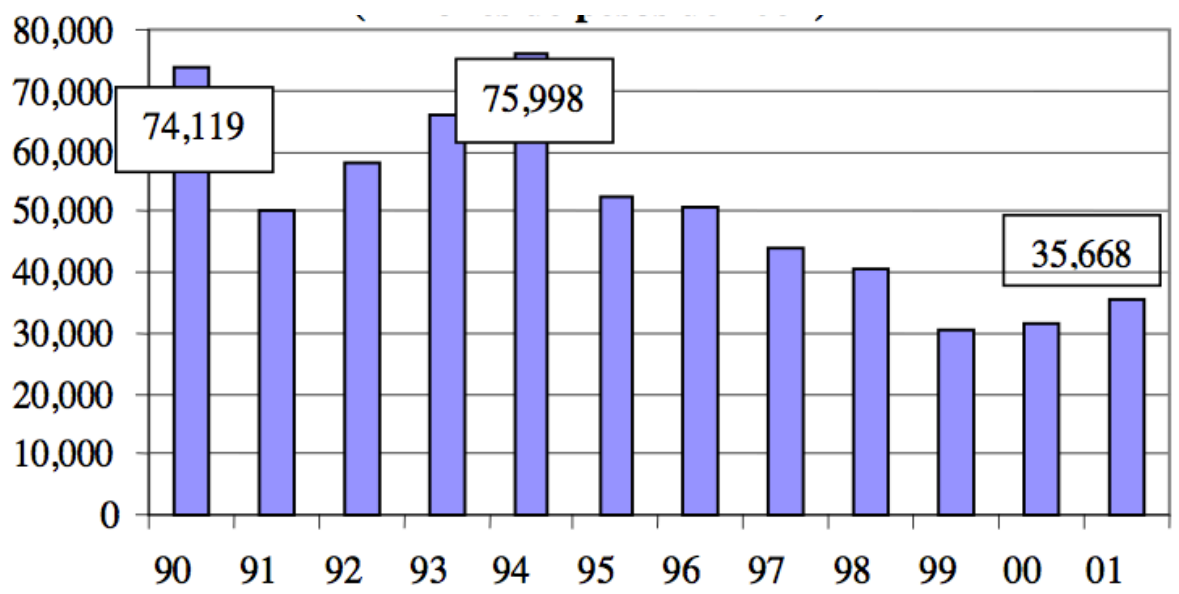

Fuente: Gómez Cruz, Manuel Ángel y Rita Schwentesius 2004: 58. 
Adicionalmente, existe una gran diferencia entre los apoyos y subsidios que cada país firmante destinan a su sector agrícola, como resulta posible observar en la gráfica siguiente:

Gráfico 2.3 Estimación de los apoyos a la agricultura en Estados Unidos, Canadá y México, 1986-2001 (\% del valor de la producción)

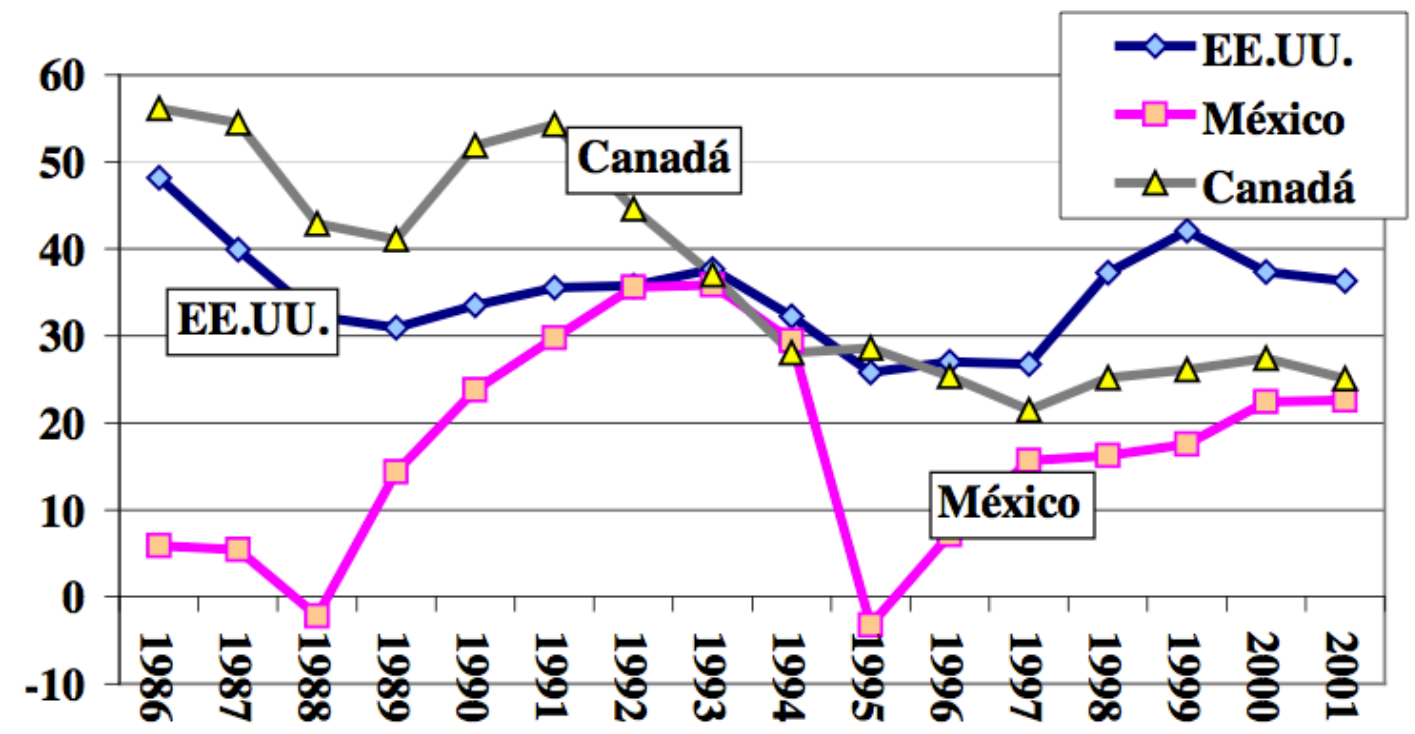

Fuente: Gómez Cruz, Manuel Ángel y Rita Schwentesius 2004: 56.

En la década de los noventa del siglo XX, la agricultura de EEUU y Canadá estaba dominada por granjas de gran escala y firmas gigantes de procesamiento de alimentos. Mientras tanto, el sector agrícola mexicano estaba integrado por pequeñas explotaciones agrícolas.

A continuación presentamos una tabla que engloba las principales asimetrías entre los países firmantes del TLCAN: 


\section{Cuadro 2.2. Asimetrías entre México, Estados Unidos y Canadá}

\begin{tabular}{|c|c|c|c|}
\hline & México & Estados Unidos & Canadá \\
\hline Población $(1,000)^{1}$ & 100,368 & 285,926 & 31,015 \\
\hline Población rural $(1,000)^{1}$ & 25,555 & 64,539 & 6,535 \\
\hline Población agrícola $(1,000)^{1}$ & 23,064 & 6,162 & 766 \\
\hline Presión demográfica (hab $/ \mathrm{km}^{2}$ ) & 51 & 30 & 3 \\
\hline Superficie total $(1,000 \mathrm{ha})^{2}$ & 195,820 & 962,909 & 997,061 \\
\hline Tierras arables $(1,000 \mathrm{ha})^{2}$ & 27,300 & 179,000 & 45,700 \\
\hline Tierra irrigada $(1,000 \mathrm{ha})^{3}$ & 6,500 & 22,400 & 720 \\
\hline PIB US\$ mil mill. $(1999)^{4}$ & 428.8 (lugar 12) & $8,351.0$ (lugar 1$)$ & 591.4 (lugar 9) \\
\hline PIB per cápita (US\$ 1999) ${ }^{4}$ & 4,400 (lugar 71) & 30,600 (lugar 8) & 19,320 (lugar 29) \\
\hline Índice de GINI ${ }^{4}$ & 53.7 & 40.8 & 31.5 \\
\hline $\begin{array}{l}\text { Concentración del ingreso en el } 10 \% \text { de la po- } \\
\text { blación con ingreso más alto }(\%)^{4}\end{array}$ & 42.8 & 30.5 & 23.8 \\
\hline Rango de competitividad (lugar) $2001^{5}$ & 51 & 2 & 11 \\
\hline Crecimiento de competitividad (lugar) & 42 & 2 & 3 \\
\hline $\begin{array}{l}\text { Gasto en investigación agropecuaria/PIB agro- } \\
\text { pecuario }(\%)\end{array}$ & 0.52 & 2.60 & \\
\hline Gasto público en educación (\% del PIB $)^{4}$ & 4.9 & 5.4 & 6.9 \\
\hline Tractores $/ 1,000$ trabajadores $^{4}$ & 20 & 1,484 & 1,642 \\
\hline Salario en la agricultura (US\$/año), $1995 / 98^{42}$ & 908 & n.d. & 30,625 \\
\hline Productividad agrícola (US\$/trabajador) ${ }^{4}$ & 2,164 & 39,001 & n.d. \\
\hline Deforestación (cambio anual \%) ${ }^{4}$ & 0.9 & $-0.3 *$ & $-0.1^{*}$ \\
\hline $\begin{array}{l}\text { Subsidios agrícolas (\% del valor de la produc- } \\
\text { ción) } 2001^{6}\end{array}$ & 22 & 36 & 25 \\
\hline $\begin{array}{l}\text { Importación agroalimentaria (1998/2000), valor } \\
\text { en } 1,000 \text { de dólares }{ }^{7}\end{array}$ & $8,935,732$ & $43,354,622$ & $11,046,062$ \\
\hline $\begin{array}{l}\text { Exportación agroalimentaria (1998/2000), valor } \\
\text { en } 1,000 \text { de dólares }{ }^{7}\end{array}$ & $7,157,371$ & $55,508,420$ & $15,253,898$ \\
\hline Balanza comercial, en 1,000 dólares & $-1,778,361$ & $12,153,798$ & $4,207,837$ \\
\hline Rendimiento de maíz $(\mathrm{t} / \mathrm{ha})^{8}$ & 2.50 & 8.55 & 7.15 \\
\hline
\end{tabular}

n.d., no definido, * el valor negativo significa que están forestando.

Fuente: Gómez Cruz, Manuel Ángel y Rita Schwentesius 2004: 67.

Cuando se generan acuerdos de integración entre socios desiguales, como es el caso de los países firmantes del TLCAN, existen mecanismos de tratamiento preferencial para los socios menos desarrollados. Uno de estos mecanismos son las ventajas arancelarias que constituyen la discriminación a los no miembros, es decir, los países que han firmado el acuerdo comercial tendrán preferencia sobre los que se encuentran fuera del acuerdo. Es por ello que el reconocimiento de todas estas asimetrías era el punto de partida para que en el TLCAN se otorgara un trato diferenciado a México y se aceptaran 
plazos especiales de desgravación antes de llegar a la liberalización total. "Los dos países encontraron una fórmula para proteger sus productos sensibles. Los Estados Unidos obtuvieron plazos y cuotas en los productos de interés para México, como las frutas y las hortalizas, mientras que México logró una gradual apertura de sus mercado de maíz, otros granos, oleaginosas y cárnicos" (Cámara de Diputados 2000: 40).

A pesar de lo anterior, el Tratado se ocupa mucho más de la inversión que de la liberalización comercial, la cual se encontraba casi resuelta antes de su negociación. La principal preocupación de EEUU y Canadá era asegurar la reducción del riesgo de una variada inversión extranjera en México:

"El papel que jugó el TLCAN para cada uno de los tres países fue diferente. Para México el TLCAN fue determinante dentro de su estrategia macroeconómica, en la orientación del mercado adoptada. La negociación en México estuvo en mayor medida relacionada con el cambio estructural, mientras que para los canadienses $y$ estadounidenses fue un mero acuerdo comercial. Para México, las decisiones tomadas en materia agrícola tendrían gran impacto en el futuro del campo. El Tratado institucionaliza el modelo económico neoliberal y pretende darle un carácter definitivo e irreversible" (Cámara de Diputados 2000: 6).

EEUU tenía un interés crucial en el TLCAN pues tanto Canadá como México son dos de sus mejores mercados para sus exportaciones agrícolas. Tan sólo en 1993 las exportaciones estadounidenses hacia ambos países fueron alrededor de 9 mil millones de dólares y representaron cerca del 20 por ciento del total de sus exportaciones agrícolas:

"De acuerdo al análisis del Departamento de Agricultura de Estados Unidos (USDA), al final del periodo de transición de quince años se espera que las exportaciones anuales de Estados Unidos a México sean mayores en $\mathbf{2 . 6}$ miles de millones de dólares, a lo que hubieran sido en ausencia del Tratado. Los granos, oleaginosas y carne serán los productos de mayor incidencia en su crecimiento. El mismo estudio proyecta un crecimiento de las exportaciones mexicanas a 
Estados Unidos sólo alrededor de 500 y 600 millones de dólares anuales, al final del periodo de transición" (Cámara de Diputados 2000: 9).

Entre los principales objetivos de los negociadores mexicanos en el TLCAN estaba aprovechar las oportunidades del comercio internacional mediante la especialización en los productos con ventajas comparativas y mejorar la balanza comercial deficitaria de los años precedentes. Así, el comercio exterior debía ser el eje del desarrollo económico en un modelo secundario exportador. Además, el Estado no debía ser el actor más importante sino alentar la participación de los agentes privados y la integración económica y comercial a través de las empresas transnacionales.

Por otro lado, el Tratado se enmarcó en el Programa Nacional de Modernización del Campo, impulsado por la administración de Salinas (19891994), dentro del que se emprendieron acciones radicales de liberalización del sector agrícola que los negociadores mexicanos apuntaron como soporte y que se detallan a continuación:

- Se reformó el Artículo 27 constitucional. A través de dicha modificación se pretendió fomentar la transformación del capital privado nacional y extranjero en el principal agente de reactivación de la economía y, sobre todo, del sector agropecuario. "En este sentido, la nueva legislación agraria, al liberar el régimen de propiedad de la tierra, busca desarrollar un mercado de tierras dinámico que permita la afluencia masiva de capitales privados y extranjeros, legalizando las acciones de privatización y renta de este tipo de tierras o los distintos contratos de asociación con los productores minifundistas" (Romero 2002: 61).

- Se racionalizó el esquema de subsidios y de sustitución por un esquema de pagos agropecuarios.

- Se desarrolló y fomentó un esquema moderno de comercialización de productos agropecuarios. 
- A través de la apertura comercial en el sector agropecuario se procuró impulsar la modernización de la producción y fomentar su especialización.

- Mediante políticas públicas se intentó combatir la pobreza de las zonas rurales.

Con respecto al contenido del Tratado, los diseñadores mexicanos de política agropecuaria buscaron compensar la liberalización unilateral de la agricultura y la economía impulsada en México a partir de su entrada al GATT en los siguientes términos:

- Garantizar el acceso de las exportaciones mexicanas al mercado de los EEUU y Canadá.

- Favorecer la capitalización del campo mediante la reducción de los costos de producción y comercialización eliminando aranceles.

- Impedir que las restricciones fitozoosanitarias fueran una barrera al comercio de productos agropecuarios.

- El establecimiento de reglas claras y equitativas para el intercambio de productos agropecuarios en el área de América del Norte.

- Sustituir los cultivos tradicionales de baja productividad por productos con un potencial mayor orientados al comercio externo.

- Establecer plazos de apertura graduales.

- Fomentar la inversión tanto nacional como extranjera en el campo.

Los objetivos explícitos a lograr a través de la negociación del TLCAN eran (Cámara de Diputados 2000:13):

- Eliminar todas las barreras arancelarias y no arancelarias entre México y EEUU con el objetivo de maximizar los beneficios derivados de una especialización creciente de la producción de acuerdo con las ventajas comparativas de cada país; así como el reconocimiento de la asimetría entre los sectores agropecuarios de los dos países.

- Plazos largos de desgravación en México para la totalidad de los productos sensibles del sector agropecuario, con el objetivo de brindar márgenes suficientes para la reconversión productiva. 
- Desgravación inmediata o a mediano plazo de los principales insumos que utiliza el sector agropecuario.

- Mecanismos ágiles para impedir que los subsidios a la exportación de países dentro o fuera de la región generasen competencia desleal para el productor mexicano.

\subsection{Contenido en materia agrícola del TLCAN}

La redacción final del texto, tal como fue aprobada por los órganos legislativos de los países firmantes, contiene el siguiente acuerdo agrícola entre México y EEUU:

- Ambos debían eliminar las barreras no arancelarias para enero de 1994 y mantener mecanismos de protección para mercancías sensibles (México, por ejemplo, mantendría protegidos el cerdo, el café instantáneo, la papa congelada y la manzana)

- Los aranceles agrícolas serían eliminados gradualmente en tres períodos quinquenales sucesivos hasta liberalizar por completo el comercio de productos agrícolas en 2008.

- Se crearon mecanismos para evitar prácticas desleales y solucionar controversias.

Por otra parte, México estableció con Canadá los siguientes compromisos

- Liberalización inmediata del $80 \%$ de las importaciones agrícolas provenientes de México (incluyendo el jugo de naranja)

- Apertura del mercado mexicano al $40.3 \%$ de las importaciones de Canadá.

- El comercio restante se sujetaría a períodos de supresión gradual de entre 5 y 15 años (excepto productos lácteos, aves, huevos y azúcar).

En este sentido, el TLCAN compromete a los países signantes a la eliminación de todos los aranceles en un plazo no mayor de quince años a 
partir de su entrada en vigencia, de acuerdo a un calendario de desgravación definido.

\begin{tabular}{|c|c|c|c|c|}
\hline \multicolumn{5}{|c|}{$\begin{array}{l}\text { Cuadro } 2.3 \text { Proceso de liberalización de productos alimentarios } \\
\text { seleccionados en el marco del TLCAN (1989-2008) }\end{array}$} \\
\hline 1989 & 1994 & 1998 & 2003 & 2008 \\
\hline \multirow[t]{3}{*}{$\begin{array}{l}\text { Se inicia el } \\
\text { Tratado de Libre } \\
\text { Comercio EEUU - } \\
\text { Canadá }\end{array}$} & $\begin{array}{l}\text { Entra en vigor el } \\
\text { TLCAN }\end{array}$ & $\begin{array}{l}\text { Desaparecen los } \\
\text { últimos aranceles } \\
\text { entre EEUU y } \\
\text { Canadá }\end{array}$ & $\begin{array}{l}\text { Continúa el } \\
\text { proceso de } \\
\text { desaparición de } \\
\text { aranceles }\end{array}$ & $\begin{array}{l}\text { Termina el } \\
\text { proceso de } \\
\text { desaparición de } \\
\text { aranceles }\end{array}$ \\
\hline & $\begin{array}{l}\text { EEUU elimina los } \\
\text { aranceles de } \\
\text { sorgo, harina de } \\
\text { arroz, naranjas, } \\
\text { toronja, } \\
\text { manzana, pera, } \\
\text { durazno, fresa } \\
\text { fresca, cacao en } \\
\text { polvo, carnes } \\
\text { bovina, porcina y } \\
\text { pollo. }\end{array}$ & $\begin{array}{l}\text { EEUU elimina los } \\
\text { aranceles de } \\
\text { trigo duro, aceite } \\
\text { de soya, } \\
\text { naranjas, higos, } \\
\text { mangos, cerezas, } \\
\text { algodón y rosas. }\end{array}$ & $\begin{array}{l}\text { EEUU elimina los } \\
\text { aranceles de } \\
\text { trigo duro, arroz, } \\
\text { harinas y } \\
\text { almidones, limón } \\
\text { persa, hortalizas } \\
\text { de invierno, fresa } \\
\text { congelada, } \\
\text { hongos, } \\
\text { aguacate, } \\
\text { papaya, chiles } \\
\text { Anaheim y } \\
\text { ancho, quesos y } \\
\text { mantequilla. }\end{array}$ & $\begin{array}{l}\text { EEUU elimina los } \\
\text { aranceles de jugo } \\
\text { de naranja, } \\
\text { hortalizas de } \\
\text { invierno (brécol, } \\
\text { pepino, } \\
\text { espárrago, } \\
\text { cebolla y ajo } \\
\text { deshidratados, } \\
\text { melón, en ciertas } \\
\text { épocas), } \\
\text { azúcares, } \\
\text { cacahuate y } \\
\text { atunes. }\end{array}$ \\
\hline & $\begin{array}{l}\text { México elimina } \\
\text { aranceles de } \\
\text { sorgo, naranja, } \\
\text { toronja, } \\
\text { mandarina, } \\
\text { limón, zanahoria, } \\
\text { guisantes, } \\
\text { cebolla, } \\
\text { garbanzo, fresa } \\
\text { fresca, higo, piña } \\
\text { y productos } \\
\text { pesqueros. }\end{array}$ & $\begin{array}{l}\text { México elimina } \\
\text { aranceles de } \\
\text { pera, ciruela, } \\
\text { melocotón, } \\
\text { chabacano, } \\
\text { cereza, kiwi, } \\
\text { algodón y maíz } \\
\text { dulce. }\end{array}$ & $\begin{array}{l}\text { México elimina } \\
\text { aranceles de } \\
\text { trigo, cebada, } \\
\text { arroz, harinas de } \\
\text { granos, lácteos, } \\
\text { harina y aceite } \\
\text { de soya, naranja, } \\
\text { manzana, fresa } \\
\text { congelada, papa, } \\
\text { productos } \\
\text { porcícolas, leche } \\
\text { en polvo y } \\
\text { tabaco. }\end{array}$ & $\begin{array}{l}\text { México elimina } \\
\text { aranceles de } \\
\text { maíz, azúcar, } \\
\text { frijol, leche en } \\
\text { polvo y productos } \\
\text { lácteos. }\end{array}$ \\
\hline
\end{tabular}

Fuente: Lechuga 2006: 113.

En este nuevo marco México tuvo que modificar el sistema de protección comercial que venía utilizando y que consistía, principalmente, en el apoyo directo a los precios. Este mecanismo tuvo que ser sustitído por un sistema de pagos directos, es decir, las ayudas debían recaer principalmente en los productores (agricultores). ${ }^{6}$ Esta transformación de los subsidios implícitos en los sistemas de precios de garantía dio origen al Programa de Apoyos Directos a los Productores, conocido ampliamente como Procampo.

Con respecto a los subsidios a la exportación, los países miembros del TLCAN se comprometen a eliminarlos en el comercio agropecuario de América 
del Norte. No obstante, la utilización de estos subsidios en el área de libre comercio no es igual para los tres países firmantes. Por ejemplo, para EEUU y Canadá están permitidos los subsidios a la exportación al mercado mexicano para contrarrestar las exportaciones subsidiadas de otros países. Mientras tano, entre dichos países están prohibida la utilización de subsidios directos a la exportación cuando los productos estén destinados a sus mercados.

En cuanto al acceso a los mercados y las salvaguardas, el TLCAN concuerda con las medidas y procedimientos adoptados por el GATT. Sus diferencias son el mayor grado y velocidad de la liberalización. Los compromisos adquiridos en el GATT-RU para la primera fase de operación son mucho más flexibles y suaves que los estipulados por el TLCAN. A pesar de ello, los negociadores mexicanos del Tratado afirmaron que las negociaciones en el área de acceso a los mercados otorgaban el tiempo necesario para que el sector productivo mexicano alcanzara niveles de competitividad al final del periodo de transición (cuestión que será comprobada o refutada en los capitulos siguientes de esta investigación).

Se ha observado que el TLCAN se negoció en condiciones de gran asimetría, magnificadas cuando se toman en cuenta las brechas entre la productividad del sector agrícola de México y el de Canadá y EEUU. Este desequilibrio se acentúa al considerar los recursos que estos dos países dedican a estimular el desarrollo sectorial y a apoyar las exportaciones. Los compromisos que se pactaron no reflejan el menor desarrollo de la agricultura mexicana en los plazos de desgravación ni en los montos de mercado para los cuales se acordaron plazos de desgravación más lenta, situación que posiblemente pudo haber sido revertida por una política integral del Estado de mexicano.

Además de las distancias económicas, había brechas en otros aspectos como el marco institucional, la valoración que cada país otorgó a la firma del acuerdo y el marco democrático que cada gobierno enfrentaba en su respectivo país. México, con su economía más intervenida y regulada, y con responsabilidades del Estado en dirección de la economía originadas en principios constitucionales distintos, asumió mayores costos al acoplar su 
modelo a la normatividad del TLCAN, en el que se plasmaron plenamente los principios que priman en las economías de EEUU y de Canadá.

Así, el TLCAN innovó integrando asimetrías inéditas: aunó la potencia mundial económica, tecnológica, militar y política con un país en desarrollo; incorporó acuerdos sobre la propiedad intelectual, el intercambio de servicios y los compromisos sobre inversión extranjera, que sólo se incluían en mercados comunes o en uniones económicas, en los cuales son centrales la integración política y la cesión de soberanía nacional en el manejo de áreas de política económica y social; y, sometió al sector agrícola al proceso de desgravación arancelaria, nunca antes incluido en los acuerdos de integración regional que buscan ganancias en productividad para el sector industrial.

El comercio exterior se consolidó como el eje del desarrollo económico para México, que a la frima del Tratado contaba con un modelo secundario exportador. En este contexto, el Estado no debía ser el actor más importante sino que debía alentar la participación de los agentes privados y la integración económica y comercial a través de empresas transnacionales.

Los negociadores mexicanos del Tratado afirmaron que los acuerdos en el área de acceso a los mercados otorgaban el tiempo necesario para que el sector productivo mexicano alcanzara niveles de competitividad al final del periodo de transición. En el próximo capítulo estudiarémos si sus supuestos fueron o no correctos, recordando que el objetivo de la presente investigación es analizar cómo impacto este proceso de liberalización económica en la productividad del sector agrícola mexicano. 


\section{CAPITULO 3 SECTOR AGRÍCOLA EN MÉXICO}

Hasta el momento se han bosquejado los aspectos geográficos, las características de su población, los niveles de ocupación, el comportamiento del PIB y las características de los consumidores del Estado de México. De igual forma, se ha abordado la teoría de la integración económica, el proceso de liberalización económica de México, los aspectos más relevantes de la negociación entre los países firmantes del TLCAN, así como el contenido referente al sector agrícola de este acuerdo comercial.

En este tercer capítulo se conocerán los principales productos que se cultivan en México, sus volúmenes de producción, el comportamiento de sus precios y la balanza comercial del sector. Para poder analizar estos datos, será necesario detallar los conceptos que se utilizarán a lo largo de este capítulo y los subsecuentes (aquellos que no hayan sido detallados en el capítulo 2, apartado 2.1 Teoría de la integración económica).

\subsection{Conceptos económicos generales}

\subsubsection{Commodity}

Los productos agrícolas constituyen un sector sumamente importante en las relaciones comerciales de los países, sobre todo aquellos que tienen algún tipo de integración económica. El término que se utiliza en el comercio internacional para hacer referencia a los bienes de este sector es commodity.

El término commodity en español, es utilizado para hacer referencia a una mercancía, un producto básico, una materia prima, un producto comercial, un artículo o un bien de consumo, según el contexto en el que se esté utilizando. Como el objetivo de la presente investigación es conocer cómo ha impactado el TLCAN en el sector agrícola mexicano, utilizaremos el término commodity para evitar ambigüedades. 
Para todos los países, los commodities ayudan a satisfacer las necesidades de consumo básicas de la población. Hay algunos países para los cuales éstos son fundamentales para la generación de ingresos y se les conoce como economías productoras de commodities (commodity-producing economies). Para otros, los commodities son un insumo crítico para la producción y se les llama economías utilizadoras de commodities (commodityusing economies).

El sector de los commodities a nivel internacional es grande y heterogéneo, está compuesto por una amplia variedad de productos e involucra distintos procesos de producción. Esto le permite abarcar desde unidades de pequeña escala, con mano de obra intensiva y escasa tecnología hasta grandes unidades de producción que tienen un uso intensivo tanto de capitales como de tecnología. La importancia de este sector permea, por consiguiente, en la configuración de los sistemas sociales y políticos de cada país productor.

Masuma Farooki y Rafael Kaplinsky (2012: 48) señalan la importancia de definir a un commodity no desde su calidad física sino desde su naturaleza como producto intercambiable. Por ello, lo definen como aquel producto indiferenciado e indistinguible de otro, características que le permiten ser fácilmente comerciado en una forma impersonal y sustituible. Por ejemplo, el comprador de una onza de oro no necesita saber quién lo produjo, pues el oro que procede de Sudáfrica, Ghana o China es idéntico para cualquier propósito. Lo mismo puede aplicarse al maíz o al café, pero no así para una computadora portátil, cuyas características físicas, funcionales y de marca las hacen diferentes unas de otras.

En su acepción de recursos naturales, existen tres categorías de commodities. La primera son las materias primas agrícolas: cereales, bebidas, cultivos, ganadería y pesca. La segunda categoría son los productos duros: metales preciosos, metales ferrosos, metales no ferrosos y minerales raros. Por último, los productos energéticos: productos derivados del petróleo, fuentes de energía nuclear, fuentes de energía renovables y carbón. 
Cuadro 3.1 Componentes de los commodities del sector primario

\begin{tabular}{|c|c|c|c|}
\hline Sector primario & Categoría & Uso principal & Ejemplos \\
\hline \multirow{6}{*}{$\begin{array}{l}\text { Materias primas } \\
\text { agrícolas }\end{array}$} & Cultivos industriales & Manufacturas & $\begin{array}{l}\text { Madera } \\
\text { Algodón }\end{array}$ \\
\hline & Pesca & \multirow{5}{*}{$\begin{array}{l}\text { Consumo final, } \\
\text { poco } \\
\text { procesados }\end{array}$} & Gambas, bacalao \\
\hline & \multirow{2}{*}{ Cereales } & & Arroz \\
\hline & & & Trigo \\
\hline & Bebidas & & Té, café, cacao \\
\hline & Ganadería & & Ganado, productos lácteos \\
\hline \multirow{4}{*}{ Productos duros } & Metales preciosos & $\begin{array}{l}\text { Reserva de } \\
\text { valor (inversión } \\
\text { financiera) } \\
\text { Manufacturas }\end{array}$ & Oro, plata, platino \\
\hline & Metales ferrosos & \multirow{2}{*}{$\begin{array}{l}\text { Infraestructura } \\
\text { y construcción }\end{array}$} & Mineral de hierro, acero \\
\hline & Metales no ferrosos & & $\begin{array}{l}\text { Cobre, zinc, plomo, } \\
\text { aluminio }\end{array}$ \\
\hline & Metales raros & Manufacturas & $\begin{array}{l}\text { Molibdeno } \\
\text { Plutonio } \\
\text { Cobalto } \\
\end{array}$ \\
\hline $\begin{array}{l}\text { Fuentes de } \\
\text { energía }\end{array}$ & $\begin{array}{l}\text { Derivados del petróleo } \\
\text { Carbón } \\
\text { Nuclear } \\
\text { Renovables }\end{array}$ & $\begin{array}{l}\text { Combustibles } \\
\text { para uso } \\
\text { industrial } \\
\text { Consumo final }\end{array}$ & $\begin{array}{l}\text { Petróleo, gas natural } \\
\text { Carbón } \\
\text { Energía nuclear } \\
\text { Energías renovables }\end{array}$ \\
\hline
\end{tabular}

Fuente: Farooky y Kaplinsky 2012:49.

\subsubsection{Volatilidad de precios}

El alto nivel de volatilidad en los precios de los commodities lo hace un fenómeno altamente estudiado. En ocasiones los precios pueden llegar a variar hasta $100 \%$ de un año a otro, impactando en los presupuestos gubernamentales, el empleo, la rentabilidad y las reservas de divisas de los países.

La volatilidad de los precios se compone de dos efectos: la frecuencia y la amplitud de los cambios. Se han llegado a identificar diferencias importantes en la persistencia de las crisis en los precios de los commodities. En general, las crisis provocadas por desastres naturales y fenómenos climáticos, que afectan los precios de las materias primas agrícolas, son de una duración menor que aquéllas que resultan de guerras, huelgas, degradación de las minas y falta de mano de obra calificada, que afectan los precios del los productos duros. (Farooky y Kaplinsky 2012:58) 
Las fluctuaciones de precios son una característica de los mercados competitivos donde la esencia del sistema de precios consiste en que la escasez de un producto motiva un aumento de su precio, provocando una reducción de su consumo. La volatilidad y el alza de precios de los alimentos son dos fenómenos que cuando se combinan afectan el bienestar y la seguridad alimentaria. Cuanto más rico sea un consumidor, menor será la probabilidad de que reduzca su consumo de alimentos a causa de un aumento en los precios. Esto se debe a que la parte correspondiente a los alimentos básicos en el gasto total de las personas es relativamente ricas es menor en relación con sus ingresos. Mientras que el alza en el precio de los alimentos obliga a los consumidores más pobres a reducir su consumo, los consumidores más ricos pueden mantener el mismo nivel de consumo, provocando una aumento de la desigualdad en la distribución global de los alimentos. (FAO 2011:9)

Se observa entonces que de la volatilidad en los precios de los commodities agrícolas es una cuestión que está directamente relacionada con la seguridad alimentaria de los países y de ahí la importancia de su estudio.

\subsection{3 Índices Nacionales de Precios}

Los Índices Nacionales de Precios (INP) son indicadores económicos que miden las variaciones a través del tiempo de los precios de los bienes y servicios que se consumen en los hogares, así como de los que se producen en el país. Existen dos tipos de INP: el Índice Nacional de Precios al Consumidor (INPC) y el Índice Nacional de Precios al Productor (INPP). El primero es un indicador que tiene como finalidad estimar la evolución de los precios de los bienes y servicios que consumen las familias en México. El segundo es un conjunto de indicadores de precios con el objetivo de medir las variaciones de los precios de los bienes y servicios que se producen en el país tanto para el consumo interno como para la exportación.

En México, a partir de 1968 se inicia formalmente el cálculo del INPC estableciendo por primera vez una base fija de comparación. Desde este año 
hasta 2011 el Banco de México era el encargado de su cálculo, pero con la entrada en vigor de la Ley del Sistema Nacional de Información Estadística y Geográfica se otorgó al INEGI la facultad exclusiva en la elaboración de estos indicadores macroeconómicos (INPC e INPP).

El gasto familiar tiene una alta relevancia en el gasto agregado de la economía. Por ello, las variaciones del INPC se consideran una buena aproximación de las variaciones de los precios de los bienes y servicios comercializados en el país. Se utiliza, principalmente, para estimar la inflación (crecimiento continuo y generalizado de los precios de los bienes y servicios). Este fenómeno de aumento en el precio de los bienes y servicios impacta directamente en el poder adquisitivo de la población, los proyectos de inversión y la distribución del ingreso.

El INPP es utilizado para la toma de decisiones de los agentes económicos como son el gobierno, el sector privado y los centros de investigación, al ser un instrumento estadístico que ayuda a reducir la incertidumbre que introducen los cambios en los precios cuando se realiza el análisis económico. EI INEGI señala que ante la imposibilidad de cotizar la totalidad de los precios de los bienes y servicios que se consumen así como de los que se producen, la construcción de los Índices y sus cálculo se realizan con base en procedimientos muestrales, que se apoyan en la estadística inferencial, cuyo método es deducir propiedades de una población a partir e una pequeña parte de la misma.

\section{Cuadro 3.2 Características del INP}

\begin{tabular}{|l|l|l|}
\hline \multicolumn{1}{|c|}{ VARIABLE } & \multicolumn{1}{c|}{ INPC } & \multicolumn{1}{c|}{ INPP } \\
\hline Canasta & $\begin{array}{l}\text { Bienes y servicios que } \\
\text { consumen las familias }\end{array}$ & $\begin{array}{l}\text { Bienes y servicios que se } \\
\text { producen en la economía }\end{array}$ \\
\hline Precios & $\begin{array}{l}\text { A los que el consumidor } \\
\text { adquiere los bienes y servicios } \\
\text { que consume }\end{array}$ & $\begin{array}{l}\text { A los que el productor vende los } \\
\text { bienes y servicios que produce }\end{array}$ \\
\hline Factor de ponderación & Gasto de las familias & Valor de la producción \\
\hline $\begin{array}{l}\text { Fuente de la } \\
\text { Ponderación }\end{array}$ & $\begin{array}{l}\text { Encuesta Nacional de Ingresos } \\
\text { y Gastos de los Hogares }\end{array}$ & $\begin{array}{l}\text { Sistema de Cuentas Nacionales } \\
\text { de México }\end{array}$ \\
\hline Números de genéricos & 283 & 600 \\
\hline Periodo de referencia & 2a quincena diciembre 2010 $^{\text {Diciembre 2003 }}$ \\
\hline Ámbito de análisis & Consumo de los hogares & $\begin{array}{l}\text { Producción para el consumo } \\
\text { interno y la exportación }\end{array}$ \\
\hline
\end{tabular}

Fuente: INEGI. 
En este sentido, el precio productor se define como "... la cantidad de dinero recibida por el productor, de parte del comprador, por cada unidad de un bien o servicio generado como producción, sin incluir el impuesto al valor agregado (IVA) u otro tipo de impuestos facturados al comprador... dicha cotización excluye cualquier cargo de transporte que no estuviera incluido en el precio y tuviera que facturarse por separado" (INEGI 2011b:1). En otras palabras, el precio productor es el precio fijado por éste a la primera instancia compradora de su producto.

De los dos índices nacionales de precios disponibles, el que será utilizado a lo largo de la presente investigación es el Índice Nacional de Precios al Productor, pues lo que interesa conocer es el impacto del TLCAN sobre los precios de ciertos productos agrícolas en México. Esto es, el comportamiento de los precios a los cuales los agricultores venden sus productos y no el precio al que el consumidor final adquiere los alimentos.

\subsubsection{Ciclos productivos y modalidades de producción}

Los ciclos agrícolas en México reciben los nombres de las estaciones del año en que se realizan las siembras y existen dos: el ciclo Primavera-Verano (PV) y el ciclo Otoño-Invierno (OI).

El ciclo PV es el periodo de siembras que comienza en abril y termina en septiembre el mismo año. Las cosechas de este ciclo inician en junio y finalizan en marzo del siguiente año. Por su parte, el ciclo OI comienza en octubre y finaliza en marzo del año subsecuente. Las cosechas inician en diciembre y terminan en septiembre del año siguiente.

En cada uno de estos ciclos productivos se utilizan dos modalidades de producción, a saber, la modalidad de riego y la modalidad de temporal. La agricultura de riego consiste en el suministro de grandes cantidades de agua a los cultivos, distribuida a través de métodos artificiales de riego. Para su utilización se requiere de una alta inversión económica. Por otro lado, la agricultura de temporal es aquella que depende de las condiciones naturales de Iluvia. Es propia de sistemas poco tecnificados de producción. 
De esta manera podemos encontrar que en el ciclo P-V la producción puede ser de riego o de temporal. Sucede lo mismo en el ciclo O-I. Más adelante podremos identificar qué ciclo productivo presenta los rendimientos más elevados.

\subsection{Principales grupos de productos ofertados por México}

El sector primario ha tenido un ritmo de crecimiento lento y su participación en el PIB total ha disminuido en los últimos años. En el cuadro expuesto a continuación se muestra que en 1890 el sector primario daba cuenta de alrededor de $4.2 \%$ del PIB total, cifra que cayó a $3.5 \%$ en 2011 . El sector secundario pasó de 32.5 a $31.7 \%$ del PIB total. Y el sector servicios presenta un crecimiento del $65.6 \%$ al $68.7 \%$ en el mismo periodo.

\section{Cuadro 3.3 PIB anual según sectores económicos 1989-2011 (miles de pesos a precios 2003)}

\begin{tabular}{|c|c|c|c|c|c|c|c|c|c|c|c|c|}
\hline Año & $\mathrm{PIB}$ & Est \% & $\begin{array}{l}\text { Var \% } \\
\text { anual } \\
\end{array}$ & PIB primario & Est \% & $\begin{array}{c}\text { Var \% } \\
\text { anual } \\
\end{array}$ & PIB Secundario & Est $\%$ & $\begin{array}{r}\text { Var \% } \\
\text { anual } \\
\end{array}$ & PIB Terciario & Est $\%$ & $\begin{array}{c}\text { Var \% } \\
\text { anual }\end{array}$ \\
\hline 1989 & $4,811,132,185$ & 100.0 & & $203,080,160$ & 4.2 & & $1,564,339,944$ & 32.5 & & $3,154,575,666$ & 65.6 & \\
\hline 1990 & $5,060,145,241$ & 100.0 & 5.2 & $217,828,710$ & 4.3 & 7.3 & $1,669,336,478$ & 33.0 & 6.7 & $3,294,426,695$ & 65.1 & 4.4 \\
\hline 1991 & $5,273,417,959$ & 100.0 & 4.2 & $222,711,613$ & 4.2 & 2.2 & $1,725,448,580$ & 32.7 & 3.4 & $3,455,581,480$ & 65.5 & 4.9 \\
\hline 1992 & $5,460,155,090$ & 100.1 & 3.5 & $217,749,133$ & 4.0 & -2.2 & $1,800,903,898$ & 33.0 & 4.4 & $3,589,626,743$ & 65.7 & 3.9 \\
\hline 1993 & $5,566,145,209$ & 100.0 & 1.9 & $224,116,884$ & 4.0 & 2.9 & $1,806,058,057$ & 32.4 & 0.3 & $3,691,911,152$ & 66.3 & 2.8 \\
\hline 1994 & $5,833,168,471$ & 100.0 & 4.8 & $233,737,660$ & 4.0 & 4.3 & $1,893,968,520$ & 32.5 & 4.9 & $3,878,667,942$ & 66.5 & 5.1 \\
\hline 1995 & $5,469,907,575$ & 100.0 & -6.2 & $236,946,648$ & 4.3 & 1.4 & $1,727,946,142$ & 31.6 & -8.8 & $3,659,983,344$ & 66.9 & -5.6 \\
\hline 1996 & $5,770,361,966$ & 100.0 & 5.5 & $244,721,481$ & 4.2 & 3.3 & $1,901,157,340$ & 32.9 & 10.0 & $3,771,214,069$ & 65.4 & 3.0 \\
\hline 1997 & $6,188,874,231$ & 100.0 & 7.3 & $249,557,339$ & 4.0 & 2.0 & $2,088,974,697$ & 33.8 & 9.9 & $3,990,254,811$ & 64.5 & 5.8 \\
\hline 1998 & $6,495,772,649$ & 100.0 & 5.0 & $254,615,046$ & 3.9 & 2.0 & $2,215,138,923$ & 34.1 & 6.0 & $4,166,059,770$ & 64.1 & 4.4 \\
\hline 1999 & $6,727,997,506$ & 100.0 & 3.6 & $265,025,376$ & 3.9 & 4.1 & $2,286,504,901$ & 34.0 & 3.2 & $4,314,495,467$ & 64.1 & 3.6 \\
\hline 2000 & $7,129,216,054$ & 100.0 & 6.0 & $269,225,087$ & 3.8 & 1.6 & $2,409,914,697$ & 33.8 & 5.4 & $4,581,519,435$ & 64.3 & 6.2 \\
\hline 2001 & $7,061,291,990$ & 100.0 & -1.0 & $278,237,349$ & 3.9 & 3.3 & $2,343,291,505$ & 33.2 & -2.8 & $4,565,700,649$ & 64.7 & -0.3 \\
\hline 2002 & $7,067,559,259$ & 100.0 & 0.1 & $277,592,194$ & 3.9 & -0.2 & $2,336,353,949$ & 33.1 & -0.3 & $4,572,493,293$ & 64.7 & 0.1 \\
\hline 2003 & $7,162,773,266$ & 100.0 & 1.3 & $285,751,473$ & 4.0 & 2.9 & $2,354,136,925$ & 32.9 & 0.8 & $4,643,272,124$ & 64.8 & 1.5 \\
\hline 2004 & $7,452,927,482$ & 100.0 & 4.1 & $292,805,623$ & 3.9 & 2.5 & $2,441,720,556$ & 32.8 & 3.7 & $4,854,170,066$ & 65.1 & 4.5 \\
\hline 2005 & $7,691,439,131$ & 100.0 & 3.2 & $285,239,601$ & 3.7 & -2.6 & $2,511,224,205$ & 32.6 & 2.8 & $5,057,170,053$ & 65.8 & 4.2 \\
\hline 2006 & $8,087,771,891$ & 100.0 & 5.2 & $303,305,214$ & 3.8 & 6.3 & $2,655,418,849$ & 32.8 & 5.7 & $5,324,101,543$ & 65.8 & 5.3 \\
\hline 2007 & $8,350,832,430$ & 100.0 & 3.3 & $310,360,384$ & 3.7 & 2.3 & $2,709,309,631$ & 32.4 & 2.0 & $5,561,330,726$ & 66.6 & 4.5 \\
\hline 2008 & $8,450,214,665$ & 100.0 & 1.2 & $314,163,689$ & 3.7 & 1.2 & $2,705,494,319$ & 32.0 & -0.1 & $5,694,226,479$ & 67.4 & 2.4 \\
\hline 2009 & $7,947,307,959$ & 100.0 & -6.0 & $304,248,308$ & 3.8 & -3.2 & $2,498,017,774$ & 31.4 & -7.7 & $5,417,556,921$ & 68.2 & -4.9 \\
\hline 2010 & $8,366,934,393$ & 100.0 & 5.3 & $313,036,831$ & 3.7 & 2.9 & $2,650,316,547$ & 31.7 & 6.1 & $5,700,255,294$ & 68.1 & 5.2 \\
\hline 2011 & $8,693,538,672$ & 100.0 & 3.9 & $305,029,689$ & 3.5 & -2.6 & $2,755,063,445$ & 31.7 & 4.0 & $5,971,686,844$ & 68.7 & 4.8 \\
\hline
\end{tabular}

Fuente: Sistema de Cuentas Nacionales de México

En 1970 México contaba con una Población Económicamente Activa (PEA) de $11,620,469$ personas, de las cuales $4,270,875$ se dedicaban al sector 
primario. En 2010, la PEA ocupada era de 43,633,759 personas, de las cuales $5,594,767$ se dedican al sector primario. Resulta posible observar que el porcentaje de personas cuya fuente de empleo se encuentra en el sector primario de la economía mexicana ha decrecido del $36.7 \%$ de 1970 al $12.82 \%$ de 2010.

La superficie sembrada por grupos de productos en México, permite observar que los cereales se han mantenido, desde 1980, como el grupo más importante. El resto de los grupos, a excepción de los forrajes, se han mantenido constantes respecto de su participación en la superficie sembrada.

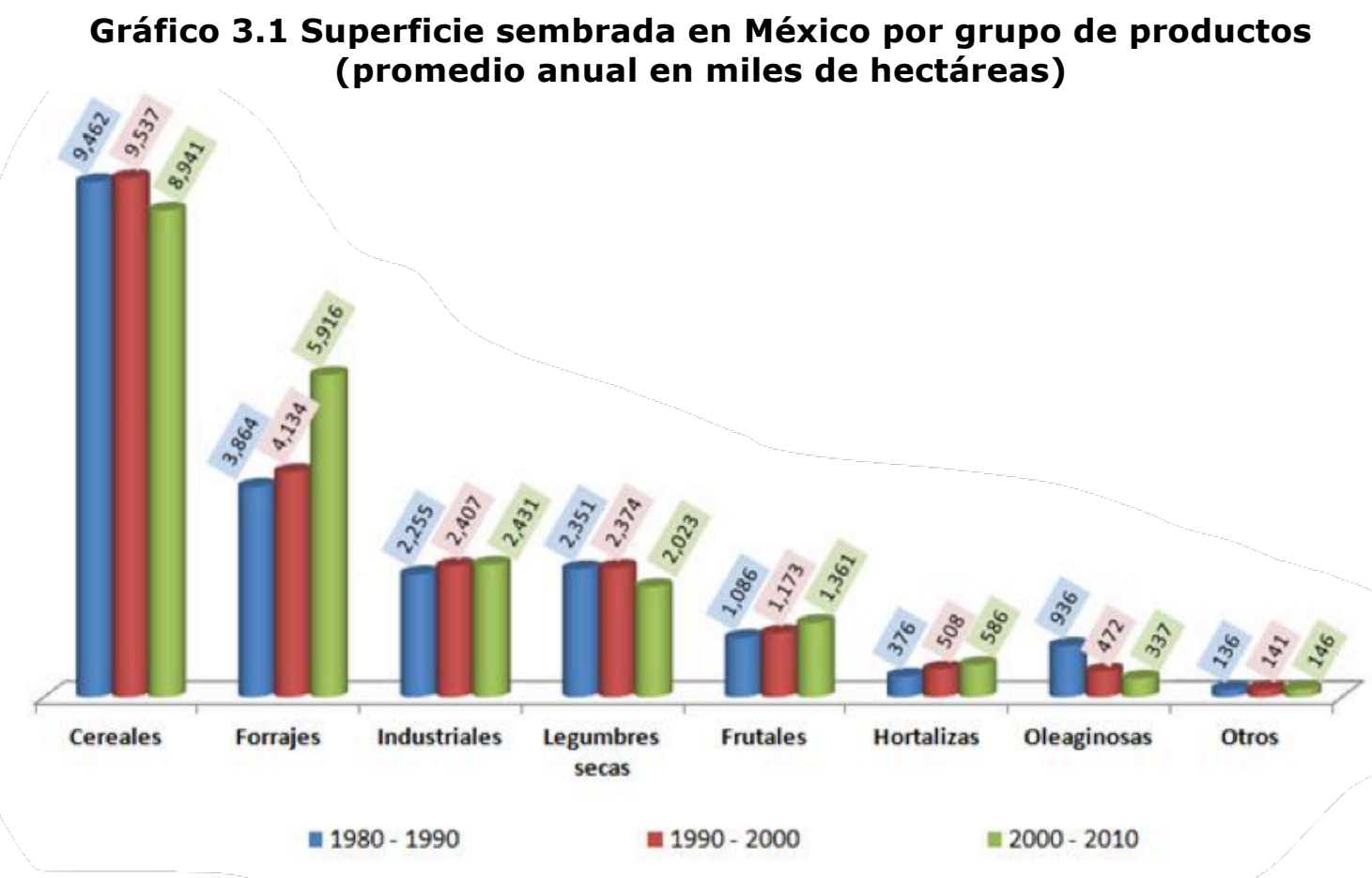

Fuente: elaboración propia con información del SIAP- SAGARPA.

A pesar de que los cereales son ocupan la mayor cantidad de superficie sembrada en el país, son los forajes los que tienen mayor nivel de producción, como resulta posible observar en el Gráfico 3.3. Después, los cultivos industriales, los cereales, los frutales y las hortalizas siguen en orden de importancia en términos del volumen generado. 


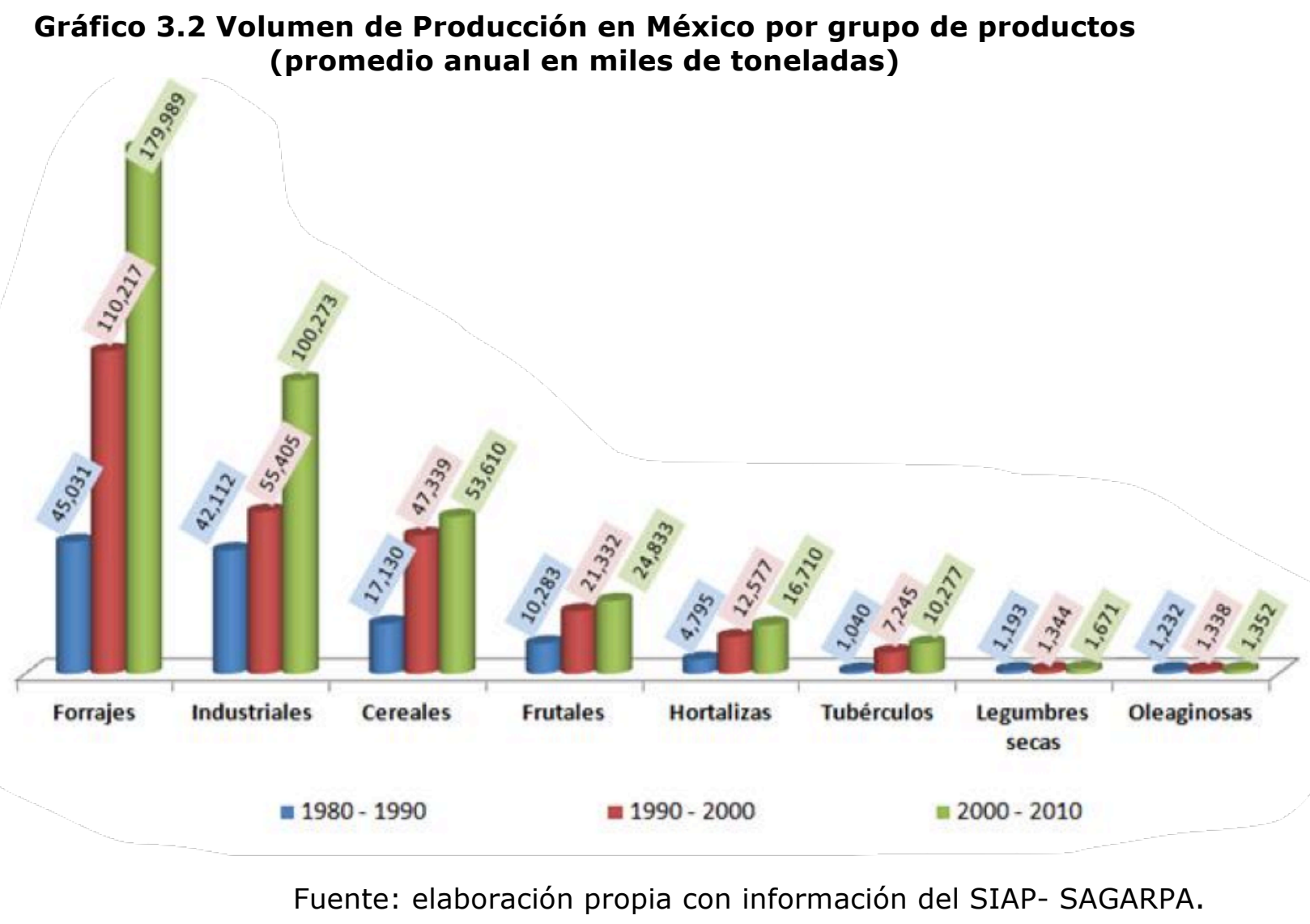

En lo referente a la disponibilidad de tierras por parte de los productores agrícolas se registra que en 1994 las fincas de menos de cinco hectáreas constituían $57.1 \%$ de todas las unidades agrícolas de México. De acuerdo con De Janvry cinco hectáreas son insuficientes para mantener a una familia y "exigen la participación extensiva de los integrantes de ésta en el mercado laboral y en la migración estacional" (de Janvry 1995: 1350). Un grupo intermedio de entre 5 y 18 hectáreas representaba $35.8 \%$ y apenas $7.1 \%$ rebasaba las 18 hectáreas. El tamaño de una finca no es, por sí mismo, indicador de la complejidad de los métodos de producción para responder mejor a las señales del mercado, pero la disponibilidad de sistemas de irrigación sí lo es. El riego corresponde sobre todo a las grandes unidades agrícolas. En las fincas más pequeñas (menos de 2 hectáreas) sólo $3.8 \%$ de la 
superficie cultivada contaba con irrigación, en tanto que las de mayor tamaño (más de 18 hectáreas) registraban 32\% de su superficie irrigada. Por tanto, las unidades productivas más grandes tienen una capacidad técnica relativamente mayor, lo que les permite dar mejor respuesta a las señales de precios.

El último censo agropecuario realizado por el INEGI en 2007, permitió identificar 5.5 millones de unidades de producción con uno o más terrenos, de los cuales 3.7 millones declararon tener actividad agrícola. De éstas, el 10.8\% dispone de sistemas de riego, $83 \%$ es de temporal y 6.2\% combina áreas de riego y áreas de temporal.

En promedio, la extensión de la superficie agrícola de las unidades de producción del país es de 8 hectáreas. Sin embargo, el 57.9\% tiene una superficie de 3 hectáreas o menos, mientras que el $15.8 \%$ tiene una superficie dedicada a la agricultura de 10 hectáreas o más (INEGI 2009). Lo anterior denota el nivel de concentración de las mejores tierras.

El dilema de la liberalización del comercio agrícola (en América Latina) a principios del decenio de los noventa es que ocurrió en un contexto adverso de caída de los precios internacionales de los productos; incremento de los tipos de cambio reales (como consecuencia del flujo de capital extranjero en forma de activos de inversión, dadas las reducidas tasas de ahorro internas); tasas de interés elevadas y subsidios a la baja (de Janvry 1997). Todos estos factores combinados crearon una crisis de rentabilidad en la agricultura.

\subsubsection{Maíz}

La mayor parte del sector agrícola se orienta a la producción de granos básicos y oleaginosas de autoconsumo. El maíz es el principal cultivo: se le dedica alrededor del $50 \%$ de la tierra cultivable. Unos 2.4 millones de productores del grano integraban $78 \%$ del campesinado mexicano en 1991. La mayoría de éstos - 2.2 millones - tiene menos de cinco hectáreas sembradas con maíz, vive en condiciones de pobreza, utiliza tecnologías básicas y obtiene rendimientos muy bajos (de Janvry 1995). 
En México, la superficie de riego se ocupa principalmente en el ciclo Otoño-Invierno (O-I), debido a la escasez de lluvias durante el mismo; en el caso del maíz grano, dicha superficie en tal ciclo aumentó en más de tres veces, pasando de 225 mil 182 toneladas en 1980 a 697 mil 176 en 2010, lo que representa un incremento del $210 \%$. La siguiente gráfica muestra la mejora en los rendimientos de la superficie de riego entre 1980 y 2010, pues permite observar un incremento en $244 \%$ al pasar de 2.5 toneladas por hectárea a 8.6. Esto significa que la producción se multiplicó casi 11 veces en dicho periodo, pasando de poco más de medio millón de toneladas en 2010 a casi seis millones en 2011 , lo que representa $962 \%$ de aumento.

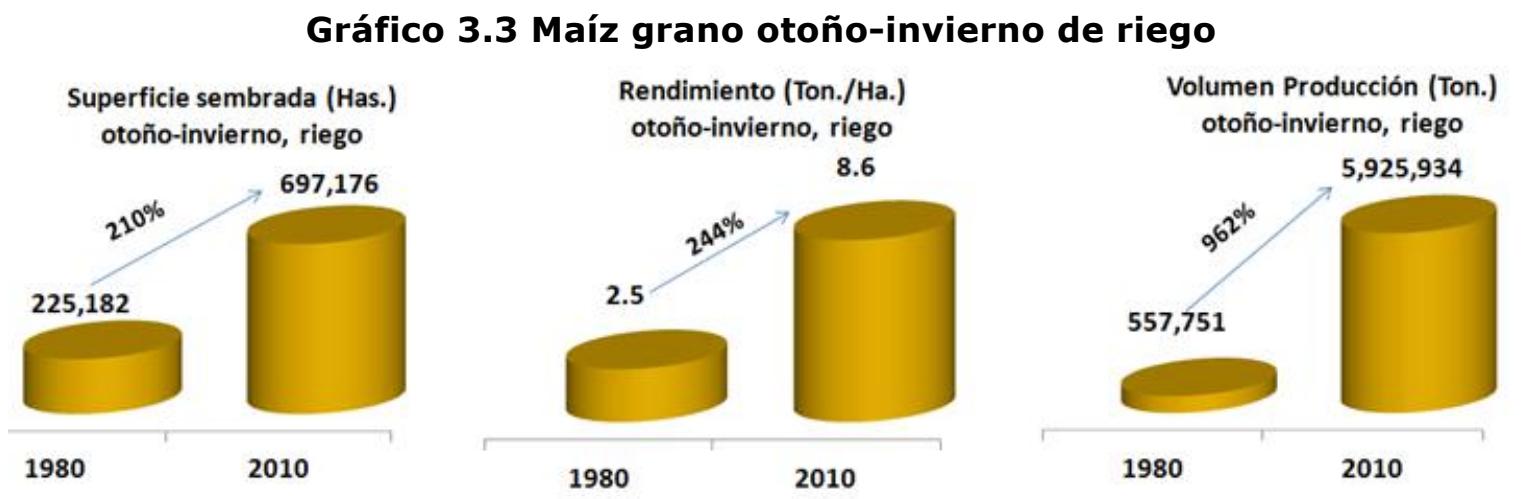

Fuente: elaboración propia con información del SIAP- SAGARPA.

El potencial de México para incrementar la superficie de riego de maíz grano se refleja en el área que se ocupa de temporal en el ciclo O-I. En 1980 dicha superficie era de casi 257 mil hectáreas y para 2010 fue de 458 mil, equivalentes a una expansión del $78 \%$ y representan el $66 \%$ de la tierra sembrada con riego en el mismo ciclo. El potencial de tal superficie también se refleja en la mejora de sus rendimientos, los cuales pasaron de 1.2 toneladas por hectárea en 1980 a 1.6 en 2010, 33\% de incremento; no obstante, los rendimientos logrados con la modalidad de riego son siete veces mayores. 


\section{Gráfico 3.4 Maíz grano otoño-invierno de temporal}
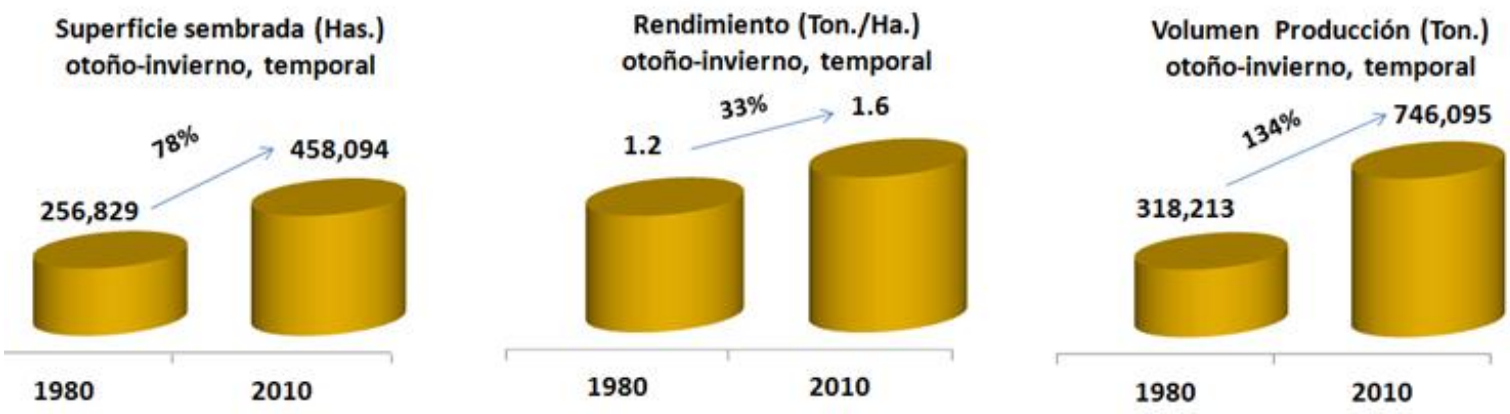

Fuente: elaboración propia con información del SIAP- SAGARPA.

En cuanto a la superficie de maíz del ciclo primavera-verano ( $\mathrm{P}-\mathrm{V})$, el mayor aprovechamiento se da debido a la precipitación natural de las lluvias. El hecho de que la superficie de maíz de temporal de dicho ciclo haya disminuido en 3.3\% al pasar de 1980 a 2010 es muestra de la limitación de la frontera agrícola bajo tal modalidad, a pesar de la mejora en los rendimientos que subieron de 1.6 toneladas por hectárea en 1980 a 2.2 en 2010 y equivalen a una mejora del 38\%, mismo que es muy bajo respecto a las 8.6 toneladas por hectárea que se lograron bajo la modalidad de riego del ciclo O-I 2010, de modo que es necesario aumentar cuatro veces el rendimiento de temporal del P-V para alcanzar al de O-I.

\section{Gráfico 3.5 Maíz grano primavera-verano de temporal}

Superficie sembrada (Has.) primavera-verano, temporal

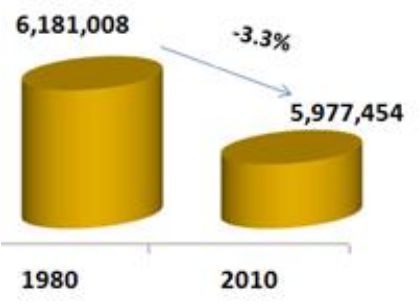

Rendimiento (Ton./Ha.)

primavera-verano, temporal

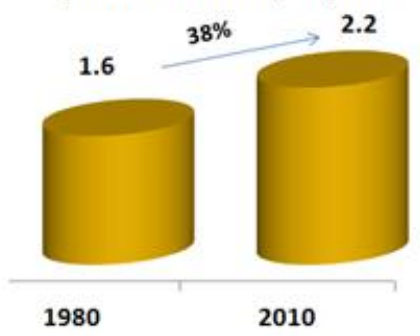

Volumen Producción (Ton.)

primavera-verano, temporal

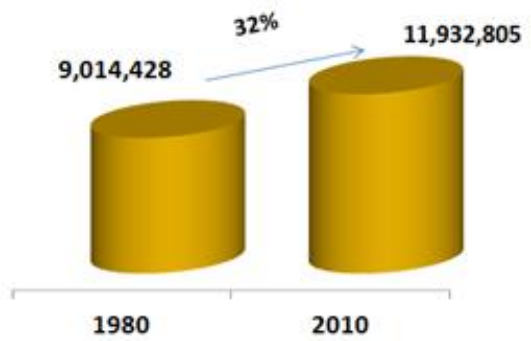

Fuente: elaboración propia con información del SIAP- SAGARPA. 
Pareciera que los incentivos para producir en el ciclo P-V bajo la modalidad de riego han disminuido, dado que la tierra con tal característica es menor en $22 \%$ en 2010 respecto a la equivalente de 1980, a pesar de la mejora aceptable en los rendimientos que alcanzaron 6.5 toneladas por hectárea en 2010 y significan una alza del 134\% al comparar con 1980.

\section{Gráfico 3.6 Maíz grano primavera-verano de riego}
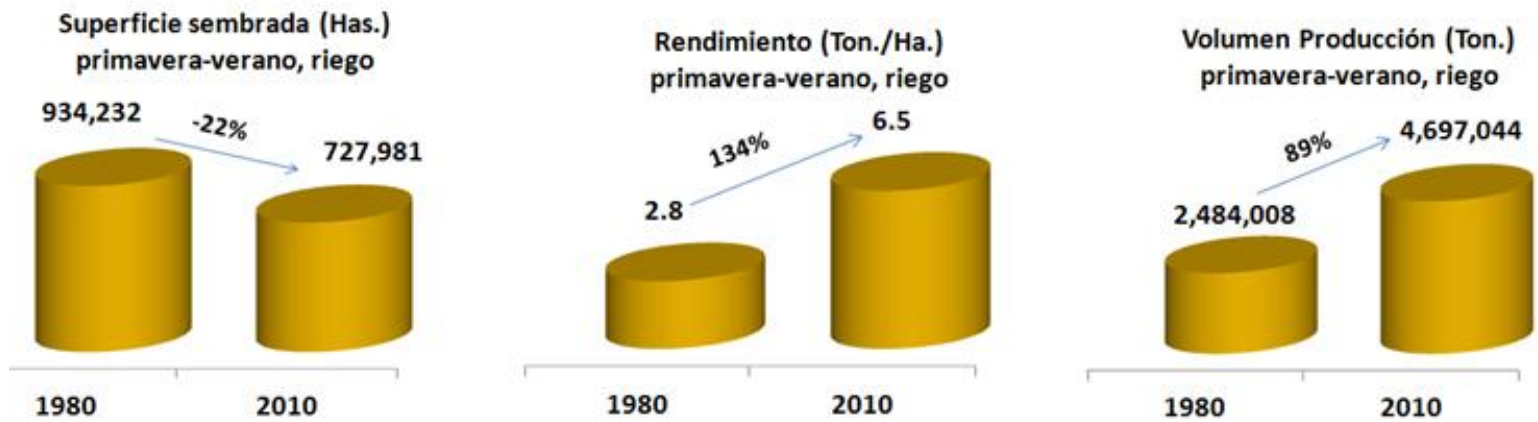

Fuente: elaboración propia con información del SIAP- SAGARPA.

Un comparativo por décadas, desde 1980, permite observar en qué periodos y bajo qué modalidad de producción se han tenido mejores comportamientos en la producción de maíz. En el ciclo O-I, durante el cual no se tienen comúnmente lluvias, se aprovechan los sistemas de riego. Sin embargo, la superficie sembrada en la década de los ochenta fue prácticamente la misma tanto en riego como en temporal, aunque para la última década de análisis la superficie de riego es mayor en casi $24 \%$. La Tasa Medida Anual de Crecimiento (TMAC) de la modalidad de riego presentó un mejor comportamiento. Ver gráfica siguiente.

\section{Cuadro 3.4 Maíz grano: comparativo de la superficie sembrada del ciclo 0-I,} 1980-2010

\begin{tabular}{|c|c|c|c|c|c|c|c|c|c|}
\hline \multicolumn{6}{|c|}{ Otofio-Invi erno, supe rficle se mbrada en promedlo anual (He ctáre as). TMAC (\%) } & \multicolumn{4}{|c|}{ Participación relativa (\%) } \\
\hline & $1980-1990$ & $1990-2000$ & $2000-2010$ & $1980-1990$ & $1990-2000$ & $2000-2010$ & $1980 \cdot 1990$ & $1990 \cdot 2000$ & $2000 \cdot 2010$ \\
\hline Riego más temporal & 540,300 & 930,849 & $1,072,486$ & 1.8 & 4.9 & 2.2 & 100.0 & 100.0 & 100.0 \\
\hline Riego & 269,092 & 491,624 & 593,023 & 3.4 & 2.3 & 5.9 & 49.8 & 52.8 & 55.3 \\
\hline Temporal & 271,208 & 439,225 & 479,463 & 0.1 & 7.4 & -1.5 & 50.2 & 47.2 & 44.7 \\
\hline
\end{tabular}

Fuente: elaboración propia con información del SIAP- SAGARPA. 
Los volúmenes de producción logrados con sistemas de riego en el O-I muestran las mejores TMAC, cuestión que se refleja también en una mayor participación del volumen total logrado en dicho ciclo.

\section{Cuadro 3.5 Maíz grano: comparativo del valor de la producción del ciclo 0-I, 1980-2010}

\begin{tabular}{|c|c|c|c|c|c|c|c|c|c|}
\hline \multicolumn{4}{|c|}{ Otoño-invierno, volumen de producción promedio anual (tons.) } & \multicolumn{3}{|l|}{$\operatorname{TMAC}(\%)$} & \multicolumn{3}{|c|}{ Participación relativa (\%) } \\
\hline & $1980-1990$ & $1990-2000$ & $2000-2010$ & 1980-1990 & $1990-2000$ & $2000-2010$ & $1980-1990$ & $1990-2000$ & $2000-2010$ \\
\hline Riego más temporal & $1,129,519$ & $3,132,325$ & $5,349,963$ & 4.8 & 9.7 & 6.5 & 100.0 & 100.0 & 100.0 \\
\hline Riego & 805,890 & $2,519,455$ & $4,584,314$ & 6.6 & 9.5 & 8.5 & 71.3 & 80.4 & 85.7 \\
\hline
\end{tabular}

Fuente: elaboración propia con información del SIAP- SAGARPA.

La superficie sembrada de maíz grano en P-V es siete veces superior a la de O-I. El área aprovechada con riego en $\mathrm{P}-\mathrm{V}$ era del $11 \%$ en la década de los ochenta, mientras que para la primera década del siglo XXI se mantiene en la misma participación.

\section{Cuadro 3.6 Maíz grano: comparativo de la superficie sembrada del ciclo P-V,} 1980-2010

\begin{tabular}{|c|c|c|c|c|c|c|c|c|c|}
\hline \multicolumn{6}{|c|}{ Primavera-verano, superficie sembrada en promedio anual (Hectáreà TMAC (\%) } & \multicolumn{4}{|c|}{ Participación relativa (\%) } \\
\hline & $1980-1990$ & $1990-2000$ & $2000-2010$ & $1980-1990$ & 1990-2000 & $2000-2010$ & 1980-1990 & $1990-2000$ & $2000-2010$ \\
\hline Riego & 754,838 & 831,590 & 703,441 & -3.7 & 0.3 & 0.9 & 10.0 & 11.0 & 10.0 \\
\hline
\end{tabular}

Fuente: elaboración propia con información del SIAP- SAGARPA.

Durante este ciclo la superficie sembrada bajo riego equivale al $11 \%$ del total de tal periodo, pero el volumen de producción logrado representa la cuarta parte de lo obtenido. Esto permite observar que los rendimientos obtenidos con la disponibilidad de agua son significativos.

\section{Cuadro 3.7 Maíz grano: comparativo del valor de la producción del ciclo P-V,} 1980-2010

\begin{tabular}{|c|c|c|c|c|c|c|c|c|c|}
\hline \multicolumn{4}{|c|}{ Primavera-verano, volumen de producción promedio anual (tons.) } & \multicolumn{3}{|l|}{$\operatorname{TMAC}(\%)$} & \multicolumn{3}{|c|}{ Participación relativa (\%) } \\
\hline & $1980-1990$ & $1990-2000$ & $2000-2010$ & 1980-1990 & $1990-2000$ & 2000-2010 & $1980-1990$ & $1990-2000$ & 2000-2010 \\
\hline Riego & $2,141,741$ & $3,397,209$ & $3,940,995$ & -1.0 & 3.3 & 4.2 & 19.0 & 24.0 & 25.0 \\
\hline
\end{tabular}

Fuente: elaboración propia con información del SIAP- SAGARPA. 
Aunque los rendimientos bajo riego y temporal, tanto en O-I como en P-V han mejorado con el transcurso del tiempo, la siguiente gráfica permite observar que el crecimiento de la modalidad irrigada ha sido mayor $y$ constante en las décadas señaladas.

Cuadro 3.8 Maíz grano: rendimiento promedio anual (tons./ha), 1980-2010

\begin{tabular}{|c|c|c|c|c|c|c|}
\hline \multicolumn{4}{|l|}{ Otoño-invierno } & \multicolumn{3}{|c|}{ Primavera-verano } \\
\hline & $1980-1990$ & $1990-2000$ & $2000-2010$ & $1980-1990$ & $1990-2000$ & $2000-2010$ \\
\hline Riego & 3.1 & 5.2 & 7.8 & 3.1 & 4.2 & 5.7 \\
\hline Temporal & 1.4 & 1.5 & 1.7 & 1.6 & 1.8 & 2.2 \\
\hline \multicolumn{7}{|l|}{$\operatorname{TMAC}(\%)$} \\
\hline Riego & 3.2 & 6.9 & 2.6 & 2.6 & 2.9 & 3.3 \\
\hline Temporal & 2.2 & 1.2 & -0.9 & 0.6 & 1.0 & 1.4 \\
\hline
\end{tabular}

Fuente: elaboración propia con información del SIAP- SAGARPA.

Una observación interesante es que en 1995-1996, cuando el tipo de cambio real tuvo una depreciación repentina - y fugaz- en virtud de la crisis del peso de 1994, la producción de maíz irrigado disminuyó como porcentaje de la superficie total. Ello indica que los grandes productores, en mejores condiciones para responder a las señales de mercado, tal vez cambiaron el maíz por cultivos de exportación para aprovechar las ventajas de un tipo de cambio más competitivo.

El incremento en la producción de maíz podría explicarse

Respecto del cultivo de este grano, y el aumento registrado en su producción, es importante recordar que México convirtió su régimen de permisos de importación en un arancel-cuota transitorio vigente durante 15 años a partir del momento en que se suscribió el TLCAN; se consideró que se requería un periodo de transición debido a los bajos rendimientos del maíz en México (2.1 toneladas por hectárea promedio en tierras de riego) frente a los de Estados Unidos (7.5 toneladas por hectárea).

Asimismo, en primera instancia, se eliminaron los precios de garantía de otros cultivos, salvo los del maíz, lo que mantuvo más elevado el precio 
relativo del grano, mientras que los precios de la cebada, el arroz, el sorgo y el trigo se mantuvieron más bajos. Todo ello ha representado un incentivo para que tanto los pequeños como los grandes productores cultiven maíz y no realicen una transición hacia cultivos con mayores niveles de rentabilidad.

\subsubsection{Producción de hortalizas}

Además del maíz, hay un sector más reducido que cultiva frutas, hortalizas y caña de azúcar. La producción de hortalizas se cultiva en casi $3 \%$ de la superficie agrícola del país, representa el $5 \%$ de la producción nacional y tres cultivos concentran más de la mitad del volumen producido: chile verde $(21 \%)$, jitomate $(20 \%)$ y cebolla $(11 \%)$. A pesar de su importancia en la generación de divisas, la oferta de tales productos se ha mantenido prácticamente en los mismos niveles en los últimos años.

Gráfico 3.7 Producción de hortalizas 2006-2010

(millones de toneladas)

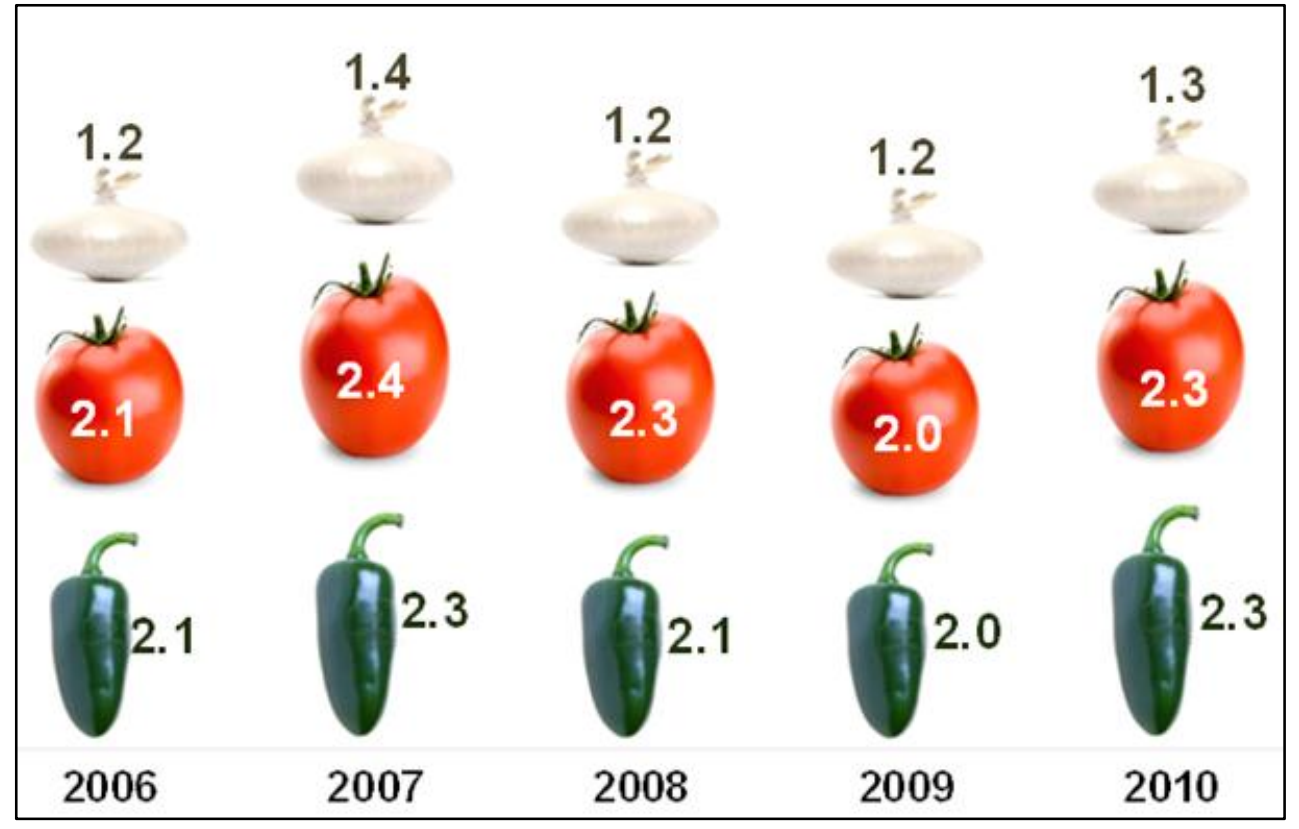

Fuente: elaboración propia con información del SIAP- SAGARPA. 
A nivel internacional, dichas hortalizas resultan sumamente importantes. La producción de chile verde en México, por ejemplo, ocupa el segundo lugar mundial con 2.3 millones de toneladas, por debajo de China (14.5 millones) y dos veces por arriba de la producción de Estados Unidos (927 mil toneladas) y España (un millón de toneladas). Por otra parte, en la producción de jitomate México tiene la décimo primera posición en el mundo con un volumen de 2.3 millones de toneladas, siendo China el primer lugar con 45.3 millones de toneladas.

México es tres veces superior en la producción de jitomate que los Chilenos (850 mil toneladas) y casi cuatro veces más que el volumen de jitomate de Argentina ( 707 mil toneladas); la producción de cebolla le permite ubicarse en el décimo tercer lugar mundial con 1.2 millones de toneladas, China es el primer lugar en el mundo con 21 millones de toneladas, pero la producción de México es casi dos veces lo que obtiene Argentina y Perú (650 mil toneladas).

\subsubsection{Frutas}

En cuanto a la producción de frutales, en 2010 la producción del país se realizó en $7 \%$ de la superficie cultivable; cinco frutos representan dos terceras partes de la producción nacional (63\%): naranja, plátano, limón, mango y aguacate, mismas que se encuentran entre las diez frutas más producidas en el mundo.

La superficie cosechada de los cinco frutos señalados ha aumentado en más del doble en el periodo 1980 a 2011, excepto en el caso de las plantaciones de plátano que se han mantenido entre 70 y 80 mil has. El incremento más significativo ha sido en la superficie cosechada de mango, que casi se ha incrementado en $200 \%$ en el lapso referido, al pasar de 63 mil 700 hectáreas a casi 176 mil en 2011.

El aumento en las superficies cosechadas, así como la mejora en los rendimientos y la renovación de plantaciones, en algunos casos, ha permitido aumentar los rendimientos, de modo que aunque las plantaciones de plátano 
prácticamente son las mismas desde 1980, también es cierto que su volumen de producción ha subido en casi un 50\% en el periodo 1980 a 2011. En el caso de limón que presenta la mejor evolución en la producción, su volumen se ha elevado casi en un $300 \%$.

Aunque el año 2011 tuvo consecuencias adversas debido a problemas de heladas a principios del año en el norte del país, además de los relacionados a sequía en la mayoría de las zonas de temporal, los frutales no se vieron tan afectados como otros cultivos, de modo que la cosecha de naranja y plátano se mantiene prácticamente con niveles de producción muy similares a los de 2011, al aumentar un 0.7 y 1.7\% respectivamente; sólo la producción de mango cayó en $6 \%$ y, por el contrario, lo obtenido de limón y aguacate se incrementó en 12.8 y $14.2 \%$.

Vale la pena señalar que la producción de frutales exóticos es un mercado potencialmente rentable que se encuentra en expansión y que se desarrolla principalmente en ciertas regiones del país cuyas condiciones agroclimáticas propician este tipo de explotación. En 2011, la producción de frutas no tradicionales alcanzó un volumen de 750 mil 146 toneladas que se obtuvo sobre una superficie de 87 mil 130 hectáreas. El Estado de México, Zacatecas y Michoacán concentran más de la mitad de la producción (58\%) de frutales exóticos.

\subsection{Comercio exterior de los productos ofertados}

\subsubsection{Comercio exterior de maíz grano}

Desde la firma del TLCAN las importaciones de maíz grano de México se han incrementado de manera constante, al pasar de 200 mil toneladas en 1993 a casi diez millones en 2011. El volumen reciente de las importaciones de maíz generó un gasto de divisas por casi tres mil millones de dólares.

El volumen importado de maíz mostrado en la gráfica siguiente presenta una tasa de crecimiento promedio anual de $26.9 \%$ en el período $1992-2011$, muy por encima del crecimiento anual de la población que ronda el $1 \%$. En el 
lapso 1992-1995 se compraron del exterior 1.3 millones de toneladas al año, para incrementarse a 4.8 millones entre 1996-2000, y en el periodo 20052009 crecieron hasta llegar a 7.4 millones de toneladas anuales. Mientras tanto, en 2010 se compraron del exterior 7.8 millones de toneladas, las cuales incrementaron un $24 \%$, lo que se traduce en 9.6 millones de toneladas en tan sólo 1 año.

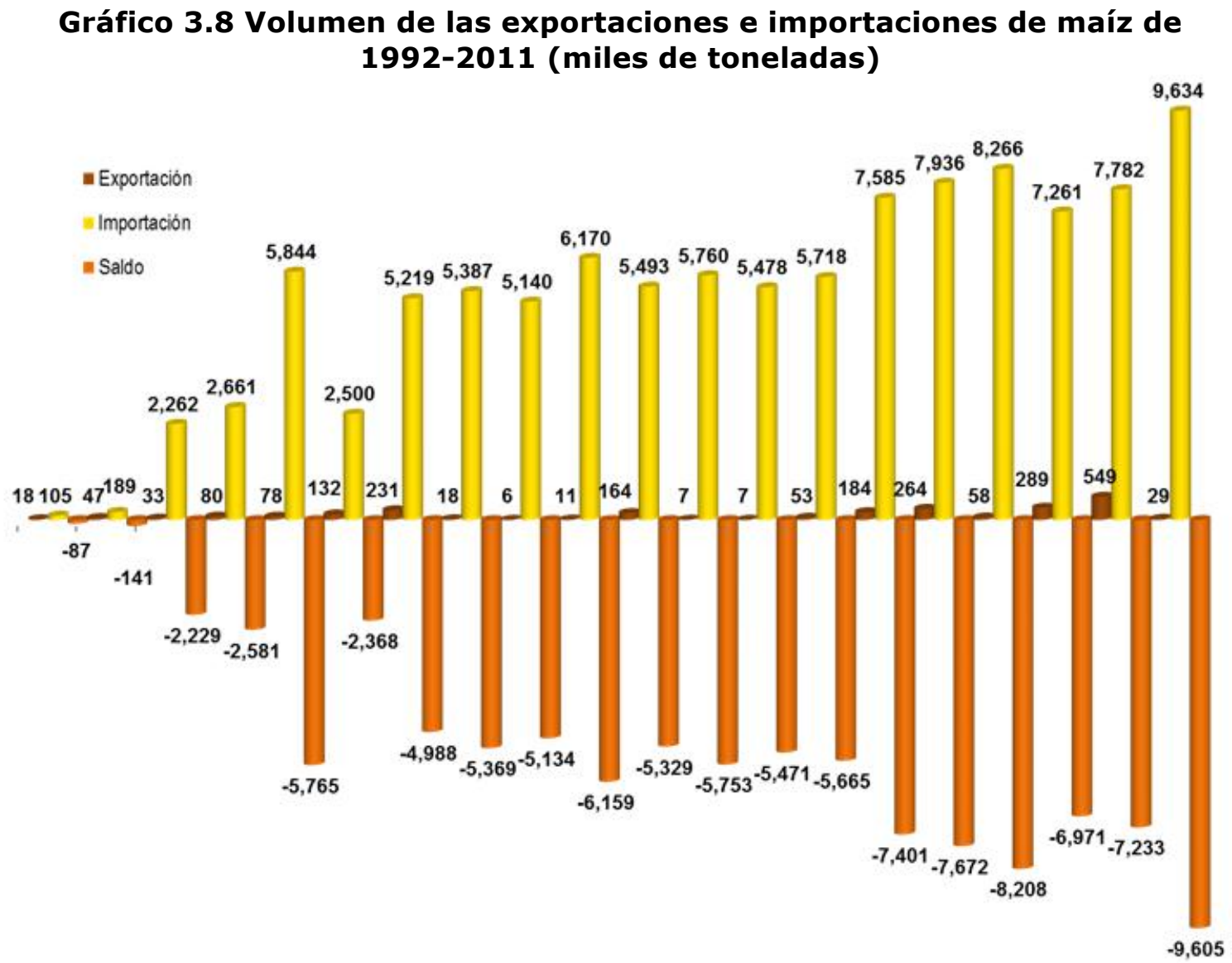

19921993199419951996199719981999200020012002200320042005200620072008200920102011 Fuente: elaboración propia con información del SIAP- SAGARPA.

Los precios por tonelada importada a partir de 1996, son menores a los que se pagaron a los productores nacionales en el periodo 1996-2000. Cada tonelada importada costó mil 98 pesos, en el de 2001-2004 el precio alcanzó mil 122 pesos, y de 2005 a 2009 costó mil 891 pesos. En 2010 el precio por tonelada importada fue de dos mil 187 pesos por tonelada y en 2011 de tres mil 573 pesos. La diferencia en los precios de estos productos no obedece a la 
calidad de los mismos, sino a los usos finales que se les dan. Por ejemplo, el maíz estadounidense es empleado para la alimentación animal, mientras que el mexicano es principalmente para consumo humano.

\section{Gráfico 3.9 Valor de las exportaciones e importaciones de maíz de 1992-2011 (millones de dólares)}

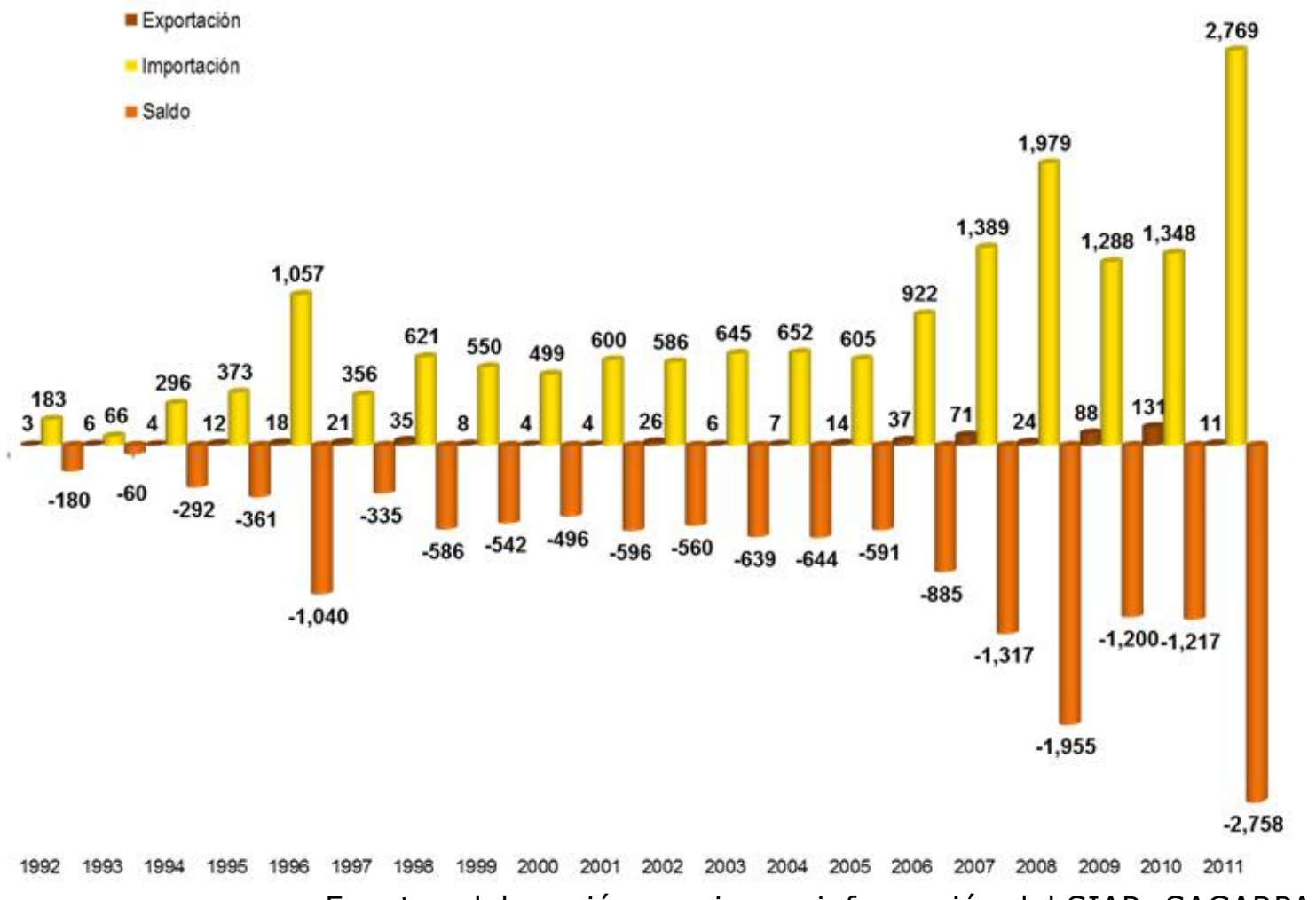

Fuente: elaboración propia con información del SIAP- SAGARPA.

\subsubsection{Hortalizas}

La balanza comercial de hortalizas es superavitaria de manera considerable. Anteriormente se ha mencionado la alternativa de cambiar cultivos forrajeros por hortalizas y frutales, pues se mostró cómo la superficie y volúmenes de producción de tales bienes ha mejorado en las últimas tres décadas. El principal mercado de exportación para tales cultivos son los Estados Unidos; las proyecciones de largo plazo del USDA señalan que para el año 2021 las importaciones de frutales de dicho país representarán el 45\% de 
su consumo interno, mientras que sus importaciones de vegetales representarán el 25\% (USDA 2012: 64).

\section{Gráfico 3.10 Valor de las exportaciones de hortalizas de 1993-2011 (millones de dólares)}

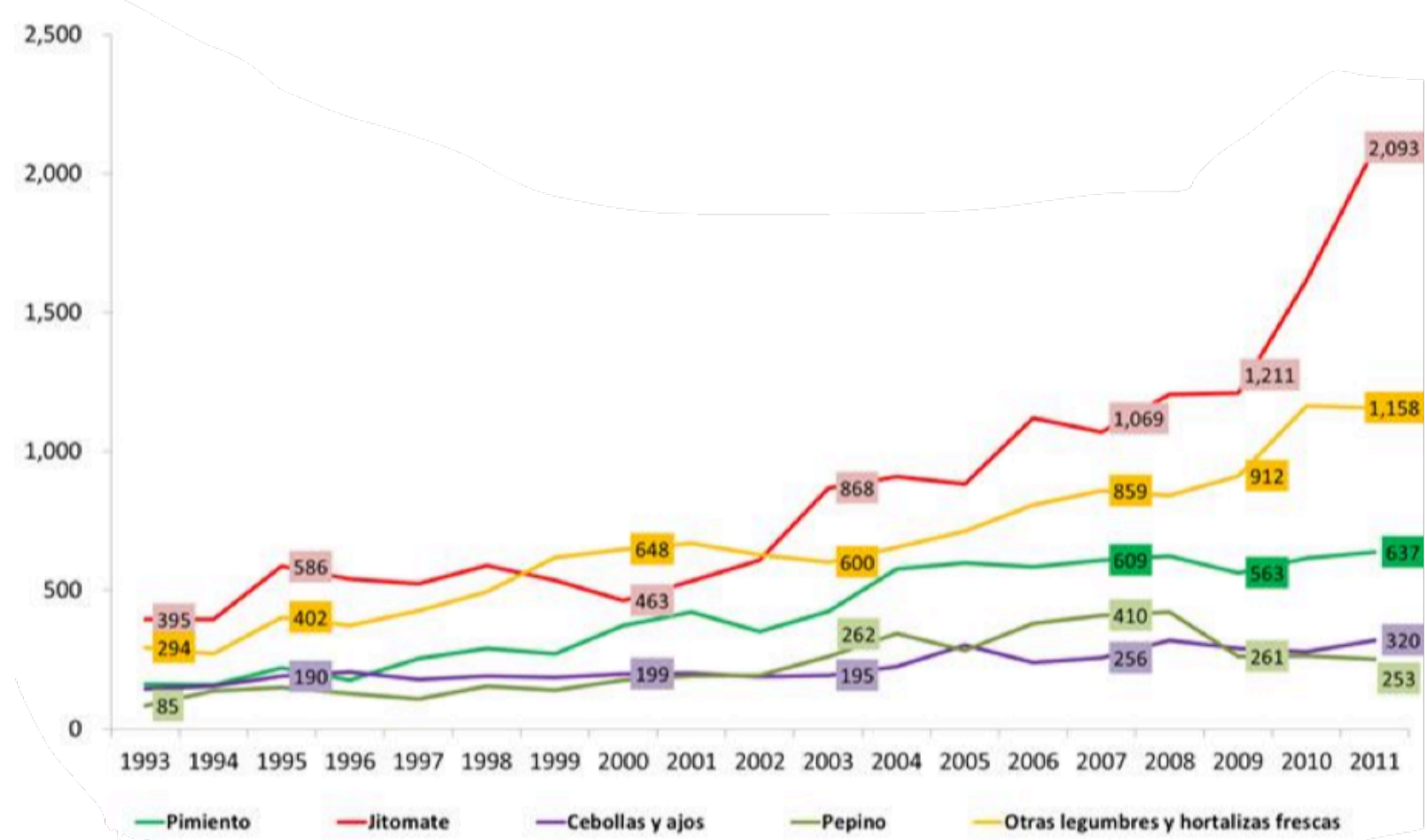

Fuente: elaboración propia con información del Banco de México.

\subsubsection{Frutas}

Se ha mencionado anteriormente que el grupo de frutales cuenta con potencial para los productores mexicanos, dado que al igual que en el caso de las hortalizas los cambios en la preferencia de los consumidores, ligados a la intención de mejorar las condiciones de salud, obligan a consumir productos frescos del campo. Además, también se cuenta con un mercado extranjero con alta y creciente demanda. La gráfica presentada a continuación permite distinguir dos momentos en el valor comercial arrojado por las principales frutas colocadas en el exterior: en la década de 1993 a 2003 se observa una relativa estabilidad en los ingresos de divisas obtenidos del extranjero por la 
venta de tales productos; en cambio, en el periodo más reciente de ocho años tal valor muestra aumentos más notables que en la década mencionada.

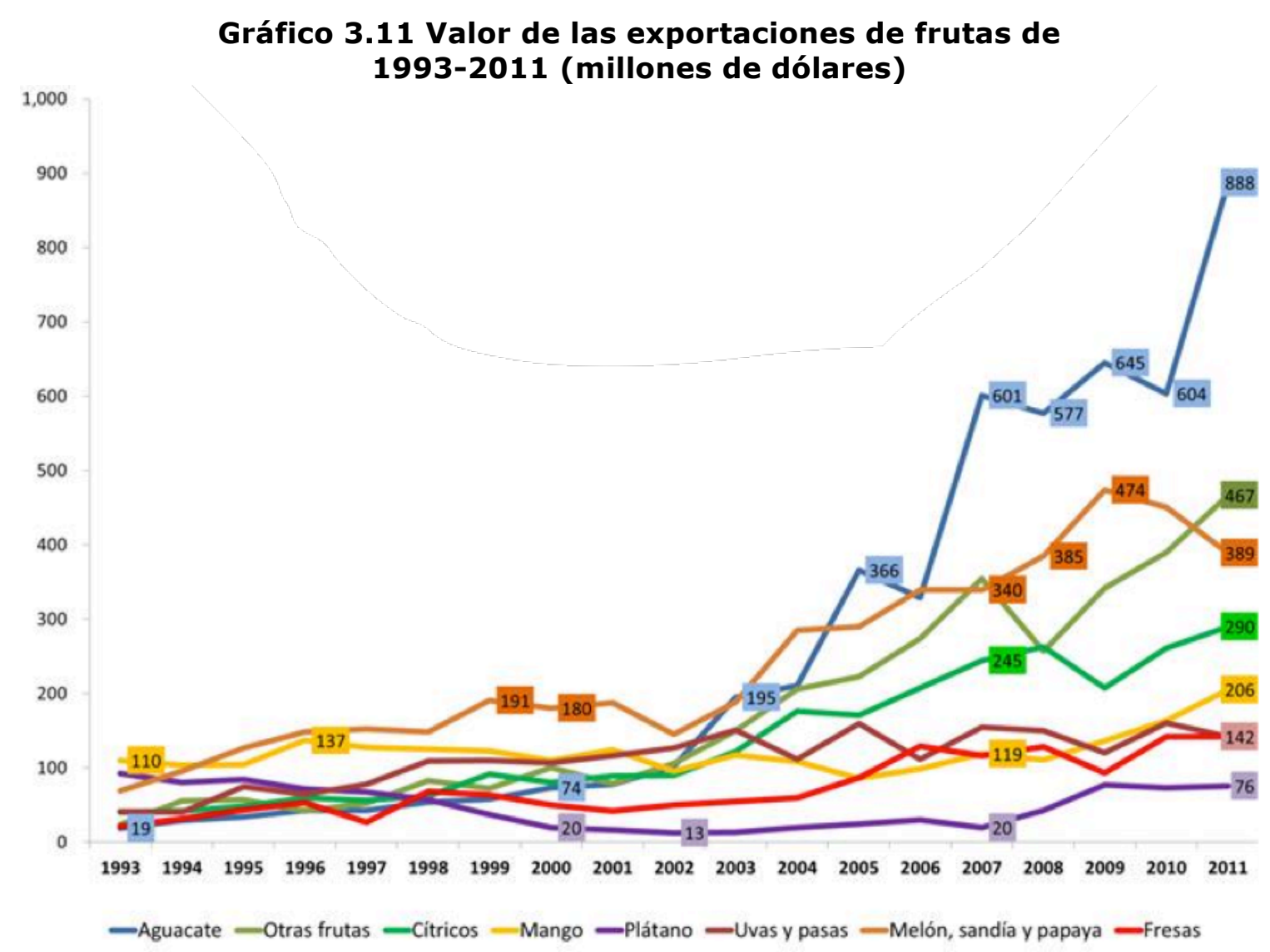

Fuente: elaboración propia con información del Banxico.

El siguiente cuadro permite notar que los envíos de aguacate al resto del mundo son los que más divisas generan, además de identificar un crecimiento del 478\% al comparar el valor agregado de 2004 a 2011 con respecto al de toda la década de 1993 a 2003. Situación similar a la del aguacate se observa con las exportaciones agrupadas en "otras frutas", así como en cítricos, fresas y la agrupación de melón, sandía y papaya. Desafortunadamente ha bajado la presencia de plátano, mango, uvas y pasas secas. 
Cuadro 3.9 Exportaciones de frutas de México (millones de dólares)

\begin{tabular}{|c|c|c|c|c|c|c|c|c|}
\hline & Otras frutas & Plátano & Aguacate & Mango & Citricos & Uvas y pasas & $\begin{array}{c}\text { Melón, sandia } \\
\text { y papaya }\end{array}$ & Fresas \\
\hline Agre gado 1993 a 2003 & 825 & 557 & 731 & 1,281 & 784 & 1,023 & 1,636 & 508 \\
\hline Agre gado 2004 a 2011 & 2,514 & 365 & 4,222 & 1,031 & 1,823 & 1,112 & 2,955 & 898 \\
\hline
\end{tabular}

Fuente: elaboración propia con información del Banco de México.

\subsubsection{Flores}

Las flores es un grupo de cultivos un tanto difícil de analizar, con respecto a otros grupos, debido a que cuenta con diversas variedades, las cuales ocupan diferentes unidades de medida para su volumen, aparte de la medición en toneladas. Por tanto, sólo tomaremos en cuenta la superficie sembrada de ornamentos, grupo al que pertenecen las flores, que tienen prácticamente toda la participación del grupo; después de los forrajes, hortalizas y frutales, son las plantaciones de ornamentales las que cuentan con mayor crecimiento en las tres décadas consideradas, al incrementar su área en $23 \%$ al comparar el año 2010 contra 2008.

\section{Gráfico 3.12 Superficie sembrada de ornamentos en México (promedio anual en miles de hectáreas)}

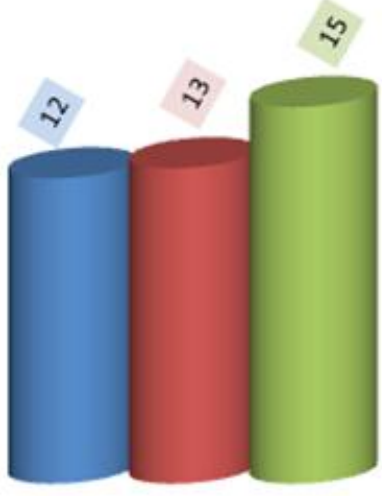

Fuente: elaboración propia con información del SIAP- SAGARPA. 
México es un exportador neto de flores, pero los envíos al extranjero en los últimos años dejan mucho que desear; de 1997 a 2001 el valor total de las exportaciones de flores ascendió a 147 mil millones de dólares, mientras que en el quinquenio de 2002 a 2006 el valor total fue de 138 mil millones de dólares, lo que significa una caída del $6 \%$ respecto a los cinco años anteriores. Pero resulta aún más grave para los cinco años siguientes, de 2007 a 2011 cuando dicho valor resulta ser de 127 mil millones de dólares, $8 \%$ menos que en los cinco años anteriores. La promoción de las exportaciones mexicanas de flores debe buscar recuperar los niveles observados durante los años noventa.

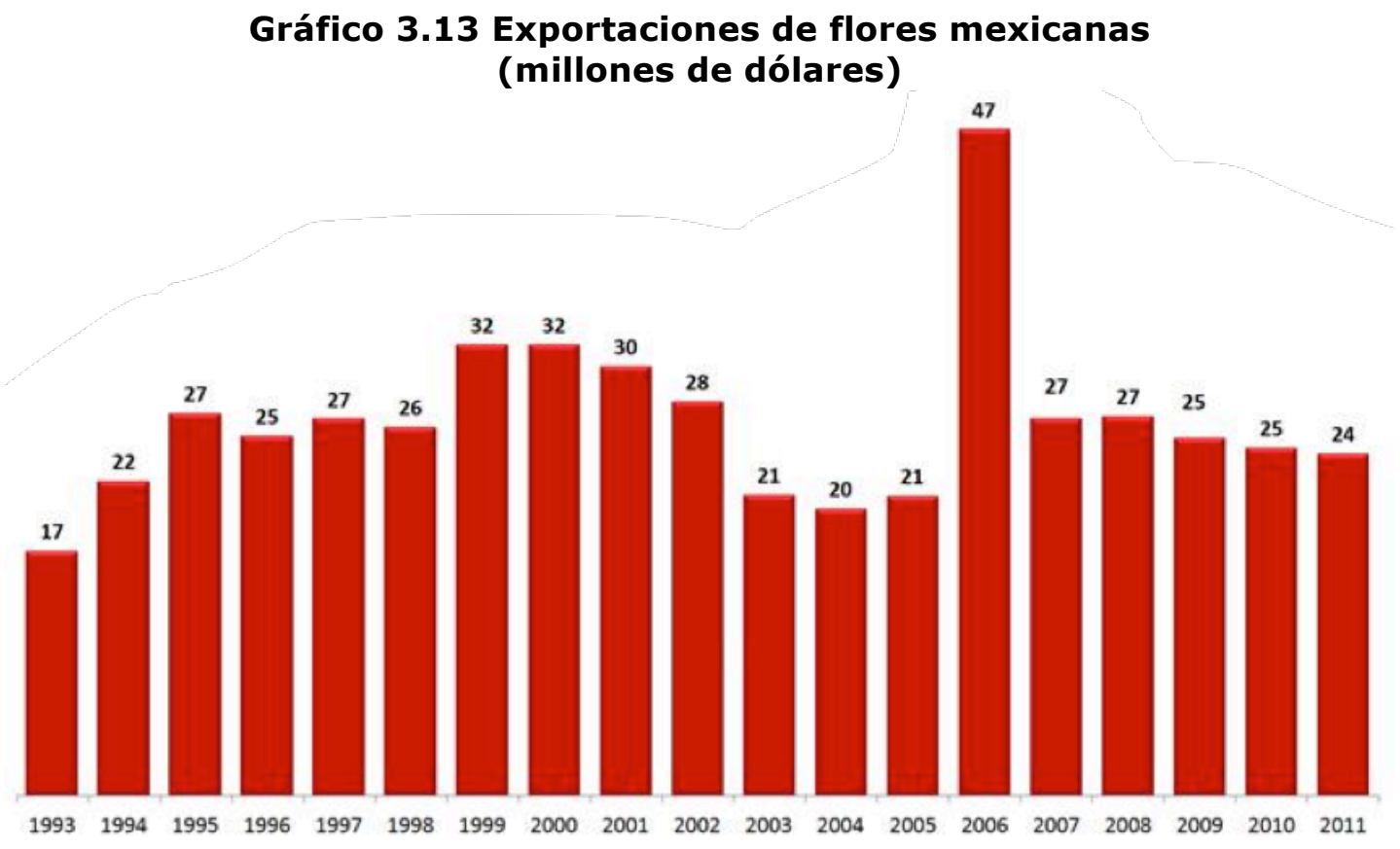

Fuente: elaboración propia con información del Banxico.

\subsubsection{Trigo}

Desde la firma del TLCAN las importaciones de trigo se han incrementado de manera continua, de modo que de no representar volúmenes significativos a inicios de la década de los noventa, para 2011 ya eran más de cuatro 
millones de toneladas. Las exportaciones también se han incrementado pues a inicios de los noventa prácticamente eran nulas y para 2011 ya representan casi un millón 500 mil toneladas que, de cualquier manera, representan para tal año sólo el 34\% del volumen importado. La evolución del volumen de trigo importado denota una tendencia de crecimiento, con un espectacular repunte en 2005 cuando se adquirieron del exterior 3.7 millones de toneladas, mientras que en 2009 se compraron del extranjero 2.8 millones de toneladas.

\section{Gráfico 3.14 Volumen de las exportaciones e importaciones de trigo de 1992-2011 (miles de toneladas)}

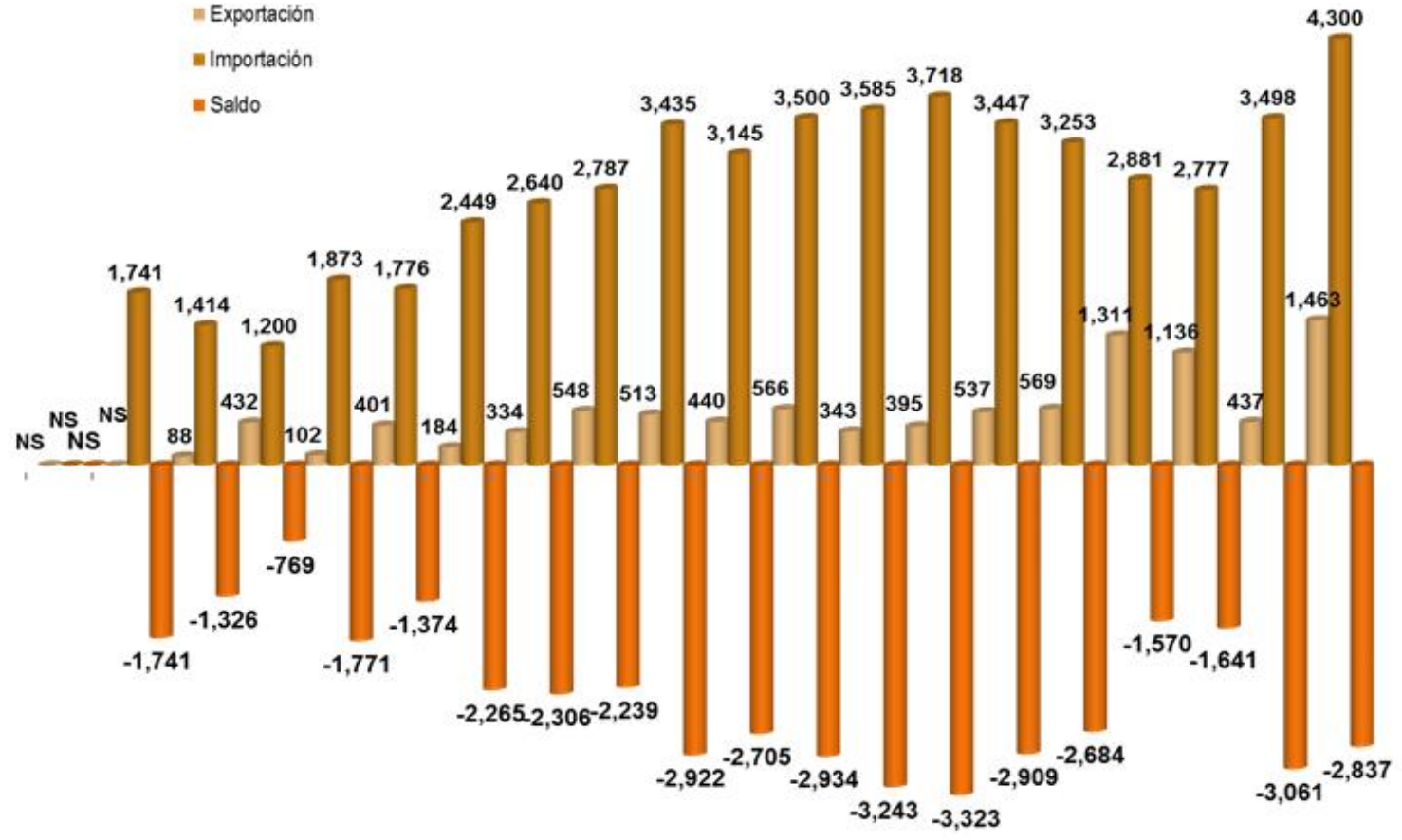

19921993199419951996199719981999200020012002200320042005200620072008200920102011

Fuente: elaboración propia con información del SIAP- SAGARPA.

El incremento en los volúmenes de importaciones de trigo se asocia fuertemente con las menores superficies dedicadas al cultivo en México. Mientras que a inicios de la década de los noventa, el promedio de superficie anual era de alrededor de un millón de hectáreas, para el último quinquenio disponible, de 2007 a 2011, tal superficie es de alrededor de 800 mil hectáreas. Lo anterior ha ocasionado que los volúmenes de producción a inicios 
de los noventa tengan niveles promedio que rondan los cuatro millones de toneladas por año $y$, debido a las menores superficies, tales niveles se mantienen muy parecidos. Esto se ha logrado gracias al aumento en los rendimientos que si a principios de los noventa eran en promedio de 4 toneladas por hectárea, para los últimos cinco años referidos llegan a 5.3 toneladas en promedio, reflejando un aumento de más del 30\%.

El incremento de las importaciones de trigo al parecer se encuentra vinculado con cuestiones estratégicas de la industria del trigo que están encaminadas a garantizar el abasto para sus procesos productivos. ¿Cómo se explica una decisión de comprar en el exterior a precios más altos que los internos? Una primera respuesta sería la calidad de lo que se adquiere.

En México todo indica que prevalece lo segundo. ¿Por qué? La producción nacional de trigo presenta pocas fluctuaciones, que sin embargo generan incertidumbre, si a ello se agrega la disminución de la superficie sembrada, la expectativa no puede ser otra.

\section{Gráfico 3.15 Valor de las exportaciones e importaciones de trigo de 1992-2011 (millones de dólares)}

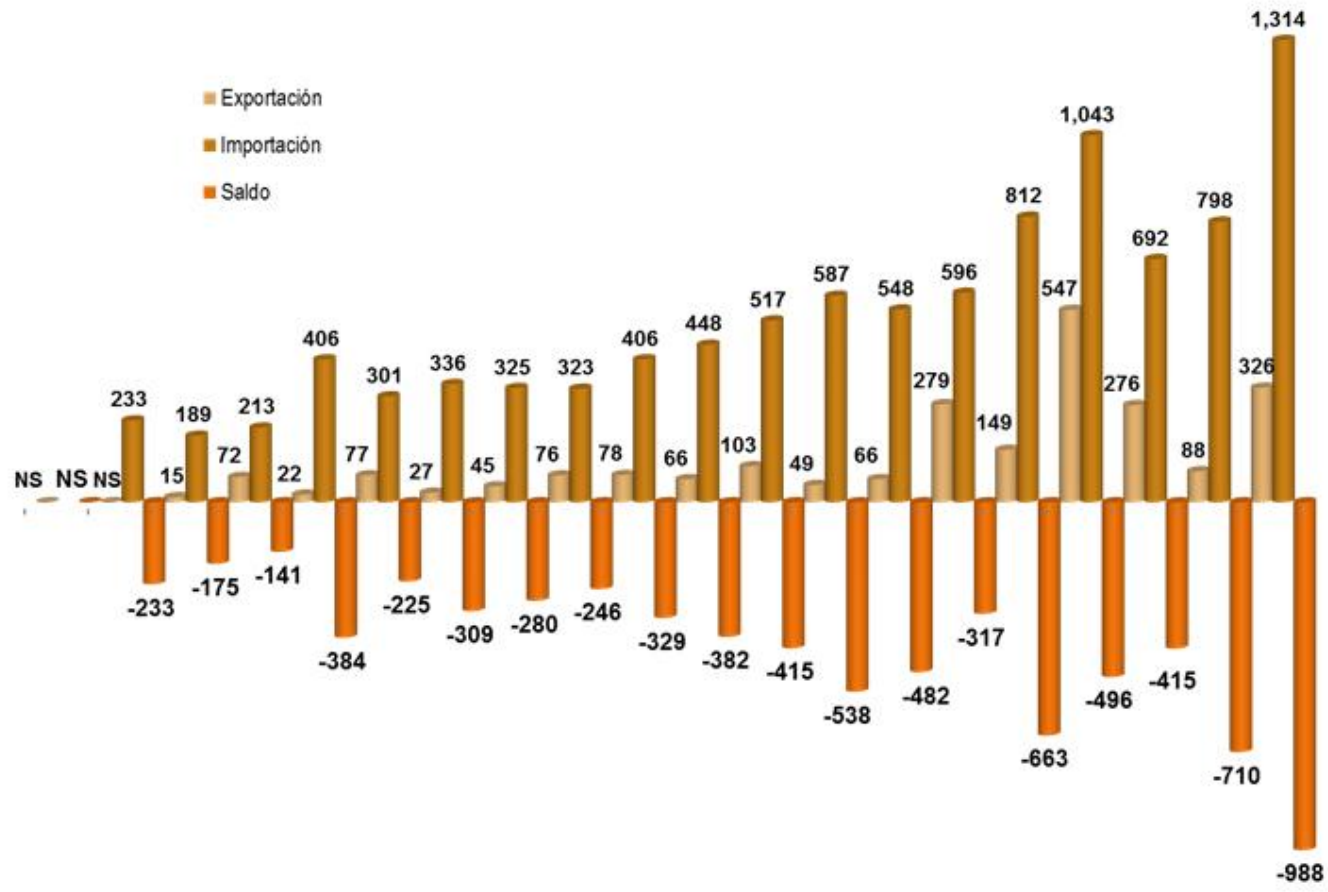

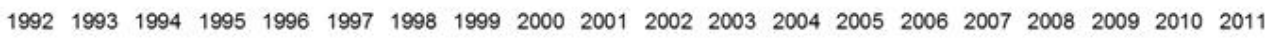

Fuente: elaboración propia con información del SIAP- SAGARPA. 
En el ámbito de los agricultores, todo indica que el nivel alcanzado por los precios internos y el rendimiento conseguido en una superficie cada vez menor, le garantizan una rentabilidad, sobre todo por grandes volúmenes generados a nivel de productores con sistemas de riego, característicos en la zona noroeste del país (Sonora y Baja California). Es necesario estar atentos al comportamiento de los mercados internacionales en términos de la oferta, dado que se han tenido en 2010 cierres productivos sin crecimiento, como el registrado por la Organización de las Naciones Unidas para la Alimentación y la Agricultura (FAO, por sus siglas en inglés). En el siguiente cuadro es posible observar cómo uno de los principales productores mundiales, la Federación Rusa, cayó de una producción promedio anual de 58.3 millones de toneladas en el periodo 2007-2009 a 41.5 millones en 2010. Afortunadamente, estas cifras crecen nuevamente en 2011 a 57 millones de toneladas, pero el efecto sobre los precios internacionales del grano fue prácticamente inmediato durante 2010 e, incluso, los efectos especulativos continuaron durante 2011. 
Cuadro 3.10 Producción mundial de trigo 2007-2011

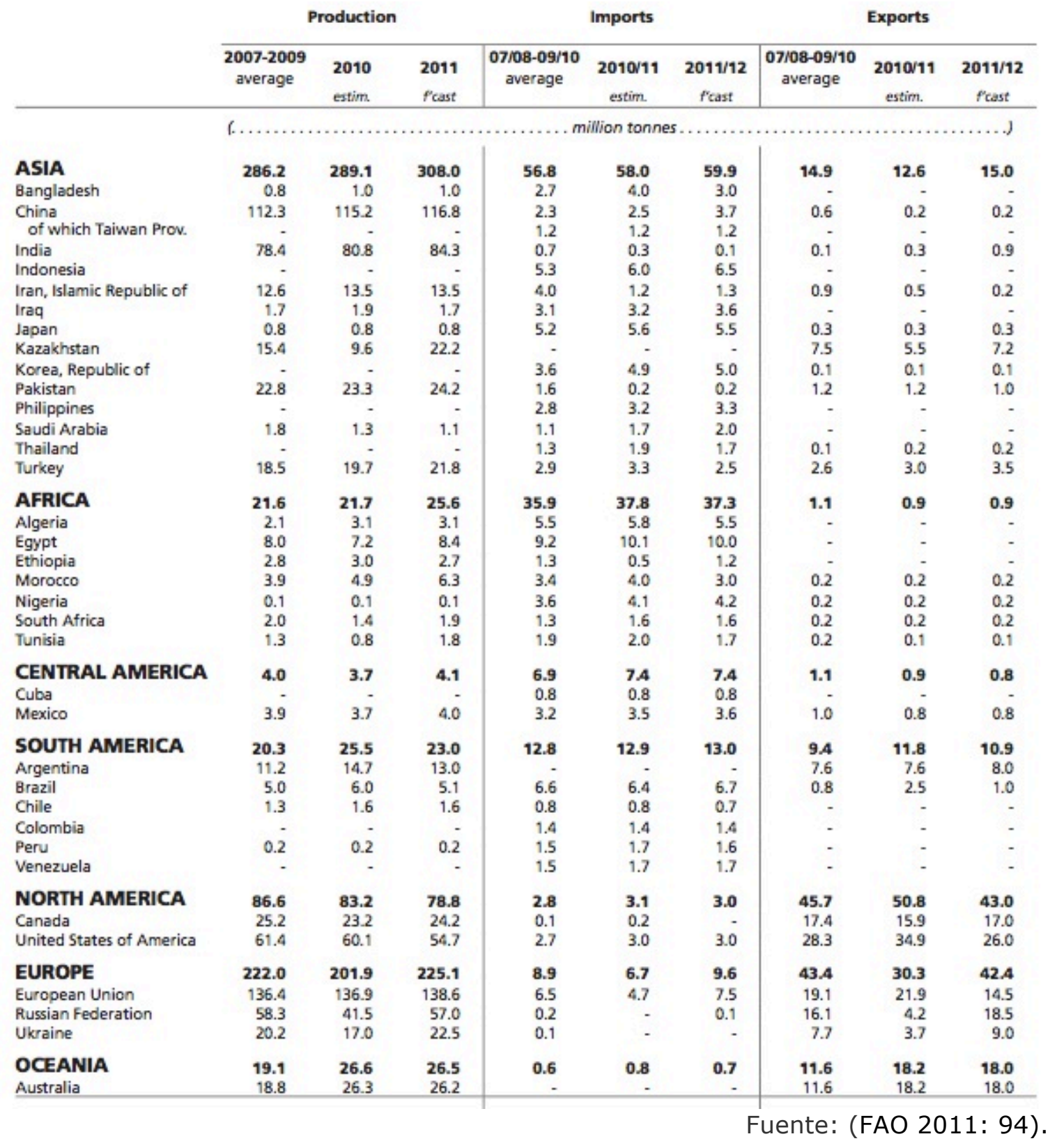

\subsubsection{Frijol}

El volumen de importaciones de frijol si bien mantiene un ritmo de crecimiento, la dinámica no guarda una relación tan estrecha con la falta de abasto por parte de la producción nacional y obedece, en buena medida, a los excedentes exportables que se tienen en otros países productores. 


\section{Gráfico 3.16 Volumen de las exportaciones e importaciones de frijol}

1992-2011 (miles de toneladas)

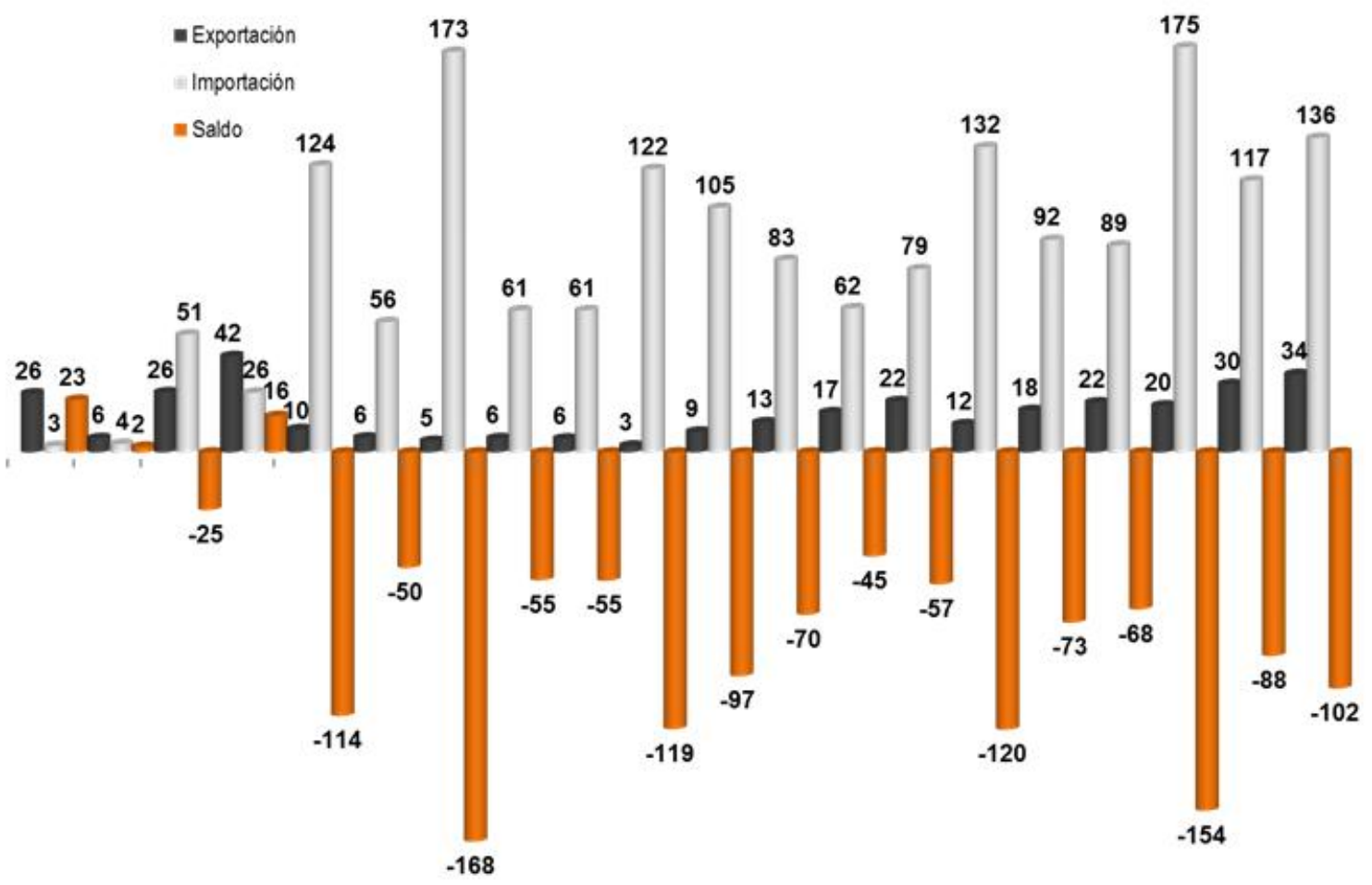

19921993199419951996199719981999200020012002200320042005200620072008200920102011

Fuente: elaboración propia con información del SIAP- SAGARPA.

¿Cuáles son los problemas que se relacionan con la producción nacional de frijol? Las eventuales sobreofertas dan lugar a caídas en el precio, a pesar de que en términos generales los precios han aumentado en la última década. Los productores de frijol han buscado acordar menores niveles de producción que les permitan aumentar los precios, no obstante los niveles de importación los obligan a mantenerlos a la baja en función de la saturación del mercado.

¿En verdad los precios de frijol se pueden considerar bajos, a pesar de sus aumentos? No. En realidad, en México se cuenta con productos sustitutos del frijol a precios más accesibles e incluso de origen animal, como lo es el huevo y la carne de pollo. 
Gráfico 3.17 Valor de las exportaciones e importaciones de frijol 1992-2009 (millones de dólares)

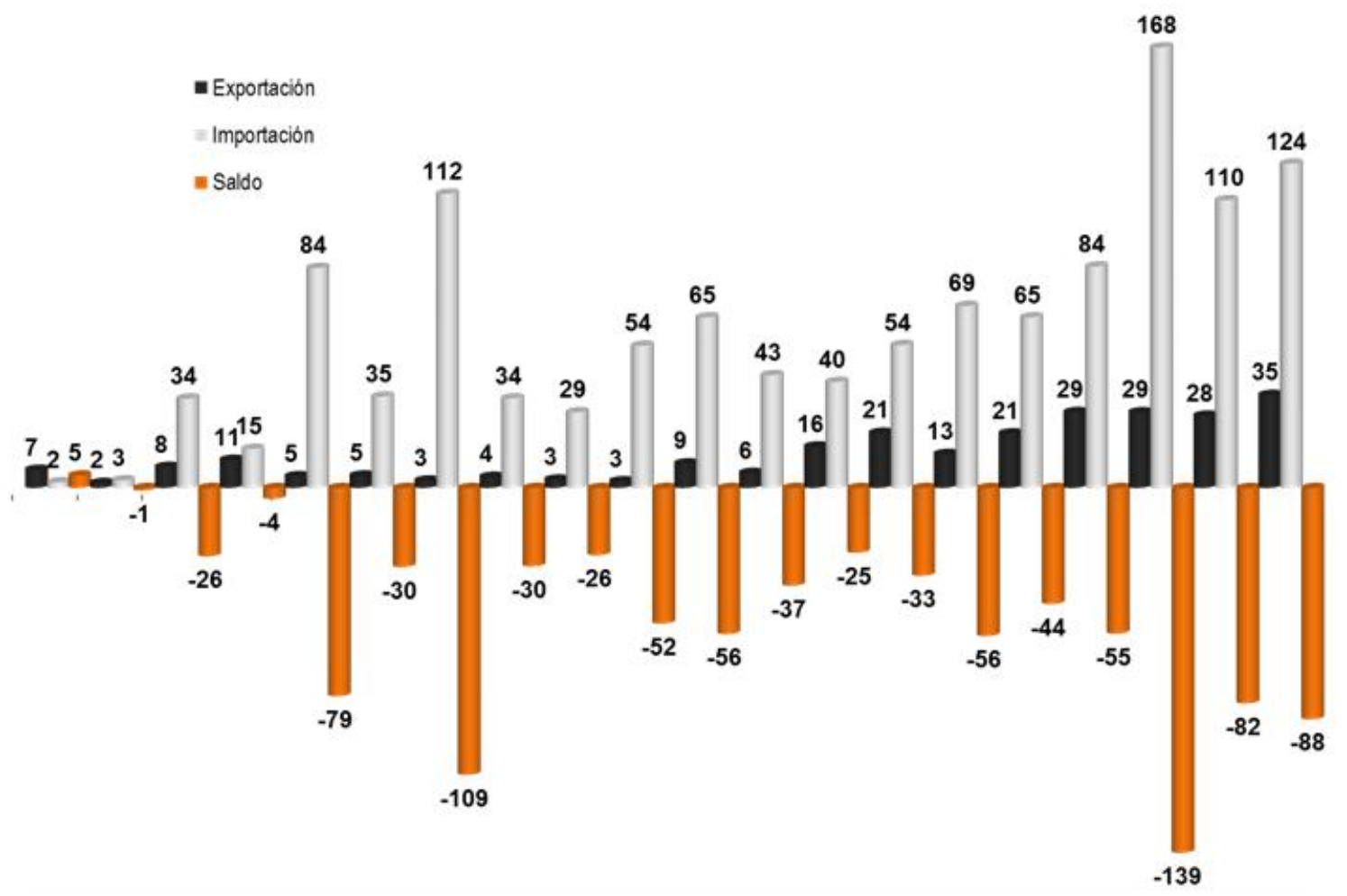

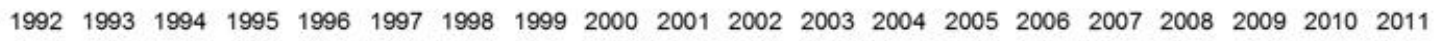

Fuente: elaboración propia con información del SIAP- SAGARPA.

¿Qué estrategias se tienen para mejorar los ingresos del productor? El Sistema Producto Frijol ha acordado apoyos con el gobierno federal, a través de la Secretaría de Agricultura, Ganadería, Desarrollo Rural, Pesca y Alimentación (SAGARPA), de modo que se continúe con los subsidios a los productores a través de las cadenas de comercialización. Parte de la estrategia, en función de la sobreoferta, debe ser bajar las superficies sembradas, dependiendo de la variedad y de la zona; el incentivar el cambio y la combinación de cultivos se considera viable. En la parte industrial la diversificación del producto -frijoles en lata, en bolsa, en caldo, en polvo-, se manifiesta en mejores precios con la desventaja de que el campesino no se encuentra vinculado a procesos de transformación. 


\subsubsection{Oleaginosas}

A nivel internacional se reconoce la importancia de las oleaginosas como fuente de proteína para la alimentación animal principalmente, incluida la alimentación humana, así como el uso de las mismas en la generación de biocombustibles. Por sus diversas características, la oleaginosa preferida, de mayor producción y demanda a nivel mundial, es la soya. No obstante, como se mostró en el apartado referente a la producción por grupos de productos, en el caso de México las oleaginosas son las que más han caído en su superficie sembrada desde la década de los ochenta, de modo que el número de hectáreas promedio sembradas en la década de los noventa es casi la tercera parte del promedio sembrado en la década anterior, a pesar de los programas que buscan fomentar su siembra en el país. La FAO, en su publicación Perspectivas alimentarias. Análisis Global de Mercados de noviembre de 2011, permite observar que para este año la participación de la producción de soya es del 58\%, pero su crecimiento esperado para 2012 podría ser menor en un $1.9 \%$, debido a la competencia que enfrenta la superficie de soya con otros cultivos como el maíz y el trigo. México debe aprovechar las ventajas que presentan sus tierras para la siembra de oleaginosas; por ejemplo, en el año agrícola 2011 fueron de los cultivos que menos afectaciones climáticas tuvieron.

El Comité Nacional Sistema Producto Oleaginosas opera en México y es un espacio donde los agentes de la cadena aprovechan sus flujos de información y bienes físicos para la mejora de la calidad de los productos, la reducción de costos y la mejora de la eficiencia de la cadena, mediante alianzas estratégicas entre los eslabones que la integran. En este espacio se generan acciones conjuntas para resolver problemas de las oleaginosas de tipo sanitario, comercial, de regulación y de investigación, que afectan a toda la cadena.

El Comité tiene carácter nacional porque agrupa 10 comités estatales de oleaginosas en Chiapas, Jalisco, Sonora, Tamaulipas, Tlaxcala, San Luis Potosí, Baja California Sur, Puebla, Veracruz e Hidalgo. Las oleaginosas de interés con las que se trabaja son soya, cártamo, canola y girasol. El objetivo principal del 
Comité Nacional es incrementar la producción nacional de oleaginosas con el fin de sustituir el 30 por ciento de las importaciones de la industria aceitera nacional para el 2012.

Los principales actores participantes en el Comité son proveedores de insumos, productores de oleaginosas, industrias procesadoras, centros de investigación y desarrollo y la SAGARPA. El Comité de oleaginosas tiene la fortaleza de integrar al sector privado de manera importante (productores agrícolas e industria), pues estos actores reconocen el beneficio de participar en la cadena. El Comité Nacional se integró en 2005 y actualmente se encuentra en una fase de fortalecimiento (Comité Nacional Sistema-Producto Oleaginosas 2011).

Como complemento al Sistema-Producto Oleaginosas, la SAGARPA cuenta con el programa de apoyo Pro-Oleaginosas, el cual tiene como objetivo general el contribuir a la conservación, uso y manejo sustentable de los recursos naturales utilizados en la producción primaria, mediante el otorgamiento de apoyos y servicios que permitan desarrollar sistemas integrales. El objetivo específico busca mejorar el ingreso de los productores mediante la conversión de áreas a cultivos de mayor rentabilidad, aprovechando el potencial productivo en el país, con la finalidad de ordenar la producción de granos básicos en las principales zonas de muy bajo y bajo potencial productivo, lo cual permita abastecer la demanda nacional y disminuir las importaciones.

El programa Pro-Oleaginosas se dirige a personas físicas y morales, cuyos predios estén ubicados en zonas de muy bajo y bajo potencial productivo, de alta siniestralidad, en zonas con producción excedentaria o en donde se promueva el ordenamiento de mercados. El apoyo se destina a productores que comercialicen su producto con la industria nacional (aceitera, pecuaria y de alimentos balanceados), por lo que no aplica para promover exportaciones, pues la intención es precisamente contribuir a cubrir las necesidades internas y reducir las importaciones. En 2011 el apoyo fue de mil 500 pesos por tonelada comercializada con la industria nacional, o su parte proporcional, y hasta la producción resultante de 100 hectáreas de riego o su equivalente en temporal por productor, de acuerdo al volumen comercializado (Sagarpa 2011a: 1-2). 
Así, el enfoque del programa parece muy aceptable y, en efecto, se ha logrado la reconversión a oleaginosas en zonas del sureste mexicano, sin embargo, queda mucho por hacer, pues aunque se tengan resultados favorables lo cierto es que los aumentos logrados últimamente en la producción no logran recuperar los niveles que se tenían en la década de los ochenta y, en consecuencia, se encuentran muy lejos de cubrir las necesidades internas del país.

El cuadro siguiente permite observar la muy baja producción de oleaginosas que tiene México a nivel mundial, lo cual se manifiesta en altas importaciones, muy similares a las de Japón, con la diferencia de que México sí cuenta con superficies con las características que permiten volúmenes y rendimientos aceptables de cosechas.

Cuadro 3.10 Estadísticas mundiales de oleaginosas (millones de toneladas)

\begin{tabular}{|c|c|c|c|c|c|c|c|c|c|}
\hline & \multicolumn{3}{|c|}{ Production' } & \multicolumn{3}{|c|}{ Imports } & \multicolumn{3}{|c|}{ Exports } \\
\hline & $\begin{array}{c}07 / 08-09 / 10 \\
\text { average }\end{array}$ & $\begin{array}{c}\text { 2010/11 } \\
\text { estim. }\end{array}$ & $\begin{array}{c}2011 / 12 \\
f^{\prime} \text { cast }\end{array}$ & $\begin{array}{c}07 / 08-09 / 10 \\
\text { average }\end{array}$ & $\begin{array}{c}\text { 2010/11 } \\
\text { estim. }\end{array}$ & $\begin{array}{c}2011 / 12 \\
f \text { cast }\end{array}$ & $\begin{array}{c}07 / 08-09 / 10 \\
\text { average }\end{array}$ & $\begin{array}{c}\text { 2010/11 } \\
\text { estim. }\end{array}$ & $\begin{array}{c}2011 / 12 \\
f^{\prime} \text { cast }\end{array}$ \\
\hline ASIA & 124.7 & 130.3 & 133.6 & 67.1 & 76.7 & 82.1 & 2.3 & 2.0 & 2.0 \\
\hline China & 57.5 & 59.7 & 59.3 & 47.8 & 56.7 & 61.3 & 1.3 & 0.9 & 0.9 \\
\hline of which Talwan Prov. & 0.1 & 0.1 & 0.1 & 2.3 & 2.4 & 2.5 & - & - & - \\
\hline Indla & 35.3 & 37.5 & 39.4 & 0.2 & 0.2 & 0.4 & 0.5 & 0.5 & 0.5 \\
\hline Indonesla & 8.4 & 9.3 & 9.9 & 1.7 & 2.1 & 2.1 & 0.1 & 0.1 & 0.1 \\
\hline Iran, islamic Republic of & 0.7 & 0.7 & 0.9 & 0.8 & 0.8 & 0.8 & - & - & - \\
\hline Japan & 0.3 & 0.3 & 0.2 & 6.2 & 5.8 & 5.9 & - & - & - \\
\hline Korea, Republic of & 0.2 & 0.2 & 0.2 & 1.4 & 1.5 & 1.6 & - & - & - \\
\hline Malaysla & 4.6 & 4.8 & 4.9 & 0.7 & 0.7 & 0.7 & - & - & - \\
\hline Pakistan & 4.8 & 4.7 & 5.1 & 1.1 & 1.0 & 1.2 & - & 0.1 & - \\
\hline Thalland & 0.7 & 0.8 & 0.8 & 1.7 & 2.2 & 2.1 & - & - & - \\
\hline Turkey & 2.1 & 2.6 & 2.6 & 2.1 & 2.2 & 2.6 & - & 0.1 & 0.1 \\
\hline AFRICA & 16.6 & 17.4 & 17.9 & 2.7 & 3.2 & 3.0 & 0.8 & 0.8 & 1.1 \\
\hline Nigerla & 4.7 & 4.7 & 4.9 & . & . & . & 0.2 & 0.2 & 0.2 \\
\hline CENTRAL AMERICA & 1.2 & 1.3 & 1.2 & 5.9 & 5.9 & 6.0 & 0.1 & 0.2 & 0.2 \\
\hline Mexico & 0.7 & 0.8 & 0.7 & 5.2 & 5.3 & 5.3 & . & . &. \\
\hline SOUTH AMERICA & 124.7 & 147.5 & 149.6 & 2.7 & 1.1 & 1.0 & 45.3 & 48.0 & 54.2 \\
\hline Argentina & 48.8 & 54.1 & 58.0 & 1.5 & 0.1 & - & 11.3 & 9.6 & 11.3 \\
\hline Brazll & 64.9 & 79.3 & 77.3 & 0.1 & . & . & 28.0 & 31.1 & 34.5 \\
\hline Paraguay & 6.5 & 8.7 & 8.7 & - & . & - & 4.5 & 5.4 & 6.4 \\
\hline NORTH AMERICA & 106.8 & 119.2 & 110.2 & 2.1 & 1.9 & 1.9 & 46.8 & 52.2 & 49.5 \\
\hline Canada & 16.1 & 18.4 & 18.0 & 0.7 & 0.7 & 0.5 & 10.0 & 10.9 & 10.7 \\
\hline United States of America & 90.7 & 100.9 & 92.2 & 1.4 & 1.3 & 1.4 & 36.8 & 41.3 & 38.8 \\
\hline EUROPE & 46.9 & 50.1 & 55.0 & 19.6 & 19.7 & 20.3 & 3.6 & 3.7 & 5.2 \\
\hline European Union & 27.5 & 29.0 & 28.7 & 18.1 & 17.9 & 18.7 & 0.8 & 0.8 & 0.8 \\
\hline Russian Federation & 8.0 & 7.5 & 11.6 & 0.9 & 1.3 & 1.0 & 0.3 & 0.1 & 0.9 \\
\hline Ukraine & 9.3 & 11.6 & 12.5 & . & . & . & 2.4 & 2.5 & 3.2 \\
\hline OCEANIA & 2.6 & 4.1 & 4.6 & 0.1 & 0.1 & 0.1 & 1.1 & 1.8 & 2.2 \\
\hline Australla & 2.2 & 3.7 & 4.2 & 0.1 & 0.1 & 0.1 & 1.0 & 1.8 & 2.1 \\
\hline WORLD & 423.4 & 469.9 & 472.0 & 100.2 & 108.7 & 114.3 & 100.1 & 108.8 & 114.3 \\
\hline Developing countries & 262.0 & 291.0 & 296.6 & 71.2 & 80.3 & 85.2 & 48.4 & 51.0 & 57.0 \\
\hline Developed countrles & 161.4 & 178.9 & 175.4 & 29.0 & 28.4 & 29.1 & 51.7 & 57.8 & 57.3 \\
\hline LIFDCS & 128.7 & 133.8 & 137.6 & 52.0 & 61.3 & 66.0 & 2.9 & 2.7 & 2.7 \\
\hline LDCs & 10.2 & 10.6 & 10.9 & 0.3 & 0.3 & 0.3 & 0.4 & 0.5 & 0.5 \\
\hline
\end{tabular}

Fuente: (FAO 2011: 107) 
Es importante observar la capacidad productiva de países como Argentina y Brasil que compiten con el principal productor mundial (Estados Unidos), que les permite ubicar a los países en vías de desarrollo con niveles competitivos que superan a los países desarrollados.

\subsubsection{Sorgo}

Es conocido en el ámbito agrícola que una de las posibles alternativas para cambiar el cultivo de maíz es la producción de sorgo, el cual también se encuentra apoyado con cobertura de precios dentro de los apoyos de ASERCA, que es un órgano administrativo desconcentrado de la SAGARPA creado con la finalidad de fortalecer la comercialización agropecuaria de granos y oleaginosas, mediante la entrega de apoyos que se otorgan para el fomento de mecanismos de mercado, diseño de esquemas de negociación entre productores y compradores, esquemas de administración de riesgo (cobertura de precios) y promoción de exportaciones, como lo hemos indicado con antelación.

Las coberturas de precios que opera ASERCA para los productores, comercializadoras y consumidores, involucran una posición en el mercado de futuros opuesta a la que tiene el participante en el mercado de físicos, de manera que cualquier pérdida en el mercado de físicos será compensada o equilibrada con la cobertura en el mercado de futuros. Las coberturas se realizan a través de instrumentos financieros derivados, específicamente con opciones sobre futuros, los cuales se negocian en bolsas de commodities (CME y New York Mercantile Exchange -NYMEX-), y que funcionan como un "seguro" contra movimientos adversos en los precios. El costo de estas operaciones es conocido por los participantes desde su colocación, y es igual a la prima cotizada en la bolsa más las comisiones de la correduría y los organismos reguladores del mercado.

A pesar de que el sorgo se encuentra dentro de los cultivos con cobertura de precios de ASERCA y de que México es de los primeros productores de sorgo a nivel mundial, sólo superado por los Estados Unidos como principal 
oferente del grano, Nigeria e India, en segundo y tercer lugar respectivamente, como se observa en el cuadro siguiente, también es cierto que México es el principal importador del cultivo.

Cuadro 3.11 Estadísticas mundiales de sorgo (millones de toneladas)

\begin{tabular}{|c|c|c|c|c|c|c|c|c|c|}
\hline & \multicolumn{3}{|c|}{ Production } & \multicolumn{3}{|c|}{ Imports } & \multicolumn{3}{|c|}{ Exports } \\
\hline & $\begin{array}{c}\mathbf{2 0 0 7 - 2 0 0 9} \\
\text { average }\end{array}$ & $\begin{array}{l}2010 \\
\text { estim. }\end{array}$ & $\begin{array}{l}2011 \\
f^{\prime} \text { cast }\end{array}$ & $\begin{array}{c}07 / 08-09 / 10 \\
\text { average }\end{array}$ & $\begin{array}{c}\text { 2010/11 } \\
\text { estim. }\end{array}$ & $\begin{array}{c}2011 / 12 \\
\text { f'cast }\end{array}$ & $\begin{array}{c}07 / 08 \cdot 09 / 10 \\
\text { average }\end{array}$ & $\begin{array}{c}\text { 2010/11 } \\
\text { estim. }\end{array}$ & $\begin{array}{c}2011 / 12 \\
f^{\prime} \text { cast }\end{array}$ \\
\hline & \multicolumn{9}{|c|}{ 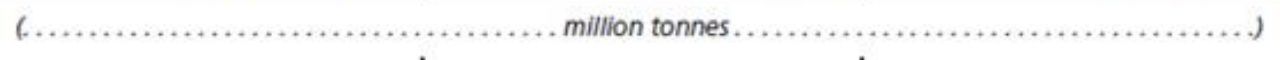 } \\
\hline ASIA & 10.2 & 10.2 & 10.5 & 1.7 & 1.7 & 1.7 & 0.1 & 0.1 & 0.1 \\
\hline China & 2.0 & 2.5 & 2.1 & 0.1 & 0.1 & 0.1 & - & 0.1 & - \\
\hline India & 7.3 & 6.8 & 7.5 & - & - & - & - & - & - \\
\hline Japan & - & - & - & 1.4 & 1.4 & 1.5 & - & - & - \\
\hline AFRICA & 25.1 & 28.0 & 25.7 & 1.1 & 0.8 & 1.0 & 0.7 & 0.9 & 0.7 \\
\hline Burkina Faso & 1.6 & 2.0 & 1.8 & - & - & - & 0.1 & 0.2 & 0.2 \\
\hline Ethiopia & 2.9 & 3.5 & 2.7 & 0.2 & - & 0.1 & 0.1 & 0.3 & - \\
\hline Nigeria & 9.0 & 8.8 & 8.7 & - & - & - & 0.1 & 0.1 & 0.1 \\
\hline Sudan & 3.6 & 4.6 & 4.0 & 0.3 & 0.2 & 0.4 & 0.2 & - & - \\
\hline CENTRAL AMERICA & 6.8 & 7.4 & 6.9 & 2.0 & 2.2 & 2.2 & - & - & - \\
\hline Mexico & 6.3 & 7.0 & 6.4 & 2.0 & 2.2 & 2.2 & - & - & - \\
\hline SOUTH AMERICA & 5.3 & 6.2 & 7.6 & 0.5 & 1.1 & 1.0 & 1.2 & 1.9 & 2.0 \\
\hline Argentina & 2.4 & 3.6 & 4.5 & - & - & - & 1.1 & 1.9 & 2.0 \\
\hline Brazil & 1.7 & 1.5 & 1.9 & - & - & - & 0.1 & - & - \\
\hline Venezuela & 0.4 & 0.4 & 0.5 & - & - & - & - & - & - \\
\hline NORTH AMERICA & 11.5 & 8.8 & 6.2 & - & - & - & 5.0 & 3.7 & 3.0 \\
\hline United States of America & 11.5 & 8.8 & 6.2 & - & - & - & 5.0 & 3.7 & 3.0 \\
\hline EUROPE & 0.6 & 0.6 & 0.6 & 2.2 & 0.9 & 0.5 & 0.1 & - & - \\
\hline European Union & 0.6 & 0.6 & 0.6 & 2.1 & 0.8 & 0.4 & 0.1 & - & - \\
\hline OCEANIA & 2.6 & 1.5 & 2.1 & 0.1 & 0.1 & 0.1 & 0.7 & 0.6 & 0.7 \\
\hline Australia & 2.6 & 1.5 & 2.1 & - & - & - & 0.7 & 0.6 & 0.7 \\
\hline WORLD & 61.9 & 62.8 & 59.7 & 7.7 & 6.8 & 6.5 & 7.8 & 7.2 & 6.5 \\
\hline Developing countries & 47.1 & 51.7 & 50.5 & 3.8 & 4.2 & 4.4 & 1.9 & 2.9 & 2.8 \\
\hline Developed countries & 14.9 & 11.1 & 9.2 & 3.9 & 2.6 & 2.1 & 5.8 & 4.3 & 3.7 \\
\hline LIFDCs & 32.9 & 35.4 & 33.8 & 1.1 & 0.7 & 1.0 & 0.7 & 0.9 & 0.7 \\
\hline LDCS & 14.3 & 17.6 & 15.4 & 0.9 & 0.5 & 0.8 & 0.6 & 0.8 & 0.6 \\
\hline
\end{tabular}

Fuente: (FAO 2011: 102)

Se tiene conocimiento de que en México los costos de producción del sorgo son menores a los del maíz; sin embargo, no se cuenta con estudios recientes sobre costos de producción de cultivos a nivel nacional, por ciclo y métodos de producción, de modo que se requiere actualizar $y$, más bien, redefinir la elaboración de tales estudios, de modo que sean verdaderamente representativos de las condiciones en las que se llevan a cabo los procesos de producción en los diferentes modos de producción en México. La información 
que sí esta disponible es la relacionada con los precios pagados al productor, por lo menos de manera anual, aunque se tiene conocimiento de la pronta publicación, por parte del Servicio de Información Agroalimentaria y Pesquera (SIAP), de manera mensual; tal disponibilidad de precios anuales permite saber que los precios pagados al productor de sorgo son menores a los precios del maíz.

Las siguientes gráficas y cuadros permiten darse cuenta que las superficies sembradas tanto de maíz grano como de sorgo grano se han mantenido sin cambios considerables e, incluso en el caso del primer cultivo, se tiene una ligera disminución en el promedio anual de superficie sembrada en la década de 2000 a 2010, en comparación con las dos décadas anteriores. Las afectaciones por diversos siniestros resultan muy similares en ambos productos, aunque la relación de superficie siniestrada a sembrada, durante las tres décadas mostradas, es mayor en maíz (13\%), mientras que en sorgo es del $11 \%$ en promedio anual. Aunque los rendimientos del sorgo grano eran $84 \%$ mayores a los de maíz grano en la década de los ochenta, para la década que va de 2000 a 2010 tal relación se reduce a tan sólo $18 \%$, de modo que las mejoras en la productividad del sorgo se quedan muy cortas al compararlas con el maíz, sin que ello signifique que en términos de la producción de maíz los rendimientos sean considerables.

\section{Gráfico 3.18 Superficie de maíz grano en México} (promedios anuales en hectáreas)

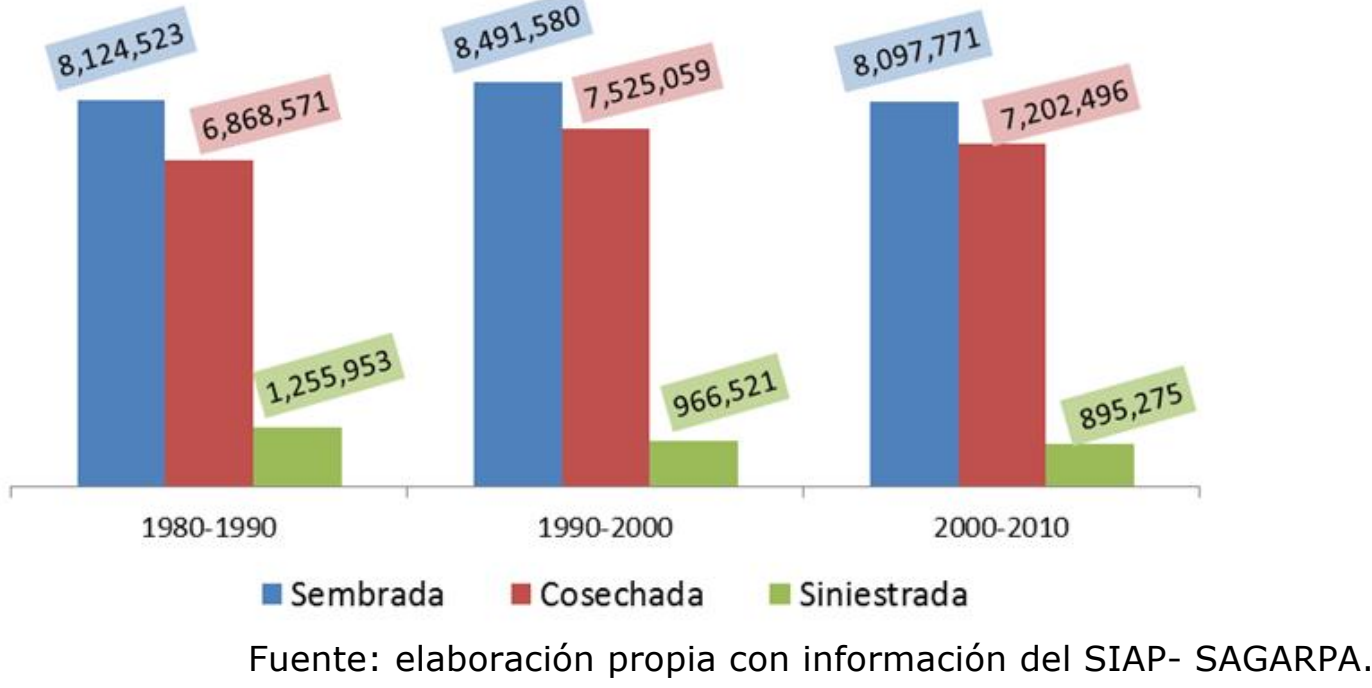


Cuadro 3.12 Comportamiento del maíz grano en México 1980-2010

\begin{tabular}{|c|c|c|c|c|c|}
\hline & & & & Var \% & \\
\hline Maíz grano & $1980-1990$ & $1990-2000$ & 2000-2010 & $\begin{array}{l}1990-2000 \text { vs } \\
1980-1990\end{array}$ & $\begin{array}{l}2000-2010 \text { vs } \\
1990-2000\end{array}$ \\
\hline Sembrada & $8,124,523$ & $8,491,580$ & $8,097,771$ & 4.52 & -4.64 \\
\hline Cosechada & $6,868,571$ & $7,525,059$ & $7,202,496$ & 9.56 & -4.29 \\
\hline Siniestrada & $1,255,953$ & 966,521 & 895,275 & -23.04 & -7.37 \\
\hline Volumen & $12,387,239$ & $17,266,403$ & $21,088,716$ & 39.39 & 22.14 \\
\hline Valor & $2,150,945,911$ & $18,770,822,128$ & $43,393,488,126$ & 772.68 & 131.18 \\
\hline Rendimiento & 1.80 & 2.29 & 2.93 & 27.42 & 27.92 \\
\hline PMR & 174 & 1,072 & 2,020 & 514.65 & 88.48 \\
\hline
\end{tabular}

Fuente: elaboración propia con información del SIAP- SAGARPA.

\section{Gráfico 3.19 Superficie de sorgo grano en México (promedios anuales en hectáreas)}

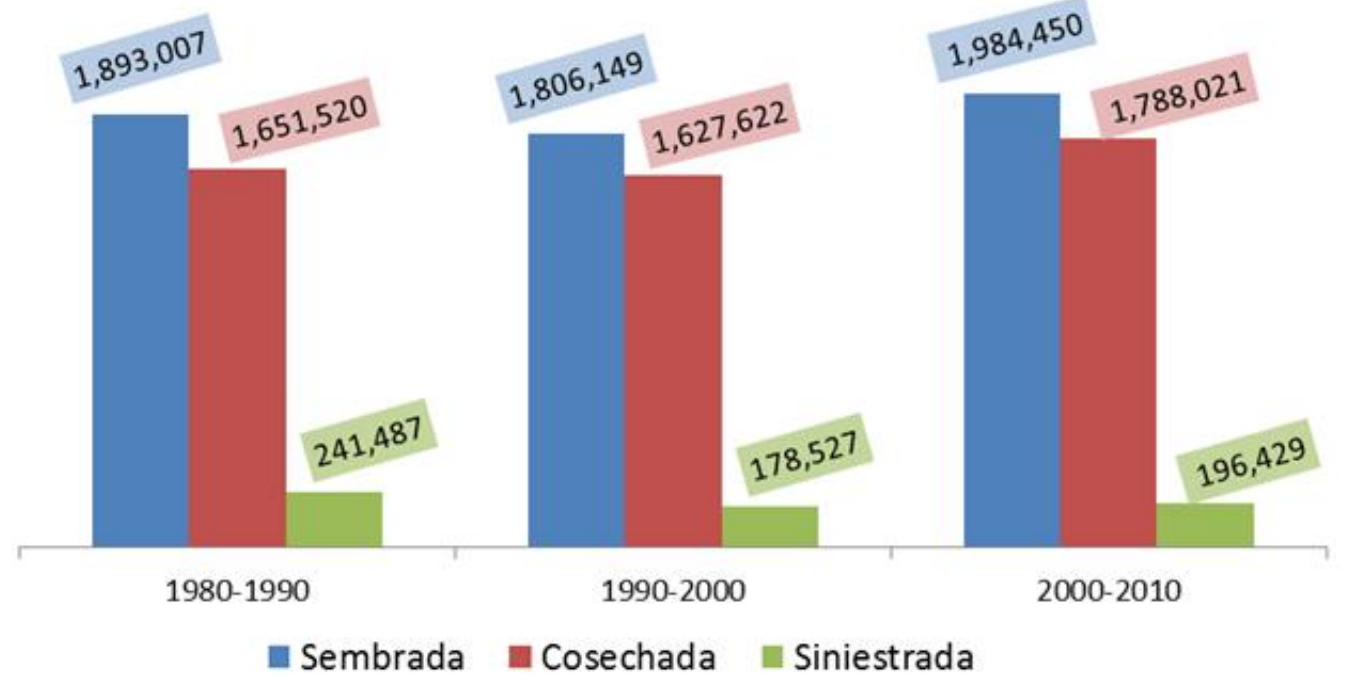

Fuente: elaboración propia con información del SIAP- SAGARPA.

Cuadro 3.13 Comportamiento del sorgo grano en México 1980-2010

\begin{tabular}{|l|r|r|r|r|r|}
\hline Sorgo grano & \multicolumn{2}{|c|}{} & \multicolumn{1}{c|}{ Var \% } \\
\hline Sembrada (Has.) & $\mathbf{1 9 8 0 - 1 9 9 0}$ & $\mathbf{1 9 9 0 - 2 0 0 0}$ & $\mathbf{2 0 0 0 - 2 0 1 0}$ & $\begin{array}{l}\mathbf{1 9 9 0 - 2 0 0 0} \text { vs } \\
\mathbf{1 9 8 0 - 1 9 9 0}\end{array}$ & $\begin{array}{l}\mathbf{2 0 0 0 - 2 0 1 0} \text { vs } \\
\mathbf{1 9 9 0 - 2 0 0 0}\end{array}$ \\
\hline Cosechada (Has.) & $1,893,007$ & $1,806,149$ & $1,984,450$ & -4.59 & 9.87 \\
\hline Siniestrada (Has.) & $1,651,520$ & $1,627,622$ & $1,788,021$ & -1.45 & 9.85 \\
\hline Volumen (Tons.) & $241, \mathbf{4 8 7}$ & $178, \mathbf{5 2 7}$ & 196,429 & -26.07 & 10.03 \\
\hline Valor (Pesos) & $\mathbf{5}, 456,713$ & $\mathbf{5 , 1 4 9 , 9 8 3}$ & $6,205,949$ & -5.62 & 20.50 \\
\hline Rendimiento (Ton/Ha) & $624,726,503$ & $4,045,096,932$ & $9,845,484,417$ & 547.50 & 143.39 \\
\hline PMR (Pesos/Ton) & 3.30 & 3.16 & 3.47 & -4.28 & 9.88 \\
\hline
\end{tabular}

Fuente: elaboración propia con información del SIAP- SAGARPA. 
La gráfica siguiente reporta al aumento de importaciones de sorgo por parte de México. Llama la atención un aparente comportamiento cíclico de aproximadamente cinco años, pero las compras al exterior aumentan cuando se tienen déficits para cubrir las necesidades de alimento para animales, sin que a la fecha se logre motivar aumentos en la oferta de tan importante forraje.

\section{Gráfico 3.20 Volumen de las exportaciones e importaciones de sorgo 1992-2011 (miles de toneladas)}

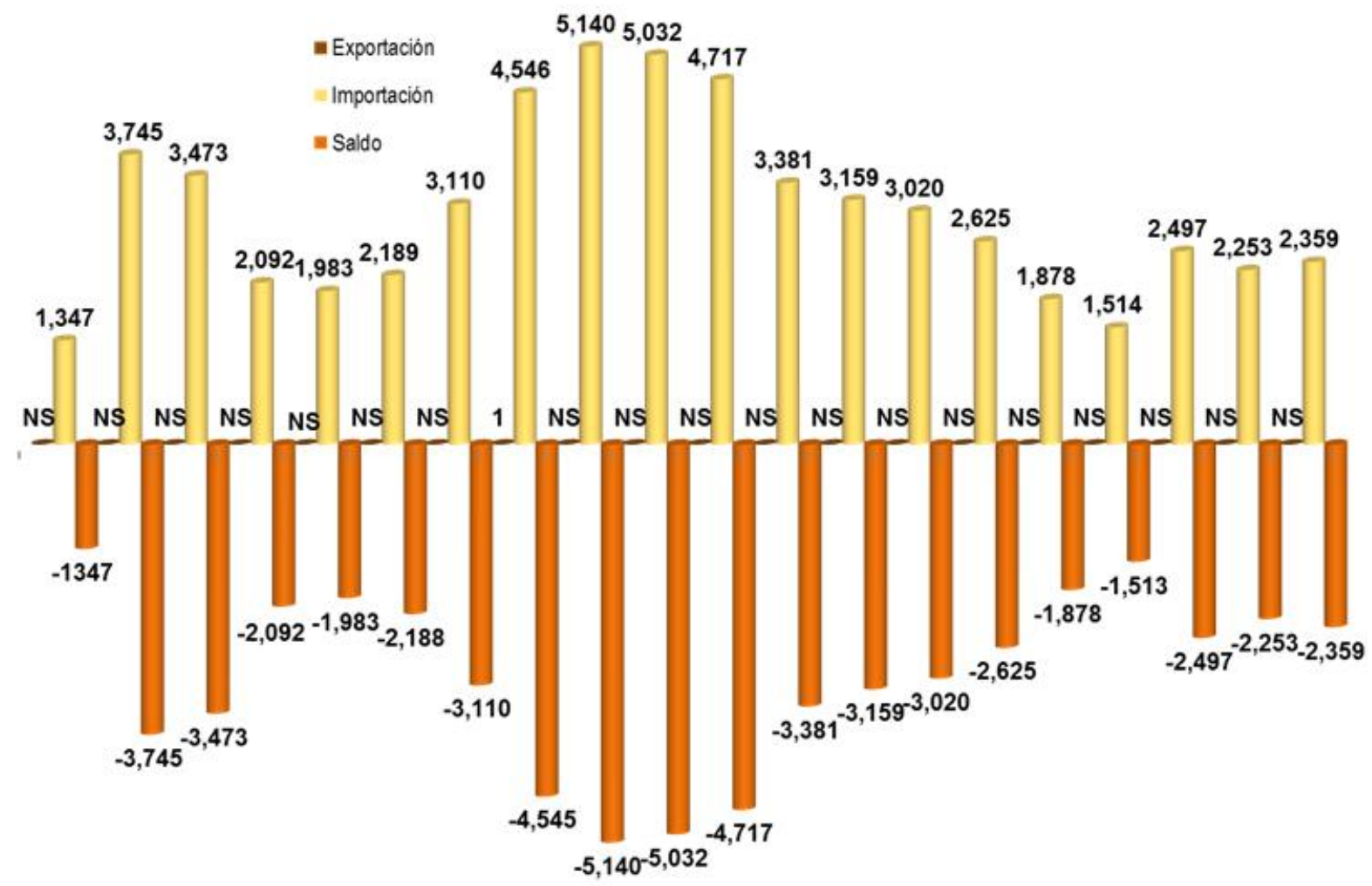

19921993199419951996199719981999200020012002200320042005200620072008200920102011

Fuente: elaboración propia con información del SIAP- SAGARPA.

En la medida en la que se motive el aumento en la producción de sorgo, con mejoras en sus niveles productivos y, si es necesario, cambiando algunos cultivos menos rentables y menos resistentes a los siniestros por este grano que tiene usos en México enfocados al alimento animal, será posible evitar fugas de divisas por la compra de tal cultivo al extranjero. 
Aunque el año agrícola 2011 se caracterizó por efectos climáticos adversos sobre buena parte de los cultivos nacionales, lo que ocasionó una menor disponibilidad de forrajes, también es cierto que esto no elevó la demanda de sorgo proveniente del extranjero. Lo anterior se explica porque el precio del sorgo importado se incrementó de manera considerable, lo cual se relaciona con el aumento en el valor de tales compras mostrado en la siguiente gráfica.

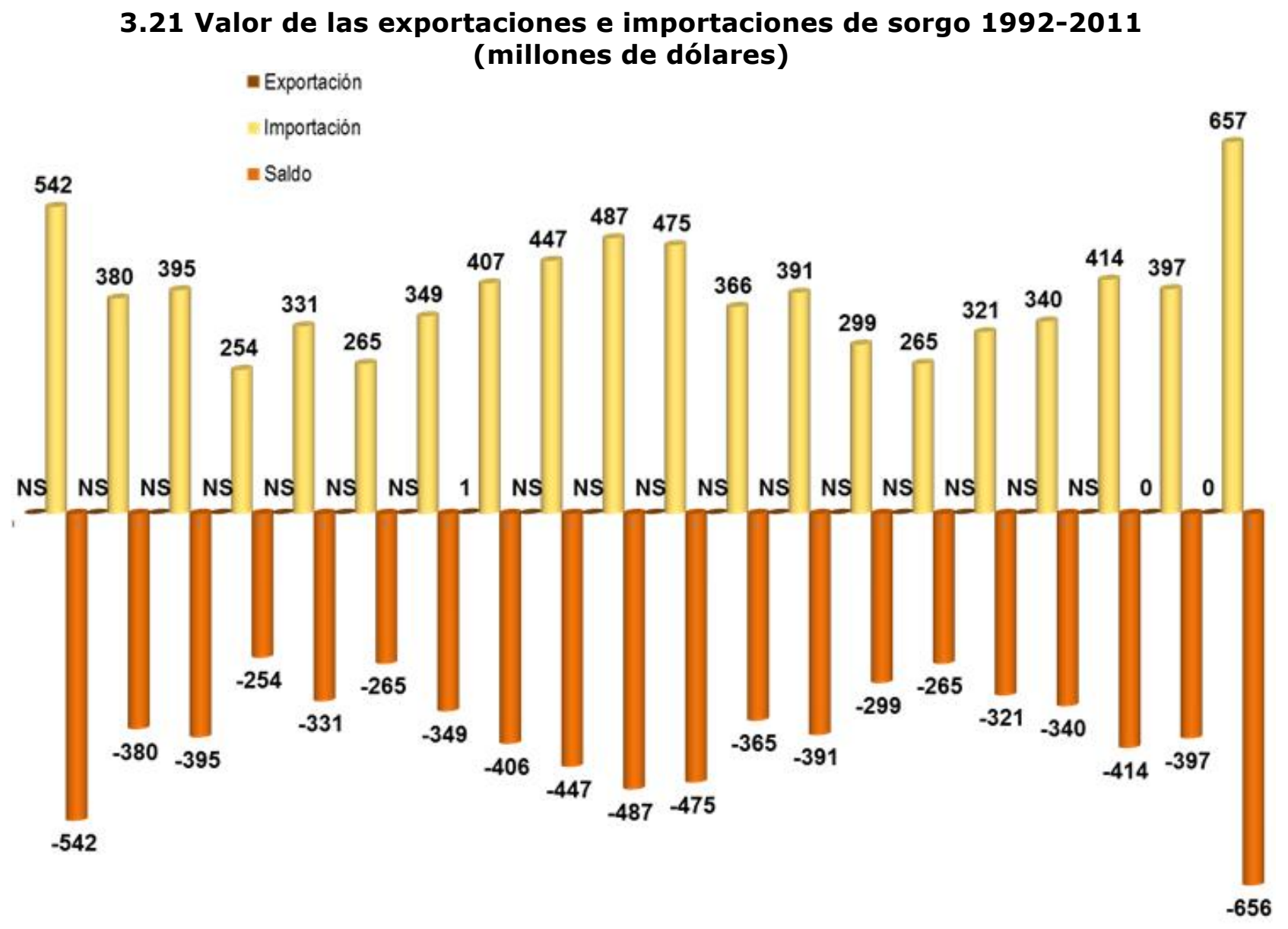

19921993199419951996199719981999200020012002200320042005200620072008200920102011 Fuente: elaboración propia con información del SIAP- SAGARPA. 


\subsection{Precios internacionales de cultivos seleccionados}

El comportamiento de los precios internacionales de los siguientes cultivos es un referente para entender la manera en que los precios de productos muy ligados al comercio internacional impactan los volúmenes de oferta y demanda de las economías abiertas.

El precio del maíz amarillo puesto en el golfo de Estados Unidos cotizado en marzo de 2012, tuvo un valor de 280.7 dólares la tonelada; aumentó $0.4 \%$ respecto a febrero, pero se redujo un $3.4 \%$ en relación con el mismo mes del año pasado y menor en $1.9 \%$ con el pico alcanzado en abril de 2010 que fue de 303.9 dólares la tonelada. El equivalente es de 3,581 pesos, mayor en 95 pesos respecto al mismo mes de 2011 que alcanzó 3,486 pesos la tonelada.

Los precios futuros del maíz muestran una tendencia a la baja para el mes de mayo, pues se tiene una cotización de 257.2 dólares la tonelada, menor en $8.4 \%$ respecto al físico de marzo.

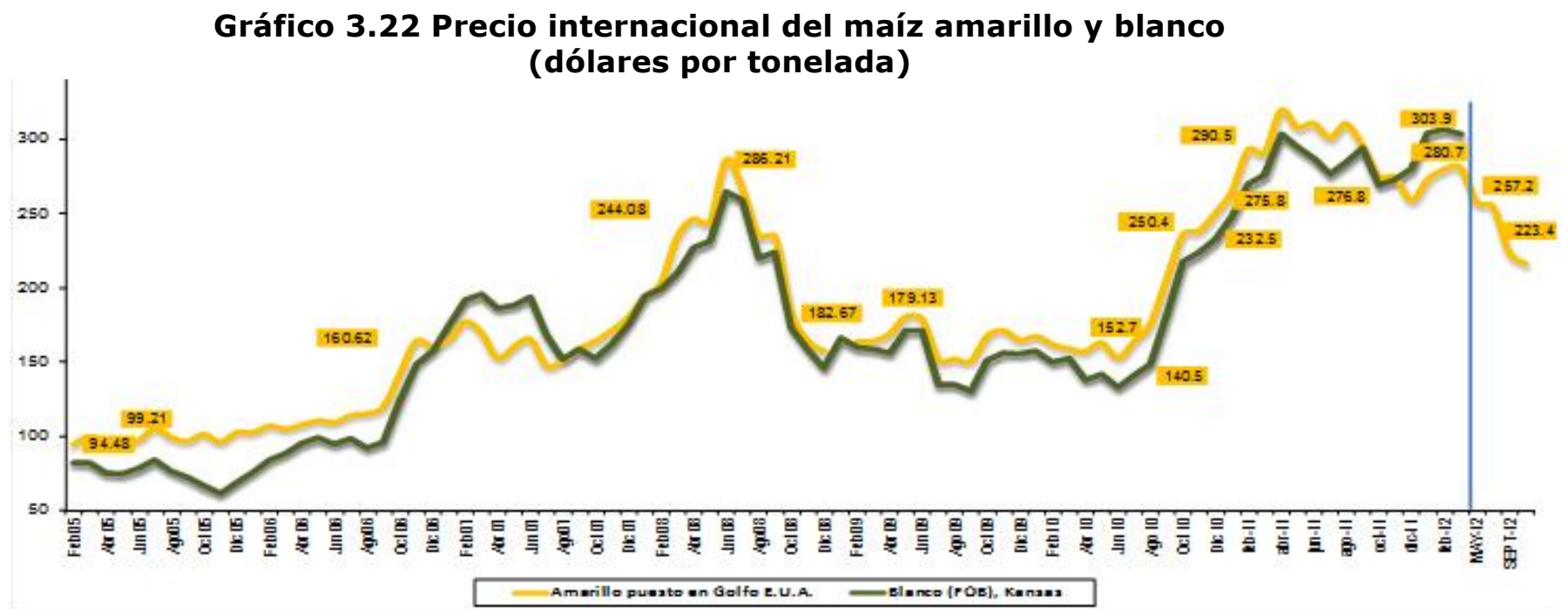

Fuente: elaboración propia con información del Banco Mundial.

Por su parte, el precio del trigo de los Estados Unidos promedió en marzo de 2012 un valor de 259.8 dólares la tonelada; menor en $1.3 \%$ respecto con el 
mes anterior. El precio del grano fue menor en $14.3 \%$ respecto con el mismo mes del año anterior, y menor en $38.1 \%$ al precio máximo que alcanzó en marzo de 2008 de 419.6 dólares la tonelada. El precio del futuro alcanzó para mayo 253.2 dólares la tonelada, menor en $2.5 \%$ con relación al costo del físico en marzo.

Gráfico 3.23 Precio internacional del trigo (dólares por tonelada)

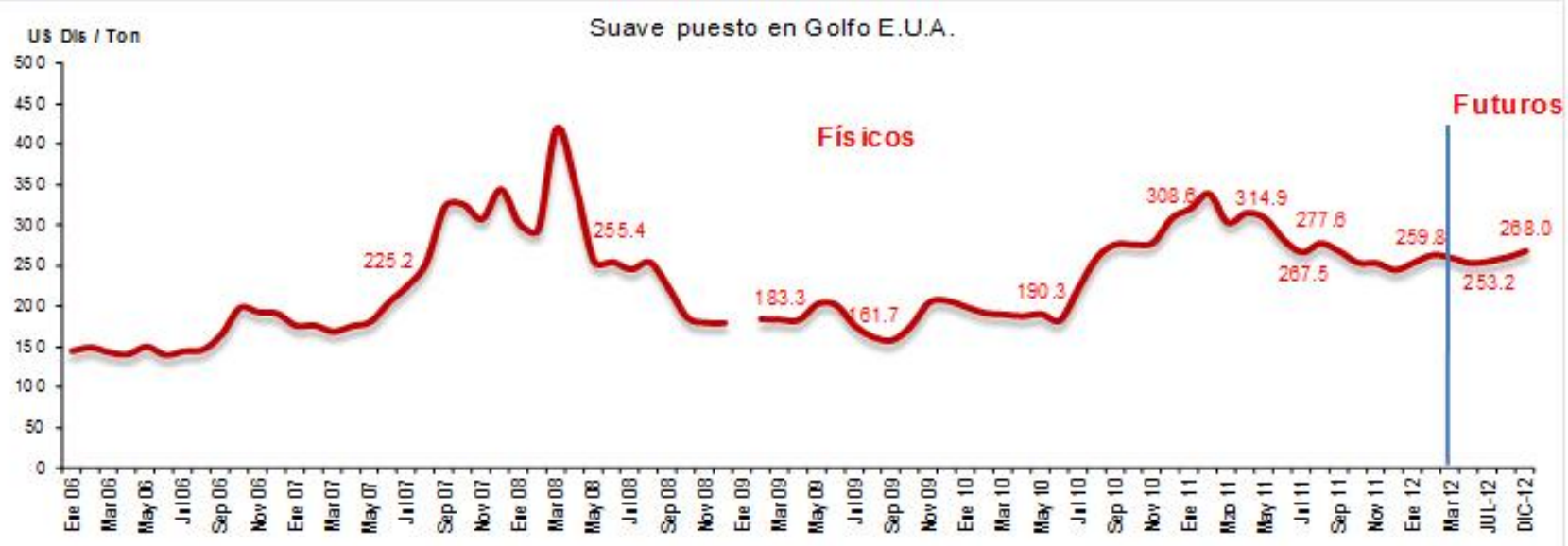

Fuente: elaboración propia con información del Banco Mundial.

En cuanto al precio internacional de frijol pinto al mayoreo en Colorado, Estados Unidos, se cotizó en marzo de 2012 en 1,458 dólares la tonelada, precio que muestra un aumento considerable de $143.1 \%$ respecto al mismo mes del año anterior, pero con un crecimiento nulo respecto con el mes anterior y se encuentra por arriba en $21 \%$ respecto al precio más alto registrado en septiembre de 2008 de 1,204 dólares la tonelada.

El precio del frijol negro al mayoreo en Michigan, Estados Unidos, fue de 1,176 dólares la tonelada en marzo, con una disminución de $3.5 \%$ respecto al mes de febrero; una variación anual de $8.8 \%$ respecto al mismo mes del año anterior y menor en $2.1 \%$ respecto al precio máximo que obtuvo en agosto de 2008 que alcanzó 1,202 dólares la tonelada. 


\subsection{Precio internacional del frijol \\ (dólares por tonelada)}

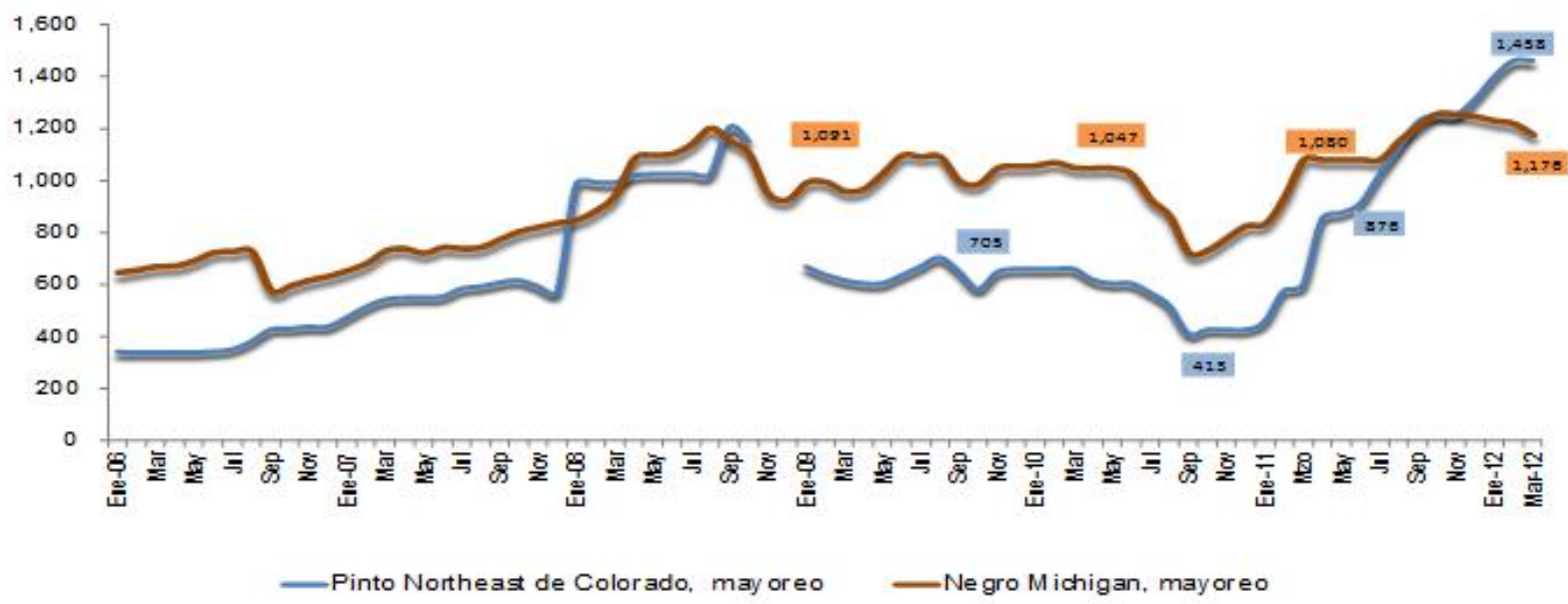

Fuente: elaboración propia con información del Banco Mundial.

El precio de la soya promedió en marzo de 2012 un monto de 481.3 dólares la tonelada; mayor en $8.3 \%$ respecto con el mismo mes del año anterior. La cotización de la soya aumentó $7.4 \%$ en relación con el mes anterior, pero disminuyó $13 \%$ respecto con el precio máximo que alcanzó en julio de 2008 de 553.4 dólares la tonelada. El precio futuro al mes de mayo de 2012 alcanza 528.9 dólares la tonelada, superior en $9.9 \%$ con respecto al precio físico de marzo.

\subsection{Precio internacional de la soya \\ (dólares por tonelada)}

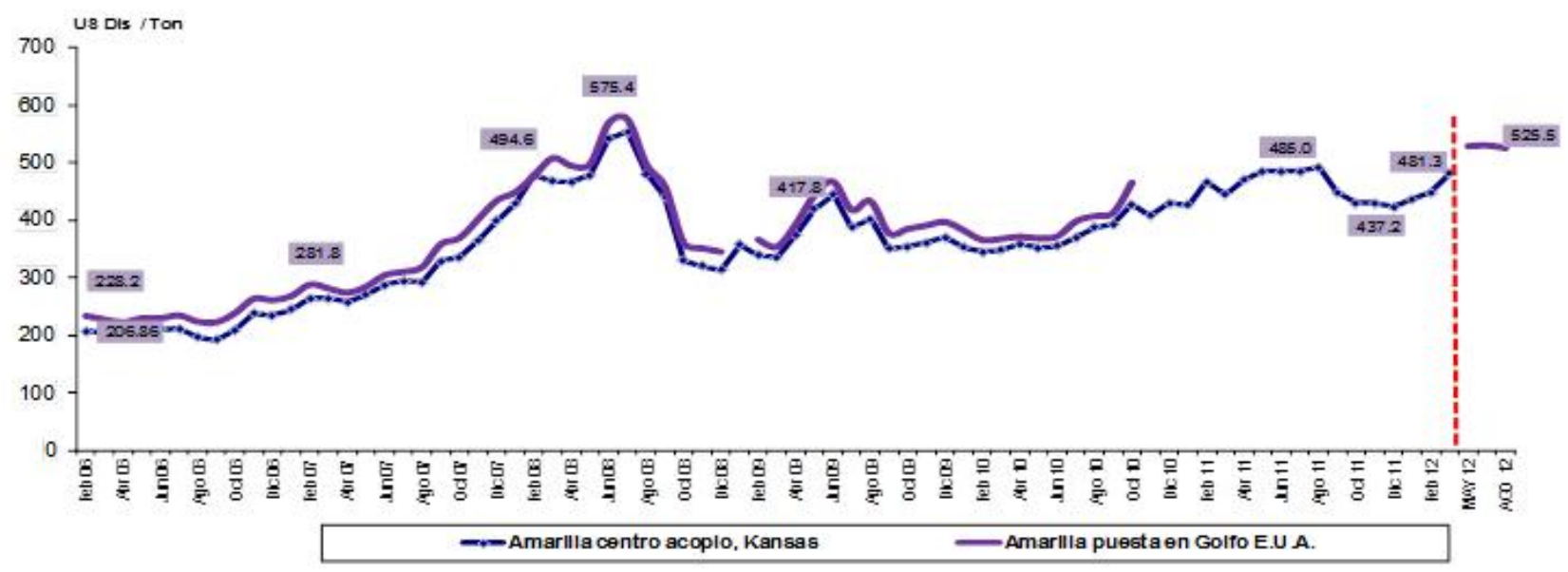

Fuente: elaboración propia con información del Banco Mundial. 


\subsection{Balanza comercial}

La balanza comercial de México con el resto del mundo es un primer referente, en términos macroeconómicos, del potencial productivo del país al compararse con las demás economías. Las cifras del Banco de México (Banxico) permiten observar un déficit continuo en la balanza, debido a un aumento proporcional en las importaciones respecto a las exportaciones, aunque vale la pena destacar que el valor de las exportaciones logra aumentos tan dinámicos como los de las importaciones, además de que la participación del saldo comercial representó en promedio, en la serie 1993 a 2011, un 3.6\% del valor de las exportaciones (cifra que no resulta tan considerable).

La balanza de pagos es un fiel reflejo de la incidencia de las relaciones comerciales entre los países, de modo que México no queda libre de los efectos económicos que acontecen a sus socios comerciales. La gráfica siguiente es un referente inequívoco, sobre todo si se considera el año 2009 en el que las condiciones internacionales obligaron a menores exportaciones e importaciones del país. A pesar de todo, el déficit de la balanza fue el menos negativo de todos los mostrados en la serie. También vale la pena notar la rápida recuperación tanto de las importaciones como de las exportaciones, además de que los saldos negativos de 2010 y 2011 fueron todavía menores a los de 2009, siendo el de 2011 el que cuenta la menor salida de divisas de toda la serie. En realidad, el país no se ha encontrado lejos de contar con exportaciones mayores a las importaciones, pero aún prevalece la falta de estrategias que permitan dar ese gran cambio. 


\subsection{Balanza comercial de México 1993-2011 \\ (millones de dólares)}

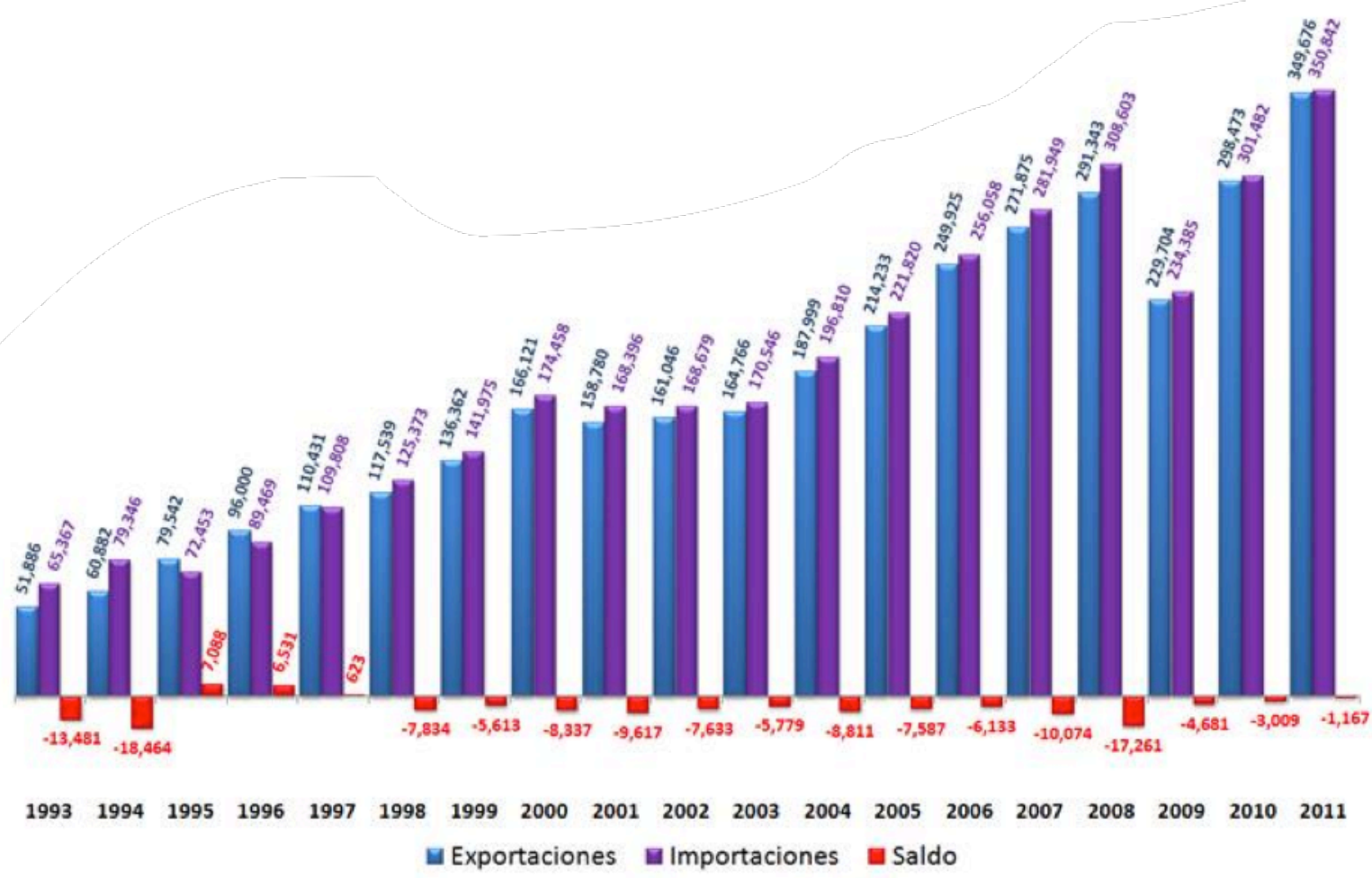

Fuente: elaboración propia con información del Banxico.

La turbulencia en los mercados financieros internacionales afectó significativamente el desempeño de la economía global en 2008. A pesar de la implementación de medidas de estímulo monetario y fiscal en un elevado número de países, la tasa de crecimiento del PIB mundial disminuyó de 5.2 por ciento en 2007 a 3.2 por ciento en 2008. Además, la desaceleración de la actividad económica afectó tanto a economías emergentes como avanzadas, si bien el debilitamiento fue más pronunciado en los países de este último grupo. En Estados Unidos, la economía entró en una fase recesiva en diciembre de 2007, que se fue agudizando a lo largo de 2008. Así, en el cuarto trimestre del año el PIB registró una contracción de 6.3 por ciento (Banxico 2008: 11). 
La actividad económica mundial se empezó a recuperar a partir del segundo trimestre de 2009, luego de la profunda contracción observada en los seis meses anteriores. La reactivación económica fue influida por los estímulos fiscales y monetarios instrumentados en la mayoría de las economías avanzadas y en algunas emergentes, así como por las diversas medidas adoptadas para normalizar la operación del sistema financiero internacional. No obstante, en el año en su conjunto el PIB global disminuyó 0.6 por ciento, la primera contracción en el período de la posguerra. La recuperación económica procedió a ritmos diferentes entre países y regiones. En Estados Unidos se observó un crecimiento importante durante la segunda mitad de 2009. En la zona del euro y en Japón también se registró una reactivación del crecimiento, aunque a un ritmo menos robusto. La expansión más vigorosa se presentó en las economías emergentes, particularmente de Asia, debido en buena medida al crecimiento de su demanda interna y de sus exportaciones (Banxico 2008: 11).

El comportamiento del valor de la balanza agropecuaria, pesquera y agroindustrial de México permite darse cuenta de que la dinámica de las actividades agropecuarias y pesqueras da lugar a mayores exportaciones que las generadas por la agroindustria encargada de procesar alimentos, bebidas y tabaco. En la serie considerada, el valor de las exportaciones de las actividades relacionadas al sector primario sumó 106 mil 800 millones de dólares, 14\% por arriba de la suma que representaron las actividades vinculadas al sector secundario y que necesariamente utilizan como materia prima a las primeras. Así, de 1993 a 2011, sólo las exportaciones agropecuarias y pesqueras han permitido saldos positivos, al menos al inicio de la serie. El potencial productivo del país, en cuanto a la producción primaria se refiere, debe incentivarse de mejor manera para aprovechar aun más los mercados externos, sin olvidar potenciar el valor agregado que da la transformación de las materias primas a través de la industria. 
3.27 Balanza agropecuaria, pesquera y agroindustrial de México (millones de dólares)

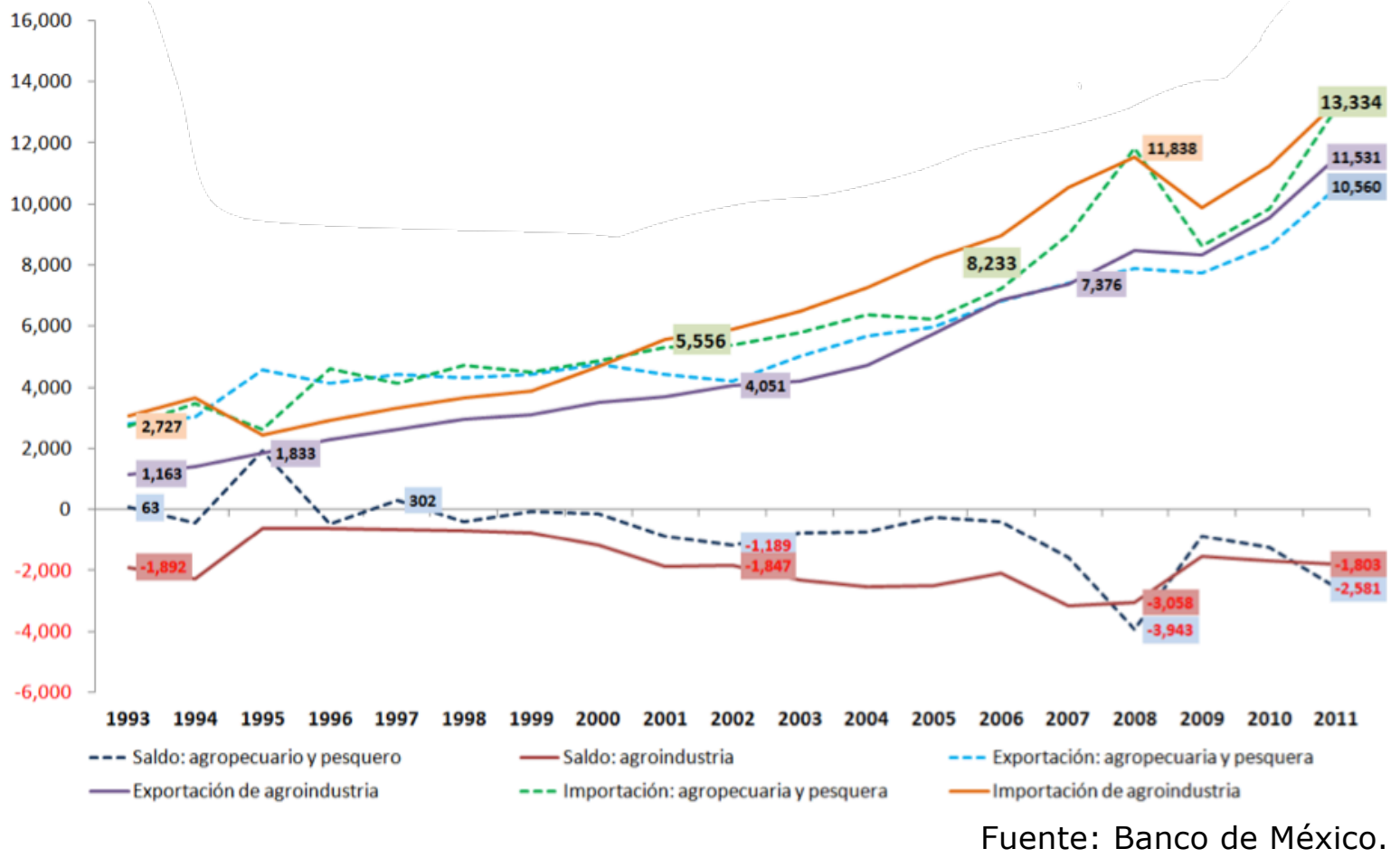




\section{CAPITULO 4}

\section{DESEMPEÑo AGRÍCOLA EN EL ESTADO DE MÉXICO}

4.1 Antecedentes históricos de los ordenamientos jurídicos en materia de agricultura en el Estado de México

El 29 de junio de 1938 se creó en el Estado de México el primer ordenamiento jurídico en materia agrícola con la expedición de la Ley de Servicios Agrícolas Gratuitos, la cual tuvo como objetivo principal fomentar la agricultura a través de donativos gubernamentales.

Tres años después, en diciembre de 1941, se expidió el Reglamento Interior de la Secretaría General de Gobierno con el cual se legalizó la creación del Departamento de Agricultura y Ganadería. Ésta tenía las atribuciones de dar seguimiento a "frutos de importación, condiciones económicas de la vida rural, agricultura y ganadería, siembra, cría de ganado, geografía, oro hidrografía, climatología, geología, hidrología, recursos hidráulicos, obras de riego, agrología, recursos forestales y de las especies ganaderas".

Posteriormente, el 21 de diciembre de 1943 se promulgó la Ley de Protección a las Semillas, Nuevas Plantaciones de Cultivos y Árboles Frutales de Ornato y Floricultura; sin embargo, no es sino hasta el 3 de diciembre de 1947 cuando el congreso estatal aprobó la Ley de Ganadería del Estado de México.

Estos ordenamientos constituyen el fundamento con el que se elaboró el Plan Integral de Desarrollo Agrícola, cuya característica principal fue la participación de los productores en el fortalecimiento de las actividades agropecuarias.

El plan incluyó programas dirigidos a fomentar las investigaciones de carácter agrícola, así como a impulsar la organización de los productores rurales, el aprovechamiento y conservación de los recursos naturales, con la participación coordinada entre productores y gobierno federal. 
Pero el ordenamiento que marcó un hito en la administración pública local fue la expedición de la Ley de Servicios Agrícolas del Estado de México (16 de noviembre de 1951), que derogaba la Ley de Servicios Agrícolas Gratuitos.

Sus preceptos constituyeron la base jurídica, instrumental, funcional y normativa para traducir los objetivos y prioridades del campo en acciones concretas. Esta Ley proporcionó el fundamento para crear la Dirección de Agricultura y Ganadería (1952) cuyas atribuciones le permitían planear los programas agrícolas, ganaderos y forestales del Estado de México, en coordinación con la Secretaría de Agricultura y Ganadería del Gobierno Federal.

Para 1957 existían en la entidad 11 ordenamientos jurídicos llamados las "11 leyes agropecuarias", mismas que constituían la base normativa del sector agrícola:

- Ley de Ganadería (1951)

- Ley de Servicios Agrícolas (1955)

- Ley que crea el Instituto de Fomento e Investigaciones Agropecuarias (1956)

- Ley de Fomento a la Avicultura (1956)

- Ley para el Estímulo de la Producción y el Empleo de Semillas Mejoradas (1956)

- Ley de Asociaciones de Productores Rurales (1956)

- Ley de Estímulos para el Mejoramiento de la Agricultura (1956)

- Ley de Fomento y Protección de Granjas Agropecuarias (1956)

- Ley de Fertilizantes y Mejoradores Agrícolas (1956)

- Ley para la Conservación de Recursos Naturales Renovables (1956)

- Ley de Extensión Agrícola (1957)

Es conveniente precisar que la Ley de Servicios Agrícolas del Estado de México es el ordenamiento básico sobre el cual se rigen las 10 restantes.

En 1970 se aprobó el Plan Ranchero con el objeto de incrementar la productividad agrícola, cuyo eje fundamental fue la coordinación con instituciones como el Banco Nacional de Crédito Rural (Banrural) y la 
Aseguradora Nacional Agrícola y Ganadera, S.A. (ANAGSA), con el aval del Gobierno del Estado de México.

Este plan se inspiraba en el principio de que la agricultura eficiente, por efecto de la demostración de sus mejores técnicas de cultivo y de su éxito económico. Además, se constituía en medio de comparación y al mismo tiempo en base de superación cuando se trataba de transformar la agricultura.

En enero de 1971 se creó el Instituto de Desarrollo Agrícola y Ganadero del Estado de México (DAGEM), con la finalidad de continuar impulsando el desarrollo agrícola y ganadero en la entidad, mediante el fortalecimiento de las acciones de los organismos estatales y federales, que habían sido creados para incrementar las actividades del hombre del campo, de los que depende la producción de alimentos y materias primas para la atención de las crecientes demandas.

Para fortalecer a dicho Instituto se creó, el 14 de octubre de 1976, la Comisión Coordinadora para el Desarrollo Agrícola y Ganadero del Estado de México (CODAGEM), como organismo público descentralizado al que le fueron otorgados facultades legales y recursos económicos. Sus funciones estaban orientadas a contribuir al desarrollo del medio rural, mediante la realización de un Plan Estatal de Trabajo. Su creación puso fin a la dicotomía que existía entre las atribuciones que legalmente tenía asignadas la Dirección de Agricultura y Ganadería y las facultades otorgadas al DAGEM.

Esta acción permitió contar con una estructura ágil y eficiente por parte de la CODAGEM, capaz de integrar, coordinar y ejecutar los programas de desarrollo agrícola y ganadero del estado, de acuerdo con las necesidades de cada comunidad.

Posteriormente, en 1980 se unificó el mando estatal-federal con la implementación de una regionalización única para el Sector y con dos representaciones de la entonces Secretaría de Agricultura y Recursos Hidráulicos del Gobierno Federal.

Con la expedición de la Ley Orgánica de la Administración Pública del Estado de México, el 17 de septiembre de 1981, se creó la Secretaría de Desarrollo Agropecuario, aunque sus atribuciones eran competencia de la 
CODAGEM, quien fungía hasta ese momento como único órgano ejecutor de las acciones en materia agropecuaria. En este sentido, con el propósito de evitar duplicidad, omisión o traslape de funciones, se consideró conveniente que la Secretaría de Desarrollo Agropecuario no se constituyera orgánicamente, toda vez que la propia Ley señalaba que la Secretaría era la instancia encargada de planear, normar, programar, evaluar, controlar y vigilar los programas sectoriales que incidían en la materia, funciones que venían desarrollando la CODAGEM y la Protectora e Industrializadora de Bosques (PROTINBOS).

Por lo anterior, el Ejecutivo del Estado ordenó la realización de un estudio de reestructuración de la Secretaría de Desarrollo Agropecuario, con el objeto de fortalecerla tanto en el sector central como en el sector auxiliar y establecer una organización dinámica, eficiente y flexible que redefiniera sus atribuciones y funciones para cumplir con los planes y programas establecidos en el Programa Nacional de Desarrollo Rural Integral (PRONADRI).

Así, en febrero de 1986, el Sector Desarrollo Agropecuario se integró por la Secretaría de Desarrollo Agropecuario, como dependencia del Poder Ejecutivo Estatal con objeto y atribuciones precisas, pero careciendo de una estructura orgánica; la CODAGEM se convirtió en un instrumento operativo; como organismos auxiliares estaban la Protectora e Industrializadora de Bosques, Fertilizantes del Estado de México S.A. y la Impulsora de Riego Tecnificado del Estado de México S.A. (IRTEMEX). Asimismo, existían organismos adscritos a otros sectores que realizaban actividades en apoyo al sector, tal es el caso del Fideicomiso para el Desarrollo Agroindustrial del Estado de México (FAIDEM), el Fondo de Fomento Económico (FOMEC) y la Central de Equipo y Maquinaria Mexiquense (CEMMEX).

A principios de 1987, la Secretaría de Desarrollo Agropecuario contaba con una estructura, funciones y atribuciones propias, y establecía la normatividad como cabeza de sector; por ello, se promovió la reforma a los Artículos 33 y 34 de la Ley Orgánica de la Administración Pública del Estado de México.

El 8 de julio de 1987, se creó el organismo público descentralizado de carácter estatal denominado Instituto de Investigación y Capacitación 
Agropecuaria, Acuícola y Forestal del Estado de México (ICAMEX), con personalidad jurídica y patrimonio propios, teniendo por objeto elevar la productividad agropecuaria, acuícola y forestal, a través de la investigación y capacitación para lograr la autosuficiencia alimentaria y así, aumentar los niveles de bienestar social de los habitantes del estado y de la sociedad en general.

En el rubro forestal, debido a la creciente deforestación de la entidad, el 13 de junio de 1990 se abrogó la Ley que crea el organismo público descentralizado PROTINBOS y se creó en su lugar el organismo público descentralizado denominado Protectora de Bosques del Estado de México (PROBOSQUE). En el mes de diciembre, la Secretaría de Desarrollo Agropecuario se desliga del mando unificado estatal-federal.

En junio de 1991, se reestructuró la Secretaría de Desarrollo Agropecuario como parte fundamental del programa de racionalización y reajuste del sector, en el que se redefinieron la estructura y funciones de las diferentes áreas de la Secretaría, a fin de hacerlas congruentes con la atención de las necesidades de los productores, el Procampo, el Plan Estatal de Desarrollo, el TLCAN y las reformas al Artículo 27 Constitucional.

Posteriormente, el 30 de marzo de 1992, se desincorporó PROBOSQUE del Sector Desarrollo Agropecuario y se integró al Sector Ecología; y en abril de 1992, con la autorización de una nueva estructura de organización de la Secretaría de Desarrollo Agropecuario, desapareció la CODAGEM. A partir de esta fecha, se llevó a cabo un reajuste del Sector Desarrollo Agropecuario, con la finalidad de incrementar la producción y productividad con base en la vigorización de las organizaciones de los productores, para elevar el nivel de vida de los mismos y de la población rural en general.

El 23 de febrero de 1993, por acuerdo del ejecutivo del estado se creó el órgano desconcentrado denominado Comisión de Apoyos y Servicios a la Comercialización Agropecuaria del Estado de México (CASERCAMEX), con el objeto de apoyar la comercialización de productos agropecuarios en los mercados estatal, nacional e internacional, a través de la concertación de 
productores, industriales, comerciantes e instituciones bancarias y oficiales relacionadas con el Sector Desarrollo Agropecuario.

El 13 de enero de 1995, por acuerdo del ejecutivo se adscribe nuevamente al sector desarrollo agropecuario el organismo público descentralizado PROBOSQUE. Más tarde, en mayo de ese mismo año, se suprime el órgano desconcentrado denominado CASERCAMEX, habiéndose transferido sus funciones a la Dirección General de Desarrollo de Productores de la Secretaría de Desarrollo Agropecuario.

Durante 1995 se llevó a cabo un estudio para reformar el marco jurídico del sector agropecuario y forestal, y en enero de 1996 se publican las siguientes leyes:

1. Ley Agrícola y Forestal del Estado de México.

2. Ley de Fomento Ganadero del Estado de México.

3. Ley de Asociaciones de Productores Rurales del Estado de México.

Con la creación de estos ordenamientos jurídicos se abrogan las siguientes leyes:

1. Ley de Servicios Agrícolas del Estado de México.

2. Ley para el Estímulo de la Producción y Empleo de Semillas Mejoradoras en el Estado de México.

3. Ley de Estímulos para el Mejoramiento de la Agricultura en el Estado de México.

4. Ley de Fomento y Protección de Granjas Agropecuarias.

5. Ley de Fertilizantes y Mejoradores Agrícolas del Estado de México.

6. Ley para la Conservación de los Recursos Naturales Renovables.

7. Ley de Extensión Agrícola.

8. Ley de Ganadería del Estado de México.

9. Ley de Fomento de la Avicultura en el Estado de México.

10. Ley de Asociaciones de Productores Rurales del Estado de México. 
Posteriormente, el 9 de noviembre de 1998, se publicaron en la Gaceta del Gobierno el Reglamento de la Ley Agrícola y Forestal del Estado de México y el Reglamento de la Ley de Fomento Ganadero del Estado de México, con el propósito de alcanzar los objetivos establecidos en las leyes y dar firmeza y seguridad jurídica a la actuación de las autoridades estatales y municipales, así como a los derechos de las personas físicas o morales relacionadas con las actividades agropecuarias y forestales.

En enero de 2000, la Secretaría de Desarrollo Agropecuario fue sujeta a un nuevo proceso de reestructuración, derivado del cual destaca la creación de la Coordinación de Delegaciones Regionales de Desarrollo Agropecuario, con la finalidad de llevar a cabo una revisión y evaluación más estrecha de las actividades que realizan las Delegaciones Regionales, lo que a su vez permitiría mejorar el impacto social de los servicios proporcionados a los productores del estado.

El 13 de diciembre de 2001, se aprobó el Código Administrativo del Estado de México, que en el Libro Noveno establece la Regulación del Fomento y Desarrollo de las Actividades Agropecuarias, Acuícolas y Forestales orientadas al establecimiento de una cultura de conservación y restauración de los recursos naturales para apoyar el desarrollo sustentable del Estado. Así, con fecha 13 de marzo de 2002, se publicó el Reglamento del Fomento y Desarrollo Agropecuario, Acuícola y Forestal del Estado de México, cuyo objeto es reglamentar las disposiciones contenidas en el Libro Noveno.

En diciembre de 2003, se publicó el Acuerdo del Ejecutivo del Estado por el que se adscribe sectorialmente a la Secretaría de Ecología, el organismo público descentralizado denominado Protectora de Bosques del Estado de México (PROBOSQUE), que había sido adscrito a Desarrollo Agropecuario en 1995, con la finalidad de vincular sus programas y actividades con las de protección al ambiente. Después, el 24 de marzo de 2006 se publicó el decreto del ejecutivo del estado por el que se vuelve a adscribir sectorialmente a la Secretaría de Desarrollo Agropecuario para reorientar y vincular sus programas y actividades al desarrollo rural. Finalmente, el 15 de noviembre de 2011 se 
publicó el decreto del Ejecutivo Estatal que lo adscribe nuevamente al área de ecología, ahora denominada Secretaría del Medio Ambiente.

Actualmente, el sector agropecuario y forestal está conformado por la Secretaría de Desarrollo Agropecuario como dependencia coordinadora del sector y sus organismos auxiliares: Instituto de Investigación y Capacitación Agropecuaria, Acuícola y Forestal del Estado de México (ICAMEX), y PROBOSQUE.

4.2 Actividad del sector agrícola en el Estado de México por ciclo productivo y sus rendimientos

En el capítulo correspondiente a población y territorio se señaló que la superficie sembrada en la entidad bajo estudio equivale a $4.1 \%$ del total nacional sembrado y que la totalidad del territorio mexiquense se encuentra inmerso en las regiones naturales templada, semiárida y trópico seco. En este apartado se verá el comportamiento de la actividad agrícola del estado desde 1980 y hasta 2010 (esto para estar en posibilidades de analizar los datos por décadas), de modo que será posible distinguir que se da una tendencia hacia ciertos cultivos, en función de cada ciclo productivo (O-I o P-V) y de la modalidad (riego o temporal), pero también se da una tendencia a sustituir unos cultivos por otros, lo cual obedece a condiciones como las señaladas en el capítulo referente a la determinación de precios, a saber:

- Para los casos en que existe, la forma de organización de los productores (sociedades de producción rural, cooperativas, confederaciones, cámaras, sistemas producto, financieras, etc.). La gran dispersión de los pequeños productores es determinante para que reciban precios muy castigados por parte de los comercializadores y transformadores. La organización de los productores les permite enfrentar mejor las condiciones de competencia, así como a los comercializadores e industriales que demandan sus cultivos, sin verse tan afectados por las tendencias monopólicas, monopsónicas u oligopólicas que podrían prevalecer en la cadena productiva relacionada a cada cultivo. 
- La forma en la que el productor decide qué cultivo sembrará está determinada por aspectos como: la idiosincrasia en cuanto al conocimiento de determinados cultivos, principalmente maíz y frijol, aunque se tienen variantes dependiendo de las zonas y sus características; el conocimiento sobre los procesos de producción de cultivos alternativos, así como de sus costos de producción; las condiciones climáticas esperadas, relacionadas a las características de los cultivos; las condiciones previas y actuales de los mercados, principalmente de precios.

\subsubsection{Primavera-Verano}

\section{a) Superficie sembrada}

En sus inicios el TLCAN consideraba que la apertura comercial debería servir para motivar el cambio de granos a hortalizas y frutales, dependiendo de las características de las zonas productoras. Para el Estado de México tal cambio no se ha dado bajo el ciclo P-V de temporal, principal ciclo productivo del estado; desde 1980 y hasta 2010 los principales cultivos para tal ciclo y modalidad han sido el maíz grano, la avena forrajera y la cebada grano. Dichos cultivos representan para el promedio anual de 2000 a 2010 el 93\% de la superficie sembrada (véase el cuadro siguiente), participación que incluso era del $97 \%$ tanto en el periodo de 1980 a 1990, como en el de 1990 a 2000.

A pesar de lo señalado, en el periodo 1990-2000 la superficie sembrada de maíz grano se redujo en casi 73 mil hectáreas en promedio por año, reducción que aumenta para el periodo 2000-2010 en el que se reducen otras 45 mil 200 hectáreas en promedio anual al comparar con 1990-2000. Esta tendencia parece obedecer a la apertura comercial; sin embargo, prácticamente todos los municipios mexiquenses continúan con la siembra de maíz, con programas de apoyo a la comercialización y a la venta bajo contrato que dan cierta certidumbre a los ingresos que espera recibir el productor en ciertos cultivos. Vale la pena señalar que en sus orígenes los registros 
estadísticos no diferenciaban con precisión algunas variedades, como en el caso del maíz grano, de modo que por tal razón se tiene tanto maíz grano sin clasificar como maíz grano amarillo y maíz grano blanco; sin embargo, actualmente tales registros son más precisos y, por lo mismo, para los años más recientes ya se muestra un nivel mayor de desglose por variedad.

Cuadro 4.1 Superficie sembrada (has), ciclo P-V de temporal

\begin{tabular}{|c|c|c|c|c|c|c|c|c|c|}
\hline \multirow[b]{2}{*}{ Cultivo } & \multicolumn{3}{|c|}{ Promedios anuales } & \multicolumn{3}{|c|}{ Promedios anuales (\%) } & \multicolumn{3}{|c|}{ Lugar } \\
\hline & $1980-1990$ & $1990-2000$ & $2000-2010$ & $1980-1990$ & $1990-2000$ & $2000-2010$ & $1980-1990$ & $1990-2000$ & $2000-2010$ \\
\hline Total & 695,705 & 653,637 & 636,767 & 100.0 & 100.0 & 100.0 & $\cdots$ & - & - \\
\hline Maiz grano (blanco) & - & - & 296,228 & - & - & 46.5 & 65 & 87 & 1 \\
\hline Maiz grano sin clasificar & 586,783 & 514,040 & 170,429 & 84 & 79 & 26.8 & 1 & 1 & 2 \\
\hline Avena forrajera en verde & 10,482 & 26,458 & 35,310 & 2 & 4 & 5.5 & 5 & 4 & 3 \\
\hline Cebada grano & 28,963 & 28,349 & 33,914 & 4 & 4 & 5.3 & 2 & 3 & 4 \\
\hline Maíz forraje ro en verde & 1,521 & 7,412 & 13,351 & 0 & 1 & 2.1 & 11 & 6 & 5 \\
\hline Avena grano & 6,211 & 3,191 & 9,785 & 1 & 0 & 1.5 & 7 & 8 & 6 \\
\hline Frijol sin clasificar & 19,530 & 20,294 & 8,721 & 3 & 3 & 1.4 & 3 & 5 & 7 \\
\hline Trigo grano fuerte & - & - & 8,450 & - & - & 1.3 & 69 & 91 & 8 \\
\hline Trigo grano sin clasificar & 19,350 & 35,974 & 7,238 & 3 & 6 & 1.1 & 4 & 2 & 9 \\
\hline Avena forrajera achicalada & - & - & 6,433 & - & - & 1.0 & 74 & 95 & 10 \\
\hline Avena forrajera seca & - & - & 5,182 & - & - & 0.8 & 75 & 96 & 11 \\
\hline Frijol flor de mayo & - & - & 4,682 & - & - & 0.7 & 107 & 121 & 12 \\
\hline Maíz grano de color & - & - & 3,640 & - & - & 0.6 & 66 & 88 & 13 \\
\hline Haba verde & 2,173 & 2,330 & 3,364 & 0 & 0 & 0.5 & 10 & 10 & 14 \\
\hline Chícharo & 4,277 & 2,642 & 3,333 & 1 & 0 & 0.5 & 8 & 9 & 15 \\
\hline Papa alpha & - & - & 2,882 & - & - & 0.5 & 131 & 131 & 16 \\
\hline Maíz grano pozole ro & - & - & 2,488 & - & - & 0.4 & 67 & 89 & 17 \\
\hline Maíz grano (amarillo) & - & - & 2,175 & - & - & 0.3 & 64 & 86 & 18 \\
\hline Tomate verde & 612 & 1,087 & 1,879 & 0 & 0 & 0.3 & 15 & 13 & 19 \\
\hline Frijol negro jamapa & - & - & 1,805 & - & - & 0.3 & 109 & 123 & 20 \\
\hline Resto & 15,804 & 11,861 & 15,477 & 2.3 & 1.8 & 2.4 & $\ldots$ & $\cdots$ & $\cdots$ \\
\hline
\end{tabular}

Fuente: elaboración propia con información del SIAP- SAGARPA.

Un programa considerado como determinante para mejorar el rendimiento de maíz y trigo a nivel nacional, e internacional, es el de labranza de conservación, instrumentado por el Centro Internacional para el Mejoramiento del Maíz y Trigo (CIMMyT). En el año presente (2012) los objetivos de tal programa en México parecen muy definidos en el mediano y largo plazo. 
El cuadro anterior también permite observar que la superficie de temporal en $\mathrm{P}-\mathrm{V}$ se ha reducido, al pasar de un promedio anual de $695 \mathrm{mil} 705$ hectáreas en la década de 1980-1990 a 653 mil 637 en 1990-2000, lo cual significa una caída del 6\%, agravada aún más al considerar el decenio de 2000 a 2010 , cuando cae $2.6 \%$ respecto a $1990-2000$ y, en consecuencia, llega a 636 mil 767 hectáreas en el último periodo de diez años considerado. Tal caída en la superficie sembrada puede considerarse como no grave, siempre y cuando se observe un aumento en la superficie de riego bajo temporal o una mejora aceptable en los rendimientos e ingresos del productor. No obstante, en el cuadro anterior se observa que, al menos en términos de la superficie sembrada, no se cumple tal condición. Más adelante se plantea lo relacionado con los rendimientos e ingreso.

En el ciclo P-V de temporal el Estado de México ofrece comúnmente 130 cultivos, de modo que al dedicarse casi exclusivamente a los ya señalado pareciera limitar sus posibilidades de diversificación y de ingreso. Es importante observar, por ejemplo, que la superficie sembrada de frijol ha disminuido en los terrenos mexiquenses, lo cual puede tomarse como una medida aceptable en el sentido de que la oferta nacional comúnmente se cubre sin mayor problema e, incluso, se llegan a tener excedentes que saturan el mercado, mismos que afectan los ingresos principalmente de los productores, pues es muy común que los grandes comercializadores mantengan precios altos para el consumidor aun cuando se tiene sobre oferta. 


\section{Gráfica 4.1 Superficie promedio anual sembrada de 2000 a 2010 (\%), ciclo P-V de temporal}

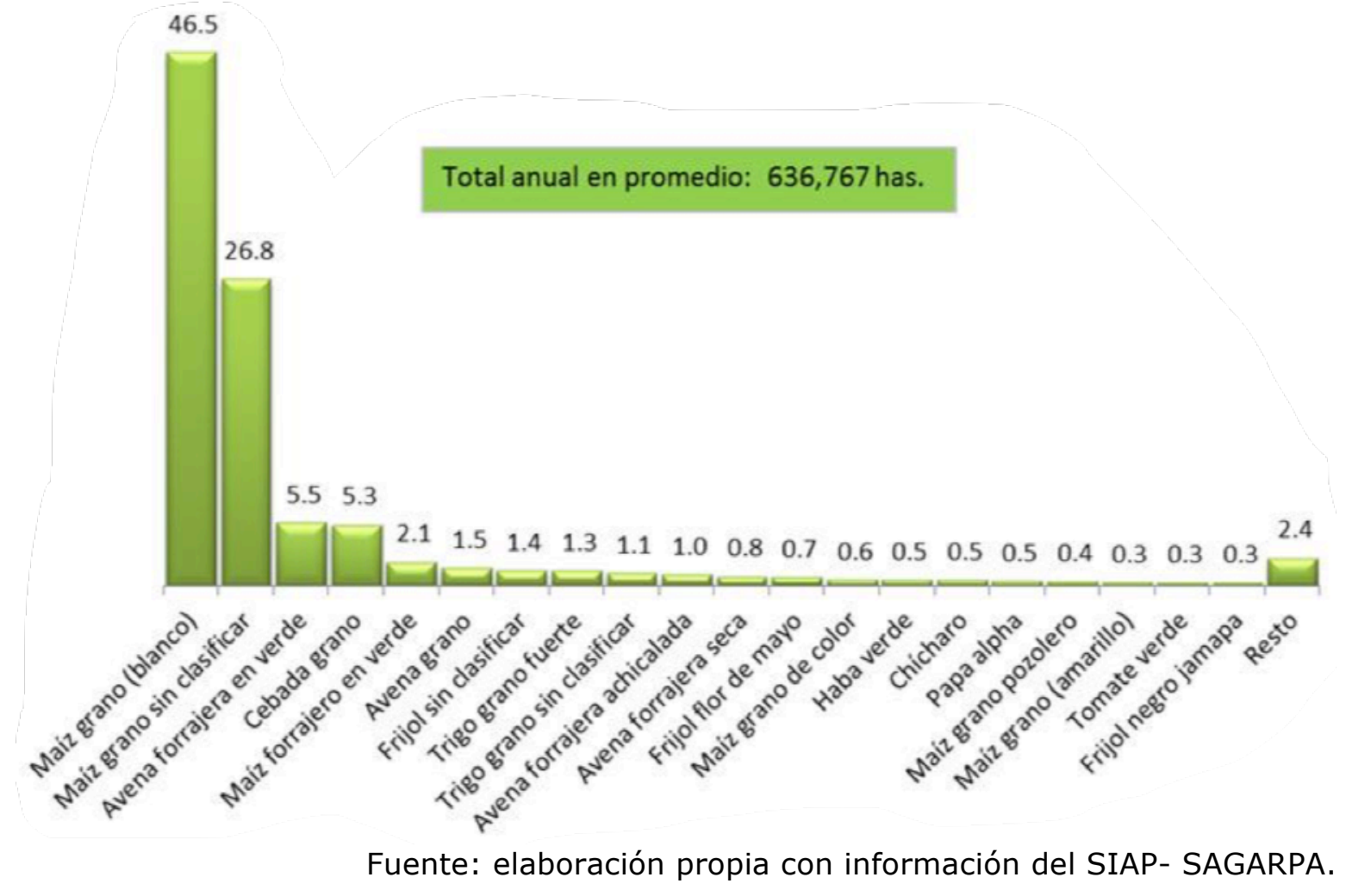

Haba, chícharo, papa y tomate, son los cultivos hortícolas que más atraen a los cultivadores mexiquenses, después de los principales granos considerados. Ninguno de los cultivos del P-V de temporal en el Estado de México cuenta de manera importante con modalidades tecnológicas identificadas, como invernaderos y agricultura protegida. Sin tales complementos tecnológicos no se esperan avances considerables en los rendimientos. 
Nótese que estos análisis inician con presentaciones desglosadas para cada cultivo genérico, de modo que, por ejemplo, en el caso de la papa se cuenta con la papa alpha y con la "papa sin clasificar"; en realidad se trata prácticamente de la primer clasificación señalada para ambos casos y, por tal razón pareciera que, en el cuadro anterior, la papa alpha sólo se produjo en el periodo 2000-2010, cuando la realidad es que su complemento está en la papa sin clasificar, la cual sí contó con oferta desde 1980 y al sumarla a la otra clasificación resulta que su posición es más ventajosa en comparación con los demás cultivos, y al efectuar comparativos por el valor total del año agrícola resulta que la papa en su conjunto se encuentra entre los diez principales cultivos del Estado de México.

Aunado a la caída de la superficie de temporal del ciclo primavera-verano en el estado de México, también el área sembrada de riego en tal ciclo ha disminuido, al pasar de 131 mil 361 hectáreas sembradas en el periodo 19801990 a 120 mil 473 en el promedio anual de 1990-2000, aunque con un pequeña recuperación respecto a este último decenio señalado, pero sin recuperar el nivel observado en la primer década comentada. Es necesario contar con estudios precisos que permitan conocer las causas por las que la superficie de riego en $\mathrm{P}-\mathrm{V}$ se han visto reducidas. Sin complementos tecnológicos adicionales y sin mayor empleo de riego durante el ciclo $\mathrm{P}-\mathrm{V}$, las expectativas de mejoras en la productividad, así como de diversificación hacia cultivos más intensivos con agricultura protegida, resultan poco favorables, como se ha mencionado con antelación.

Dentro de los principales veinte cultivos del P-V de riego destaca, después de la producción, principalmente de maíz grano, la oferta de algunas hortalizas como tomate verde, haba verde, elote, chícharo y calabacita. También es importante notar que el cultivo de flores destaca entre la superficie de los veinte principales del $\mathrm{P}-\mathrm{V}$ de riego, en particular para las especies de crisantemo y gladiola. 
Cuadro 4.2 Superficie sembrada (has), ciclo P-V de riego

\begin{tabular}{|c|c|c|c|c|c|c|c|c|c|}
\hline \multirow[b]{2}{*}{ Cultivo } & \multicolumn{3}{|c|}{ Promedios anuales } & \multicolumn{3}{|c|}{ Promedios anuales $(\%)$} & \multicolumn{3}{|c|}{ Lugar } \\
\hline & $1980-1990$ & $1990-2000$ & $2000-2010$ & $1980-1990$ & $1990-2000$ & $2000-2010$ & $1980-1990$ & $1990-2000$ & $2000-2010$ \\
\hline Total & 131,361 & 120,473 & 122,777 & 100.0 & 100.0 & 100.0 & $\cdots$ & $\cdots$ & $\cdots$ \\
\hline Maíz grano (blanco) & - & - & 62,418 & - & - & 50.8 & 77 & 92 & . \\
\hline Maíz grano sin clasificar & 118,995 & 103,724 & 36,944 & 90.59 & 86.10 & 30.1 & 1 & 1 & . \\
\hline Maíz forra jero en verde & 4,848 & 6,651 & 10,882 & 3.69 & 5.52 & 8.9 & 2 & 2 & ? \\
\hline Avena forrajera en verde & 1,098 & 1,808 & 2,365 & 0.84 & 1.50 & 1.9 & 3 & 3 & 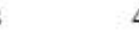 \\
\hline Maíz grano de color & - & - & 1,173 & - & - & 1.0 & 78 & 93 & 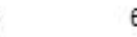 \\
\hline Tomate verde & 320 & 1,029 & 999 & 0.24 & 0.85 & 0.8 & 9 & 4 & . \\
\hline Maíz grano (amarillo) & - & - & 989 & - & - & 0.8 & 76 & 91 & 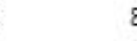 \\
\hline Haba verde & 112 & 442 & 417 & 0.09 & 0.37 & 0.3 & 25 & 10 & 9 \\
\hline Frijol flor de mayo & - & - & 392 & - & - & 0.3 & 110 & 117 & 10 \\
\hline Frijol sin clasificar & 931 & 772 & 354 & 0.71 & 0.64 & 0.3 & 4 & 5 & 11 \\
\hline Elote & 373 & 402 & 326 & 0.28 & 0.33 & 0.3 & 7 & 12 & 13 \\
\hline Avena grano & 195 & 39 & 270 & 0.15 & 0.03 & 0.2 & 13 & 33 & 14 \\
\hline Calabacita sin clasificar & 231 & 456 & 262 & 0.18 & 0.38 & 0.2 & 11 & 7 & 15 \\
\hline Chicharo & 149 & 442 & 259 & 0.11 & 0.37 & 0.2 & 19 & 9 & 16 \\
\hline Avena forrajera achicalada & - & - & 256 & - & - & 0.2 & 84 & 98 & 17 \\
\hline Trigo grano cristalino & - & - & 191 & - & - & 0.2 & 79 & 94 & 18 \\
\hline Calabacita italiana & - & - & 173 & - & - & 0.1 & 92 & 103 & 19 \\
\hline Cebada grano & 326 & 76 & 154 & 0.25 & 0.06 & 0.1 & 8 & 25 & 20 \\
\hline Resto & 3,673 & 4,107 & 2,055 & 2.8 & 3.4 & 1.7 & $\cdots$ & $\ldots$ & $\ldots$ \\
\hline
\end{tabular}

Fuente: elaboración propia con información del SIAP- SAGARPA.

Es importante tener en cuenta que durante el $\mathrm{P}-\mathrm{V}$ de riego la diversificación que permite el contar con agua es mayor que durante la época natural de lluvias, aun cuando el mayor área se sigue enfocando a pocos cultivos; el maíz grano representa sin ningún problema el $80 \%$ en la última década de estudio, aunque en las dos décadas anteriores se encontró cerca del $90 \%$, lo cual pareciera reforzar la recomendación de inicios de la firma del TLCAN, en el sentido de buscar cultivos alternativos con mayor rentabilidad; aun así, la motivación a los agricultores se queda muy corta, pues resulta evidente que el aprovechamiento de la agricultura protegida en el Estado de México está muy lejos de considerarse como desarrollada. 


\section{Gráfica 4.2 Superficie promedio anual sembrada de 2000 a $2010(\%)$, ciclo P-V de riego}

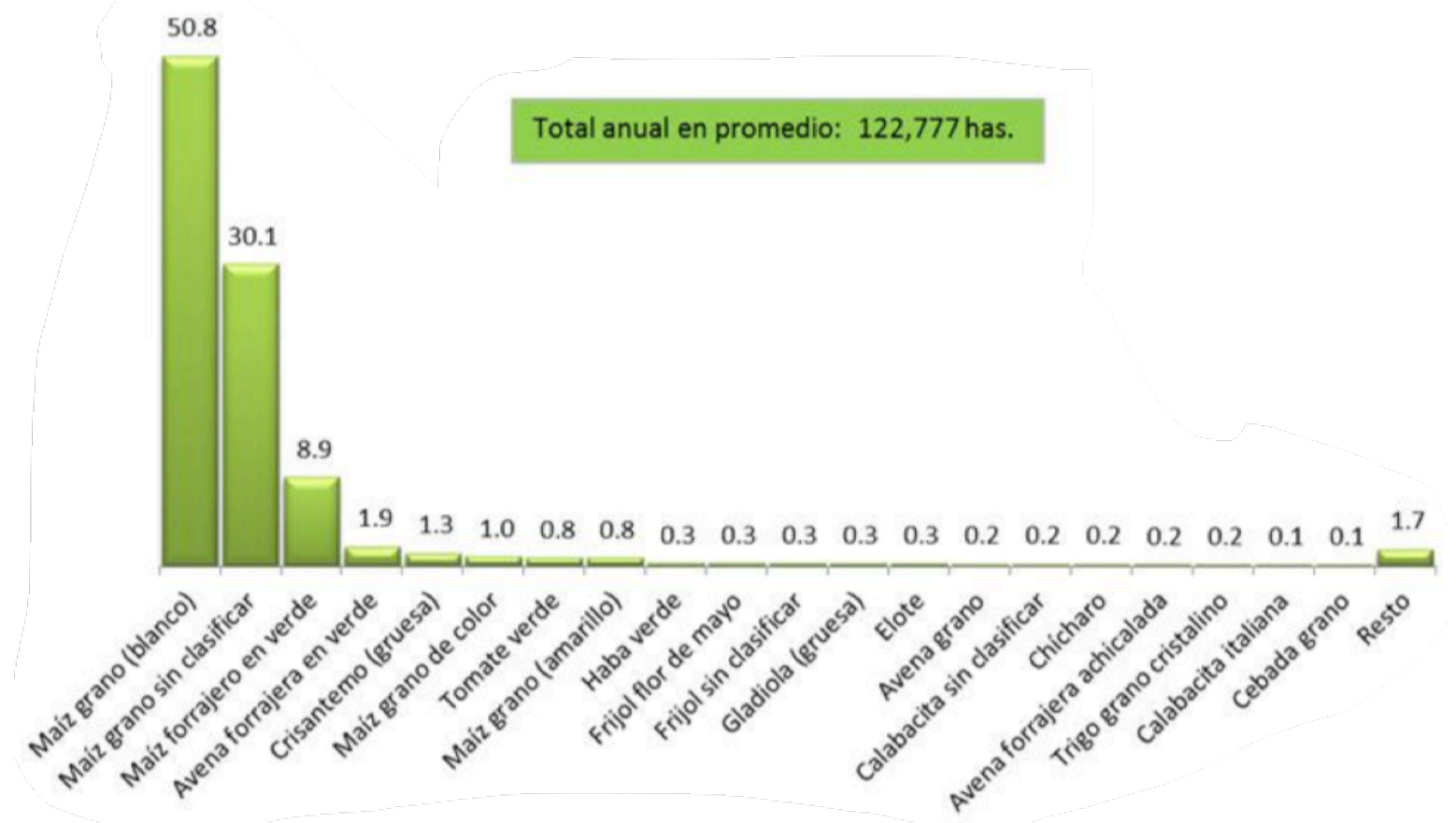

Fuente: elaboración propia con información del SIAP- SAGARPA.

A diferencia del P-V de temporal, en el que no se observan tecnologías de agricultura protegida, en el mismo ciclo pero con riego sí se da el uso tecnologías de agricultura protegida, con la gran desventaja de que tales superficies son muy poco representativas, pues las mismas tienen registro de aplicación sólo a partir de 2005, de modo que al compararlas con la superficie promedio de la década 2000-2010 su participación resulta muy baja y queda en sólo 422 hectáreas, como se observa en la siguiente tabla. Se requiere motivar la producción bajo tales esquemas de operación productiva, además de asegurar su registro de manera oficial. 
b) Superficie siniestrada

Los promedios anuales de la superficie siniestrada para los tres periodos considerados permiten observar qué tanto se han mantenido las afectaciones a los cultivos durante el PV de temporal, sin olvidar tener presente que la misma superficie sembrada de tal ciclo ha caído.

Cuadro 4.4 Superficie siniestrada (has), ciclo P-V de temporal

\begin{tabular}{|c|c|c|c|c|c|c|c|c|c|}
\hline \multirow[b]{2}{*}{ Cultivo } & \multicolumn{3}{|c|}{ Prome dios anuales } & \multicolumn{3}{|c|}{ Promedios anuales $(\%)$} & \multicolumn{3}{|c|}{ Lugar } \\
\hline & $1980-1990$ & $1990-2000$ & $2000-2010$ & $1980-1990$ & $1990-2000$ & $2000-2010$ & $1980-1990$ & $1990-2000$ & $2000-2010$ \\
\hline Total & 49,778 & 18,224 & 19,674 & 100.0 & $\quad 100.0$ & $\quad 100.0$ & & & \\
\hline Maíz grano & 44,107 & 13,974 & 13,341 & 88.6 & 76.7 & 67.8 & 1 & 1 & 1 \\
\hline Cebada grano & 1,516 & 1,297 & 4,594 & 3.0 & 7.1 & 23.3 & 3 & 3 & 2 \\
\hline Frijol & 2,562 & 1,551 & 571 & 5.1 & 8.5 & 2.9 & 2 & 2 & 3 \\
\hline Maíz forrajero & 0 & 1 & 328 & 0.0 & 0.0 & 1.7 & 87 & 22 & 4 \\
\hline Avena forrajera & 188 & 97 & 257 & 0.4 & 0.5 & 1.3 & 5 & 5 & 5 \\
\hline Trigo grano & 980 & 1,165 & 201 & 2.0 & 6.4 & 1.0 & 4 & 4 & 6 \\
\hline Avena grano & 168 & 0 & 149 & 0.3 & 0.0 & 0.8 & 6 & 39 & 7 \\
\hline Canola & 0 & 0 & 51 & 0.0 & 0.0 & 0.3 & 44 & 46 & 8 \\
\hline Haba verde & 44 & 5 & 30 & 0.1 & 0.0 & 0.2 & 8 & 13 & 9 \\
\hline Papa & 26 & 1 & 21 & 0.1 & 0.0 & 0.1 & 9 & 16 & 10 \\
\hline Chícharo & 101 & 11 & 18 & 0.2 & 0.1 & 0.1 & 7 & 11 & 11 \\
\hline Zanahoria & 2 & 0 & 16 & 0.0 & 0.0 & 0.1 & 18 & 133 & 12 \\
\hline Calabacita & 5 & 9 & 16 & 0.0 & 0.1 & 0.1 & 16 & 12 & 13 \\
\hline Lechuga & 0 & 0 & 15 & 0.0 & 0.0 & 0.1 & 81 & 25 & 14 \\
\hline Nube (manojo) & 0 & 1 & 10 & 0.0 & 0.0 & 0.0 & 104 & 21 & 15 \\
\hline Triticale grano & 0 & 0 & 10 & 0.0 & 0.0 & 0.0 & 132 & 131 & 16 \\
\hline Tomate verde & 8 & 2 & 8 & 0.0 & 0.0 & 0.0 & 14 & 15 & 17 \\
\hline Sorgo grano & 0 & 0 & 5 & 0.0 & 0.0 & 0.0 & 122 & 122 & 18 \\
\hline Cacahuate & 0 & 0 & 5 & 0.0 & 0.0 & 0.0 & 40 & 42 & 19 \\
\hline Alheli (manojo) & 0 & 3 & 4 & 0.0 & 0.0 & 0.0 & 33 & 14 & 20 \\
\hline Resto & 71 & 107 & 25 & 0.1 & 0.6 & 0.1 & $\ldots$ & $\ldots$ & $\ldots$ \\
\hline
\end{tabular}

Fuente: elaboración propia con información del SIAP- SAGARPA.

La gráfica y cuadro mostrados en este apartado reflejan no sólo las mayores afectaciones por cultivo, sino también la importancia de los cultivos más dañados; vale la pena observar que aunque la superficie sembrada de frijol ha ido de más a menos, se ha mantenido desde 1980 y hasta 2010 entre los tres principales cultivos afectados por fenómenos adversos. 


\section{Gráfica 4.3 Superficie promedio anual siniestrada de 2000 a 2010 (\%), ciclo}

P-V de temporal

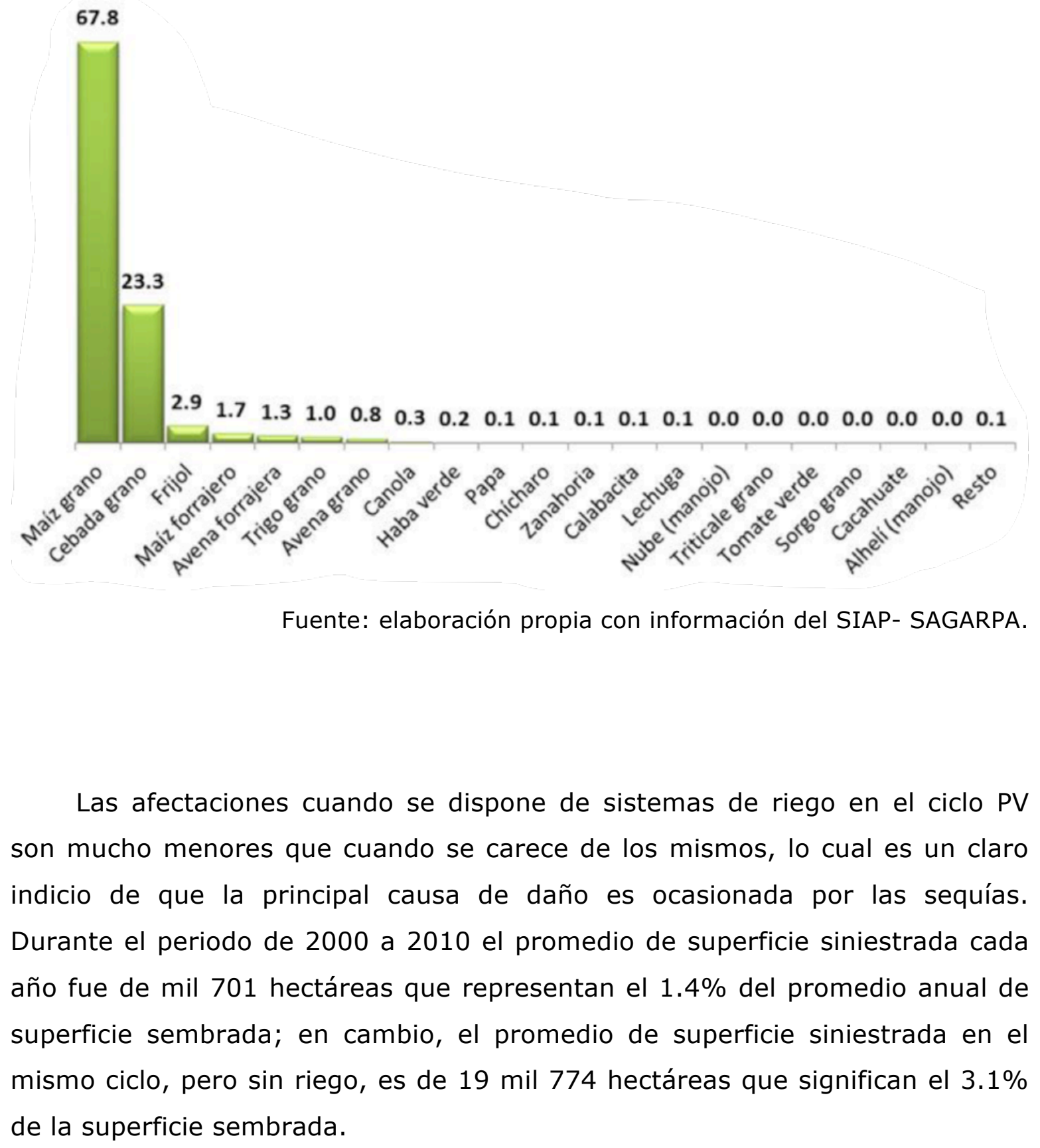




\section{Gráfica 4.4 Superficie promedio anual siniestrada de 2000 a 2010 (\%), ciclo $P-V$ de riego}

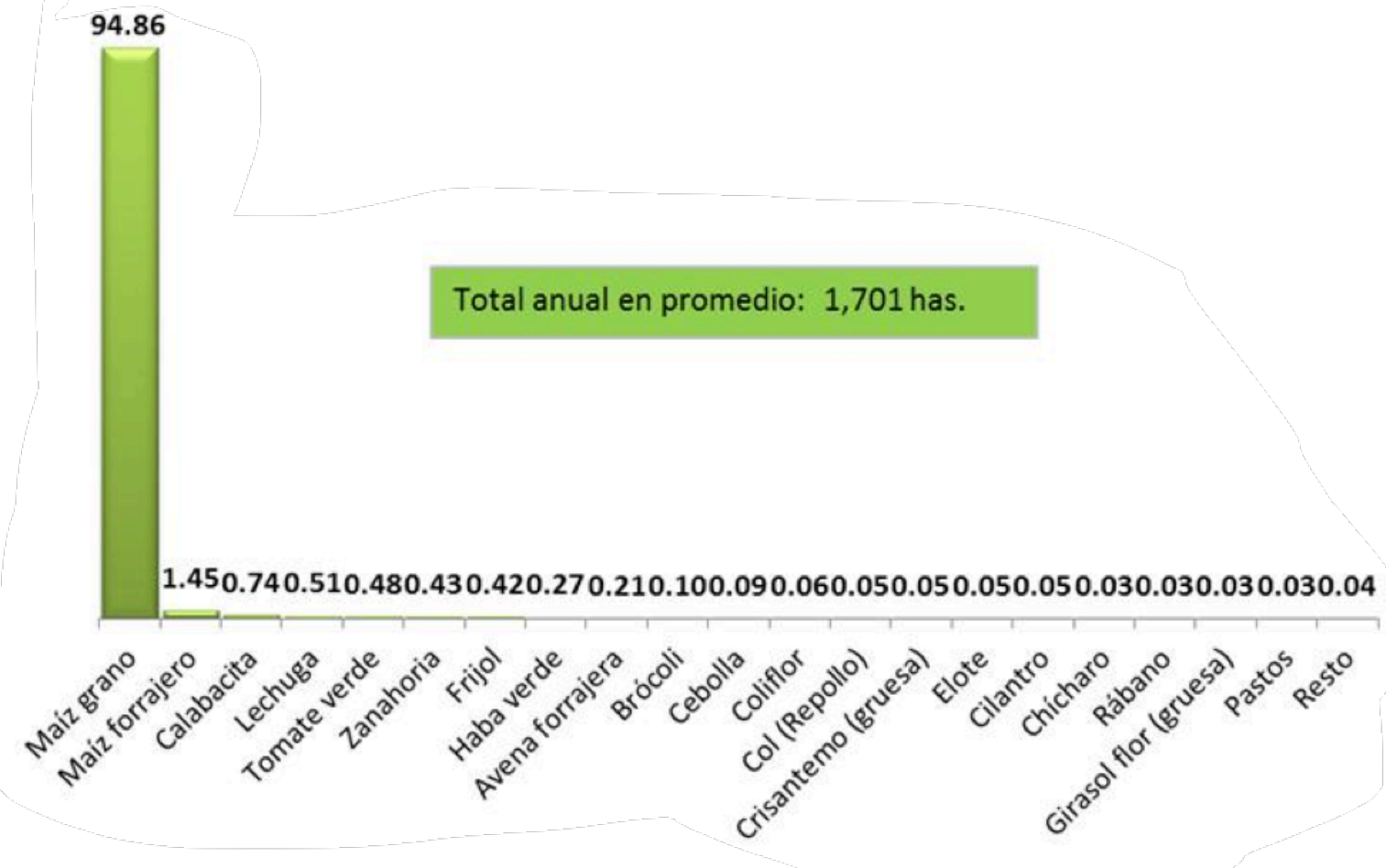

Fuente: elaboración propia con información del SIAP- SAGARPA.

c) Volúmenes cosechados

Se ha mostrado ya como la superficie sembrada de plantaciones cíclicas de PV de temporal se redujeron de 695 mil hectáreas en promedio por año, durante los años 1980 a 1990, a 637 mil durante 2000 a 2010; sólo la mejora en los rendimientos ha logrado superar tales caídas de las superficies. El volumen agregado de producción de los diferentes cultivos logrados durante el ciclo de análisis pasó de dos millones de toneladas anuales en promedio en el periodo 1980-1990 a más de tres millones en el lapso 2000-2010. Evidentemente, los avances en los métodos de producción han permitido a los agricultores incrementar su capacidad productiva, además de tener presentes las aportaciones de instituciones de investigación agropecuaria, como lo son el 
Instituto Nacional de Investigaciones Agropecuarias (INIFAP) de la SAGARPA en la investigación de semillas, nuevas variedades de cultivos, control de enfermedades, etc.; el Servicio Nacional de Sanidad, Inocuidad y Calidad Agroalimentaria (SENASICA), también de la SAGARPA, en el control y combate de plagas; las instituciones educativas de investigación superior; etc.

\section{Cuadro 4.5 Volumen de producción (ton), ciclo P-V de temporal}

\begin{tabular}{|c|c|c|c|c|c|c|c|c|c|}
\hline \multirow[b]{2}{*}{ Cultivo } & \multicolumn{3}{|c|}{ Promedios anuales } & \multicolumn{3}{|c|}{ Promedios anuales (\%) } & \multicolumn{3}{|c|}{ Lugar } \\
\hline & $1980-1990$ & $1990-2000$ & $2000-2010$ & $1980-1990$ & $1990-2000$ & $2000-2010$ & $1980-1990$ & $1990-2000$ & $2000-2010$ \\
\hline Total & $2,027,714$ & $2,777,013$ & $3,304,384$ & 100.0 & 100.0 & 100.0 & & & \\
\hline Maíz grano & $1,431,043$ & $1,499,304$ & $1,360,913$ & 71.6 & 54.8 & 41.3 & 1 & 1 & 1 \\
\hline Avena forrajera & 174,769 & 527,204 & $1,017,545$ & 8.7 & 19.3 & 30.9 & 2 & 2 & 2 \\
\hline Maíz forrajero & 73,475 & 316,936 & 501,267 & 3.7 & 11.6 & 15.2 & 4 & 3 & 3 \\
\hline Papa & 104,157 & 98,860 & 121,974 & 5.2 & 3.6 & 3.7 & 3 & 4 & 4 \\
\hline Cebada grano & 45,157 & 44,723 & 50,068 & 2.3 & 1.6 & 1.5 & 5 & 6 & 5 \\
\hline Zanahoria & 21,245 & 25,816 & 47,335 & 1.1 & 0.9 & 1.4 & 7 & 9 & 6 \\
\hline Trigo grano & 35,697 & 76,741 & 43,074 & 1.8 & 2.8 & 1.3 & 6 & 5 & 7 \\
\hline Tomate verde & 5,912 & 13,989 & 27,979 & 0.3 & 0.5 & 0.8 & 15 & 10 & 8 \\
\hline Haba verde & 7,616 & 12,015 & 19,653 & 0.4 & 0.4 & 0.6 & 14 & 12 & 9 \\
\hline Tomate rojo (Jitomate) & 9,856 & 26,166 & 16,660 & 0.5 & 1.0 & 0.5 & 12 & 8 & 10 \\
\hline Avena grano & 12,557 & 5,915 & 14,755 & 0.6 & 0.2 & 0.4 & 10 & 15 & 11 \\
\hline Chícharo & 16,218 & 10,798 & 13,915 & 0.8 & 0.4 & 0.4 & 8 & 13 & 12 \\
\hline Frijol & 14,604 & 13,646 & 13,790 & 0.7 & 0.5 & 0.4 & 9 & 11 & 13 \\
\hline Elote & 1,273 & 4,950 & 8,289 & 0.1 & 0.2 & 0.3 & 22 & 16 & 14 \\
\hline Calabacita & 3,706 & 4,701 & 8,073 & 0.2 & 0.2 & 0.2 & 18 & 17 & 15 \\
\hline Cebolla & 10,272 & 6,656 & 4,253 & 0.5 & 0.2 & 0.1 & 11 & 14 & 16 \\
\hline Lechuga & 958 & 3,294 & 3,963 & 0.0 & 0.1 & 0.1 & 23 & 18 & 17 \\
\hline Chilacayote & 81 & 836 & 2,935 & 0.0 & 0.0 & 0.1 & 37 & 25 & 18 \\
\hline Sorgo forrajero verde & 345 & 868 & 2,299 & 0.0 & 0.0 & 0.1 & 29 & 24 & 19 \\
\hline Betabel & 694 & 814 & 1,728 & 0.0 & 0.0 & 0.1 & 25 & 26 & 20 \\
\hline Resto & 29,040 & 41,391 & 11,958 & 1.5 & 1.5 & 0.4 & --- & --- & --- \\
\hline
\end{tabular}

Fuente: elaboración propia con información del SIAP- SAGARPA.

Es de tomarse en cuenta el hecho de que en términos de volumen obtenido en el PV de temporal, es el maíz grano el que mantiene la mayor aportación, pero después de éste son los forrajes los que manifiestan su supremacía, lo cual resulta de particular interés porque México es deficitario en la producción de forrajes, por lo que el Estado de México cuenta con un mercado potencial. 


\section{Gráfica 4.5 Volumen de producción promedio anual de 2000 a 2010 (\%), ciclo P-V de temporal}

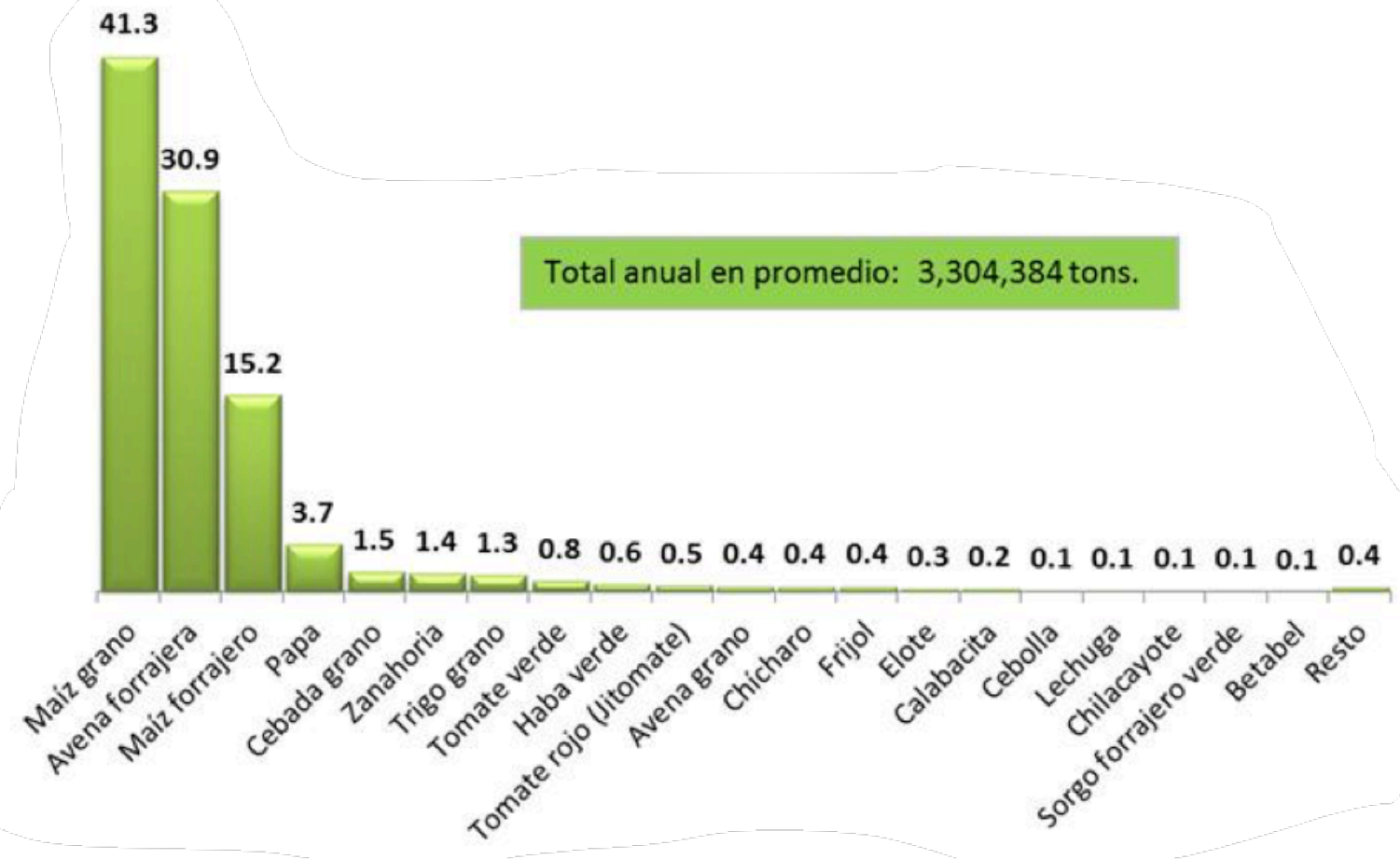

Fuente: elaboración propia con información del SIAP- SAGARPA.

Si los rendimientos del PV de temporal han permitido mejorar los volúmenes obtenidos, a pesar de la caída en las áreas cultivadas, los resultados no pueden ser menores en el caso de los sistemas de riego durante tal ciclo y se manifiestan en el hecho de que de 1980 a 1990 se obtuvieron en promedio anual 745 mil 900 toneladas de plantaciones del estado, las cuales se incrementaron a un millón 187 mil toneladas de 2000 a 2010.

Al igual que en el PV de temporal, nuevamente en tal ciclo con riego los cultivos forrajeros manifiestan su potencial, de modo que de 1980 a 1990 y de 2000 a 2010 aportan alrededor del 90\% de todo el volumen de los cultivos del estado bajo tal ciclo y modalidad. Llama la atención el periodo de 1990 a 2000, durante el cual el volumen cosechado tanto de maíz forrajero, como de maíz grano, fue sustituido por la dedicación al clavel que durante tal periodo representó prácticamente el 37\% del resto de cultivos (en el cuadro siguiente no se observa tal cultivo porque el orden se dio con el volumen generado durante el último lapso mostrado). 
Cuadro 4.6 Volumen de producción (ton), ciclo P-V de riego

\begin{tabular}{|c|c|c|c|c|c|c|c|c|c|c|}
\hline \multirow[b]{2}{*}{ Cultivo } & \multicolumn{3}{|c|}{ Promedios anuales } & \multicolumn{3}{|c|}{ Promedios anuales $(\%)$} & \multicolumn{4}{|c|}{ Lugar } \\
\hline & $1980-1990$ & $1990-2000$ & $2000-2010$ & $1980-1990$ & $1990-2000$ & $2000-2010$ & $1980-1990$ & $1990-2000$ & $2000-201$ & \\
\hline Totales & 745,905 & $1,547,365$ & $1,186,719$ & 100.0 & 100.0 & 100.0 & & & & \\
\hline Máz forrajero & 258,339 & 451,482 & 653,405 & 34.6 & 29.2 & 55.1 & 2 & 2 & 2 & 1 \\
\hline Máz grano & 393,199 & 417,361 & 401,983 & 52.7 & 27.0 & 33.9 & 1 & 1 & 3 & 2 \\
\hline Avena forrajera & 24,219 & 42,674 & 54,918 & 3.2 & 28 & 4.6 & 3 & 3 & 4 & 3 \\
\hline Tomate rojo (Jitomate) & 2,381 & 2,751 & 24,261 & 0.3 & 0.2 & 2.0 & 13 & 12 & 14 & 4 \\
\hline Tomate verde & 4,162 & 14,738 & 12,439 & 0.6 & 1.0 & 1.0 & 7 & 7 & 5 & 5 \\
\hline Calabacita & 3,119 & 7,038 & 6,945 & 0.4 & 0.5 & 0.6 & 10 & 0 & 7 & 6 \\
\hline Cebolla & 2,007 & 5,145 & 5,077 & 0.3 & 0.3 & 0.4 & 16 & 6 & 9 & 7 \\
\hline Papa & 4,215 & 7,220 & 4,501 & 0.6 & 0.5 & 0.4 & 6 & 6 & 6 & 8 \\
\hline Zanahoria & 3,788 & 5,412 & 3,228 & 0.5 & 0.3 & 0.3 & 8 & 8 & 8 & 9 \\
\hline Habaverde & 532 & 3,333 & 3,003 & 0.1 & 0.2 & 0.3 & 26 & 12 & 12 & 10 \\
\hline Elote & 6,259 & 2,756 & 2,904 & 0.8 & 0.2 & 0.2 & 5 & 13 & 13 & 11 \\
\hline Lechuga & 3,582 & 3,550 & 2,376 & 0.5 & 0.2 & 0.2 & 9 & 10 & 10 & 12 \\
\hline Sorgo forraj ero verde & 2,035 & 3,409 & 1,317 & 0.3 & 0.2 & 0.1 & 15 & $1:$ & 11 & 13 \\
\hline Chicharo & 763 & 2,374 & 1,256 & 0.1 & 0.2 & 0.1 & 23 & 15 & 15 & 14 \\
\hline Pepino & 2,198 & 1,195 & 1,165 & 0.3 & 0.1 & 0.1 & 14 & 17 & 17 & 15 \\
\hline Frijol & 1,260 & 942 & 1,165 & 0.2 & 0.1 & 0.1 & 17 & 19 & 19 & 16 \\
\hline Pastos & 0 & 876 & 1,026 & 0.0 & 0.1 & 0.1 & 95 & 20 & 20 & 17 \\
\hline Coliflor & 402 & 1,015 & 781 & 0.1 & 0.1 & 0.1 & 27 & 18 & 18 & 18 \\
\hline Cilantro & 40 & 494 & 679 & 0.0 & 0.0 & 0.1 & 38 & 2 & 24 & 19 \\
\hline Trigograno & 1,134 & 1,270 & 585 & 0.2 & 0.1 & 0.0 & 18 & 16 & 16 & 20 \\
\hline Resto & 32,273 & 572,328 & 3,706 & 4.3 & 37.0 & 0.3 & -.. & -. & - & -.. \\
\hline
\end{tabular}

Fuente: elaboración propia con información del SIAP- SAGARPA.

Gráfica 4.6 Volumen de producción promedio anual de 2000 a $2010(\%)$, ciclo P-V de riego

41.3

Total anual en promedio: $1,186,719$ tons.

15.2

3.7

$\begin{array}{llllllllllllllllll}1.5 & 1.4 & 1.3 & 0.8 & 0.6 & 0.5 & 0.4 & 0.4 & 0.4 & 0.3 & 0.2 & 0.1 & 0.1 & 0.1 & 0.1 & 0.1 & 0.4\end{array}$

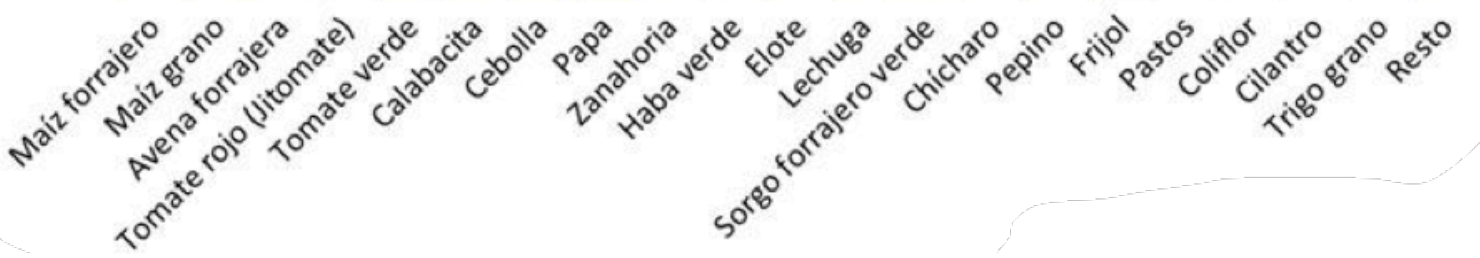

Fuente: elaboración propia con información del SIAP- SAGARPA. 
d) Rendimientos

El comportamiento de los rendimientos logrados en temporal para plantaciones relacionadas a la oferta de flores reflejan, en buen medida, el por qué la entidad ha enfocado buena parte de sus tierras a tales cultivos, la evidencia la representan plantas como polar y terciopelo, mostrados en el cuadro siguiente. El buscar mantener tales cultivos como recurrentes puede ser una de las opciones viables en la entidad.

La mejora en los rendimientos de chile, sorgo y papa explican, en lo que cabe, la preferencia por los mismos. También deben evaluarse otros cultivos no recurrentes que han logrado mejoras aceptables en su productividad, como la calabaza, ejote, chilacayote, brócoli, coliflor, etc. 


\section{Cuadro 4.7 Rendimientos (tons/has), ciclo P-V de temporal (var \%)}

\begin{tabular}{|c|c|c|c|c|}
\hline Cultivo & $\begin{array}{c}(1990-2000) / \\
(1980-1990)\end{array}$ & $\begin{array}{c}(2000-2010) / \\
(1990-2000)\end{array}$ & $\begin{array}{r}(2000-2010) / \\
(1980-1990)\end{array}$ & Frecuencia de siembra \\
\hline Polar (gruesa) & $x$ & 528.3 & $x$ & No recurrente \\
\hline Terciopelo (manojo) & $x$ & 275.9 & $>$ & No recurrente \\
\hline Statice (manojo) & $x$ & 252.9 & $x$ & No recurrente \\
\hline Calabaza & -43.3 & 244.9 & 95.4 & No recurrente \\
\hline Inmortal (manojo) & $x$ & 228.2 & $x$ & No recurrente \\
\hline Ejote & 54.2 & 175.7 & 325.0 & No recurrente \\
\hline Chilacayote & 22.1 & 69.6 & 107.0 & No recurrente \\
\hline Cacahuate & 21.7 & 54.8 & 88.4 & \\
\hline Brócoli & $x$ & 49.3 & $>$ & No recurrente \\
\hline Chile verde & 108.4 & 46.8 & 205.9 & \\
\hline Sorgo grano & 14.7 & 45.8 & 67.2 & \\
\hline Betabel & -34.2 & 43.0 & -5.9 & \\
\hline Coliflor & 213.3 & 37.5 & 331.0 & No recurrente \\
\hline Рapa & 35.4 & 37.2 & 85.8 & \\
\hline Sorgo forrajero verde & -1.0 & 32.9 & 31.6 & \\
\hline Zempoalxochit! & 75.4 & 24.9 & 119.1 & No recurrente \\
\hline Haba grano & -16.4 & 21.3 & 1.4 & No recurrente \\
\hline Tomate verde & 22.3 & 16.8 & 42.7 & \\
\hline Frijol & -14.7 & 16.4 & -0.8 & \\
\hline Triticale grano & $x$ & 16.4 & $>$ & No recurrente \\
\hline Haba verde & 11.6 & 14.6 & 27.9 & \\
\hline Tomate rojo (Jitomate) & 36.0 & 14.3 & 55.5 & \\
\hline Jicama & $x$ & 13.1 & $x$ & Recurrente a partir de 1996 \\
\hline Amaranto & 30.4 & 11.2 & 45.0 & Recurrente a partir de 1996 \\
\hline Avena forrajera & 13.7 & 10.8 & 26.0 & \\
\hline Calabacita & 19.2 & 9.7 & 30.7 & \\
\hline Gladiola (gruesa) & -10.7 & 9.3 & -2.3 & Recurrente a partir de 1987 \\
\hline Camote & 56.3 & 8.5 & 69.6 & Recurrente a partir de 1987 \\
\hline Trigo grano & 0.5 & 7.6 & 8.2 & \\
\hline Chicharo & 6.8 & 2.8 & 9.8 & \\
\hline Elote & -26.0 & 2.5 & -24.2 & \\
\hline Cebolla & 23.9 & 0.7 & 24.8 & \\
\hline Col de bruselas & 45.0 & -1.7 & 42.6 & Recurrente a partir de 2002 \\
\hline Cebada grano & -4.1 & -1.8 & -5.8 & \\
\hline Maiz grano & 16.1 & -2.0 & 13.7 & \\
\hline Zanahoria & -13.1 & -5.0 & -17.4 & \\
\hline Epazote & 30.7 & -5.1 & 24.1 & Recurrente a partir de 1989 \\
\hline Maiz forrajero & -12.8 & -5.9 & -18.0 & \\
\hline Col (Repollo) & -10.0 & -9.7 & -18.7 & \\
\hline Crisantemo (gruesa) & $x$ & -12.5 & $x$ & Recurrente a partir de 1992 \\
\hline Pepino & 13.6 & -15.7 & -4.3 & \\
\hline Avena grano & -7.7 & -16.3 & -22.8 & \\
\hline Remolacha forrajera & 33.4 & -17.4 & 10.2 & \\
\hline Cilantro & $x$ & -19.6 & $x$ & Recurrente a partir de 1997 \\
\hline Pastos & $x$ & -25.0 & $x$ & No recurrente \\
\hline Alheli (manojo) & x & -29.7 & $x$ & Recurrente a partir de 1995 \\
\hline Lechuga & -19.1 & -32.1 & -45.0 & \\
\hline Cebada forrajera en verde & 64.5 & -36.3 & 4.8 & \\
\hline Girasol flor (gruesa) & $x$ & -36.4 & $>$ & Recurrente a partir de 2000 \\
\hline Ebo (Janamargo o Veza) & -7.6 & -39.5 & -44.1 & \\
\hline Nube (manojo) & $x$ & -40.0 & $x$ & Recurrente a partir de 1994 \\
\hline Arvejón & 221.1 & -41.5 & 87.8 & Recurrente a partir de 1994 \\
\hline Espinaca & -38.0 & -56.0 & -72.7 & Recurrente a partir de 1988 \\
\hline Nabo & $x$ & -56.3 & $x$ & No recurrente \\
\hline Manzanilla & 9.1 & -65.2 & -62.1 & Recurrente a partir de 2001 \\
\hline Zempoalxochitl (manojo) & $x$ & -73.8 & $>$ & Recurrente a partir de 1997 \\
\hline
\end{tabular}

Fuente: SIAP-SAGARPA. 


\section{Cuadro 4.8 Rendimientos (tons/has), ciclo P-V de riego (var \%)}

\begin{tabular}{|c|c|c|c|c|}
\hline Cultivo & $\begin{array}{c}(1990-2000) / \\
(1980-1990)\end{array}$ & $\begin{array}{c}(2000-2010) / \\
(1990-2000)\end{array}$ & $\begin{array}{r}(2000-2010) / \\
(1980-1990)\end{array}$ & Frecuencia de siembra \\
\hline Flores (gruesa) & 27.2 & 970.1 & $1,261.0$ & No recurrente \\
\hline Tomate rojo (Jitomate) & 33.9 & 690.4 & 958.2 & No recurrente \\
\hline Statice (manojo) & $x$ & 193.9 & $x$ & No recurrente \\
\hline Nabo & -47.8 & 156.2 & 33.7 & No recurrente \\
\hline Chile verde & 25.7 & 140.1 & 201.9 & No recurrente \\
\hline Epazote & $x$ & 128.2 & $>$ & No recurrente \\
\hline Cacahuate & 22.6 & 65.5 & 102.9 & No recurrente \\
\hline Coliflor & 13.0 & 53.7 & 73.6 & No recurrente \\
\hline Col (Repollo) & -22.9 & 50.1 & 15.8 & No recurrente \\
\hline Margarita (manojo) & $x$ & 45.6 & $>$ & No recurrente \\
\hline Sorgo grano & 21.5 & 43.2 & 74.0 & No recurrente \\
\hline Camote & 45.0 & 43.1 & 107.5 & No recurrente \\
\hline Polar (gruesa) & 2.4 & 37.9 & 41.2 & No recurrente \\
\hline Papa & 15.0 & 33.0 & 53.0 & No recurrente \\
\hline Arvejón & 228.6 & 27.8 & 320.0 & No recurrente \\
\hline Crisantemo (gruesa) & -1.7 & 25.0 & 22.9 & No recurrente \\
\hline Acelga & 366.4 & 25.0 & 482.7 & No recurrente \\
\hline Brócoli & $x$ & 21.1 & $x$ & No recurrente \\
\hline Arroz palay & 63.8 & 20.5 & 97.4 & Recurrente \\
\hline Haba grano & -29.6 & 20.3 & $-15,4$ & No recurrente \\
\hline Betabel & 2.1 & 18.1 & 20.5 & No recurrente \\
\hline Remolacha forrajera & -19.9 & 6.2 & -15.0 & Recurrente \\
\hline Alcachofa & 45.2 & 5.9 & 53.8 & No recurrente \\
\hline Frijol & -6.9 & 5.4 & -1.9 & Recurrente \\
\hline Haba verde & 45.2 & 4.7 & 52.0 & Recurrente a partir de 1986 \\
\hline Calabacita & 23.6 & 3.9 & 28.5 & Recurrente \\
\hline Pepino & 23.8 & 2.3 & 26.7 & Recurrente \\
\hline Col de bruselas & $x$ & 1.5 & $>$ & No recurrente \\
\hline Gladiola (gruesa) & -18.2 & 1.3 & -17.1 & Recurrente a partir de 1987 \\
\hline Cebolla & 35.9 & -0.8 & 34.8 & Recurrente \\
\hline Chicharo & -3.0 & -2.0 & -5.0 & Recurrente \\
\hline Maiz grano & 21.8 & -2.3 & 19.0 & Recurrente \\
\hline Ajo & 51.2 & -2.5 & 47.4 & No recurrente \\
\hline Zanahoria & -3.7 & -9.5 & -12.8 & Recurrente \\
\hline Maiz forrajero & 18.5 & -9.7 & 7.0 & Recurrente \\
\hline Tomate verde & 18.6 & -12.5 & 3.7 & Recurrente \\
\hline Rábano & -21.3 & -13.5 & -31.9 & Recurrente a partir de 1995 \\
\hline Cebada grano & -3.7 & -13.8 & -17.0 & Recurrente a partir de 1997 \\
\hline Poro & -5.9 & -14.4 & -19.5 & Recurrente a partir de 1987 \\
\hline Elote & -9.7 & -15.6 & -23.8 & Recurrente \\
\hline Avena forrajera & 9.9 & -17.5 & -9.3 & Recurrente \\
\hline Pastos & $x$ & -19.3 & $x$ & No recurrente \\
\hline Espinaca & -30.9 & -19.7 & -44.5 & Recurrente a partir de 1995 \\
\hline Avena grano & -1.2 & -20.9 & -21.9 & Recurrente a partir de 1995 \\
\hline Cebada forrajera en verde & 199.2 & -21.2 & 135.8 & No recurrente \\
\hline Trigo grano & 7.2 & -22.7 & -17.1 & Recurrente \\
\hline Ebo (Janamargo o Veza) & 8.6 & -22.8 & -16.1 & Recurrente \\
\hline Lechuga & 1.0 & -23.4 & -22.6 & Recurrente \\
\hline Pon-Pon (gruesa) & -43.5 & -26.6 & -58.5 & No recurrente \\
\hline Cilantro & 67.1 & -26.9 & 22.1 & Recuerrente a partir de 1987 \\
\hline Sorgo forrajero verde & 40.6 & -34.6 & -8.1 & Recurrente \\
\hline Ejote & 188.3 & -42.0 & 67.1 & Recurrente a partir de 1995 \\
\hline Nube (manojo) & $x$ & -52.8 & $>$ & No recurrente \\
\hline Zempoalxochiti (manojo) & $x$ & -67.4 & $x$ & Recurrente a partir de 2001 \\
\hline Zempoalxochitl (ramo) & & & & \\
\hline
\end{tabular}

Fuente: SIAP-SAGARPA. 
El cuadro anterior es una muestra elocuente de que los productores del Estado de México deben de considerar seriamente aquellos cultivos en los que sus siembras no son recurrentes, pero cuentan con los aumentos más considerables en su productividad, como el caso de flores y jitomate que observan aumentos cercanos al mil por ciento en sus respectivas productividades. Incluso varios de los cultivos mostrados empiezan a tener siembras regulares en los últimos años, lo cual es muestra de la disposición de los agricultores mexiquenses a intentar mejores beneficios con cultivos alternativos. Es importante recordar el papel del extensionismo para motivar a los productores a la diversificación, con mejores elementos técnicos.

\subsubsection{Otoño-Invierno}

\section{a) Superficie sembrada}

El comportamiento productivo de los cultivos sembrados en el Estado de México se manifiesta, en parte, en las superficies ocupadas para tales fines en el transcurso del tiempo. Si bien es cierto que comúnmente se observa cierta predominancia de los cultivos más aceptados por los agricultores, con pocas variantes con el transcurso de los años, también es cierto que tal tendencia no es muy común en la entidad bajo estudio, lo cual busca aprovecharse sobre todo cuando se cuenta con sistemas de producción más intensivos, como lo refleja el uso de sistemas de riego, además de la ventaja de adaptación por parte de ciertos productos, como lo es con las hortalizas.

El cultivo más aceptado por los agricultores del Estado de México, bajo la modalidad de riego en $\mathrm{O}-\mathrm{I}$, es y ha sido para las tres décadas consideradas, la avena forrajera en verde, a la que se dedica la tercera parte de la superficie sembrada con riego. El área dedicada a los cultivos de chícharo, haba verde y tomate verde, han seguido en importancia al de la avena forrajera, de modo que los cuatro cultivos en comento han ido de menos a más al pasar de ocupar seis mil hectáreas en promedio anual durante los ochentas a nueve mil durante los noventas, lo cual les ha permitido pasar del $55 \%$ de la superficie total 
sembrada en el estado durante la primer década referida, a $67 \%$ en el último periodo decenal señalado.

\section{Cuadro 4.9 Superficie sembrada (has), ciclo O-I de riego}

\begin{tabular}{|c|c|c|c|c|c|c|c|c|c|}
\hline \multirow[b]{2}{*}{ Cultivo } & \multicolumn{3}{|c|}{ Promedios anuales } & \multicolumn{3}{|c|}{ Promedios anuales $(\%)$} & \multicolumn{3}{|c|}{ Lugar } \\
\hline & $1980-1990$ & $1990-2000$ & $2000-2010$ & $1980-1990$ & $1990-2000$ & $2000-2010$ & $1980-1990$ & $1990-2000$ & $2000-2010$ \\
\hline Total & 11,123 & 13,495 & 13,560 & 100.0 & 100.0 & 100.0 & -- & - & - \\
\hline Avena forrajera en verde & 3,084 & 3,076 & 4,711 & 27.7 & 22.8 & 34.7 & 1 & 1 & . \\
\hline Chicharo & 1,746 & 2,634 & 2,446 & 15.7 & 19.5 & 18.0 & 3 & 3 & \\
\hline Haba verde & 483 & 1,018 & 1,105 & 4.3 & 7.5 & 8.2 & 5 & 4 & t. \\
\hline Tomate verde & 839 & 996 & 793 & 7.5 & 7.4 & 5.8 & 4 & 5 & 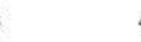 \\
\hline Elote & 97 & 213 & 451 & 0.9 & 1.6 & 3.3 & 18 & 10 & \\
\hline Papasin clasificar & 2,049 & 2,773 & 402 & 18.4 & 20.5 & 3.0 & 2 & 2 & ? \\
\hline Maíz grano (blanco) & - & - & 376 & - & - & 2.8 & 58 & 75 & \\
\hline Gladiola (gruesa) & 137 & 170 & 330 & 1.2 & 1.3 & 2.4 & 14 & 12 & \\
\hline Ebo (Janamargo o Veza) & 259 & 222 & 297 & 2.3 & 1.6 & 2.2 & 7 & 9 & 1 \\
\hline Cebollablanca & - & - & 255 & - & - & 1.9 & 72 & 85 & 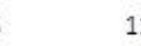 \\
\hline Avena forrajera seca & - & - & 150 & - & - & 1.1 & 64 & 80 & 1 \\
\hline Tomate rojo (Saladette) & - & - & 111 & - & - & 0.8 & 87 & 99 & 1 \\
\hline PapaAlpha & - & - & 104 & - & - & 0.8 & 113 & 114 & 1 \\
\hline Maíz grano sin clasif icar & 166 & 527 & 100 & 1.5 & 3.9 & 0.7 & 11 & 6 & 1 \\
\hline Calabacita italiana & - & - & 91 & - & - & 0.7 & 71 & 84 & 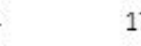 \\
\hline Girasol flor (gruesa) & - & 2 & 81 & - & 0.0 & 0.6 & 99 & 48 & 1 \\
\hline Calabacitasin clasificar & 127 & 115 & 62 & 1.1 & 0.8 & 0.5 & 16 & 14 & 1 \\
\hline Frijol flor de mayo & - & - & 56 & - & - & 0.4 & 91 & 102 & . \\
\hline Resto & 1,946 & 1,243 & 889 & 17.5 & 9.2 & 6.6 & - & - & 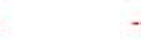 \\
\hline
\end{tabular}

Fuente: elaboración propia con información del SIAP- SAGARPA. Nota: Tabla que se refiere al ciclo O-I Riego con uso de tecnologías de agricultura protegida.

Es de llamar la atención la posición lograda con la oferta de crisantemo, pues en el primer periodo decenal considerado tenía la posición 98 dentro de todos los cultivos sembrados con riego en el estado; sin embargo, para la segunda etapa de diez años, logró ocupar la posición quince y para los años de 2000 a 2010 pasó a ocupar la quinta posición entre todos los cultivos sembrados por la entidad. Lo señalado es muestra de la versatilidad con la que los cultivos de riego pueden adaptarse a las condiciones del mercado y refleja, en cierta forma, el por qué la vocación del estado se ha manifestado en la preferencia de ciertas plantas y flores. 


\section{Gráfica 4.7 Superficie promedio anual sembrada de 2000 a 2010 (\%), ciclo O-I de riego}

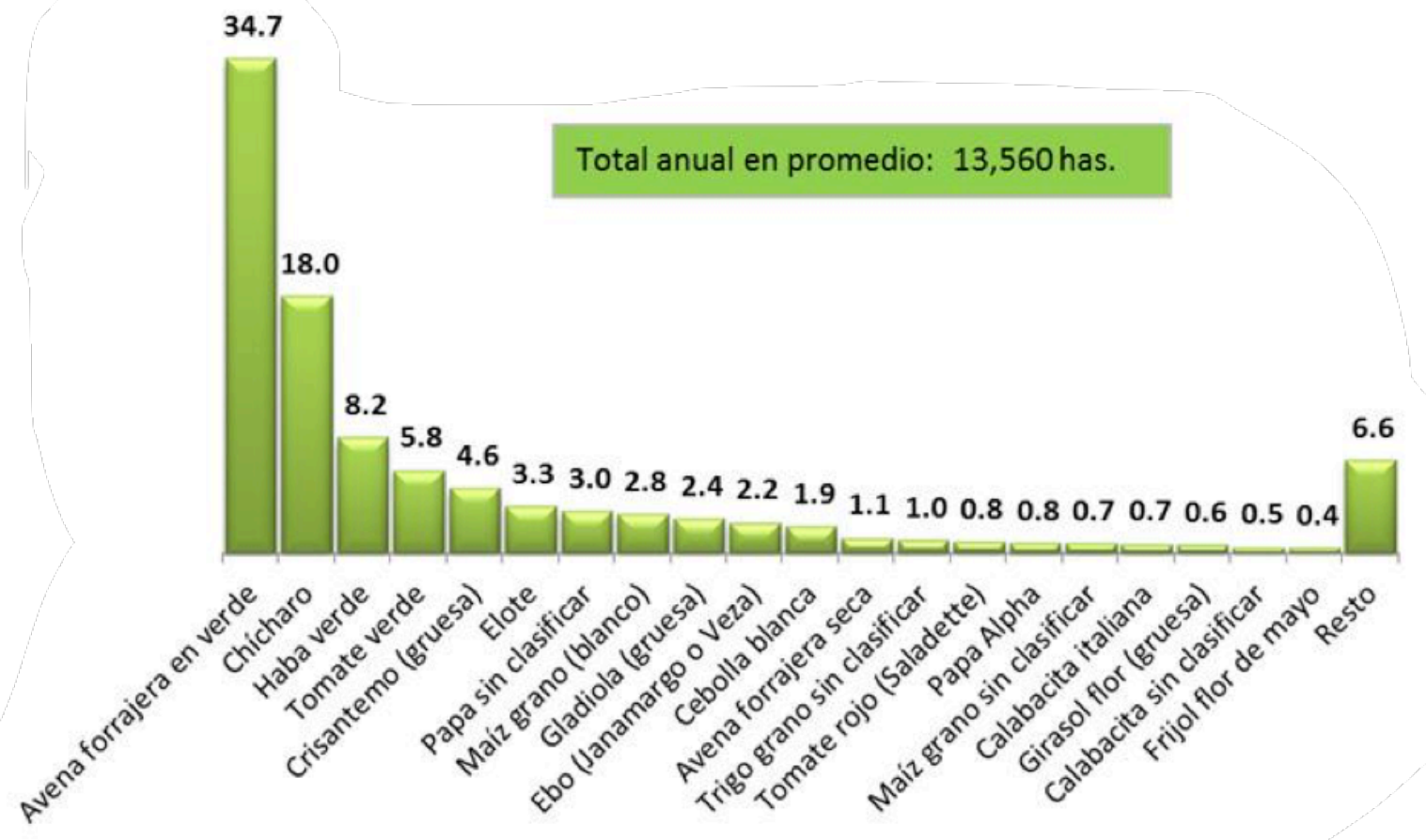

Fuente: elaboración propia con información del SIAP- SAGARPA.

Sería de esperar que durante el O-I de riego se contara con mayores registros de cultivos con agricultura protegida; sin embargo, la realidad es que las estadísticas sólo identifican algunos cultivos (Lilium, solidago y chile verde morrón) a partir de 2005, los cuales usan como complemento tecnológico a los invernaderos y no representan en el promedio anual de 2000 a 2010 ni 100 hectáreas. Esto es una evidencia más del retraso en el uso de tales tecnologías.

Por otro lado, la superficie sembrada de temporal en el ciclo O-I del Estado de México representó el 30\% respecto de la superficie de riego del mismo ciclo, durante los años 1980 a 1990, lo cual es muestra de la necesidad de cambiar de modalidad productiva, de temporal a riego. Para el periodo 1990-2000 el promedio anual de tierras de temporal baja de manera importante, comparado con 1980-1990, al pasar de tres mil 283 hectáreas por año a 816 , o sea un $75 \%$ menos, que resulta consistente con el aumento de 
riego para tal ciclo, pues se pasó de 11 mil 123 hectáreas sembradas con riego, en promedio anual durante 1980-1990, a 13 mil 495 en los años de 1990-2000, de modo que el crecimiento relativo es del 21\% (2,372 hectáreas).

\subsection{Superficie sembrada (has), ciclo O-I de temporal}

\begin{tabular}{|c|c|c|c|c|c|c|c|c|c|}
\hline \multirow[b]{2}{*}{ Cultivo } & \multicolumn{3}{|c|}{ Promedios anuales } & \multicolumn{3}{|c|}{ Promedios anuales (\%) } & \multicolumn{3}{|c|}{ Lugar } \\
\hline & $1980-1990$ & $1990-2000$ & $2000-2010$ & $1980-1990$ & $1990-2000$ & $2000-2010$ & $1980-1990$ & $1990-2000$ & $2000-2010$ \\
\hline Total & 3,283 & 816 & 864 & 100.0 & 100.0 & 100.0 & - & - & - \\
\hline Chicharo & 846 & 581 & 490 & 25.76 & 71.29 & 56.72 & 1 & 1 & 1 \\
\hline Haba verde & 170 & 39 & 151 & 5.17 & 4.73 & 17.46 & 6 & 3 & 2 \\
\hline Avena forraje ra en verde & 522 & 56 & 146 & 15.88 & 6.89 & 16.91 & 3 & 2 & 3 \\
\hline Ebo (janamargo o veza) & 68 & 31 & 35 & 2.08 & 3.85 & 4.05 & 8 & 4 & 4 \\
\hline Trigo grano sin clasificar & 156 & 26 & 15 & 4.75 & 3.13 & 1.79 & 7 & 5 & 5 \\
\hline Trigo grano cristalino & - & - & 11 & - & - & 1.26 & 23 & 32 & 6 \\
\hline Trigo grano fuerte & - & - & 6 & - & - & 0.68 & 24 & 33 & 7 \\
\hline Chayote & - & - & 5 & - & - & 0.53 & 27 & 35 & 8 \\
\hline Trigo grano suave & - & - & 4 & - & - & 0.42 & 25 & 34 & 9 \\
\hline Canola & - & - & 1 & - & - & 0.09 & 31 & 36 & 10 \\
\hline Elote & - & 20 & 0 & - & 2.44 & 0.05 & 28 & 6 & 11 \\
\hline Total & - & 6 & 0 & - & 0.69 & 0.01 & 34 & 10 & 12 \\
\hline Nube (manojo) & - & 0 & 0 & - & 0.01 & 0.01 & 33 & 22 & 13 \\
\hline Papa sin clasificar & 672 & 13 & - & 20.48 & 1.64 & - & 2 & 7 & 14 \\
\hline Tomate rojo(jitomate)s/clasificar & 14 & 8 & - & 0.44 & 0.96 & - & 15 & 8 & 15 \\
\hline Ce bada forraje ra en verde & 46 & 7 & - & 1.41 & 0.84 & - & 11 & 9 & 16 \\
\hline Gladiola & - & 6 & - & - & 0.68 & - & 32 & 11 & 17 \\
\hline Avena grano & 55 & 5 & - & 1.66 & 0.67 & - & 9 & 12 & 18 \\
\hline Calabacita sin clasificar & - & 5 & - & - & 0.59 & - & 26 & 13 & 19 \\
\hline Tomate verde & 53 & 4 & - & 1.63 & 0.51 & - & 10 & 14 & 20 \\
\hline Pepino sin clasificar & - & 3 & - & - & 0.38 & - & 29 & 15 & 21 \\
\hline Resto & 680 & 6 & - & 20.72 & 0.71 & - & - & - & - \\
\hline
\end{tabular}

Fuente: elaboración propia con información del SIAP- SAGARPA.

Al pasar del periodo decenal de 1990-2000 a 2000-2010 la situación es algo similar, aunque no se da disminución en el promedio anual de las tierras ocupadas como de temporal, pues más bien crecen en un $6 \%$ al pasar de 816 a 864 hectáreas. También es cierto que los terrenos de riego aumentan de 13 mil 495 hectáreas en promedio anual a 13 mil 560. 
b) Superficie siniestrada

Aparentemente la superficie siniestrada de temporal durante el ciclo OI en el Estado de México es muy poca, pero obedece a que relativamente se siembran muy pocos cultivos de temporal durante tal periodo, debido a que se está fuera de la época de lluvias. El promedio anual de superficie sembrada pasó de tres mil 283 hectáreas durante los años 1980-1990 a sólo 864 por año en el periodo 2000-2010. Este indicador no resultará desfavorable, sobre todo si la superficie con riego durante el mismo OI es mayor, además de que posiblemente cuente con menos siniestros.

\section{Gráfica 4.8 Superficie promedio anual siniestrada (has), ciclo O-I de temporal}

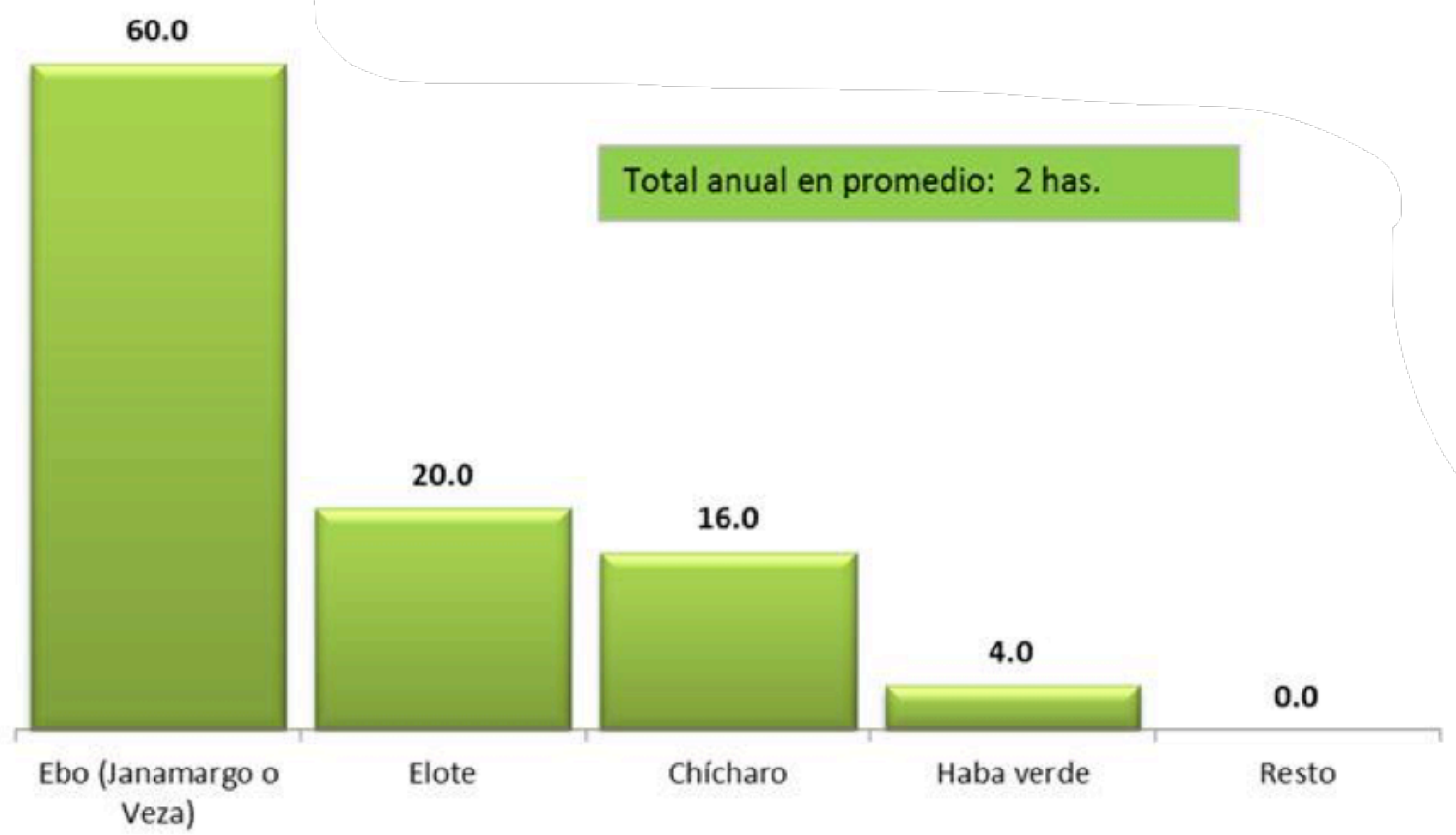

Fuente: elaboración propia con información del SIAP- SAGARPA.

El número de hectáreas siniestradas en promedio durante el periodo 2000-2010 del OI de riego, asciende a 74 hectáreas que representan el 0.5\% de la superficie sembrada; tal participación es muy baja y representa una buena alternativa para los productores, la cual debe de ser fomentada con esquemas adecuados de apoyo financiero y de uso de complementos tecnológicos. 


\section{Gráfica 4.9 Superficie promedio anual siniestrada (has), ciclo 0-I de riego}

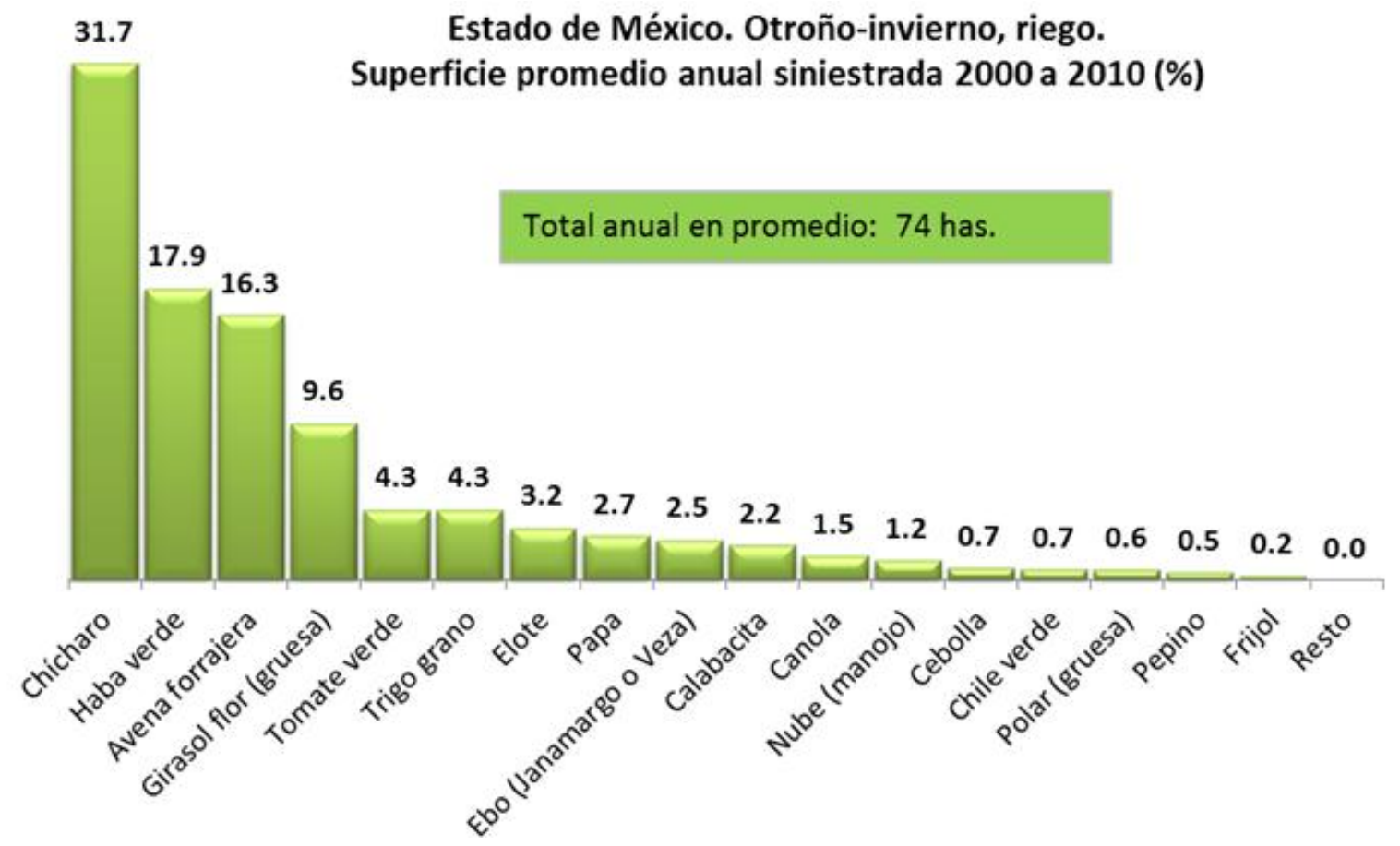

Fuente: elaboración propia con información del SIAP- SAGARPA.

c) Volúmenes cosechados

Ya se mostró en el apartado sobre superficie sembrada que la correspondiente a OI de riego aumentó $21 \%$ al pasar de la serie anual de 1980-1990 a la de 1990-2000. Así, sería de esperarse que a partir de la firma del TLCAN todavía se notara más tal aumento, a fin de enfrentar mejor al mercado internacional; no obstante, al transitar del lapso de 1990-2000 a 2000-2010 el incremento fue de tan sólo 4.7\%. El cuestionamiento a las medidas de política económica que deben de buscar mejorar tales formas de explotación es necesario; debe de mejorarse la asignación de apoyos y recursos, pues es evidente que existen. 
Cuadro 4.11 Volumen de producción (ton), ciclo O-I de riego

\begin{tabular}{|c|c|c|c|c|c|c|c|c|c|}
\hline \multirow[b]{2}{*}{ Cultivo } & \multicolumn{3}{|c|}{ Promedios anuales } & \multicolumn{3}{|c|}{ Promedios anuales $(\%)$} & \multicolumn{3}{|c|}{ Luga } \\
\hline & $1980-1990$ & $1990-2000$ & $2000-2010$ & $1980-1990$ & $1990-2000$ & $2000-2010$ & $1980-1990$ & $1990-2000$ & $2000-2010$ \\
\hline Total & 144,527 & 160,106 & 167,597 & 100.0 & 100.0 & 100.0 & & & \\
\hline Avena forrajera & 58,785 & 63,056 & 100,614 & 40.7 & 39.4 & 60.0 & 1 & 1 & 1 \\
\hline Chicharo & 8,816 & 11,984 & 12,993 & 6.1 & 7.5 & 7.8 & 5 & 4 & 2 \\
\hline Tomate verde & 9,739 & 12,289 & 11,163 & 6.7 & 7.7 & 6.7 & 4 & 3 & 3 \\
\hline Papa & 28,797 & 38,701 & 9,312 & 19.9 & 24.2 & 5.6 & 2 & 2 & 4 \\
\hline Habaverde & 2,215 & 5,337 & 7,801 & 1.5 & 3.3 & 4.7 & 9 & 7 & 5 \\
\hline Elote & 715 & 1,901 & 6,011 & 0.5 & 1.2 & 3.6 & 15 & 9 & 6 \\
\hline Cebolla & 2,016 & 3,822 & 4,307 & 1.4 & 2.4 & 2.6 & 10 & 8 & 7 \\
\hline Tomate rojo (Jitomate) & 1,242 & 6,540 & 3,184 & 0.9 & 4.1 & 1.9 & 13 & 5 & 8 \\
\hline Maiz forrajero & 5,445 & 1,347 & 1,647 & 3.8 & 0.8 & 1.0 & 6 & 12 & 9 \\
\hline Calabacita & 1,245 & 1,139 & 1,484 & 0.9 & 0.7 & 0.9 & 12 & 13 & 10 \\
\hline Rye grass en verde & 0 & 0 & 1,385 & 0.0 & 0.0 & 0.8 & 102 & 104 & 11 \\
\hline Maíz grano & 441 & 1,418 & 1,349 & 0.3 & 0.9 & 0.8 & 17 & 11 & 12 \\
\hline Trigo grano & 430 & 1,132 & 687 & 0.3 & 0.7 & 0.4 & 18 & 14 & 13 \\
\hline Sorgo forrajero verde & 373 & 343 & 683 & 0.3 & 0.2 & 0.4 & 19 & 17 & 14 \\
\hline Zanahoria & 1,654 & 596 & 536 & 1.1 & 0.4 & 0.3 & 11 & 16 & 15 \\
\hline Lechuga & 254 & 270 & 509 & 0.2 & 0.2 & 0.3 & 21 & 18 & 16 \\
\hline Chile verde & 22 & 102 & 502 & 0.0 & 0.1 & 0.3 & 35 & 24 & 17 \\
\hline Fresa & 114 & 11 & 470 & 0.1 & 0.0 & 0.3 & 25 & 35 & 18 \\
\hline Pastos & 0 & 6,472 & 449 & 0.0 & 4.0 & 0.3 & 95 & 6 & 19 \\
\hline Pepino & 139 & 601 & 445 & 0.1 & 0.4 & 0.3 & 23 & 15 & 20 \\
\hline Resto & 22,084 & 3,044 & 2,064 & 15.3 & 1.9 & 12 & $\ldots$ & $\ldots$ & $\ldots$ \\
\hline
\end{tabular}

Fuente: elaboración propia con información del SIAP- SAGARPA.

\subsection{Volumen de producción promedio anual de 2000 a 2010 (\%), ciclo O-I de riego}

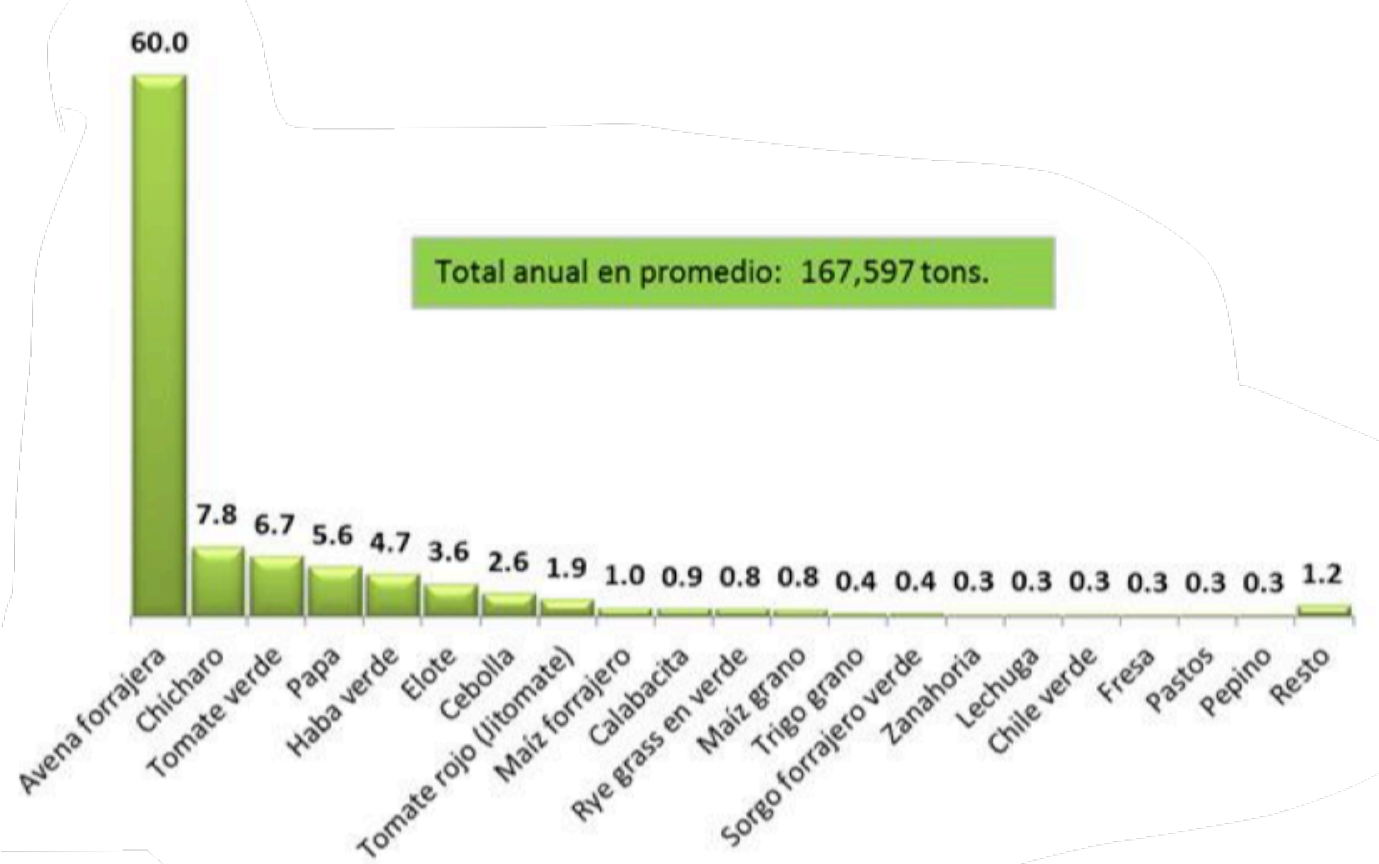

Fuente: elaboración propia con información del SIAP- SAGARPA. 
La avena forrajera es una clara muestra de que es posible aumentar la capacidad productiva, sobre todo si se emplean sistemas de riego; su aportación al volumen bajó del 41\% durante 1980-1990 al 39\% de 1990-2000, pero con un repunte considerable para 2000-2010, de modo que alcanza una participación del $60 \%$.

La reducción en la superficie sembrada de temporal durante OI era más que esperada a partir de la firma del TLCAN, aunque resulta mucho más notoria desde 1980, de modo que al pasar del periodo de tiempo de 19801990 a 1990-2000 tal área cayó en 75\%, para quedar en 816 hectáreas sembradas en promedio anual durante el segundo periodo señalado, la cual se mantiene en prácticamente los mismo niveles para el periodo 2000-2010.

Cuadro 4.12 Volumen de producción (ton), ciclo O-I de temporal

\begin{tabular}{|c|c|c|c|c|c|c|c|c|c|c|}
\hline \multirow[b]{2}{*}{ Cultivo } & \multicolumn{3}{|c|}{ Promedios anuales } & \multicolumn{3}{|c|}{ Promedios anuales $(\%)$} & \multicolumn{4}{|c|}{ Lugar } \\
\hline & $1980-1990$ & $1990-2000$ & $2000-2010$ & $1980-1990$ & $1990-2000$ & $2000-2010$ & $1980-1990$ & $1990-2000$ & $2000-201$ & \\
\hline Total & 23,659 & 4,254 & 5,144 & 100.0 & 100.0 & 100.0 & & & & \\
\hline Avena forrajera & 9,210 & 958 & 2,288 & 38.9 & 22.5 & 44.5 & 1 & 2 & 2 & \\
\hline Chicharo & 3,076 & 2,356 & 1,976 & 13.0 & 55.4 & 38.4 & 3 & 1 & 1 & \\
\hline Habaverde & 772 & 186 & 748 & 3.3 & 4.4 & 14.5 & 6 & & 3 & \\
\hline Chayote & 0 & 0 & 68 & 0.0 & 0.0 & 1.3 & 44 & 48 & 8 & \\
\hline Trigograno & 301 & 32 & 61 & 1.3 & 0.8 & 1.2 & 9 & 12 & 2 & \\
\hline Canola & 0 & 0 & 2 & 0.0 & 0.0 & 0.0 & 38 & 42 & 2 & \\
\hline Elote & 0 & 142 & 0 & 0.0 & 3.3 & 0.0 & 53 & 4 & 4 & \\
\hline Papa & 6,314 & 129 & 0 & 26.7 & 3.0 & 0.0 & 2 & 5 & 5 & \\
\hline Cebada forrajeraen verde & 597 & 110 & 0 & 2.5 & 26 & 0.0 & 7 & 6 & 6 & \\
\hline Tomate rojo (Jitomate) & 91 & 100 & 0 & 0.4 & 2.3 & 0.0 & 11 & 7 & 7 & 10 \\
\hline Calabacita & 0 & 56 & 0 & 0.0 & 1.3 & 0.0 & 35 & 8 & 8 & 11 \\
\hline Gladiola & 0 & 55 & 0 & 0.0 & 1.3 & 0.0 & 62 & 9 & 9 & 12 \\
\hline Pepino & 0 & 46 & 0 & 0.0 & 1.1 & 0.0 & 90 & 10 & 0 & 13 \\
\hline Tomate verde & 334 & 38 & 0 & 1.4 & 0.9 & 0.0 & 8 & 11 & 1 & 14 \\
\hline Cebolla & 5 & 23 & 0 & 0.0 & 0.5 & 0.0 & 16 & 13 & 3 & 15 \\
\hline Avenagrano & 112 & 8 & 0 & 0.5 & 0.2 & 0.0 & 10 & 14 & 4 & 16 \\
\hline Arvejón & 0 & 5 & 0 & 0.0 & 0.1 & 0.0 & 30 & 15 & 5 & 17 \\
\hline Camote & 0 & 5 & 0 & 0.0 & 0.1 & 0.0 & 37 & 16 & 6 & 18 \\
\hline Máz grano & 86 & 3 & 0 & 0.4 & 0.1 & 0.0 & 12 & 17 & 7 & 19 \\
\hline Trigograno semilla & 0 & 0 & 0 & 0.0 & 0.0 & 0.0 & 106 & 18 & 8 & 20 \\
\hline Resto & 2,761 & 0 & 0 & 11.7 & 0.0 & 0.0 & $\ldots$. & $\ldots$ & & $\ldots$ \\
\hline
\end{tabular}

Fuente: elaboración propia con información del SIAP- SAGARPA.

Aunque el volumen de participación de los cultivos sembrados en OI de temporal es muy bajo al compararse con las aportaciones de los otros ciclos y modalidades, de cualquier manera puede representar un marco de referencia que vale la pena analizar para considerar plantaciones que pueden tener 
aportaciones aceptables ante situaciones de contingencias climáticas, como lo son las sequías.

\subsection{Volumen de producción promedio anual de 2000 a 2010 (\%), ciclo 0-I de temporal}

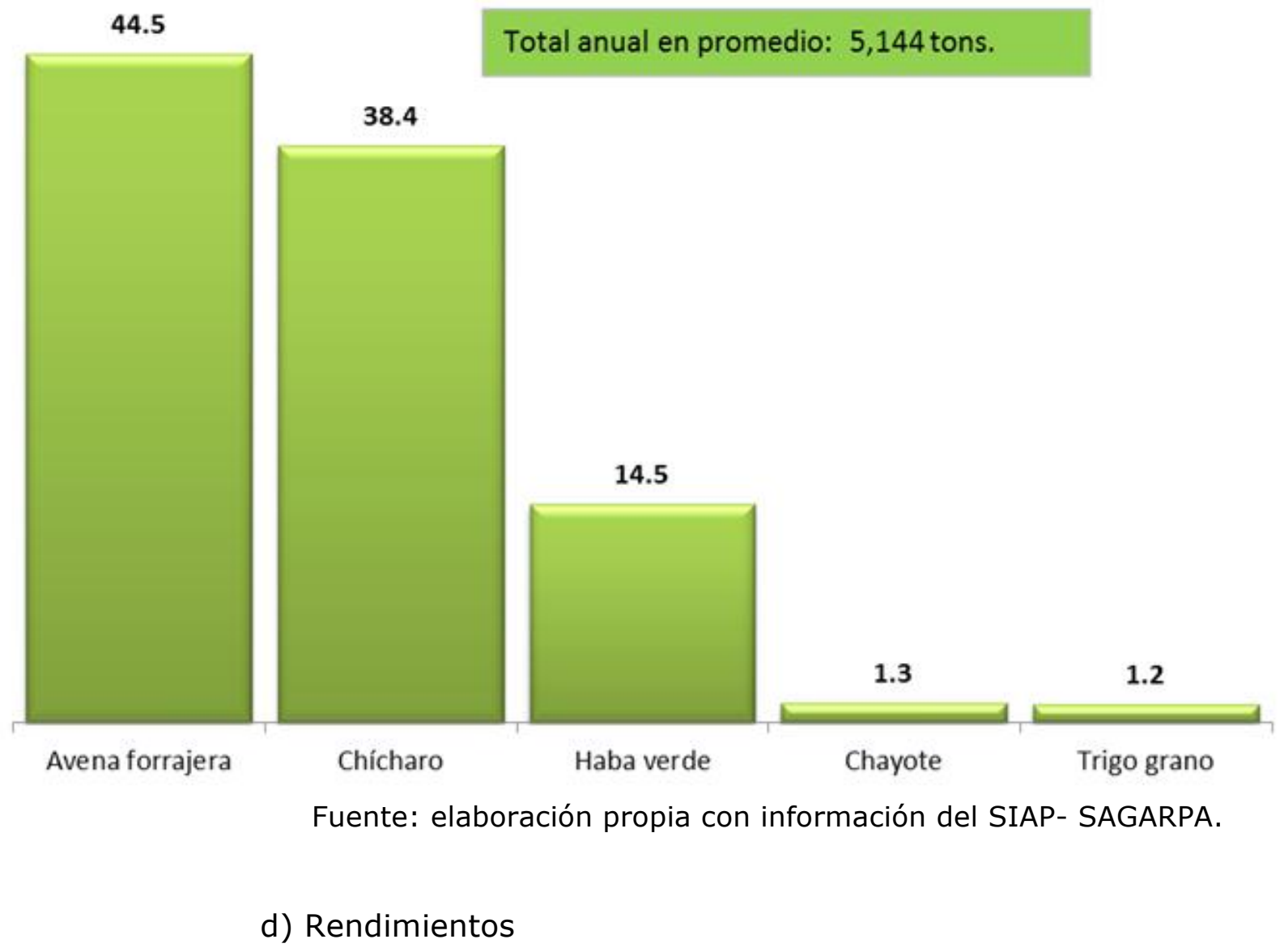

En el siguiente cuadro se tienen los rendimientos de riego obtenidos de los principales cultivos identificados con producción en el Estado de México; no se muestran aquellas plantaciones que no cuentan con regularidad de siembras en el transcurso del tiempo, pero sí aquellas que aunque no se llegan a sembrar todos los años, sí es más común su presencia. Resulta interesante observar que los cultivos con mayores rendimientos son aquellos que no tienen siembras constantes. Así, se tienen en la tabla 13 cultivos con siembras no recurrentes, pero con crecimientos en sus rendimientos que deben obligar a investigarlos en un contexto más amplio, a fin de considerarlos como 
potenciales de mayor crecimiento. El seguimiento a las superficies sembradas, cosechadas, siniestradas, así como a los volúmenes de producción, rendimientos, precios y colocación en mercados potenciales, debe de ser una estrategia para fomentar innovaciones tecnológicas, financiamientos y aprovechamiento de apoyos, sobre todo al investigar cultivos con alta capacidad de mejora en sus rendimientos; es importante recordar la ventaja de estar dentro de los dos mercados a nivel de entidad federativa (Estado de México y Distrito Federal) con el mayor número de consumidores de todo el país.

Cuadro 4.13 Rendimientos (tons/has), ciclo O-I riego (var \%)

\begin{tabular}{|c|c|c|c|c|c|c|c|}
\hline \multirow[b]{2}{*}{ Cultivo } & \multicolumn{3}{|c|}{ Promedios simples } & \multicolumn{3}{|c|}{ Var. \% } & \multirow[b]{2}{*}{ Frecuencia de siembra } \\
\hline & 1980-1990 & $1990-2000$ & $2000-2010$ & $\begin{array}{c}(1990-2000) / \\
(1980-1990)\end{array}$ & $\begin{array}{c}(2000-2010) / \\
(1990-2000)\end{array}$ & $\begin{array}{c}(2000-2010) / \\
(1980-1990)\end{array}$ & \\
\hline Ejote & 4.67 & 3.61 & 10.45 & -22.6 & 189.3 & 124.0 & No recurrente \\
\hline Chile verde & 3.48 & 6.70 & 14.01 & 92.4 & 109.3 & 302.7 & Recurrente desde 1985 \\
\hline Fresa & 11.00 & 8.42 & 17.59 & -23.5 & 109.0 & 59.9 & No recurrente \\
\hline Yuca alimenticia & $x$ & 5.50 & 11.06 & $x$ & 101.1 & $><$ & No recurrente \\
\hline Sorgo forrajero verde & 24.62 & 19.02 & 36.04 & -22.7 & 89.5 & 46.4 & Recurrente \\
\hline Jicama & 15.60 & 6.00 & 10.71 & -61.5 & 78.6 & -31.3 & No recurrente \\
\hline Col (Repollo) & 22.50 & 17.12 & 27.71 & -23.9 & 61.9 & 23.2 & Recurrente \\
\hline Betabel & 17.39 & 11.46 & 18.42 & -34.1 & 60.7 & 5.9 & No recurrente \\
\hline Acelga & $x$ & 5.78 & 8.63 & $x$ & 49.3 & $><$ & No recurrente \\
\hline Elote & 7.86 & 9.33 & 12.84 & 18.6 & 37.7 & 63.3 & Recurrente \\
\hline Рара & 13.90 & 14.75 & 19.70 & 6.1 & 33.6 & 41.8 & Recurrente \\
\hline Haba verde & 4.61 & 5.35 & 7.13 & 16.1 & 33.4 & 54.8 & No recurrente \\
\hline Cilantro & 9.00 & 7.25 & 9.62 & -19.5 & 32.7 & 6.9 & No recurrente \\
\hline Brócoli & $x$ & 7.53 & 9.96 & $x$ & 32.2 & $x$ & No recurrente \\
\hline Poro & 12.71 & 11.75 & 14.94 & -7.5 & 27.1 & 17.6 & No recurrente \\
\hline Col de bruselas & $x$ & 8.00 & 9.91 & $x$ & 23.8 & $>$ & No recurrente \\
\hline Coliflor & 14.18 & 13.96 & 17.03 & -1.5 & 22.0 & 20.2 & No recurrente \\
\hline Trigo grano & 2.33 & 2.26 & 2.64 & -3.0 & 16.7 & 13.2 & Recurrente \\
\hline Zanahoria & 26.79 & 19.87 & 22.98 & -25.8 & 15.7 & -14.2 & Recurrente \\
\hline Chicharo & 5.13 & 4.70 & 5.36 & -8.4 & 14.1 & 4.5 & Recurrente \\
\hline Maiz forrajero & 35.69 & 27.84 & 31.40 & -22.0 & 12.8 & -12.0 & Recurrente \\
\hline Maiz grano & 2.64 & 2.59 & 2.83 & -1.9 & 9.3 & 7.3 & Recurrente \\
\hline Tomate verde & 11.65 & 12.88 & 14.00 & 10.6 & 8.7 & 20.2 & Recurrente \\
\hline Frijol & 1.29 & 1.09 & 1.17 & -16.2 & 8.2 & -9.3 & Recurrente \\
\hline Pepino & 13.98 & 14.22 & 15.30 & 1.7 & 7.6 & 9.5 & Recurrente \\
\hline Camote & 9.89 & 14.09 & 14.43 & 42.5 & 2.4 & 45.9 & Recurrente \\
\hline Avena forrajera & 19.72 & 20.50 & 20.65 & 3.9 & 0.7 & 4.7 & Recurrente \\
\hline Ebo (Janamargo o Veza) & 15.06 & 16.31 & 16.19 & 8.3 & -0.7 & 7.5 & Recurrente \\
\hline Cebada forrajera en verde & 17.32 & 16.99 & 16.60 & -1.9 & -2.2 & -4.1 & Recurrente \\
\hline Sandia & 18.33 & 25.10 & 24.44 & 36.9 & -2.6 & 33.3 & Recurrente \\
\hline Calabacita & 10.11 & 10.22 & 9.80 & 1.1 & -4.2 & -3.1 & Recurrente \\
\hline Tomate rojo (Jitomate) & 11.11 & 18.29 & 17.23 & 64.6 & -5.8 & 55.1 & Recurrente \\
\hline Ajo & 4.91 & 6.26 & 5.79 & 27.4 & -7.6 & 17.8 & No recurrente \\
\hline Rábano & 8.02 & 6.77 & 6.25 & -15.6 & $\cdot 7.7$ & -22.0 & No recurrente \\
\hline Haba grano & 4.75 & 1.60 & 1.45 & -66.3 & -9.4 & -69.4 & No recurrente \\
\hline Lechuga & 21.56 & 18.13 & 15.61 & -15.9 & -13.9 & -27.6 & No recurrente \\
\hline Cebolla & 12.79 & 18.39 & 15.80 & 43.8 & -14.1 & 23.5 & No recurrente \\
\hline Cebada grano & 2.79 & 2.83 & 2.00 & 1.5 & -29.5 & -28.4 & No recurrente \\
\hline Alpiste verde & $x$ & 4.13 & 1.07 & $x$ & -74.2 & $x$ & No recurrente \\
\hline Linaza & 4.63 & 6.60 & 1.50 & 42.7 & -77.3 & -67.6 & No recurrente \\
\hline
\end{tabular}

Fuente: SIAP-SAGARPA. 
Resulta difícil de creer que algunos cultivos todavía tengan rendimientos en el periodo 2000-2010 menores a los observados antes de la firma del TLCAN en el lapso 1980-1990; por ejemplo, en maíz forrajero el cual disminuyó en $12 \%$ el número de toneladas obtenidas al comparar el periodo más reciente señalado contra el más antiguo. El seguimiento a tales cultivos debe de plantear la necesidad de mejorarlos a través de paquetes tecnológicos alternativos o, como última medida, recomendar el evitar su cultivo.

La falta de regularidad en prácticamente todos los cultivos de OI de temporal complica su análisis e impide dar certeza a la productividad lograda o por esperarse, razón por la cual no se presenta un desglose de los cultivos sembrados en tal ciclo y modalidad.

\subsubsection{Perennes}

\section{a) Superficie sembrada}

Emitir comentarios sobre los cultivos perennes obliga a recordar que en la gran mayoría de los casos se trata de cultivos que por sus características intrínsecas pueden delimitarse dentro del espacio temporal del año calendario, de modo que sus volúmenes de producción se registran dentro de los doce meses del año comúnmente conocido. Además, dadas sus características de permanencia, evitan siembras recurrentes, cuentan con mayor resistencia a los siniestros, salvo en aquellos casos en que las áreas son totalmente devastadas junto con las plantaciones. Por tales razones se considera, en primera instancia, el análisis de las tierras cosechadas; la presente tesis no tiene dentro de sus objetivos el revisar situaciones en las que los siniestros han dado lugar a afectaciones a perennes, lo cual permite aprovechar de mejor manera la estadística del SIAP, que se enfoca en tal sentido y, en caso de tenerse daños por siniestros, estos se reflejan de cierta manera en los altibajos de la producción sin que necesariamente sean la única causal.

El cuadro siguiente no deja lugar a dudas en la primacía de la siembra de pastos, como parte de los perennes de temporal en el Estado de México, con 
una participación que pasó del $70 \%$ en promedio anual del total de la superficie cosechada en la entidad para el periodo 1980-1990 a 80\% para el promedio anual de 2000 a 2010. Las recomendaciones sobre la explotación racional de los recursos naturales representan un freno para aumentar todavía más tales áreas.

Cuadro 4.14 Superficie cosechada (has), ciclo perennes de temporal

\begin{tabular}{|c|c|c|c|c|c|c|c|c|c|}
\hline \multirow[b]{2}{*}{ Cultivo } & \multicolumn{3}{|c|}{ Promedios anuales } & \multicolumn{3}{|c|}{ Promedios anuales (\%) } & \multicolumn{3}{|c|}{ Lugar } \\
\hline & $1980-1990$ & $1990-2000$ & $2000-2010$ & $1980-1990$ & $1990-2000$ & $2000-2010$ & $1980-1990$ & $1990-2000$ & $2000-2010$ \\
\hline Total & 54,971 & 47,621 & 105,139 & 100.0 & 100.0 & 100.0 & & & \\
\hline Pastos & 38,322 & 31,173 & 84,218 & 69.7 & 65.5 & 80.10 & 1 & & 1 \\
\hline Tuna & 10,118 & 10,928 & 15,792 & 18.4 & 22.9 & 15.02 & 2 & & 2 \\
\hline Durazno & 1,443 & 1,582 & 1,113 & 2.6 & 3.3 & 1.06 & 3 & & 3 \\
\hline Aguacate & 838 & 824 & 769 & 1.5 & 1.7 & 0.73 & 5 & & 5 \\
\hline Maguey pulquero (miles de its.) & 963 & 1,364 & 727 & 1.8 & 29 & 0.69 & 4 & & 4 \\
\hline Ciruela & 324 & 221 & 403 & 0.6 & 0.5 & 0.38 & 9 & 8 & 8 \\
\hline Cáé cereza & 202 & 168 & 387 & 0.4 & 0.4 & 0.37 & 12 & 10 & 0 \\
\hline Rye grass en verde & 119 & 0 & 336 & 0.2 & 0.0 & 0.32 & 15 & 33 & 3 \\
\hline Alfalfaverde & 405 & 188 & 261 & 0.7 & 0.4 & 0.25 & 6 & 9 & 9 \\
\hline Mango & 228 & 237 & 235 & 0.4 & 0.5 & 0.22 & 11 & & 10 \\
\hline Manzana & 232 & 333 & 151 & 0.4 & 0.7 & 0.14 & 10 & & 11 \\
\hline Nopalitos & 69 & 61 & 128 & 0.1 & 0.1 & 0.12 & 18 & 14 & 12 \\
\hline Nuez & 132 & 156 & 86 & 0.2 & 0.3 & 0.08 & 13 & 11 & 13 \\
\hline Pera & 75 & 116 & 74 & 0.1 & 0.2 & 0.07 & 16 & 12 & 14 \\
\hline Limón & 129 & 64 & 71 & 0.2 & 0.1 & 0.07 & 14 & 13 & 15 \\
\hline Guayaba & 70 & 31 & 59 & 0.1 & 0.1 & 0.06 & 17 & 17 & 16 \\
\hline Naranja & 43 & 27 & 38 & 0.1 & 0.1 & 0.04 & 22 & 18 & 17 \\
\hline Caña de arúcar otro uso & 17 & 5 & 37 & 0.0 & 0.0 & 0.04 & 30 & 25 & 18 \\
\hline Chayote & 13 & 6 & 34 & 0.0 & 0.0 & 0.03 & 33 & 24 & 19 \\
\hline Árbol de navidad (planta) & 12 & 0 & 32 & 0.0 & 0.0 & 0.03 & 35 & 42 & 20 \\
\hline Resto & 1,218 & 137 & 187 & 2.2 & 0.3 & 0.18 & $\cdots$ & $\cdots$ & $\cdots$ \\
\hline
\end{tabular}

Fuente: elaboración propia con información del SIAP- SAGARPA.

Previo a la firma del TLCAN, para mejorar los ingresos de los campesinos se recomendó el dedicarse a cultivos alternativos, como los representados por perennes con mercados potenciales tanto nacionales como internacionales. La contradicción en el Estado de México respecto a tal consideración se da porque el promedio anual de superficie cosechada de 1980 a 1990 fue de casi 55 mil hectáreas y se duplicó para el periodo 2000 a 2010 al pasar a 105 mil hectáreas. No obstante, el único cultivo que presentó aumentos significativos fueron los pastos, dejando el resto de perennes sin movimientos relevantes.

Aunque el área de tuna se encuentra lejos de la cubierta por los pastos, también es cierto que la superficie cubierta por este segundo cultivo deja muy abajo al resto de plantaciones y le permite quedar en el séptimo lugar por el 
valor agrícola aportado en la entidad, lo cual deja de manifiesto, nuevamente, que la variedad de perennes no es de lo más aceptable.

\section{Gráfica 4.12 Superficie promedio anual cosechada de 2000 a 2010 (\%), ciclo perennes de temporal}

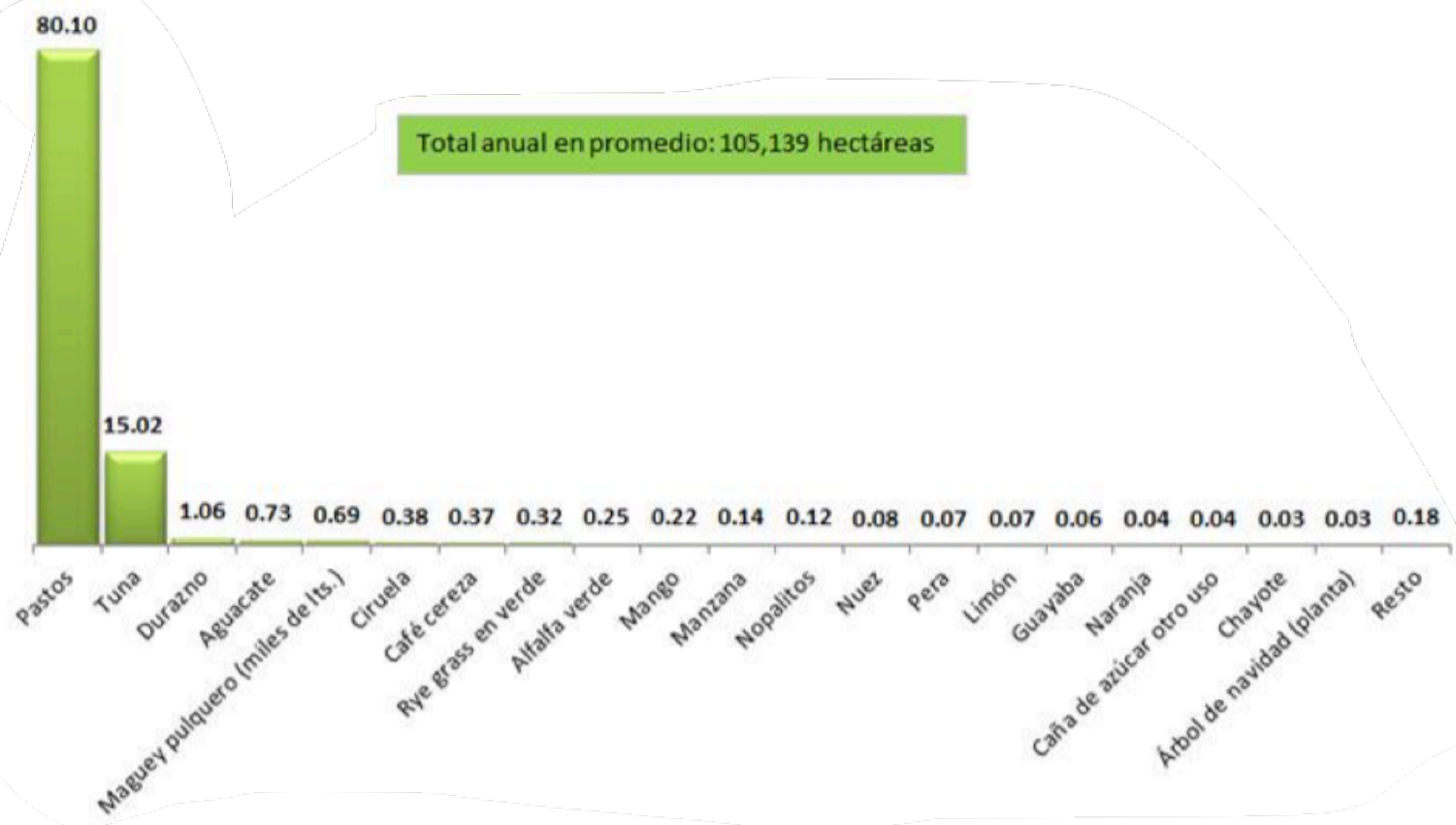

Fuente: elaboración propia con información del SIAP- SAGARPA.

La superficie cosechada de perennes bajo la modalidad de riego permite observar la caída de la misma al pasar del periodo 1980-1990 a 2000-2010, pues el promedio anual de hectáreas bajo tal modalidad pasó de casi 27 mil en el primer lapso de tiempo a 20 mil 873 en el segundo. Se supone que los perennes podrían ser una alternativa viable para competir con mayor eficacia en el mercado del TLCAN y es bien sabido que el uso de riego es parte de las estrategias para mejorar los rendimientos. Sin embargo, la especialización estatal continúa con los mismos productos, pero con menos superficies, salvo algunos cultivos que aumentan sus hectáreas cosechadas, pero sin superar el promedio anual de mil hectáreas, como es el caso durazno, aguacate y guayaba. 
Cuadro 4.15 Superficie cosechada (has), ciclo perennes de riego

\begin{tabular}{|c|c|c|c|c|c|c|c|c|c|}
\hline \multirow[b]{2}{*}{ Cultivo } & \multicolumn{3}{|c|}{ Promedios anuales } & \multicolumn{3}{|c|}{ Promedios anuales $(\%)$} & \multicolumn{3}{|c|}{ Lugar } \\
\hline & $1980-1990$ & $1990-2000$ & $2000-2010$ & $1980-1990$ & $1990-2000$ & $2000-2010$ & $1980-1990$ & $1990-2000$ & $2000-2010$ \\
\hline Total & 26,916 & $5 \quad 20,927$ & 20,873 & 100.0 & $0 \quad 100.0$ & 100.0 & & & \\
\hline A lfalfaverde & 14,467 & 13,690 & 10,727 & 53.75 & 65.42 & 51.39 & 1 & 1 & 1 \\
\hline Pastos & 2,810 & 3,305 & 2,628 & 10.44 & 15.79 & 12.59 & 2 & 2 & 2 \\
\hline Durazno & 1,269 & 668 & 2,065 & 4.72 & 3.19 & 9.89 & 4 & 4 & 4 \\
\hline Aguacate & 1,863 & 1,269 & 1,145 & 6.92 & 6.07 & 5.49 & 3 & 3 & 3 \\
\hline Guayaba & 331 & 312 & 741 & 1.23 & 1.49 & 3.55 & 9 & 6 & 6 \\
\hline Rye grass en verde & 0 & 0 & 711 & 0.00 & 0.00 & 3.40 & 49 & 50 & 0 \\
\hline Clavel (gruesa) & 0 & 132 & 647 & 0.00 & 0.63 & 3.10 & 43 & 11 & 1 \\
\hline Nopalitos & 5 & 78 & 536 & 0.02 & 0.37 & 2.57 & 36 & 13 & 3 \\
\hline Caña de arúcar otro uso & 6 & 134 & 323 & 0.02 & 0.64 & 1.55 & 34 & 10 & 0 \\
\hline Mango & 208 & 318 & 318 & 0.77 & 1.52 & 1.52 & 18 & & 10 \\
\hline Fresa & 0 & 83 & 205 & 0.00 & 0.40 & 0.98 & 45 & 12 & 11 \\
\hline Manzana & 442 & 206 & 96 & 1.64 & 0.98 & 0.46 & 8 & & 12 \\
\hline Limón & 904 & 172 & 89 & 3.36 & 0.82 & 0.43 & 5 & & 13 \\
\hline Ave del paráso (gruesa) & 0 & 15 & 74 & 0.00 & 0.07 & 0.35 & 40 & 24 & 14 \\
\hline Cáé cereza & 123 & 21 & 62 & 0.46 & 0.10 & 0.30 & 25 & 20 & 15 \\
\hline Nardo (gruesa) & 0 & 0 & 53 & 0.00 & 0.00 & 0.25 & 46 & 48 & 16 \\
\hline Dólar (manojo) & 0 & 0 & 52 & 0.00 & 0.00 & 0.25 & 44 & 47 & 17 \\
\hline Zarzamora & 0 & 26 & 39 & 0.00 & 0.12 & 0.19 & 50 & 19 & 18 \\
\hline Mamey & 273 & 31 & 39 & 1.01 & 0.15 & 0.18 & 14 & 17 & 19 \\
\hline Lima & 168 & 48 & 35 & 0.63 & 0.23 & 0.17 & 21 & 15 & 20 \\
\hline Resto & 4,047 & 419 & 290 & 15.04 & 2.00 & 1.39 & $\ldots . .$. & $\ldots$. & $\ldots$. \\
\hline
\end{tabular}

Fuente: elaboración propia con información del SIAP- SAGARPA.

Gráfica 4.13 Superficie promedio anual cosechada de 2000 a 2010 (\%), ciclo perennes de riego

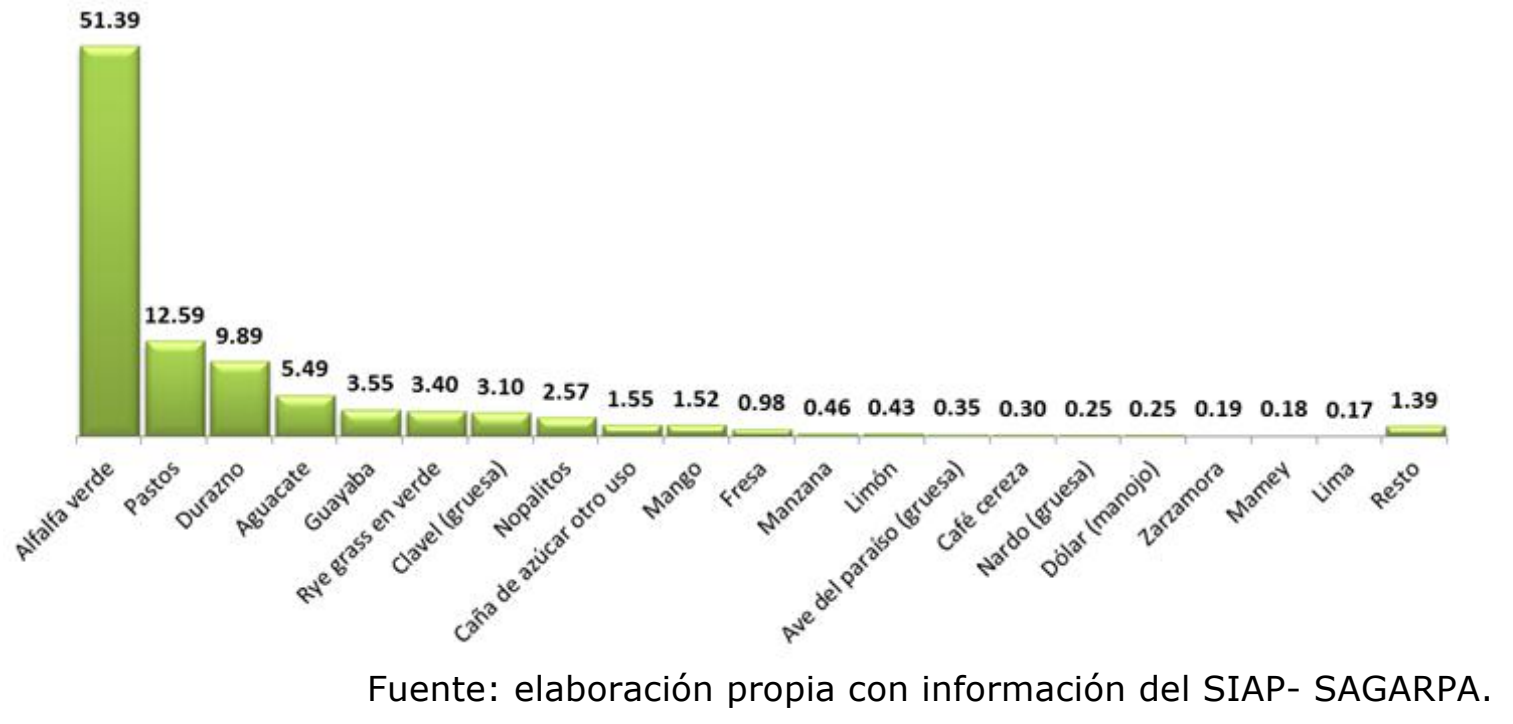




\section{b) Volúmenes cosechados}

Ya se aludió a lo preocupante que resulta observar disminuciones en la superficie cosechada de perennes, a pesar de haber sido considerados en el preámbulo del TLCAN como cultivos alternativos de alto potencial. El reflejo en los volúmenes cosechados no es muy alentador y sólo es salvado, en cierta medida, por los mayores rendimientos, de modo que al pasar de los años 1980-1990 a 2000-2010 se incrementan los agregados de volúmenes de todos los perennes, del ciclo y modalidad aludidos, en $17.3 \%$.

Cuadro 4.16 Volumen de producción (ton), ciclo perennes de riego

\begin{tabular}{|c|c|c|c|c|c|c|c|c|c|}
\hline \multirow[b]{2}{*}{ Cultivo } & \multicolumn{3}{|c|}{\begin{tabular}{|l|} 
Promedios anuales \\
\end{tabular}} & \multicolumn{3}{|c|}{ Prome dios anuales $(\%)$} & \multicolumn{3}{|c|}{ Lugar } \\
\hline & $1980-1990$ & $1990-2000$ & $2000-2010$ & $1980-1990$ & $1990-2000$ & $2000-2010$ & $1980-1990$ & $1990-2000$ & $2000-2010$ \\
\hline Total & $1,193,014$ & $1,072,106$ & $1,398,967$ & 100.0 & 100.0 & 100.0 & & & \\
\hline Alfalfa verde & $1,102,548$ & $1,019,158$ & 842,331 & 92.42 & 95.06 & 60.21 & 1 & 1 & 1 \\
\hline Noche buena (planta) & 0 & 0 & 383,010 & 0.00 & 0.00 & 27.38 & 41 & 43 & 2 \\
\hline Nopalitos & 98 & 2,633 & 54,382 & 0.01 & 0.25 & 3.89 & 32 & 8 & 3 \\
\hline Rye grass en verde & 0 & 0 & 34,843 & 0.00 & 0.00 & 2.49 & 43 & 44 & 4 \\
\hline Cấa de azúcar otro uso & 213 & 7,560 & 25,705 & 0.02 & 0.71 & 1.84 & 28 & 4 & 5 \\
\hline Durazno & 9,874 & 6,182 & 24,787 & 0.83 & 0.58 & 1.77 & 4 & 5 & 6 \\
\hline Aguacate & 17,575 & 9,857 & 12,085 & 1.47 & 0.92 & 0.86 & 2 & 3 & 7 \\
\hline Guayaba & 2,683 & 2,772 & 9,262 & 0.22 & 0.26 & 0.66 & 12 & 7 & 8 \\
\hline Fresa & 0 & 1,384 & 4,447 & 0.00 & 0.13 & 0.32 & 40 & 11 & 9 \\
\hline Mango & 1,723 & 3,162 & 2,730 & 0.14 & 0.29 & 0.20 & 15 & 6 & 10 \\
\hline Limōn & 5,020 & 1,525 & 942 & 0.42 & 0.14 & 0.07 & 6 & 10 & 11 \\
\hline Manzana & 3,628 & 1,582 & 873 & 0.30 & 0.15 & 0.06 & 10 & 9 & 12 \\
\hline Papaya & 1,560 & 425 & 408 & 0.13 & 0.04 & 0.03 & 16 & 13 & 13 \\
\hline Mamey & 2,388 & 314 & 405 & 0.20 & 0.03 & 0.03 & 13 & 14 & 14 \\
\hline Tuna & 5,820 & 75 & 397 & 0.49 & 0.01 & 0.03 & 5 & 23 & 15 \\
\hline Pera & 1,374 & 776 & 375 & 0.12 & 0.07 & 0.03 & 17 & 12 & 16 \\
\hline Zarzamora & 0 & 169 & 317 & 0.00 & 0.02 & 0.02 & 44 & 18 & 17 \\
\hline Plátano & 1,240 & 131 & 242 & 0.10 & 0.01 & 0.02 & 19 & 19 & 18 \\
\hline Lima & 1,094 & 263 & 216 & 0.09 & 0.02 & 0.02 & 20 & 15 & 19 \\
\hline Frambuesa & 2 & 98 & 200 & 0.00 & 0.01 & 0.01 & 36 & 20 & 20 \\
\hline Resto & 36,173 & 14,043 & 1,010 & 3.03 & 1.31 & 0.07 & -... & -.. & $\ldots$ \\
\hline
\end{tabular}

Fuente: elaboración propia con información del SIAP- SAGARPA.

Los volúmenes cosechados de plantaciones perennes con riego son una muestra más de las posibilidades de diversificación, pues resulta interesante resaltar el hecho de que a pesar de la importancia de la alfalfa verde como principal cultivo, también se ha dado el cambio a siembras de Noche Buena, 
nopalitos, rye grass y hasta caña de azúcar. Tan solo la Noche Buena, como planta, pasó de ocupar, en promedio, el lugar 43 durante los años 1980 a 2000 al lugar número 2 para el periodo 2000-2010. Lo importante es tener la seguridad del potencial productivo de la tierra, así como la seguridad de colocación del producto en los mercados.

\section{Gráfica 4.14 Volumen de producción promedio anual de 2000 a 2010 (\%), ciclo perennes de riego}

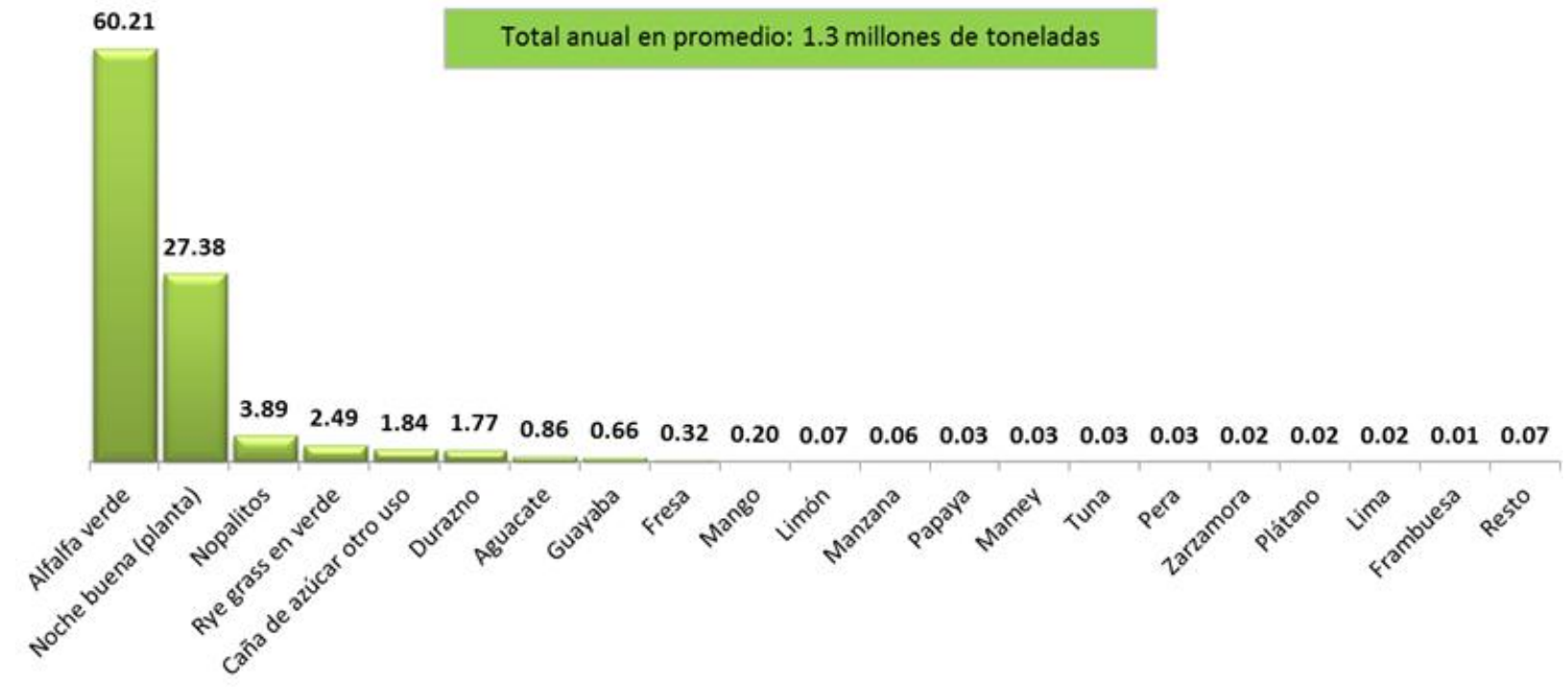

Fuente: elaboración propia con información del SIAP- SAGARPA.

Las características propias de los perennes los hacen más resistentes a las inclemencias del tiempo, sin que ello signifique que su aportación en volumen se compare con la lograda con sistemas de riego, lo cual se nota al observar que a pesar de la caída en los volúmenes logrados con sistemas de irrigación, la participación de lo obtenido en temporal durante el lapso de 2000-2010 representa el $15 \%$ de lo logrado con las mayores ventajas tecnológicas de aprovechamiento del agua. 


\section{Cuadro 4.17 Volumen de producción (ton), ciclo perennes de temporal}

\begin{tabular}{|c|c|c|c|c|c|c|c|c|c|}
\hline \multirow[b]{2}{*}{ Cultivo } & \multicolumn{3}{|c|}{ Promedios anuales } & \multicolumn{3}{|c|}{ Promedios anuales $(\%)$} & \multicolumn{3}{|c|}{ Lugar } \\
\hline & $1980-1990$ & $1990-2000$ & $2000-2010$ & $1980-1990$ & $1990-2000$ & $2000-2010$ & $1980-1990$ & $1990-2000$ & $2000-2010$ \\
\hline Total & 132,432 & $\quad 131,111$ & 214,745 & 100.0 & 100.0 & 100.0 & & & \\
\hline Tuna & 40,042 & 98,101 & 161,416 & 30.2 & 74.8 & 75.17 & 1 & 1 & 1 \\
\hline Alfalfaverde & 39,878 & 8,568 & 12,776 & 30.1 & 6.5 & 5.95 & 2 & 3 & 2 \\
\hline Rye grass en verde & 0 & 0 & 9,720 & 0.0 & 0.0 & 4.53 & 37 & 42 & 3 \\
\hline Durazno & 10,588 & 9,031 & 8,182 & 8.0 & 6.9 & 3.81 & 4 & 2 & 4 \\
\hline Aguacate & 6,911 & 5,656 & 5,851 & 5.2 & 4.3 & 2.72 & 5 & 4 & 5 \\
\hline Nopalitos & 145 & 1,242 & 3,566 & 0.1 & 0.9 & 1.66 & 29 & 7 & 6 \\
\hline Ciruela & 809 & 1,077 & 2,883 & 0.6 & 0.8 & 1.34 & 15 & 8 & 7 \\
\hline Mango & 1,486 & 1,999 & 2,079 & 1.1 & 1.5 & 0.97 & 9 & 5 & 8 \\
\hline Cáé cereza & 101 & 221 & 1,475 & 0.1 & 0.2 & 0.69 & 31 & 13 & 9 \\
\hline Caña de arúcar otro uso & 179 & 136 & 1,117 & 0.1 & 0.1 & 0.52 & 27 & 17 & 10 \\
\hline Manzana & 1,673 & 1,939 & 942 & 1.3 & 1.5 & 0.44 & 8 & 6 & 11 \\
\hline Agave & 0 & 0 & 822 & 0.0 & 0.0 & 0.38 & 38 & 43 & 12 \\
\hline Chayote & 0 & 100 & 639 & 0.0 & 0.1 & 0.30 & 39 & 20 & 13 \\
\hline Pera & 238 & 655 & 465 & 0.2 & 0.5 & 0.22 & 25 & 10 & 14 \\
\hline Guayaba & 884 & 169 & 433 & 0.7 & 0.1 & 0.20 & 14 & 16 & 15 \\
\hline Limón & 1,337 & 350 & 410 & 1.0 & 0.3 & 0.19 & 10 & 11 & 16 \\
\hline Nuez & 722 & 789 & 361 & 0.5 & 0.6 & 0.17 & 16 & 9 & 17 \\
\hline Plááano & 299 & 123 & 324 & 0.2 & 0.1 & 0.15 & 22 & 19 & 18 \\
\hline Papaya & 93 & 207 & 323 & 0.1 & 0.2 & 0.15 & 32 & 14 & 19 \\
\hline Naranja & 956 & 200 & 263 & 0.7 & 0.2 & 0.1 & 13 & 15 & 20 \\
\hline Resto & 26,091 & 549 & 697 & 19.7 & 0.4 & 0.3 & .... & $\ldots$ & .... \\
\hline
\end{tabular}

Fuente: elaboración propia con información del SIAP- SAGARPA.

Resulta interesante la participación de la tuna como el cultivo que más volumen aporta, desde 1980, en el total de cultivos perennes generados bajo temporal, cuya participación lejos de disminuir ha aumentado. Esto no debe de restarle importancia a la consideración de perennes alternativos, como la alfalfa verde, rye grass, durazno, aguacate y nopalitos, sólo por mencionar los más relevantes. 


\section{Gráfica 4.14 Volumen de producción promedio anual de 2000 a 2010 (\%), ciclo perennes de temporal}

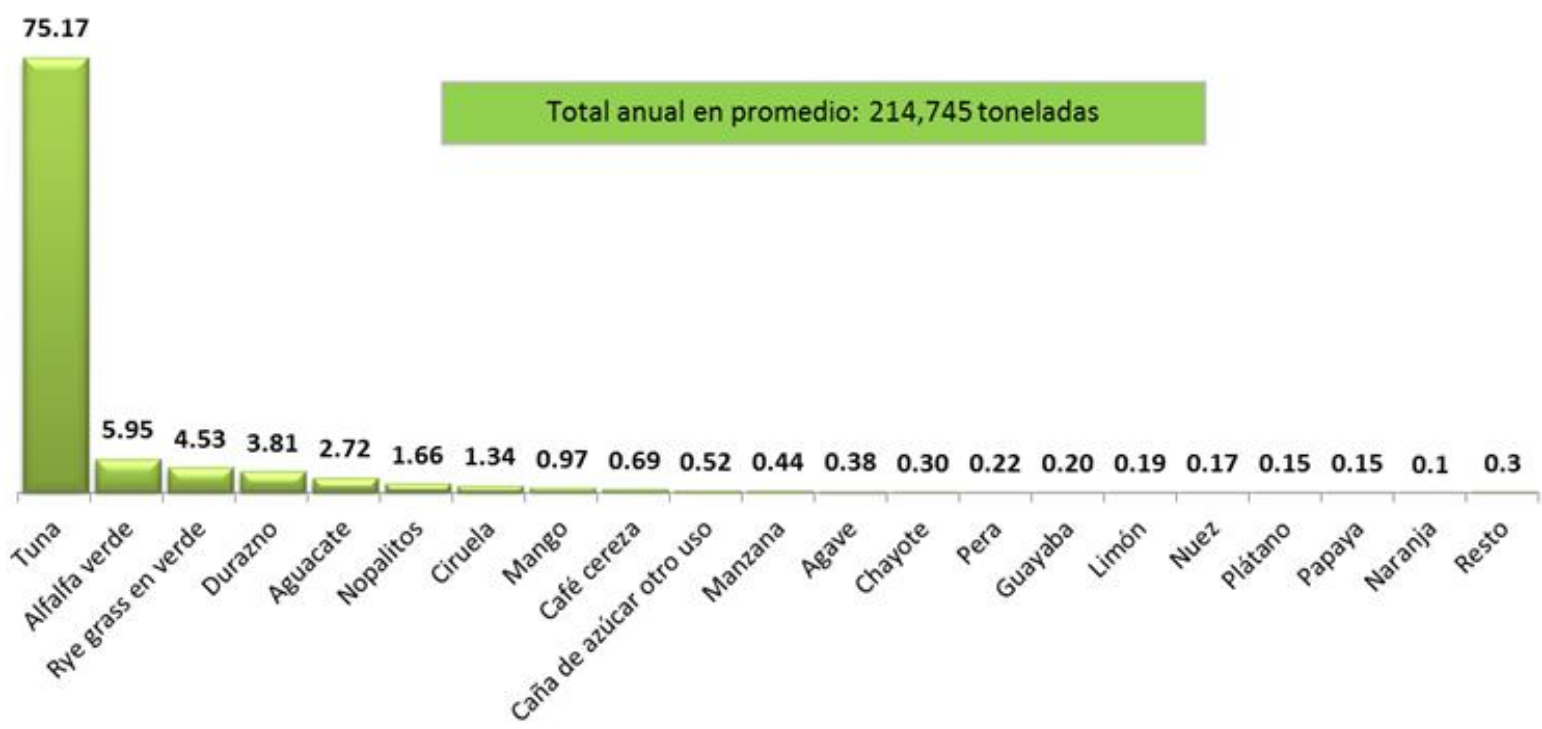

Fuente: elaboración propia con información del SIAP- SAGARPA.

b) Rendimientos

Los rendimientos en los perennes de riego son una muestra más de la búsqueda de plantaciones alternativas por parte de los campesinos del Estado de México. El cultivo de flores se manifiesta como una constante en casi todas las modalidades de producción y observa cada vez comportamientos más estables. 


\section{Cuadro 4.18 Rendimientos (tons/has), ciclo perennes de riego (var \%)}

\begin{tabular}{|c|c|c|c|c|}
\hline Cultivo & $\begin{array}{r}(1990-2000) / \\
(1980-1990)\end{array}$ & $\begin{array}{c}(2000-2010) / \\
(1990-2000)\end{array}$ & $\begin{array}{r}(2000-2010) / \\
(1980-1990)\end{array}$ & Frecuencia de siembra \\
\hline Agapando (gruesa) & $x$ & 270.6 & $x$ & Recurrente a partir de 1992 \\
\hline Nopalitos & 87.4 & 176.6 & 418.3 & Recurrente a partir de 1992 \\
\hline Gerbera (gruesa) & $x$ & 124.7 & $x$ & Recurrente a partir de 1992 \\
\hline Frambuesa & 80.9 & 78.2 & 222.3 & Recurrente a partir de 1992 \\
\hline Plátano & -14.6 & 71.1 & 46.2 & Recurrente a partir de 1992 \\
\hline Caña de azúcar otro uso & 69.2 & 67.4 & 183.3 & Recurrente a partir de 1992 \\
\hline Zarzamora & $x$ & 55.5 & $x$ & Recurrente a partir de 1992 \\
\hline Rosa (gruesa) & 135.3 & 54.8 & 264.3 & No recurrente \\
\hline Guayaba & 10.7 & 45.8 & 61.4 & Recurrente \\
\hline Pera & 25.0 & 40.8 & 76.1 & Recurrente \\
\hline Aguacate & -13.5 & 35.3 & 17.1 & Recurrente \\
\hline Rosa (planta) & $6,012.8$ & 35.0 & $8,152.6$ & No recurrente \\
\hline Begonia (planta) & $x$ & 34.4 & $x$ & Recurrente a partir de 1996 \\
\hline Durazno & 27.5 & 33.2 & 69.8 & Recurrente \\
\hline Fresa & $x$ & 32.0 & $x$ & No recurrente \\
\hline Nispero & -29.1 & 24.9 & -11.4 & Recurrente a partir de 1997 \\
\hline Calancoe (planta) & $x$ & 24.1 & $x$ & Recurrente a partir de 1997 \\
\hline Tuna & -15.3 & 19.1 & 1.0 & Recurrente a partir de 2000 \\
\hline Café cereza & -7.7 & 18.8 & 9.6 & Recurrente \\
\hline Cyclamen (planta) & $x$ & 17.6 & $x$ & Recurrente a partir de 1997 \\
\hline Petunia (planta) & $x$ & 17.5 & $x$ & Recurrente a partir de 1997 \\
\hline Ciruela & 56.7 & 16.6 & 82.8 & Recurrente \\
\hline Manzana & 7.3 & 15.6 & 24.0 & Recurrente \\
\hline Granada & -17.5 & 11.6 & -7.9 & Recurrente \\
\hline Lima & -19.5 & 10.7 & -10.9 & Recurrente \\
\hline Limón & 54.1 & 9.6 & 69.0 & Recurrente \\
\hline Alfalfa verde & -2.0 & 6.5 & 4.4 & Recurrente \\
\hline Papaya & -14.4 & 6.2 & -9.1 & Recurrente \\
\hline Mamey & -6.1 & 5.6 & -0.8 & Recurrente \\
\hline Cineraria (planta) & $x$ & 4.0 & $x$ & Recurrente a partir de 1997 \\
\hline Piña & $\infty$ & 1.8 & $x$ & Recurrente a partir de 1996 \\
\hline Alstroemeria (gruesa) & $x$ & $x$ & $x$ & Recurrente a partir de 2002 \\
\hline Aretillo (planta) & $x$ & $x$ & $x$ & Recurrente a partir de 2005 \\
\hline Aster (manojo) & $x$ & $x$ & $x$ & Recurrente a partir de 2005 \\
\hline Belén (planta) & $x$ & $x$ & $x$ & Recurrente a partir de 2005 \\
\hline Blueberry & $x$ & $><$ & $x$ & No recurrente \\
\hline Caña de azúcar & 7.4 & $><$ & $x$ & No recurrente \\
\hline Crisantemo (planta) & $x$ & $x$ & $x$ & Recurrente a partir de 2005 \\
\hline Doblar (manojo) & $x$ & $x$ & $x$ & Recurrente a partir de 2001 \\
\hline Flores (planta) & $x$ & $x$ & $x$ & No recurrente \\
\hline Hortensia (planta) & $x$ & $>$ & $x$ & Recurrente a partir de 2005 \\
\hline Nardo (gruesa) & $x$ & $><$ & $x$ & Recurrente a partir de 2001 \\
\hline Noche buena (planta) & $x$ & $x$ & $x$ & Recurrente a partir de 2001 \\
\hline Pensamiento (planta) & $x$ & $x$ & $x$ & Recurrente a partir de 2005 \\
\hline Rosa de invernadero (grue & $x$ & $x$ & $x$ & Recurrente a partir de 2004 \\
\hline Rosa de invernadero (plan) & $x$ & $x$ & $x$ & Recurrente a partir de 2005 \\
\hline Zapote & $x$ & $x$ & 4.1 & Recurrente a partir de $\mathbf{2 0 0 2}$ \\
\hline Zempoalxochitl (planta) & $x$ & $x$ & $x$ & Recurrente a partir de 2005 \\
\hline Geranio (planta) & $x$ & -2.0 & $x$ & Recurrente a partir de 1999 \\
\hline Naranja & -11.1 & -10.7 & -20.6 & Recurrente \\
\hline Ave del paraiso (gruesa) & $x$ & -11.3 & $x$ & Recurrente a partir de 1996 \\
\hline Mango & 20.1 & -13.1 & 4.4 & Recurrente \\
\hline Pastos & 8.1 & -27.0 & -21.1 & Recurrente \\
\hline Alcachofa & $x$ & -29.3 & $x$ & Recurrente a partir de 1996 \\
\hline Clavel (gruesa) & $x$ & -32.0 & $x$ & Recurrente a partir de 1999 \\
\hline Doblar (gruesa) & $><$ & -52.5 & $x$ & No recurrente \\
\hline
\end{tabular}

Fuente: SIAP-SAGARPA. 
El mantener cultivos ya tradicionales en la producción de perennes deja ver el conocimiento de los agricultores en aquellas variedades que les generan mejores beneficios, lo cual se nota en el cuadro que sigue y que permite identificar siembras recurrentes en la mayoría de los productos.

\section{Cuadro 4.19 Rendimientos (tons/has), ciclo perennes de temporal (var \%)}

\begin{tabular}{|c|c|c|c|c|}
\hline Cultivo & $\begin{array}{c}(1990-2000) / \\
(1980-1990)\end{array}$ & $\begin{array}{c}(2000-2010) / \\
(1990-2000)\end{array}$ & $\begin{array}{c}(2000-2010) / \\
(1980-1990)\end{array}$ & Frecuencia de siembra \\
\hline Tamarindo & 10.6 & 204.5 & 236.9 & Recurrentes desde 1992 \\
\hline Café cereza & -53.0 & 167.1 & 25.4 & Recurrente \\
\hline Plátano & 2.0 & 165.3 & 170.6 & Recurrente \\
\hline Frambuesa & $x$ & 75.8 & $x$ & Recurrente desde 1996 \\
\hline Guayaba & -24.3 & 58.2 & 19.7 & Recurrente \\
\hline Tejocote & -35.1 & 50.1 & -2.5 & Recurrente desde 1991 \\
\hline Ciruela & 60.7 & 49.7 & 140.5 & Recurrente \\
\hline Nopalitos & 3.6 & 42.7 & 47.8 & Recurrente \\
\hline Granada & -23.3 & 29.4 & -0.8 & Recurrente desde 1994 \\
\hline Pastos & -45.4 & 28.5 & -29.9 & Recurrente \\
\hline Durazno & -11.2 & 26.2 & 12.2 & Recurrente \\
\hline Nispero & -26.8 & 24.0 & -9.2 & No recurrente \\
\hline Tuna & 2.0 & 17.2 & 19.6 & Recurrente \\
\hline Capulin & 32.3 & 17.2 & 55.0 & Recurrentes desde 1992 \\
\hline Chayote & $x$ & 14.8 & $x$ & No recurrente \\
\hline Alcachofa & $x$ & 12.9 & $x$ & No recurrente \\
\hline Aguacate & -11.2 & 12.1 & -0.5 & Recurrente \\
\hline Lima & -4.4 & 11.3 & 6.5 & No recurrente \\
\hline Limón & -2.5 & 10.2 & 7.5 & Recurrente \\
\hline Pera & -7.3 & 3.2 & -4.3 & Recurrente \\
\hline Manzana & -18.3 & 2.2 & -16.5 & Recurrente \\
\hline Mango & 29.5 & 1.9 & 31.9 & Recurrente \\
\hline Caña de azúcar otro uso & 24.2 & 0.2 & 24.4 & No recurrente \\
\hline Alfalfa verde & -6.3 & 0.0 & -6.2 & Recurrente \\
\hline Naranja & -38.0 & -5.9 & -41.7 & Recurrente \\
\hline Nuez & 12.8 & -10.0 & 1.5 & Recurrente \\
\hline Zarzamora & $x$ & -12.0 & $x$ & No recurrente \\
\hline Membrillo & -26.0 & -13.1 & -35.6 & Recurrente \\
\hline Papaya & 29.0 & -17.3 & 6.8 & No recurrente \\
\hline Mamey & 26.6 & -47.3 & -33.3 & Recurrente \\
\hline Maguey pulquero (miles di & -56.3 & -52.5 & -79.2 & Recurrente \\
\hline Piña & $x$ & -73.3 & $x$ & No recurrente \\
\hline
\end{tabular}

Fuente: SIAP-SAGARPA. 
4.3. Principales cultivos comercializados por el Estado de México con el resto del mundo

A partir de información preliminar proporcionada por el SAT al SIAPSAGARPA, fue posible efectuar una aproximación del comercio exterior agropecuario y pesquero realizado por entidad federativa en México en el año 2011, registrados en los capítulos uno al catorce catalogados de acuerdo con la clasificación de la Tarifa de los Impuestos Generales de Importación y de Exportación (TIGIE). Así, la siguiente tabla permite observar que el Estado de México es uno de los que más importan productos agropecuarios y pesqueros; en 2011 ocupó el cuarto lugar nacional por el valor de compras realizadas al exterior, las cuales fueron por más de 17 mil millones de pesos, en cambio, sus exportaciones se colocaron en el lugar 16 con 2 mil millones de pesos. En el año referido el Estado de México ocupó la tercera posición en cuanto al dato negativo de su saldo comercial, el cual fue de 15 mil millones de pesos.

El desglose del comercio exterior sólo con los productos agrícolas del Estado de México permite observar, en el tabulado siguiente, que la participación de las importaciones agrícolas en el total de productos agropecuarios y pesqueros comprados al exterior por tal entidad es del $66 \%$, lo que refleja la necesidad de motivar más la producción agrícola en el estado.

La mayor participación de las importaciones del capítulo 12 "Semillas y frutos oleaginosos; semillas y frutos diversos; plantas industriales 0 medicinales; paja y forrajes" que representaron el $45 \%$ del valor de compras agrícolas, es muestra de la poca vocación de los productores mexiquenses respecto a tales cultivos y obliga a investigar la relación beneficio-costo sobre todo para oleaginosas, pues su siembra es prácticamente nula en la demarcación estatal. Como ya se ha indicado, la motivación hacia cultivos forrajeros es importante debido a la mayor demanda del subsector pecuario. La baja participación de las exportaciones $(0.5 \%)$ de tal capítulo refuerza lo señalado. 


\section{Cuadro 4.20 Comercio exterior de productos agropecuarios y pequeros por entidad federativa al 2011}

\begin{tabular}{|c|c|c|c|c|c|c|c|c|c|}
\hline \multirow{2}{*}{\multicolumn{2}{|c|}{ Entidad federativa }} & \multicolumn{3}{|c|}{$\begin{array}{l}\text { Exportaciones } \\
\text { (millones de pesos) }\end{array}$} & \multicolumn{3}{|c|}{$\begin{array}{l}\text { Importaciones } \\
\text { (millones de pesos) }\end{array}$} & \multicolumn{2}{|c|}{$\begin{array}{c}\text { Saldo comercial }^{3} \\
\text { (millones de pesos) }\end{array}$} \\
\hline & & Absoluto & $\%$ & Lugar & Absoluto & $\%$ & Lugar & Absoluto & Lugar \\
\hline 00 & Estados Unidos Mexicanos & 123,026 & 100.0 & & 210,669 & 100.0 & & $-87,643$ & \\
\hline 01 & Aguascalientes & 1,253 & 1.0 & $18^{\circ}$ & 1,215 & 0.6 & $17^{\circ}$ & 38 & $20^{\circ}$ \\
\hline 02 & Baja California & 11,063 & 9.0 & $5^{\circ}$ & 7,379 & 3.5 & $10^{\circ}$ & 3,683 & $30^{\circ}$ \\
\hline 03 & Baja California Sur & 2,076 & 1.7 & $15^{\circ}$ & 367 & 0.2 & $24^{\circ}$ & 1,709 & $29^{\circ}$ \\
\hline 04 & Campeche & 240 & 0.2 & $27^{\circ}$ & 89 & 0.0 & $29^{\circ}$ & 151 & $23^{\circ}$ \\
\hline 07 & Chiapas & 2,198 & 1.8 & $14^{\circ}$ & 635 & 0.3 & $21^{\circ}$ & 1,564 & $28^{\circ}$ \\
\hline 08 & Chihuahua & 5,039 & 4.1 & $8^{\circ}$ & 7,597 & 3.6 & $9^{\circ}$ & $-2,558$ & $9^{\circ}$ \\
\hline 05 & Coahuila de Zaragoza & 1,270 & 1.0 & $17^{\circ}$ & 2,110 & 1.0 & $16^{\circ}$ & -840 & $12^{\circ}$ \\
\hline 06 & Colima & 1,001 & 0.8 & $20^{\circ}$ & 156 & 0.1 & $26^{\circ}$ & 846 & $27^{\circ}$ \\
\hline 09 & Distrito Federal & 7,899 & 6.4 & $6^{\circ}$ & 60,786 & 28.9 & $1^{\circ}$ & $-52,887$ & $1^{\circ}$ \\
\hline 10 & Durango & 1,149 & 0.9 & $19^{\circ}$ & 7,851 & 3.7 & $8^{\circ}$ & $-6,702$ & $6^{\circ}$ \\
\hline 11 & Guanajuato & 7,517 & 6.1 & $7^{\circ}$ & 8,180 & 3.9 & $7^{\circ}$ & -663 & $13^{\circ}$ \\
\hline 12 & Guerrero & 25 & 0.0 & $31^{\circ}$ & 1 & 0.0 & $32^{\circ}$ & 24 & $18^{\circ}$ \\
\hline 13 & Hidalgo & 34 & 0.0 & $30^{\circ}$ & 14 & 0.0 & $30^{\circ}$ & 20 & $17^{\circ}$ \\
\hline 14 & Jalisco & 11,440 & 9.3 & $4^{\circ}$ & 25,111 & 11.9 & $3^{\circ}$ & $-13,670$ & $4^{\circ}$ \\
\hline 15 & México & 2,074 & 1.7 & $16^{\circ}$ & 17,079 & 8.1 & $4^{\circ}$ & $-15,005$ & $3^{\circ}$ \\
\hline 16 & Michoacán de Ocampo & 17,227 & 14.0 & $1^{\circ}$ & 678 & 0.3 & $20^{\circ}$ & 16,549 & $33^{\circ}$ \\
\hline 17 & Morelos & 443 & 0.4 & $24^{\circ}$ & 415 & 0.2 & $23^{\circ}$ & 28 & $19^{\circ}$ \\
\hline 18 & Nayarit & 346 & 0.3 & $25^{\circ}$ & 7 & 0.0 & $31^{\circ}$ & 340 & $25^{\circ}$ \\
\hline 19 & Nuevo León & 3,068 & 2.5 & $12^{\circ}$ & 25,716 & 12.2 & $2^{\circ}$ & $-22,649$ & $2^{\circ}$ \\
\hline 20 & Oaxaca & 284 & 0.2 & $26^{\circ}$ & 193 & 0.1 & $25^{\circ}$ & 91 & $21^{\circ}$ \\
\hline 21 & Puebla & 2,272 & 1.8 & $13^{\circ}$ & 3,755 & 1.8 & $14^{\circ}$ & $-1,483$ & $10^{\circ}$ \\
\hline 22 & Querétaro Arteaga & 522 & 0.4 & $23^{\circ}$ & 8,351 & 4.0 & $6^{\circ}$ & $-7,829$ & $5^{\circ}$ \\
\hline 23 & Quintana Roo & 226 & 0.2 & $28^{\circ}$ & 755 & 0.4 & $19^{\circ}$ & -528 & $14^{\circ}$ \\
\hline 24 & San Luis Potosi & 927 & 0.8 & $21^{\circ}$ & 597 & 0.3 & $22^{\circ}$ & 330 & $24^{\circ}$ \\
\hline 25 & Sinaloa & 15,652 & 12.7 & $2^{\circ}$ & 6,827 & 3.2 & $12^{\circ}$ & 8,825 & $31^{\circ}$ \\
\hline 26 & Sonora & 14,528 & 11.8 & $3^{\circ}$ & 2,592 & 1.2 & $15^{\circ}$ & 11,936 & $32^{\circ}$ \\
\hline 27 & Tabasco & 225 & 0.2 & $29^{\circ}$ & 110 & 0.1 & $28^{\circ}$ & 115 & $22^{\circ}$ \\
\hline 28 & Tamaulipas & 3,248 & 2.6 & $11^{\circ}$ & 8,674 & 4.1 & $5^{\circ}$ & $-5,426$ & $7^{\circ}$ \\
\hline 29 & Tlaxcala & 0 & 0.0 & $32^{\circ}$ & 126 & 0.1 & $27^{\circ}$ & -126 & $16^{\circ}$ \\
\hline 30 & Veracruz de Ignacio de La Llave & 4,689 & 3.8 & $9^{\circ}$ & 5,553 & 2.6 & $13^{\circ}$ & -864 & $11^{\circ}$ \\
\hline 31 & Yucatán & 3,841 & 3.1 & $10^{\circ}$ & 6,861 & 3.3 & $11^{\circ}$ & $-3,020$ & $8^{\circ}$ \\
\hline \multirow{2}{*}{32} & Zacatecas & 733 & 0.6 & $22^{\circ}$ & 884 & 0.4 & $18^{\circ}$ & -151 & $15^{\circ}$ \\
\hline & Mo especificado & 517 & 0.4 & & 6 & 0.0 & & 511 & $26^{\circ}$ \\
\hline
\end{tabular}

Fuente: SIAP.

La importación de cereales ocupa el segundo lugar por capítulo de productos adquiridos en el extranjero para la entidad mexiquense. A pesar de que el maíz grano es representativo en la producción, con el primer lugar por la generación de valor aportado en el periodo 2000-2010, y se cultiva en prácticamente todos los municipios de la entidad, los volúmenes de producción 
de cereales aun son insuficientes, a pesar de que la cebada y el trigo grano se encuentran entre los 30 cultivos con mayor aportación de valor; las compras de cereales significaron el pago al extranjero de casi cuatro mil 500 millones de pesos en 2011.

\section{Cuadro 4.21 Comercio exterior agrícola del Estado de México al 2011 (mdp)}

\begin{tabular}{|c|c|c|c|c|c|}
\hline Capitulo & Descripción & Importaciones & Exportaciones & Importaciones (\%) & Exportaciones (\%) \\
\hline Total & Comercio exterior, capitulos 6 a 14 & 11,344 & 1,503 & 100.00 & 100.00 \\
\hline 12 & $\begin{array}{l}\text { Semillas y frutos oleaginosos; semillas y frutos diversos; } \\
\text { plantas industriales o medicinales; paja y forrajes. }\end{array}$ & 5,071 & 8 & 44.70 & 0.53 \\
\hline 10 & Cereales. & 4,445 & 18 & 39.18 & 1.18 \\
\hline 8 & $\begin{array}{l}\text { Frutas y frutos comestibles; cortezas de agrios (citricos), } \\
\text { melones o sandias. }\end{array}$ & 706 & 36 & 6.23 & 2.39 \\
\hline 6 & Plantas vivas y productos de floricultura. & 343 & 162 & 3.02 & 10.79 \\
\hline 13 & Gomas, resinas y demás jugos y extractos vegetales. & 280 & 6 & 2.47 & 0.43 \\
\hline 7 & Hortalizas, plantas, raices y tubérculos alimenticios. & 220 & 875 & 1.94 & 58.20 \\
\hline 11 & $\begin{array}{l}\text { Productos de la molineria; malta; almidón y fécula; inulina; } \\
\text { gluten de trigo. }\end{array}$ & 184 & 340 & 1.62 & 22.61 \\
\hline 9 & Café, té, yerba mate y especias. & 92 & 42 & 0.81 & 2.77 \\
\hline 14 & $\begin{array}{l}\text { Materias trenzables y demás productos de origen vegetal, } \\
\text { no expresados ni comprendidos en otra parte. }\end{array}$ & 3 & 17 & 0.03 & 1.11 \\
\hline
\end{tabular}

Fuente: SIAP.

Las exportaciones del capítulo 7 "Hortalizas, plantas, raíces y tubérculos alimenticios" son las que favorecen en mayor manera al estado, pero sólo representan el $17 \%$ de las importaciones relacionadas con el capítulo 12 . Es necesario impulsar más la producción de hortalizas con miras a cubrir más el mercado nacional e internacional.

Los bienes del capítulo 11 "Productos de la molinería; malta; almidón y fécula; inulina; y gluten de trigo" son una muestra de que el generar valor agregado permite abrir nuevos nichos de mercado, ya que la demarcación del Estado de México no se caracteriza por una autosuficiencia en la producción de cereales, lo cual se demuestra con las altas importaciones de los mismos; sin embargo, las exportaciones del capítulo 11 dejan ver la potencialidad de los bienes transformados. 
En suma, los objetivos del campo mexiquense respecto al comercio exterior deben estar enfocados a aumentar la producción a niveles que permitan llegar a cubrir los montos de importaciones con exportaciones. 


\section{CAPITULO 5}

\section{VALOR DE LA PRODUCCIÓN AGRÍCOLA DEL ESTADO DE MÉXICO}

En el capítulo segundo se aludió a los factores que, de manera general, impactan a los precios agrícolas en el contexto de una economía de libre comercio. Las particularidades que pueden tomar los precios a nivel estatal o de localidad, se asocian en muy buena medida con los mismos factores que influyen a nivel del país, aunque tendrán variantes en función de las estructuras de mercado que operen. Por tanto, es importante tener presentes aspectos como:

1. Los niveles de oferta, demanda y usos de los cultivos.

2. Las condiciones de la tierra y los niveles tecnológicos empleados.

3. Las estructuras de mercado prevalecientes, no sólo a nivel de los productores, sino también de los distribuidores, transformadores y comercializadores a todos sus niveles.

4. La forma de organización de los productores.

Dentro de las economías globalizadas actuales la demanda de cultivos no tiene límites y está determinada principalmente por:

1. Los crecimientos poblaciones.

2. Las nuevas necesidades de la población vinculadas a gustos, cambios en las dietas $y$, por lo mismo, a diversificaciones constantes, lo que incide en los diferentes usos y destinos de tales insumos.

3. Nivel de ingresos de los consumidores.

En consecuencia, los estudios sobre la demanda de cultivos deben de enfocarse, más que a tratar de motivar la demanda de los consumidores, a ubicar a los consumidores y a definir las estrategias para movilizar tales bienes del campo, sin olvidar que se está en un mundo de libre competencia.

Por el lado de la oferta, se tiene una relación estrecha con las condiciones de la tierra y los niveles tecnológicos empleados. Los siguientes apartados dentro de este capítulo se enfocan a relacionar la actividad agrícola de los 
municipios del Estado de México en cada uno de sus ciclos y modalidades productivas, lo que permitirá entender la capacidad productiva de la entidad, los retos que enfrenta en tal sentido y las posibilidades reales de mejora. Desafortunadamente los registros estadísticos de la SAGARPA no cuentan con el desglose por municipio para años anteriores a 2003, situación que obligó a que el análisis con tal nivel de detalles se enfocara para años posteriores a éste.

\subsection{Valor de producción por municipio}

Iniciar el análisis municipal con el valor de la producción agrícola en el Estado de México permite enfocar los comentarios posteriores, sobre todo, en los municipios y cultivos que más aportan a la entidad, sin que ello signifique olvidarse del resto de espacios geográficos con potencial, sino más bien dar elementos que permitan ubicar zonas con potencial de ser replicado. Así, vale la pena señalar que el valor de los cultivos cíclicos de O-I aumentó de manera significativa de 2003 a 2010, a pesar de representar la menor participación al comparar con los cultivos de PV y perennes, como puede observarse en la siguiente tabla.

Tabla 5.1 Valor de producción (mdp) de los ciclos productivos en el Estado de México

\begin{tabular}{lrrrrrrrrr}
\hline & 2003 & 2004 & 2005 & 2006 & 2007 & 2008 & 2009 & 2010 & $2010 / 2003(\%)$ \\
\hline Ciclo & 9,733 & 9,832 & 10,233 & 12,256 & 15,501 & 15,520 & 13,730 & 14,527 & 49.3 \\
Otoño-invierno & 448 & 559 & 612 & 762 & 914 & 777 & 897 & 904 & 101.9 \\
primavera-verano & 6,087 & 5,941 & 5,922 & 7,660 & 10,185 & 10,363 & 8,703 & 9,277 & 52.4 \\
$\begin{array}{l}\text { Perennes } \\
\text { Estructura porcentual }\end{array}$ & 3,199 & 3,333 & 3,699 & 3,834 & 4,402 & 4,379 & 4,130 & 4,347 & 35.9 \\
$\begin{array}{l}\text { Otoño-invierno } \\
\text { primavera-verano }\end{array}$ & & & & & & & & & \\
Perennes & 4.60 & 5.68 & 5.98 & 6.22 & 5.90 & 5.01 & 6.53 & 6.22 & $\ldots$ \\
& 32.84 & 60.42 & 57.87 & 62.50 & 65.70 & 66.77 & 63.39 & 63.86 & $\ldots$ \\
\hline
\end{tabular}

Fuente: elaboración propia con información del SIAP- SAGARPA. 
En los apartados referentes a las superficies sembradas se ha descrito la prevalencia de las áreas dedicadas al cultivo de maíz grano que, en la superficie promedio anual de $\mathrm{P}-\mathrm{V}$ tanto de temporal como de riego se ha ubicado en primer lugar del estado, con casi la mitad de la superficie sembrada, mientras que en O-I no cuenta con una participación relevante. A pesar de cubrir tales superficies, es importante indicar que las mismas se han reducido en el Estado de México, pues de 2000 a 2010 el promedio anual de temporal fue de 296 mil 228 hectáreas sembradas versus 586 mil 783 de los años 1980 a 1990; en el P-V de riego también ha bajado el área plantada de maíz, ya que de 1980 a 1990 se tuvieron casi 119 mil hectáreas plantadas y de 2000 a 2010 se redujeron a poco más de 99 mil. A pesar del cambio a cultivos alternativos en la producción de maíz, lo cierto es que dicho grano tiene la aportación más destacada en el valor de producción de toda la entidad, de 2003 a 2010 aportó en promedio tres mil 964 millones de pesos por año, lo cual significa la tercera parte (31\%) de todos los ingresos agrícolas del estado.

En tierras mexiquenses la producción de flores en conjunto representa un mercado competitivo contra la producción de maíz, con el detalle de que la siembra del grano se da comúnmente en P-V de temporal. La floricultura, en cambio, se ha enfocado al cultivo de riego en ambos ciclos productivos, lo cual es una muestra de que los agricultores de la entidad están dispuestos a invertir en infraestructura, como la de invernaderos, la cual les permita recuperar sus montos de inversión con márgenes aceptables de ganancias. 


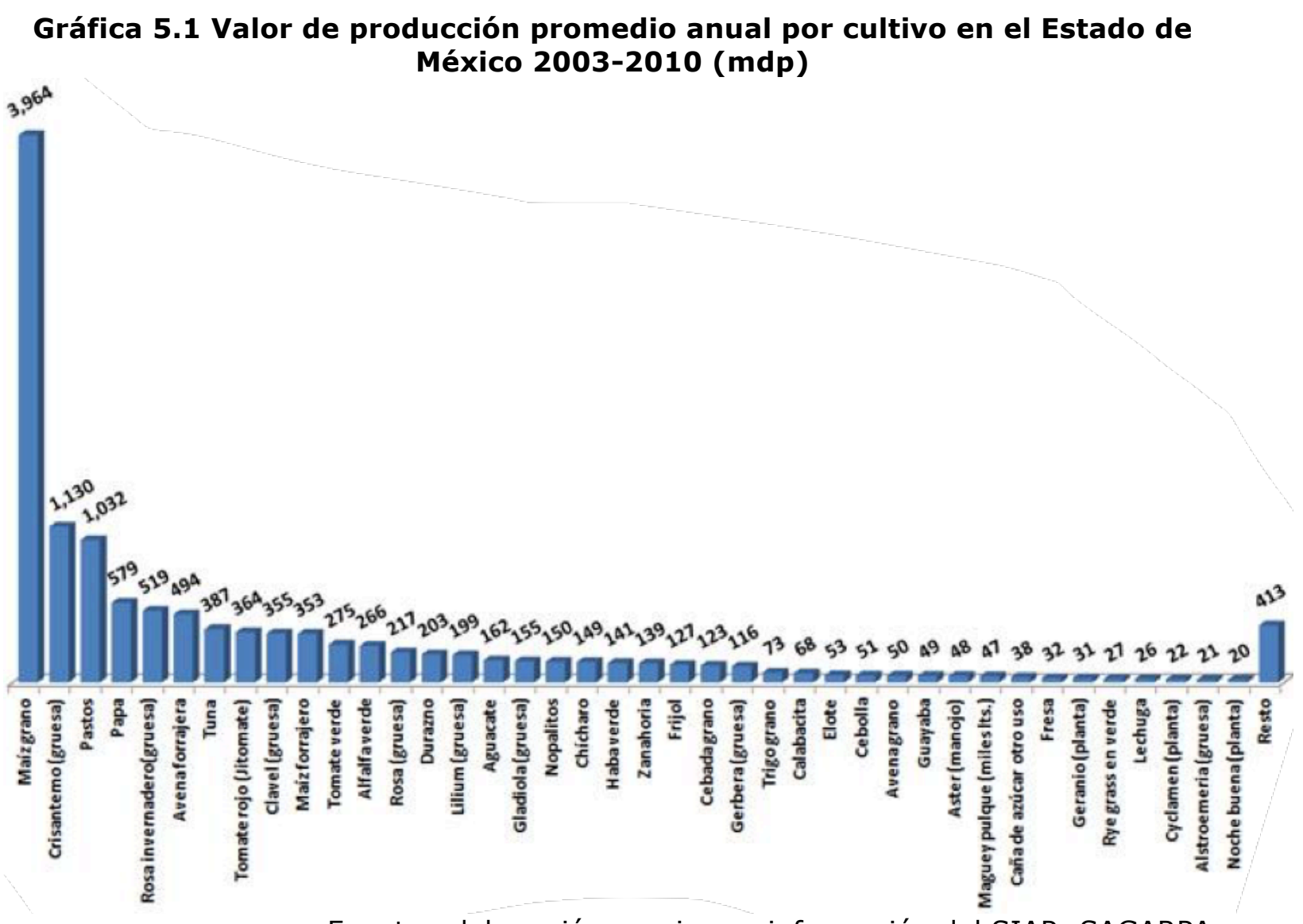

Fuente: elaboración propia con información del SIAP- SAGARPA.

Para los años de 2003 a 2010 se contabilizaron en la entidad 123 municipios con producción agrícola, pero tan sólo 15 de ellos aportaron el 50\% del valor de la producción promedio anual en el periodo aludido. 
La siguiente gráfica permite comprobar lo anterior, además permite observar que el $50 \%$ restante del valor de producción se reparte de manera gradual en las demás zonas municipales, de tal modo que la columna que representa tres mil 45 millones de pesos para el resto de municipios considera 35 de tales delimitaciones, las cuales aportan el $24 \%$ del valor de producción de la entidad. Así, se tiene una muestra más de la falta de homogeneidad productiva en la entidad.

\section{Gráfica 5.2 Valor de producción promedio anual por municipio en el Estado de México 2003-2010 (mdp)}

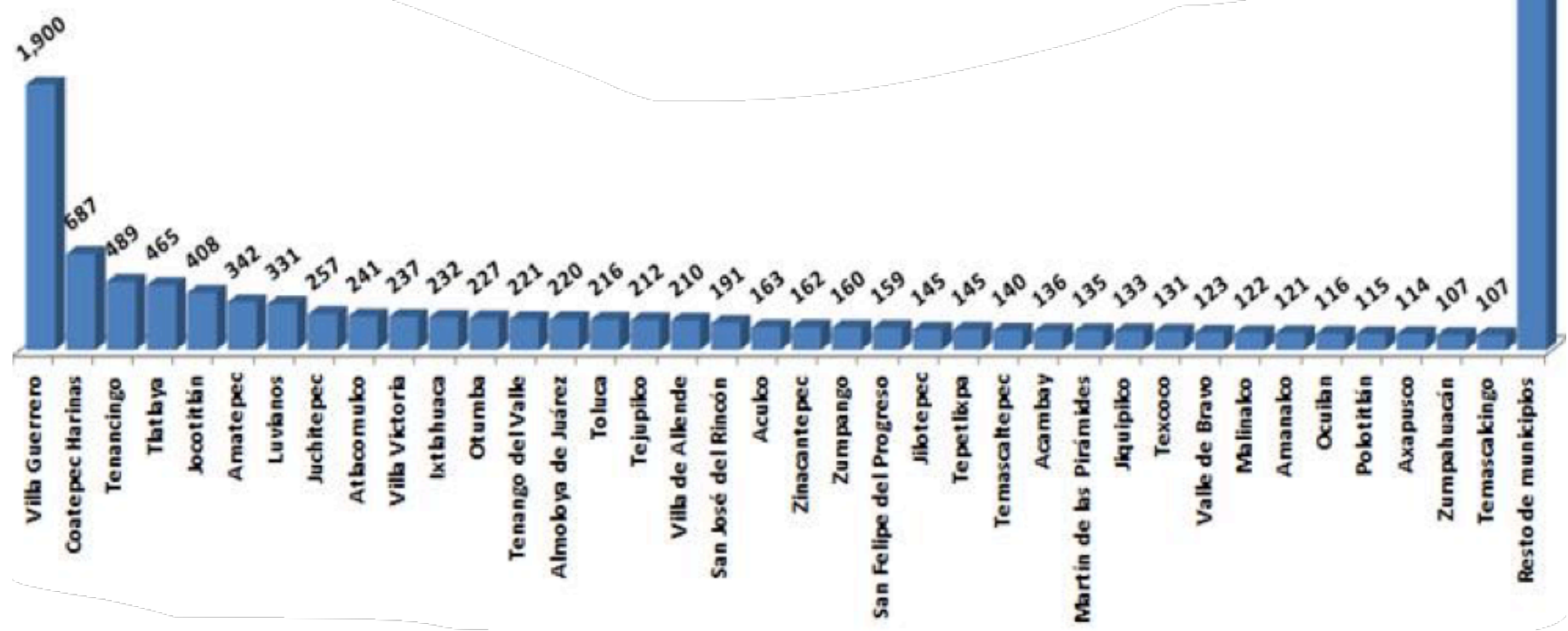

Fuente: elaboración propia con información del SIAP- SAGARPA. 
El siguiente mapa es una referencia excelente para dimensionar el potencial estatal actual en unos cuantos municipios, pues el área de oportunidad está en mejorar sus niveles de producción, rendimientos y, en consecuencia, sus ingresos.

\section{Gráfico 5.3 Participación porcentual por municipio en el valor total de la producción del Estado de México 2003-2010 (mdp)}

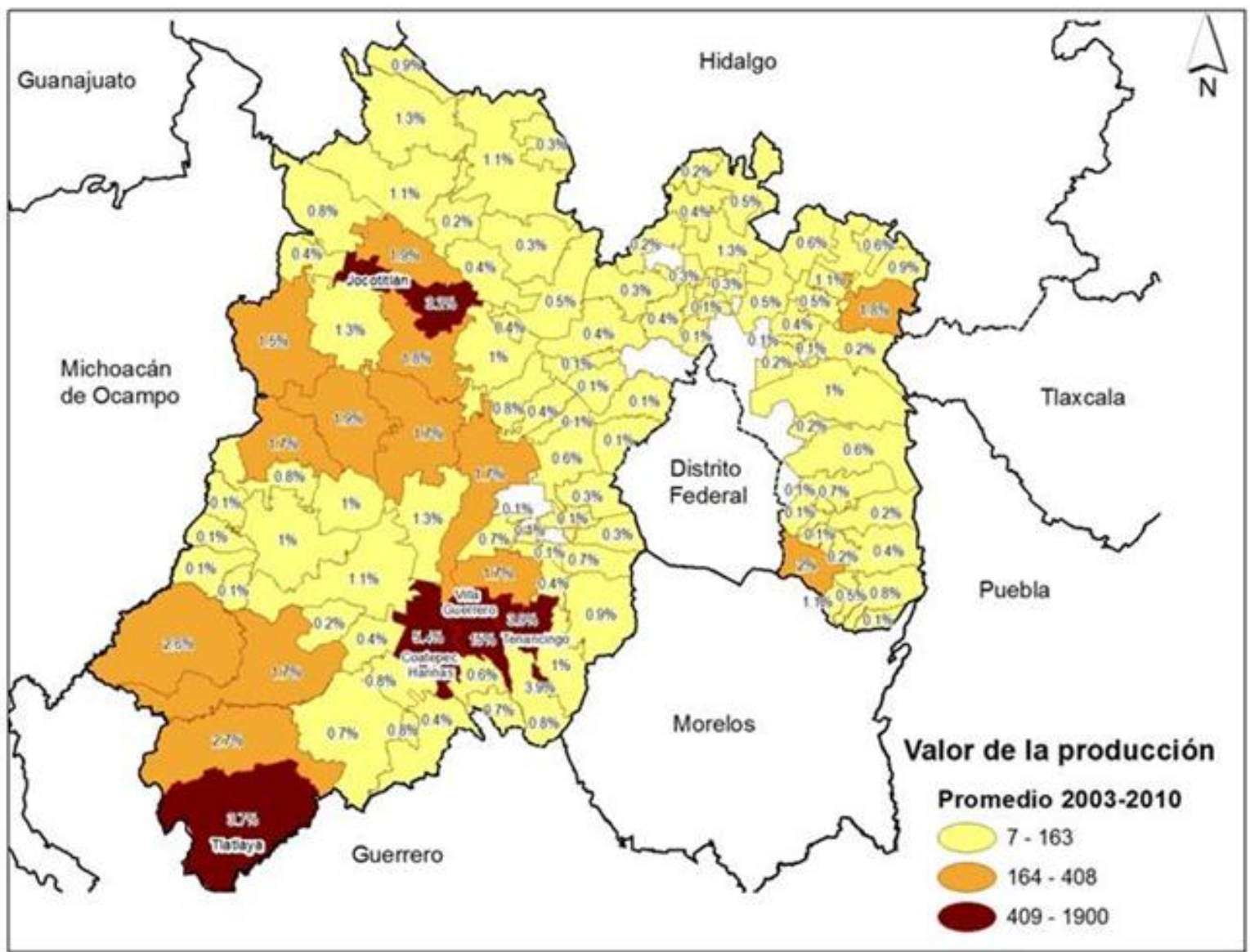

Fuente: elaboración propia con datos del SIAP-SAGARPA.

Vale la pena la identificación del valor de producción de los principales cultivos en aquellos municipios que se distinguen por su vocación agrícola en el estado más poblado del país. En la gráfica anterior se tiene que, sin lugar a dudas, el municipio de Villa Guerrero es el más destacado, genera el 15\% de los ingresos agrícolas. Tan sólo la producción de crisantemo aportó, en el 
promedio anual de 2003 a 2010, casi la mitad (46\%) de todos los recursos monetarios agrícolas de tal demarcación geográfica. Las ocho principales plantaciones, con mayor valor, son flores y dan lugar al $96 \%$ de todo el ingreso agrícola del municipio; de 2003 a 2010 aportaron más de mil 800 millones de pesos en promedio anual.

\section{Gráfica 5.4 Promedio anual del valor de producción por cultivo 2003-2010 (mdp) para el municipio de Villa Guerrero}

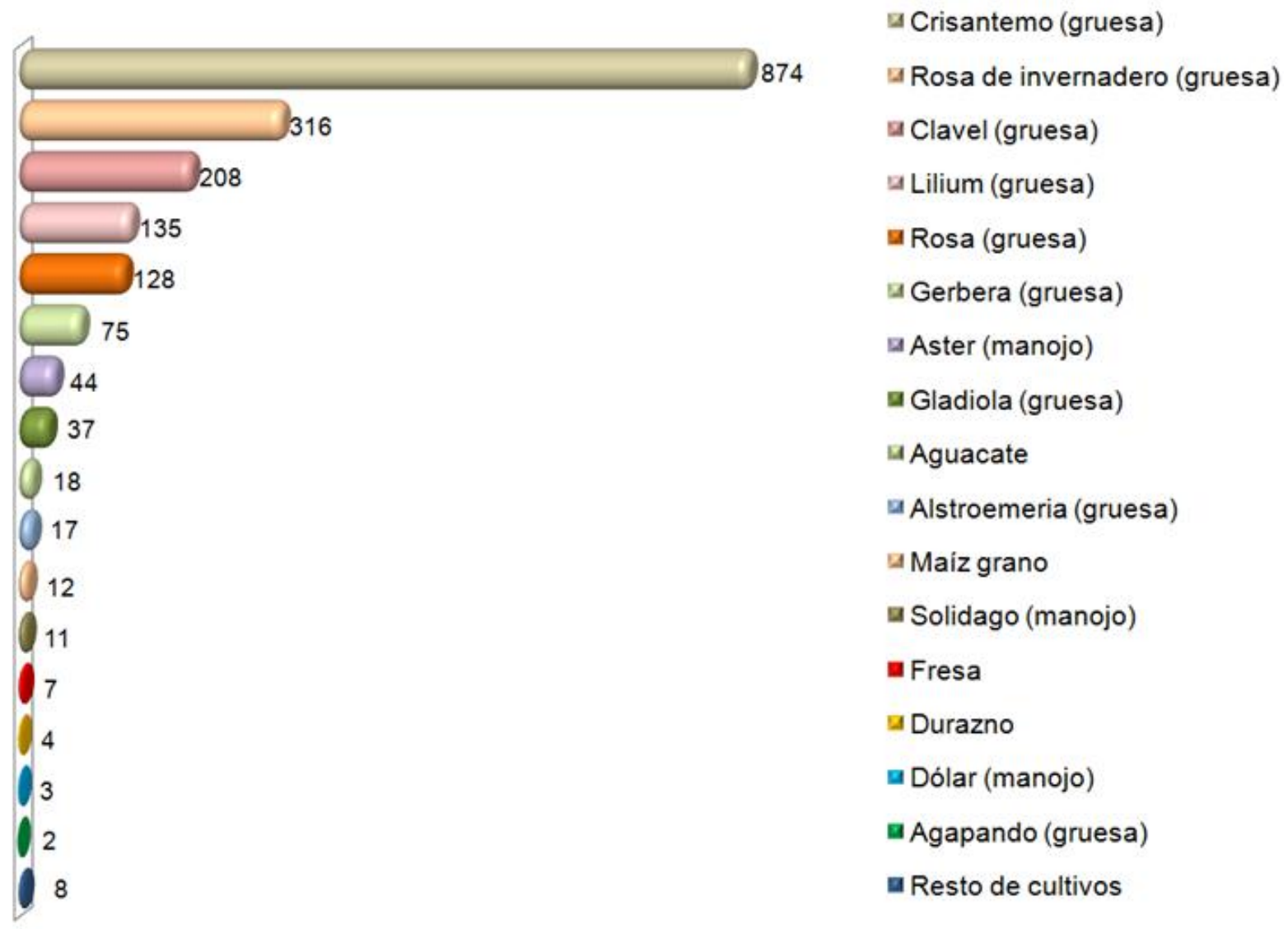

Fuente: elaboración propia con información del SIAP- SAGARPA.

Coatepec Harinas es el municipio que compite más de cerca contra Villa Guerrero en la aportación de valor agrícola al Estado de México, con la diferencia de que este último da el $15 \%$ de tal valor de la entidad $y$, en cambio, Coatepec Harinas aporta el 5.4\%. La producción de durazno le permitió a esta última demarcación obtener 137 millones de pesos en 
promedio anual para los años 2003 a 2010; sus nueve principales cultivos dan lugar al $80 \%$ del valor de producción, con una gama que cubre perennes, flores y granos. La diversidad geográfica de los municipios de la entidad permite aportar diferentes plantaciones que se ofrecen, en buena medida, en las dos demarcaciones federativas más pobladas de todo el país, o sea en la que es objeto de estudio de la presente tesis y en el Distrito Federal.

\section{Gráfica 5.5 Promedio anual del valor de producción por cultivo 2003-2010 (mdp) para el municipio de Coatepec Harinas}
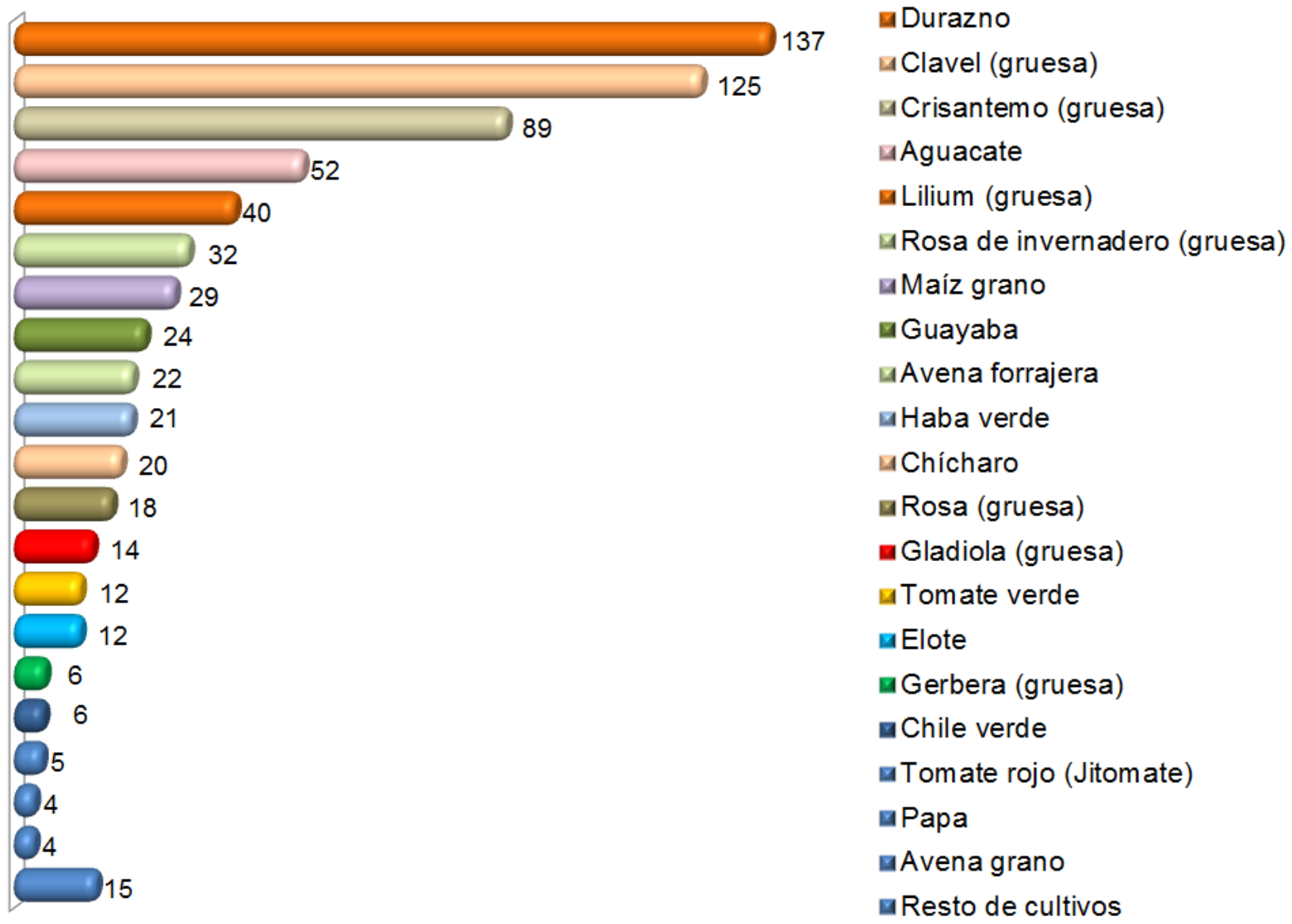

Fuente: elaboración propia con información del SIAP- SAGARPA.

El tercer lugar por el valor de producción agrícola aportado lo ocupa Tenancingo con $4 \%$ del valor generado en todo el estado. Nuevamente la producción de flores se manifiesta como la actividad agrícola preferida y al igual que en el municipio de Villa Guerrero la siembra de crisantemo se 
posiciona en primer lugar. Las cinco flores que tienen el mayor potencial de todos los cultivos aportaron de 2003 a 2010 el $80 \%$ del valor de producción agrícola de Tenancingo, con un promedio anual de 392 millones de pesos. El grano que más compite con las flores es el maíz grano, pero tan sólo la gerbera lo supera con casi $50 \%$ más de valor aportado.

\title{
Gráfica 5.6 Promedio anual del valor de producción por cultivo 2003-2010 (mdp) para el municipio de Tenancingo
}

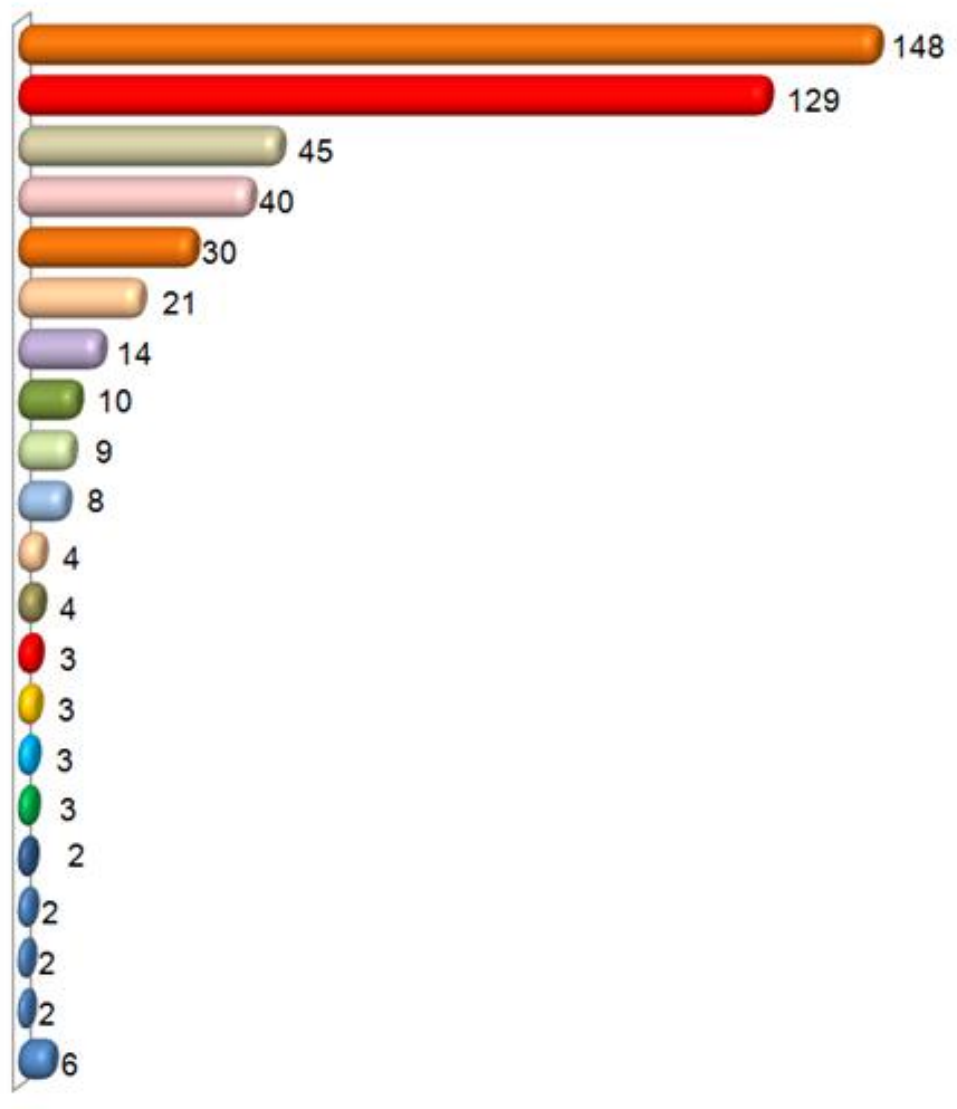

\author{
Crisantemo (gruesa) \\ - Rosa de invernadero (gruesa) \\ a Rosa (gruesa) \\ $\square$ Gladiola (gruesa) \\ a Gerbera (gruesa) \\ Maíz grano \\ Aguacate \\ 日 Lilium (gruesa) \\ Chicharo \\ Solidago (manojo) \\ Maiz forrajero \\ Aster (manojo) \\ avena forrajera \\ $\square$ Tomate verde \\ G Chayote \\ - Clavel (gruesa) \\ - Durazno \\ Calabacita \\ 口Statice (manojo) \\ arijol \\ Resto de cultivos
}

Fuente: elaboración propia con información del SIAP- SAGARPA.

El cuarto lugar en el valor de producción generado lo ocupa el municipio de Jocotitlán, el cual es una clara muestra de que el potencial no se encuentra sólo en la oferta de flores, sino también en el cultivo de jitomate, el cual le permite a este municipio obtener el $62 \%$ de todo su ingreso agrícola junto con la producción de maíz grano, que tiene el segundo lugar, se da lugar a más del $90 \%$ de dicho ingreso. 


\section{Gráfica 5.7 Promedio anual del valor de producción por cultivo 2003-2010 (mdp) para el municipio de Jocotitlán}

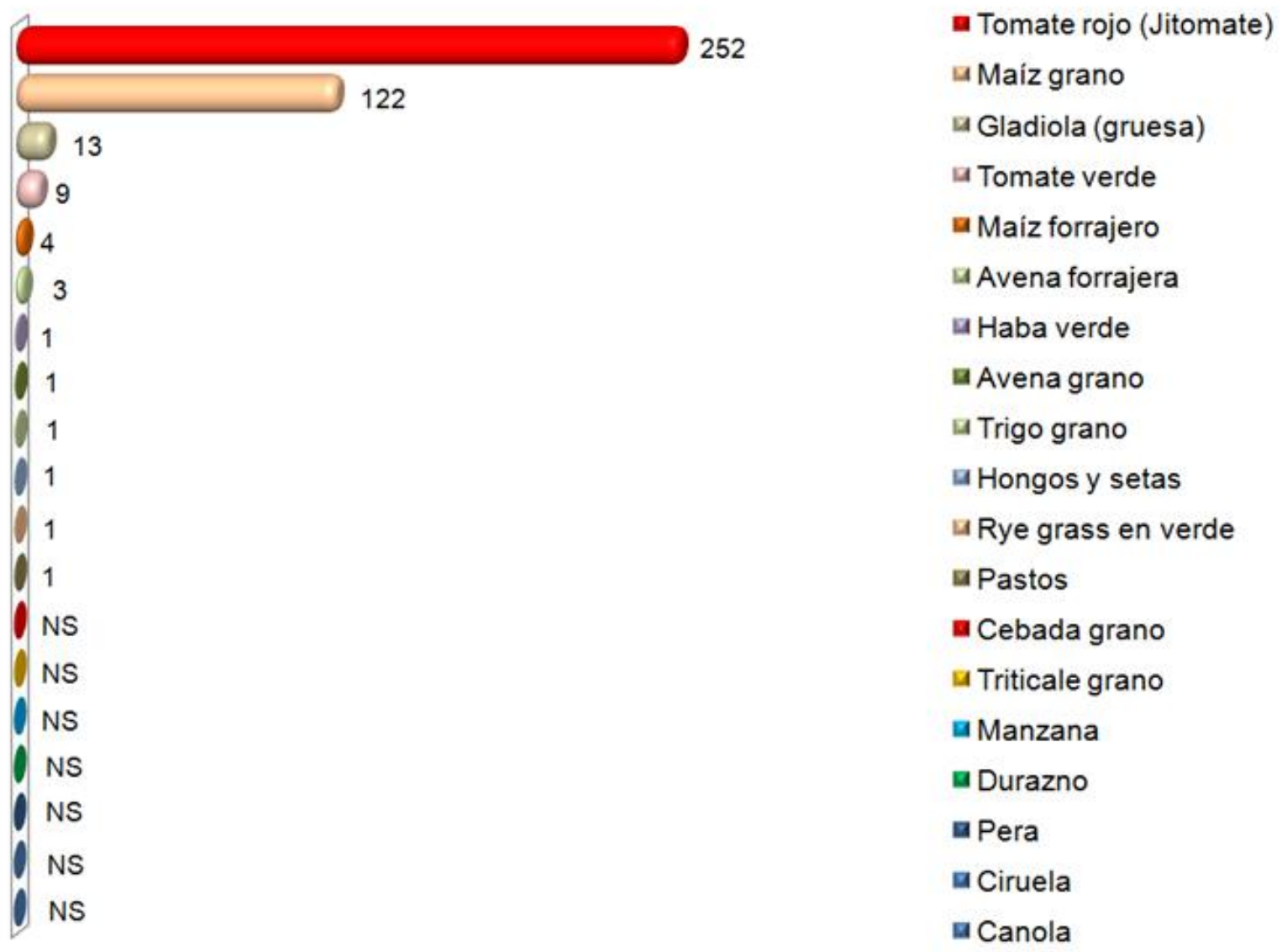

Fuente: elaboración propia con información del SIAP- SAGARPA.

En el quinto sitio por el valor de producción obtenido se encuentra el municipio de Tlatlaya, como muestra de la diversificación de cultivos, en función también de las características propias de algunas zonas. La ventaja competitiva con la oferta de pastos de la zona de Tlatlaya es indiscutible dentro de los límites estatales, casi el $80 \%$ del valor de producción en esta demarcación es aportado con el cultivo de pasturas. El maíz grano sigue a los pastos y junto con estos da lugar a prácticamente el $100 \%$ de las aportaciones agrícolas monetarias. 
Gráfica 5.8 Promedio anual del valor de producción por cultivo 2003-2010 (mdp) para el municipio de Tlatlaya

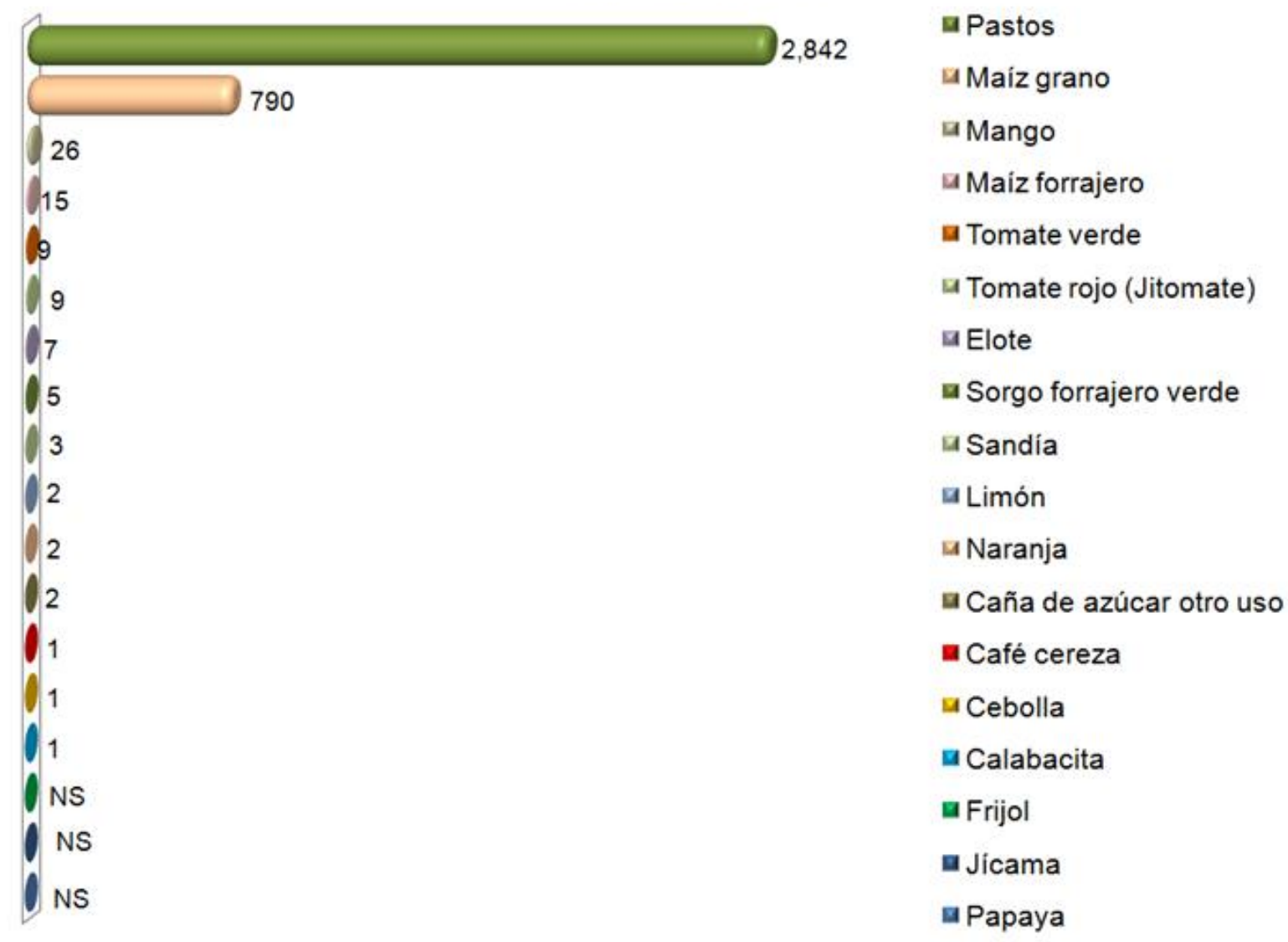

Fuente: elaboración propia con información del SIAP- SAGARPA. 


\subsection{Valor de producción por cultivo}

En apartados anteriores se ha hecho referencia a las superficies sembradas en el Estado de México, con énfasis en los ciclos productivos (O-I, $\mathrm{P}-\mathrm{V}$ y perennes), así como en las modalidades empleadas (riego y temporal), de modo que no es nada nuevo afirmar que las mejores oportunidades de desarrollo en el sector agrícola dependen, en muy buena medida, de las características propias de la tierra, disponibilidad de insumos y uso de innovaciones tecnológicas. En este apartado se relacionan los cultivos que mayor valor agrícola aportan al estado, por municipio, con aquellas variables determinantes en su desarrollo. El énfasis se hará sobre maíz grano, crisantemo, pastos y papa, dado que además de aportar el mayor valor de producción también son representativos de los grupos de cultivos más fuertes en la entidad bajo estudio.

El primer cultivo bajo análisis, debido a que ocupa el primer lugar indiscutible en la aportación del valor del municipio, es el maíz grano. El cultivo aludido registra comúnmente producción en 123 municipios. Resulta interesante observar que el rendimiento promedio de maíz grano en la entidad es de 2.8 toneladas por hectárea, todavía por debajo del promedio nacional que de 2008 a 2010 es de 3.3 toneladas por hectárea. La deducción parece obvia, si el promedio nacional todavía es bajo y tiene posibilidades de incrementarse, entonces los mexiquenses deben de buscar o aprovechar las estrategias que permitan mejorar sus niveles de productividad en la oferta de maíz grano, sin olvidar otras alternativas para aquellas zonas menos aptas.

El cuadro siguiente respalda lo comentado y, además, permite observar que los mayores rendimientos se logran en los municipios que aportan mayor valor de producción, pues el cuadro está ordenado conforme a la mayor aportación de valor de los municipios, con el año 2010 como referencia. No obstante, nótese la existencia de municipios que a pesar de no estar entre los primeros diez con mayor valor de producción, sí son de los que tienen mejores rendimientos. Tal es el caso de Zumpango que cuenta con rendimientos de, al 
menos, cuatro toneladas por hectárea; ello obliga a realizar evaluaciones del potencial productivo y su ampliación, con la adecuada consideración de la frontera agrícola en cada municipio, la resistencia a plagas, enfermedades, efectos del cambio climático, etc.

Tabla 5.2 Principales variables por municipios productores en el Estado de México para maíz grano (2003 y 2010)

\begin{tabular}{|c|c|c|c|c|c|c|c|c|c|c|c|c|}
\hline \multirow[b]{3}{*}{ Munidäpio } & \multicolumn{6}{|c|}{2008} & \multicolumn{6}{|c|}{2010} \\
\hline & \multicolumn{3}{|c|}{ Siniestrede } & \multicolumn{9}{|c|}{ Siniestra da } \\
\hline & $\begin{array}{c}\text { Cosechads } \\
\text { (hes) }\end{array}$ & $\begin{array}{c}\text { /sembreds } \\
{[\%]}\end{array}$ & $\begin{array}{l}\text { Praducción } \\
\text { (tons) }\end{array}$ & $\begin{array}{l}\text { Rdmto. } \\
\text { (ton/ha) }\end{array}$ & Volor (pesos) & $\begin{array}{c}\text { PMR } \\
(5 / \text { ton }) \\
\end{array}$ & $\begin{array}{c}\text { Cosechade } \\
\text { (hes) }\end{array}$ & $\begin{array}{c}\text { Kembreda } \\
|\%|\end{array}$ & $\begin{array}{l}\text { Producoión } \\
\text { (tons) }\end{array}$ & $\begin{array}{l}\text { Rdm to. } \\
\text { [ton/ha] }\end{array}$ & Volor (pesos) & $\begin{array}{c}\text { PMR } \\
\text { [5/ton] }\end{array}$ \\
\hline Totel & 572,864 & 3.14 & $1,923,209$ & 3.4 & $2,979,183,536$ & 1549 & 544,357 & 3.22 & $1,549,545$ & 2.8 & $4,799,117,619$ & 3,097 \\
\hline Almoloya de Juárez & 25,498 & 9.4 & 88,345 & 3.5 & $114,842,747$ & 1,300 & 26,812 & $\cdot$ & 97,697 & 3.6 & $285,019,698$ & 2,917 \\
\hline Ixt ahuaca & 25,088 & 5.1 & 94.515 & 3.8 & $141,772,350$ & 1,500 & 23,641 & - & 73,642 & 3.1 & $265,109,940$ & 3,600 \\
\hline Toluca & 20,226 & 112 & 96,564 & 4.8 & $115,876,692$ & 1,200 & 23,505 & 0.4 & 86,605 & 3.7 & $247,408,410$ & 2,857 \\
\hline San Felipe del Progreso & 22,602 & 2.2 & 59,923 & 2.7 & $89,834,350$ & 1,500 & 23,290 & - & 63,930 & 2.7 & $172,610,450$ & 2,700 \\
\hline Temascaldingo & 13,549 & 18 & 47,562 & 3.5 & $61,830,093$ & 1,300 & 15,200 & - & 59,550 & 3.9 & $166,740,000$ & 2,800 \\
\hline Aambay & 16,762 & 11 & 53,186 & 3.2 & $74,450,372$ & 1,400 & 20,165 & . & 45,119 & 2.3 & $141,270,900$ & 3,063 \\
\hline Villa Victoria & 19,280 & 0.0 & 72,731 & 3.8 & $101,823,470$ & 1,400 & 14,287 & . & 41,543 & 2.9 & $125,673,600$ & $3, Q 25$ \\
\hline Filotepec & 11,484 & - & 49,372 & 4.3 & $74,058,255$ & 1,500 & 13,400 & 0.4 & 34,460 & 2.6 & 124056,000 & 3,600 \\
\hline Aclco & 14,500 & - & 55,259 & 3.8 & $82,832,245$ & 1,500 & 13,646 & 0.7 & 33,709 & 2.5 & 121351,600 & 3,600 \\
\hline Villa de Allende & $17, \infty 00$ & $\cdot$ & 51,274 & 3.0 & $71,783,516$ & 1,400 & 13,200 & $\cdot$ & 39,600 & 3.0 & $118,800,000$ & 3,000 \\
\hline Jocotit in & 17,769 & 2.9 & 65,677 & 3.7 & $96,514,810$ & 1,500 & 17,508 & - & 51,163 & 29 & $117,674,095$ & 2,300 \\
\hline Tenango del Vale & 8,938 & 11.6 & 51.807 & 5.8 & $72,529,394$ & 1,400 & 8,892 & - & 36,635 & 4.1 & $117,232,000$ & 3,200 \\
\hline Atacomulco & 11,418 & 3.2 & 39,749 & 3.5 & $59,623,560$ & 1,500 & 11300 & - & 32,892 & 2.8 & $115,122,000$ & 3,500 \\
\hline Lerm: & 9,448 & 111 & 21,373 & 2.3 & $29,922,116$ & 1,400 & 10,214 & 2.5 & 36,506 & 3.6 & $109,472,100$ & 2,99 \\
\hline Zumpango & 4.771 & $\cdot$ & 22,367 & 4.7 & $40,297,410$ & 1300 & 7,631 & 3.2 & 30,860 & 4.0 & $108,009,965$ & 3,500 \\
\hline Temorya & 11,825 & 7.3 & 52,882 & 4.5 & $74,035,248$ & 1,400 & 10,737 & - & 34,035 & 3.2 & $95,996,840$ & 2,221 \\
\hline That $\mathbf{a} y \mathbf{a}$ & 15,563 & - & 48,651 & 3.1 & $99,267,969$ & 2,040 & 11,976 & - & 23,966 & 2.0 & 91130,368 & 3,798 \\
\hline fiquépilco & 13,856 & 7.2 & 60.232 & 4.3 & $72,278,040$ & 1,200 & 12,511 & - & 31,169 & 2.5 & $87,142,500$ & 2,796 \\
\hline Znacantepec & 10,239 & 9.8 & 31581 & 3.1 & $47,371,230$ & 1,500 & 11,739 & - & 36,98 & 3.2 & $85,056,504$ & 2,300 \\
\hline San Jor del Rincón & 18,518 & 0.4 & 49,877 & 2.7 & $59.352,424$ & 1.200 & 21,250 & . & 42,500 & 20 & $85,000,000$ & 2,000 \\
\hline Otzol otepec & 5,905 & 7.5 & 19,134 & 3.2 & $26,738,090$ & 1,400 & 6,796 & - & 25,502 & 3.8 & $77,406,000$ & 3,00 \\
\hline Calimaya & 5,479 & 116 & 23,743 & 4.3 & $33,247,083$ & 1,400 & 6,307 & - & 25,871 & 3.8 & $76.232,300$ & 2,947 \\
\hline Luvianos & 11,117 & $\cdot$ & 34.276 & 3.1 & $60,545,080$ & 2,000 & 11,736 & - & 19,506 & 1.7 & $75,0 \mathrm{B3}, 960$ & 3,349 \\
\hline Amatepec & 13,505 & - & 41,436 & 3.1 & $82,963,820$ & 2,000 & 11,218 & - & 19,971 & 18 & $73,892,40$ & 3,700 \\
\hline Tejupilco & 10,010 & - & 31171 & 3.1 & $62,335,120$ & $2, \infty 00$ & 9,109 & - & 18,204 & 20 & $70,033,620$ & 3,350 \\
\hline Chalco & 7,954 & - & 14,461 & 1.8 & $21,775,109$ & 1.504 & 6,170 & - & 21690 & 3.5 & $69,585,544$ & 3,206 \\
\hline Morelos & 7,792 & 0.7 & 22,131 & 2.8 & $30,984,044$ & 1,400 & 7,698 & $\cdot$ & 17,634 & 2.3 & $61,717,600$ & 3,500 \\
\hline Villa del Carbón & 6,650 & $\cdot$ & 24,670 & 3.7 & $37,004,535$ & 1,500 & 6,550 & 3.0 & $17, \infty 00$ & 2.6 & $59,500,000$ & 3,500 \\
\hline Amana:co & 6,887 & 0.2 & 26,434 & 3.8 & $42,374,832$ & 1,600 & 6,500 & $\cdot$ & 19,500 & 3.0 & $58,500,000$ & 3,000 \\
\hline Tianguistenco & 5,486 & 116 & 16,202 & 2.9 & $25,922,928$ & 1,600 & 5,260 & $\cdot$ & 18,515 & 3.5 & $53,693,558$ & 2,900 \\
\hline Otres municipios & 133,697 & 14 & 556,477 & 3.0 & $964,303,599$ & 1,733 & 154,547 & 11.1 & 412,251 & 27 & $1,343,508,037$ & 3,259 \\
\hline
\end{tabular}

Fuente: elaboración propia con información del SIAP- SAGARPA. 
Es importante señalar que 2010 fue un año en el que las afectaciones climáticas al sector agrícola representaron el $9 \%$ de la superficie sembrada de maíz grano a nivel nacional. En tierras mexiquense tal relación fue del 3.2\%, situación muy similar a la de 2003, pero la superficie cosechada en 2003 fue mayor a la de 2010, con un detalle aún más revelador reflejado en el rendimiento, pues cayó $11 \%$ de 2003 a 2010. Sin embargo, a nivel nacional el rendimiento pasó de 2.8 toneladas en 2003 a 3.3 en 2010; mientras la productividad a nivel nacional mejora con aumentos que aun dejan mucho que desear, la situación en la entidad bajo estudio es menos aceptable.

La producción de crisantemo en el Estado de México ocupa el segundo lugar en la aportación del valor agrícola; el maíz grano aportó $250 \%$ más que el crisantemo, en el promedio del valor anual de 2000 a 2010. La diferencia en la aportación del valor por parte de ambos cultivos parece bastante considerable, lo cual también se observa al comparar sólo los años 2003 y 2010.

Tabla 5.3 Principales variables por municipios productores en el Estado de México para crisantemo (2003 y 2010)

\begin{tabular}{|c|c|c|c|c|c|c|c|c|c|c|c|c|}
\hline \multirow[b]{2}{*}{ Muniajpio } & \multicolumn{6}{|c|}{2003} & \multicolumn{6}{|c|}{2010} \\
\hline & $\begin{array}{c}\text { Cosechade } \\
\text { [hes] }\end{array}$ & $\begin{array}{c}\text { Siniestrado } \\
\text { /sembrado } \\
\text { (\%) }\end{array}$ & $\begin{array}{c}\text { Producción } \\
\text { (grueses| }\end{array}$ & $\begin{array}{c}\text { Rdmto. } \\
\text { [gruezs' } \\
\text { ha) }\end{array}$ & Valor (pesos) & $\begin{array}{c}\text { PMR } \\
\text { (5/gruess) }\end{array}$ & $\begin{array}{c}\text { Cosechede } \\
\text { (has) }\end{array}$ & $\begin{array}{c}\text { Siniestrada } \\
\text { /sembreda } \\
\text { (\%) }\end{array}$ & $\begin{array}{c}\text { Praducción } \\
\text { [grueses] }\end{array}$ & $\begin{array}{c}\text { Rdmto. } \\
\text { [grueses/ } \\
\text { ho) }\end{array}$ & Valor (pesos) & $\begin{array}{c}\text { PMR } \\
\text { [5/gruess] }\end{array}$ \\
\hline Totel & 2,347 & 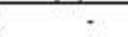 & $10,332,750$ & 4,4025 & $910,456,500$ & 58.1 & 2,379 & - & $10,233,150$ & $4,301.5$ & $1,073,529,955$ & 104.9 \\
\hline Villa Guerrero & 1.813 & - & B.,069,160 & 4.450 .7 & $719,544,500$ & 89.2 & 1,785 & - & $7,755,090$ & 4.344 .6 & $816,333,450$ & 105.3 \\
\hline Tenancingo & 295 & - & $1,180,185$ & 4000.6 & $108,623,600$ & 87.8 & 327 & - & $1,364,025$ & 4232.5 & $141,155,250$ & 102.0 \\
\hline Coatepecharinas & 162 & - & 786,510 & 4.855 .0 & $61,914,600$ & 78.7 & 227 & - & 953,745 & 4201.5 & $100,847,225$ & 105.7 \\
\hline Zumpahuacain & 15 & - & BQ, 895 & $5,393.0$ & $4,853,700$ & 60.0 & 22 & - & 79,090 & $3,595.0$ & $8,452,630$ & 107.0 \\
\hline Texcoco & 60 & - & 210,000 & $3,500.0$ & $19,950,000$ & 95.0 & 8 & - & 27,600 & $3,450.0$ & $3,422,400$ & 1240 \\
\hline Ixtapan de la Sal & $\cdot$ & - & $\cdot$ & $\cdot$ & $\cdot$ & $\cdot$ & 8 & $\cdot$ & 30,200 & $3,775.0$ & $3,020,000$ & 100.0 \\
\hline Tenango del Valle & $\cdot$ & - & - & $\cdot$ & $\cdot$ & $\cdot$ & 2 & - & 3,400 & $1,700.0$ & 289,000 & 85.0 \\
\hline Ocuilan & 2 & - & 6,000 & $3,000.0$ & 570,000 & 95.0 & $\cdot$ & - & $\cdot$ & - & $\cdot$ & $\cdot$ \\
\hline
\end{tabular}

Fuente: elaboración propia con información del SIAP- SAGARPA. 
El desglose disponible por municipio a partir de 2003 permite identificar que en el caso de maíz grano son 123 demarcaciones, de 125, que se dedican a su siembra y, en cambio, sólo 8 municipios se concentran en la siembra de crisantemo. Esto obliga a una comparación sencilla, pero elocuente: al comparar el ingreso generado por cada municipio en términos de cada producto, la venta de maíz grano generó, en 2010, un promedio de 39 mdp y la venta de crisantemo aportó en promedio $179 \mathrm{mdp}$. Es importante recordar que los ambientes controlados, usados comúnmente en la floricultura, reducen la siniestralidad.

A partir de lo señalado, la deducción obligada es en el sentido de considerar la cantidad de dinero que se generaría al cambiar de maíz grano a floricultura de crisantemo para las zonas en que resulta factible. Esto lleva nuevamente a tener presente la necesidad de contar con investigaciones federales y estatales respecto a los potenciales productivos ya mencionados, sin olvidar la importancia de los estudios representativos de los costos de producción, al menos de los cultivos más importantes y con mayor potencial en cada entidad del país.

La SAGARPA, a través del SIAP, ha elaborado estudios sobre costos de producción agrícolas, pero los más recientes son de 2007. La fuerza de la costumbre en la producción de maíz a nivel nacional y la falta de conocimiento de los productores acerca de los cultivos alternativos a su alcance, son dos de los obstáculos más grandes del campo mexicano.

Otro aspecto determinante en el cambio de cultivos se asocia necesariamente con el conocimiento de los mercados que permitan una rápida colocación de los productos al mejor precio y, de ser necesario, con la incorporación del valor agregado que los haga más atractivos.

La producción de pastos en el Estado de México ocupa el tercer lugar en la generación de ingresos agrícolas. A inicios de los años ochenta el cultivo de pastos a nivel nacional fue un tanto ocasional, registró altibajos considerables en su superficie y, en consecuencia, en los volúmenes de producción. 
Las recomendaciones sobre evitar la tumba, roza y quema, también conocida como agricultura nómada o itinerante tienen mucho que ver, pues se han relacionado frecuentemente con la degradación del ambiente. El debate se centra en la idoneidad de este sistema dadas las condiciones ambientales de las selvas, que son los sistemas donde se emplea con mayor intensidad.

La fertilidad de los suelos selváticos es por lo general reducida, lo que hace imposible lograr cosechas abundantes durante largo tiempo sin fertilizar el suelo. La productividad del suelo se recupera dejando que la parcela descanse por varios años, con la ventaja de no usar agroquímicos que representen un riesgo a la salud o al ambiente.

Sin embargo, en las últimas décadas la superficie destinada a esta forma de explotación ha crecido considerablemente, mientras que los ciclos de descanso se han acortado. Esto no sólo ha impactado negativamente a la producción sino que representa una amenaza al entorno. El uso del fuego para la agricultura es responsable de un importante número de incendios forestales. Resultado de ello, el suelo de la selva se degrada y numerosas especies típicas de la vegetación madura son incapaces de sobrevivir bajo un régimen de incendios constantes (SEMARNAT 2003).

En el periodo de 2000 a 2010 la superficie de pastos se "estabiliza" a nivel nacional en alrededor de dos millones de hectáreas, después de que desde la década de los ochenta se mantuvo con altibajos que no permitían definir una tendencia. Incluso el cuadro mostrado a continuación a nivel de municipios permite observar que tan sólo al pasar de 2003 a 2010 varios ayuntamientos interrumpieron tal cultivo, pues de 89 demarcaciones que lo sembraron en 2003 se redujeron a menos de la tercera parte (23) en 2010, con una disminución de 80 mil a 86 mil hectáreas que significaron una disminución en el volumen de producción de tres millones de toneladas a dos millones 600 mil. 


\section{Tabla 5.4 Principales variables por municipios productores en el Estado de México para pasto (2003 y 2010)}

\begin{tabular}{|c|c|c|c|c|c|c|c|c|c|c|c|c|}
\hline \multirow[b]{3}{*}{ Munidpio } & \multicolumn{6}{|c|}{2003} & \multicolumn{6}{|c|}{2010} \\
\hline & \multicolumn{3}{|c|}{ Siniestre de } & \multicolumn{9}{|c|}{ Siniestreda } \\
\hline & $\begin{array}{c}\text { Cosecheds } \\
\text { (hes) }\end{array}$ & $\begin{array}{c}\text { /sem brado } \\
\text { (\%) }\end{array}$ & $\begin{array}{l}\text { Producción } \\
\text { (tons) }\end{array}$ & $\begin{array}{l}\text { Rdm to. } \\
\text { (ton/ha) }\end{array}$ & Velor (pesos) & $\begin{array}{c}\text { PMR } \\
\text { [5/ton] }\end{array}$ & $\begin{array}{c}\text { Cosechede } \\
\text { (hes) }\end{array}$ & $\begin{array}{c}\text { /sem breda } \\
\text { (\%) }\end{array}$ & $\begin{array}{l}\text { Producción } \\
\text { |tons| }\end{array}$ & $\begin{array}{l}\text { Rdm to. } \\
\text { (ton/ha) }\end{array}$ & Valor (pesos) & $\begin{array}{c}\text { PMR } \\
{[5 / \text { ton }]}\end{array}$ \\
\hline Total & 88,002 & $\cdot$ & $3,033,827$ & 34.5 & $879,899,487$ & 290 & 86,273 & 0.04 & $2,645,546$ & 30.7 & $1,011,553,100$ & 362 \\
\hline Tlat ay $\mathbf{z}$ & 28,845 & . & $1,000,921$ & 34.7 & $270,248,670$ & 270 & 28,112 & - & 926,653 & 33.0 & $360,916,326$ & 389 \\
\hline Amatepec & 19,223 & - & 667,083 & 34.7 & $150,100,250$ & 270 & 18,525 & - & 620,530 & 33.5 & $232,717,500$ & 375 \\
\hline Luvianos & 14,172 & - & 491760 & 34.7 & $132,777,360$ & 270 & 13,322 & - & 463,645 & 33.5 & $174,144,665$ & 376 \\
\hline Tejupileo & 10930 & - & 379,271 & 34.7 & $102,403,170$ & 270 & 10,645 & - & 351,250 & 33.0 & $122,245,440$ & 348 \\
\hline Sultepec & 5,493 & - & 109,840 & 20.0 & $54,920,000$ & 500 & 5,308 & 0.5 & 74.342 & 14.0 & $31,217,690$ & 420 \\
\hline Temascaltepec & 2,396 & - & 83,141 & 34.7 & $22,442,070$ & 270 & 2,290 & $\cdot$ & 74.425 & 32.5 & $27,562,403$ & 371 \\
\hline Otzoloapan & 50 & - & 300 & 16.0 & 320,000 & 400 & 2,100 & - & 34950 & 16.6 & $17,475, \infty 00$ & 500 \\
\hline Santo Tomis & 50 & - & 800 & 16.0 & 320,000 & 400 & 1.800 & - & 30,600 & 17.0 & $15,300,000$ & 500 \\
\hline Zacazonapan & 50 & - & 300 & 16.0 & 320,000 & 400 & 1,700 & - & 28,900 & 17.0 & $14,450,000$ & 500 \\
\hline SenSimón de Guerrero & 796 & - & 27,690 & 34.7 & $7,476,300$ & 270 & 775 & - & 25,575 & 33.0 & $9,199,839$ & 360 \\
\hline Texcalitin & 483 & - & 8.860 & 18.4 & $4,4,0,000$ & 500 & 499 & - & 4760 & 9.6 & $2,179,938$ & 457 \\
\hline Zacuapan & 450 & . & 6.750 & 15.0 & $3,087,500$ & 450 & 250 & . & 3,000 & 12.0 & $1,260,000$ & 420 \\
\hline Malinalco & 195 & . & 3.510 & 18.0 & $1,755,000$ & 500 & 102 & - & 1,887 & 18.5 & 754.800 & 400 \\
\hline Zumpahuacin & 200 & - & 3,000 & 15.0 & $1,500,000$ & 500 & 145 & . & 1,660 & 11.5 & 708,688 & 425 \\
\hline Tenancingo & 100 & - & 1,920 & 19.2 & $1,152,000$ & 600 & 70 & - & 1006 & 14.4 & 459,600 & 457 \\
\hline Coatepecharinas & 30 & - & 450 & 15.0 & 180,000 & 400 & 40 & - & 616 & 15.4 & 274.120 & 445 \\
\hline Tonatico & 150 & - & 2,700 & 18.0 & $1,350,000$ & 500 & 25 & - & 570 & 22.8 & 247,950 & 435 \\
\hline |xtapan de la 5a| & 100 & - & 2000 & 20.0 & $1,000,000$ & 500 & 15 & $\cdot$ & 323 & 21.5 & 137,063 & 425 \\
\hline Almoloya de Alqu'siras & 50 & - & 750 & 15.0 & 300,000 & 400 & 30 & 25.0 & 300 & 10.0 & 135,000 & 450 \\
\hline Villa Vietoria & - & . & $\cdot$ & - & - & - & 10 & $\cdot$ & 150 & 15.0 & 97,500 & 650 \\
\hline Ixtapen del Oro & 47 & - & 564 & 12.0 & 197,400 & 350 & 5 & - & 70 & 14.0 & 31,500 & 450 \\
\hline Vale de Bravo & 40 & . & 600 & 15.0 & 240,000 & 400 & 5 & - & 40 & 8.0 & $18, \infty 0$ & 450 \\
\hline$A a m b a y$ & 250 & - & 12,425 & 49.7 & $4,970,000$ & 400 & $\cdot$ & - & $\cdot$ & $\cdot$ & $\cdot$ & $\cdot$ \\
\hline Otros municipios & 3,900 & . & 228,209 & 58.5 & $86,443,757$ & 388 & - & . & - & - & - & - \\
\hline
\end{tabular}

Fuente: elaboración propia con información del SIAP- SAGARPA.

No hay que olvidar la necesidad de vincular, en la medida de lo posible, la explotación de pastos con apoyos a los campesinos, a fin de contribuir a la protección del medio ambiente. Es importante también recordar la siembra de cultivos forrajeros alternativos, como se ha indicado, por señalar un ejemplo el caso del sorgo; nuevamente las evaluaciones de viabilidad resultan determinantes.

La última muestra relacionada con la capacidad productiva del Estado de México se relaciona con la producción de papa, cuarto lugar en el valor de producción agrícola en la entidad. El comportamiento en la superficie sembrada del tubérculo a nivel nacional ha ido de más a menos, pues en 1980 se sembraron más de 80 mil hectáreas, para 2010 tal área fue de 55 mil 645, lo que representa una caía del 30\%. El comportamiento en el Estado de México 
es aún más a la baja; en 1980 la entidad mexiquense sembró 19 mil hectáreas, mientras que para 2010 fueron cuatro mil, lo que representa una caída del 79\%.

Tabla 5.5 Principales variables por municipios productores en el Estado de México para papa (2003 y 2010)

\begin{tabular}{|c|c|c|c|c|c|c|c|c|c|c|c|c|}
\hline \multirow[b]{3}{*}{ Munidpio } & \multicolumn{6}{|c|}{2003} & \multicolumn{6}{|c|}{2010} \\
\hline & \multicolumn{3}{|c|}{ Siniestre de } & \multicolumn{9}{|c|}{ Siniestreds } \\
\hline & $\begin{array}{c}\text { Cosechede } \\
\text { (hes) }\end{array}$ & $\begin{array}{c}\text { /sem breds } \\
\text { (\%) }\end{array}$ & $\begin{array}{l}\text { Producción } \\
\text { (tons) }\end{array}$ & $\begin{array}{l}\text { Rdm to. } \\
\text { (ton/ha) }\end{array}$ & Valor (pesos) & PMR $15 /$ to & $\begin{array}{c}\text { Cosechede } \\
\text { (has) }\end{array}$ & $\begin{array}{c}\text { /sem brede } \\
\text { (\%) }\end{array}$ & $\begin{array}{l}\text { Producción } \\
\text { (tons) }\end{array}$ & $\begin{array}{l}\text { Rdm to. } \\
\text { (ton/he) }\end{array}$ & Valor $\{p e s o s\}$ & PMR $15 /$ ton \\
\hline Total & 4,465 & - & 112,132 & 25.1 & $408,047,190$ & 3,639 & 4,031 & 0.15 & 107,667 & 26.7 & $659,517,700$ & 6,126 \\
\hline Juchitepec & 290 & - & 10,150 & 35.0 & $39,331,250$ & 3,875 & 800 & - & 30,400 & 36.0 & $130,720,000$ & 4,300 \\
\hline Znacantepec & 740 & - & 12,600 & 17.0 & $44,100,000$ & 3,500 & 758 & - & 15,013 & 19.8 & $100,342,900$ & 6.604 \\
\hline Tenango del Valle & 350 & - & 10,500 & 30.0 & $42, \infty 00, \infty 00$ & 4,000 & 560 & $\cdot$ & 10,640 & 19.0 & $79,800,000$ & 7,500 \\
\hline Villa de Allende & 470 & - & 11,700 & 24.9 & $46,700,000$ & 3,991 & 355 & - & 12,425 & 35.0 & $74,550,000$ & 6,000 \\
\hline San Jose del Rincón & 1000 & - & 28,000 & 28.0 & $96,000,000$ & 3,500 & 400 & - & 11,200 & 28.0 & $70,560,000$ & 6,300 \\
\hline Villa Vietoria & 400 & - & 14,000 & 35.0 & $49,000,000$ & 3,500 & 200 & - & B., $\infty 00$ & 40.0 & $64,000,000$ & $3, \infty 00$ \\
\hline Amanalco & 500 & - & 9,400 & 18.8 & $36,700,000$ & 3,904 & 100 & 10 & 3,000 & 30.0 & $24,000,000$ & 8,000 \\
\hline Valle de Bravo & 60 & - & 1,200 & 20.0 & $4,200,000$ & 3,500 & 115 & 4.2 & 3.571 & 31.1 & $21,424,500$ & 6,000 \\
\hline Tianguistence & 35 & - & 665 & 190 & $1,582,700$ & 2,380 & 110 & $\cdot$ & 1925 & 17.5 & $14,437,500$ & 7,500 \\
\hline Temascal tepec & 28 & - & 458 & 16.4 & $1,374,000$ & 3,000 & 9 & - & 1610 & 16.3 & $12,096,500$ & 7,515 \\
\hline$X=1$ at $:$ :co & 66 & - & 1.452 & 220 & $2,207,040$ & 1,520 & 30 & - & 1600 & 20.0 & $12,000,000$ & 7,500 \\
\hline Joquidingo & 60 & - & 1.440 & 240 & $5,760,000$ & 4,000 & 60 & - & 1086 & 18.1 & $8,145,000$ & 7,500 \\
\hline Donato Guem & 45 & - & 795 & 17.7 & $3,180,000$ & 4,000 & 60 & - & 1,100 & 18.3 & $7,800,000$ & 7,091 \\
\hline San Felipe del Progreso & 100 & - & 3,000 & 30.0 & $10,500,000$ & 3,500 & 80 & $\cdot$ & 1.40 & 18.0 & $7,200,000$ & 5,000 \\
\hline Coatepecharinas & 50 & - & 1292 & 25.8 & $5,360,000$ & 4.164 & 52 & $\cdot$ & 993 & 18.3 & $6,969,655$ & 7,337 \\
\hline Morelos & $\cdot$ & - & - & $\cdot$ & $\cdot$ & $\cdot$ & 20 & - & 520 & 26.0 & $4,600,000$ & $9, \infty 0$ \\
\hline Jiqu'pilso & 22 & - & 297 & 13.5 & $1,188,000$ & 4,000 & 40 & - & 430 & 12.0 & $3,840,000$ & 8,000 \\
\hline Ocoposcas & - & - & $\cdot$ & - & - & $\cdot$ & 20 & $\cdot$ & 400 & 20.0 & $3,000,000$ & 7,500 \\
\hline Rayón & 30 & - & 720 & 240 & $2,880,000$ & 4,000 & 20 & - & 380 & 19.0 & $2,350,000$ & 7,500 \\
\hline Capulhuas & 10 & - & 190 & 190 & 451,250 & 2,375 & 28 & - & 507 & 18.1 & $2,790,150$ & 5,500 \\
\hline Calimayz & 90 & - & 2,160 & 24.0 & $6,430,000$ & 3,000 & 20 & - & 438 & 25.0 & $2,601,250$ & 5,500 \\
\hline Toluce & 5 & - & 110 & 22.0 & 275,000 & 2,500 & 15 & $\cdot$ & 360 & 24.0 & $2,520,000$ & 7,000 \\
\hline San Antonio la is a & 5 & - & 120 & 240 & 480,000 & 4,000 & 7 & - & 126 & 18.0 & $\$ 45,000$ & 7,500 \\
\hline Texcoco & - & - & - & - & - & - & 5 & - & 108 & 20.5 & 707,250 & 6,900 \\
\hline Almoloya de Alqu'siras & 8 & - & 150 & 18.8 & 525,000 & 3,500 & 6 & $\cdot$ & 90 & 15.0 & 540,000 & $6, \infty 00$ \\
\hline SanSimón de Guemero & 1 & - & 14 & 14.0 & 58,800 & 4,200 & 6 & $\cdot$ & 72 & 12.0 & 481995 & 6,720 \\
\hline isdro fabela & 20 & - & 270 & 13.5 & 758,000 & 2,307 & 15 & - & 150 & 12.0 & 414,000 & 2,300 \\
\hline Almoloya de JuÁrez & 21 & - & 248 & 12.0 & $1,242,000$ & 5,000 & $\cdot$ & - & - & $\cdot$ & $\cdot$ & - \\
\hline Almoloya del Rio & 5 & - & 85 & 17.0 & 204,000 & 2,400 & $\cdot$ & $\cdot$ & - & - & $\cdot$ & $\cdot$ \\
\hline Amecameca & $\cdot$ & - & - & $\cdot$ & $\cdot$ & $\cdot$ & - & - & - & - & $\cdot$ & - \\
\hline Atizapin & 2 & - & 36 & 18.0 & 86,400 & 2,400 & - & - & - & - & $\cdot$ & - \\
\hline Atacomulco & $\cdot$ & - & - & - & - & - & - & - & - & - & - & - \\
\hline Hux́xquiluan & $\cdot$ & - & - & - & - & - & - & - & - & - & - & $\cdot$ \\
\hline Lerma & 2 & - & 40 & 20.0 & 160,000 & 4,000 & - & - & - & - & - & - \\
\hline Metepec & 35 & - & 770 & 22.0 & $2,310,000$ & 3,000 & - & - & - & - & - & - \\
\hline Tepetlaoxtoc & 12 & - & 252 & 210 & 382,000 & 3,500 & - & - & - & - & - & - \\
\hline Talmanalco & 3 & - & 18 & 6.0 & 51,750 & 2,875 & - & - & - & - & - & - \\
\hline
\end{tabular}

Fuente: elaboración propia con información del SIAP- SAGARPA. 
La revisión de los cultivos que mayor valor agrícola aportan a la entidad mexiquense permite deducir, sin mayores complicaciones, que la tendencia en las decisiones sobre qué producir, cuánto producir, cómo producir, dónde producir y por qué producir, no tiene un parámetro definido ni obedece a aspectos relacionados con la apertura comercial, pues se carece de una orientación pública en tal sentido.

Evidentemente los programas de la SAGARPA, como es el caso de los apoyos a la comercialización de productos agropecuarios y las compras por contrato, tratan de encauzar la producción pero lo cierto es que esos mismos programas alientan todavía la siembra de cultivos como el maíz y el frijol, sin haber motivado diversificaciones hacia otros cultivos ni, mucho menos, la generación de valor agregado al recomendar la transformación de los productos por parte de los campesinos.

La información disponible por municipio para el periodo de 2003 a 2010 permite observar que el Estado de México cuenta con diferentes capacidades productivas que denotan una heterogeneidad resultado no sólo de las menores superficies sembradas, sino también de la diversa capacidad que tienen los productores, de modo que los diversos apoyos otorgados no han logrado dar homogeneidad a los niveles productivos $y$, en consecuencia, las diferencias en rendimientos, calidades e ingresos son notables. La gráfica siguiente representa a los 37 municipios del Estado de México con mayor superficie sembrada, los cuales registran el $70 \%$ de la superficie plantada, a pesar de que el estado contabilizó 123 municipios con área sembrada en los años mencionados. 
Gráfica 5.10 Superficie promedio anual sembrada en el Estado de México 2003- 2010 (miles de hectáreas)

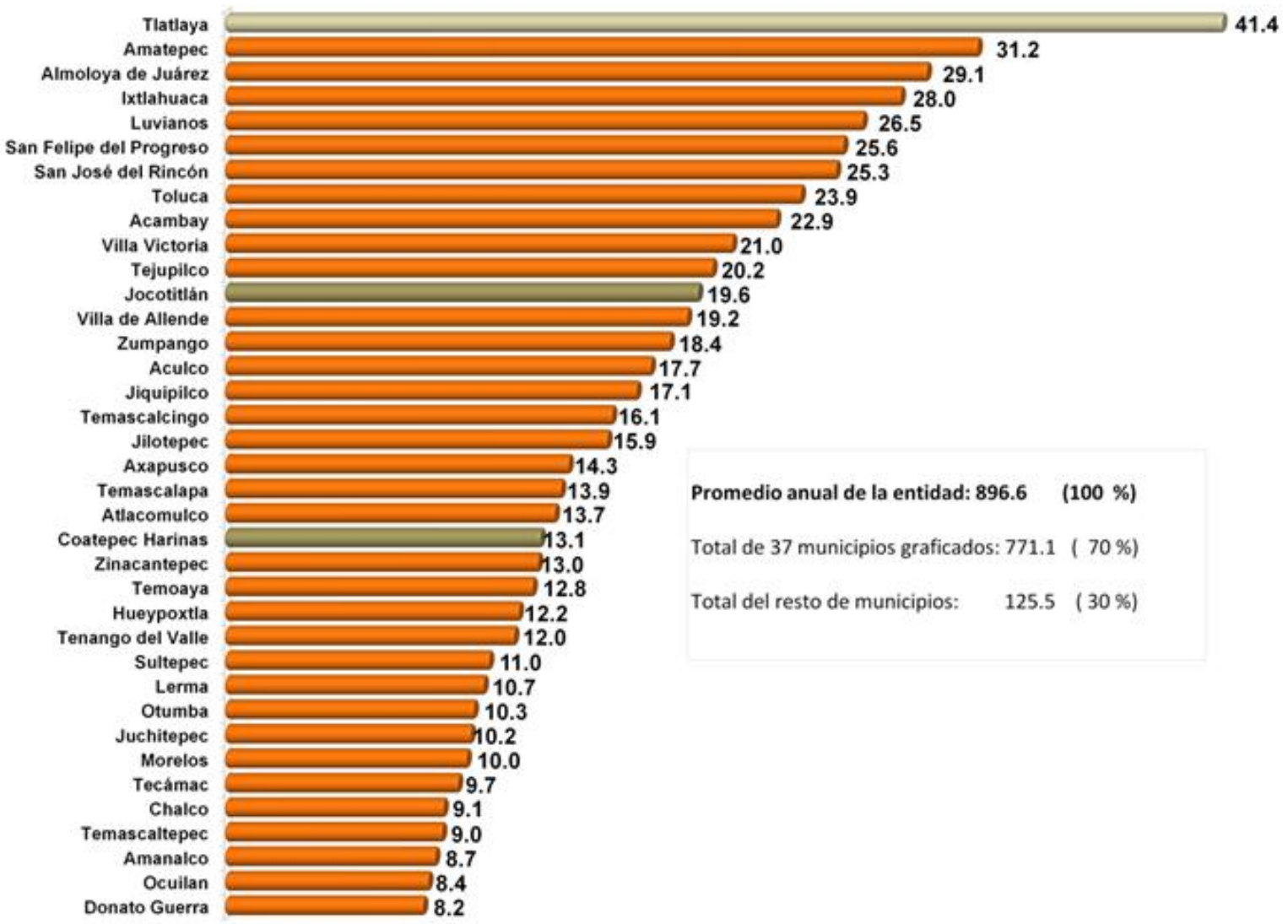

Fuente: elaboración propia con información del SIAP- SAGARPA.

Como complemento a la gráfica anterior, en términos generales, de 2003 a 2010 la superficie sembrada del territorio mexiquense lejos de incrementarse se vio reducida en $3 \%$, de modo que los principales municipios con terrenos de siembra mantuvieron sus superficies sin cambios en el área plantada. Así, son los rendimientos los que juegan un papel determinante para aumentar la producción en la entidad más poblada del país. El siguiente mapa ilustra las superficies sembradas por municipio en el Estado de México y permite darse cuenta que no necesariamente los municipios de mayor extensión territorial son los que aportan la más superficie. 
Gráfico 5.11 Participación porcentual en la superficie sembrada total del Estado de México por 2003- 2010 (miles de hectáreas)

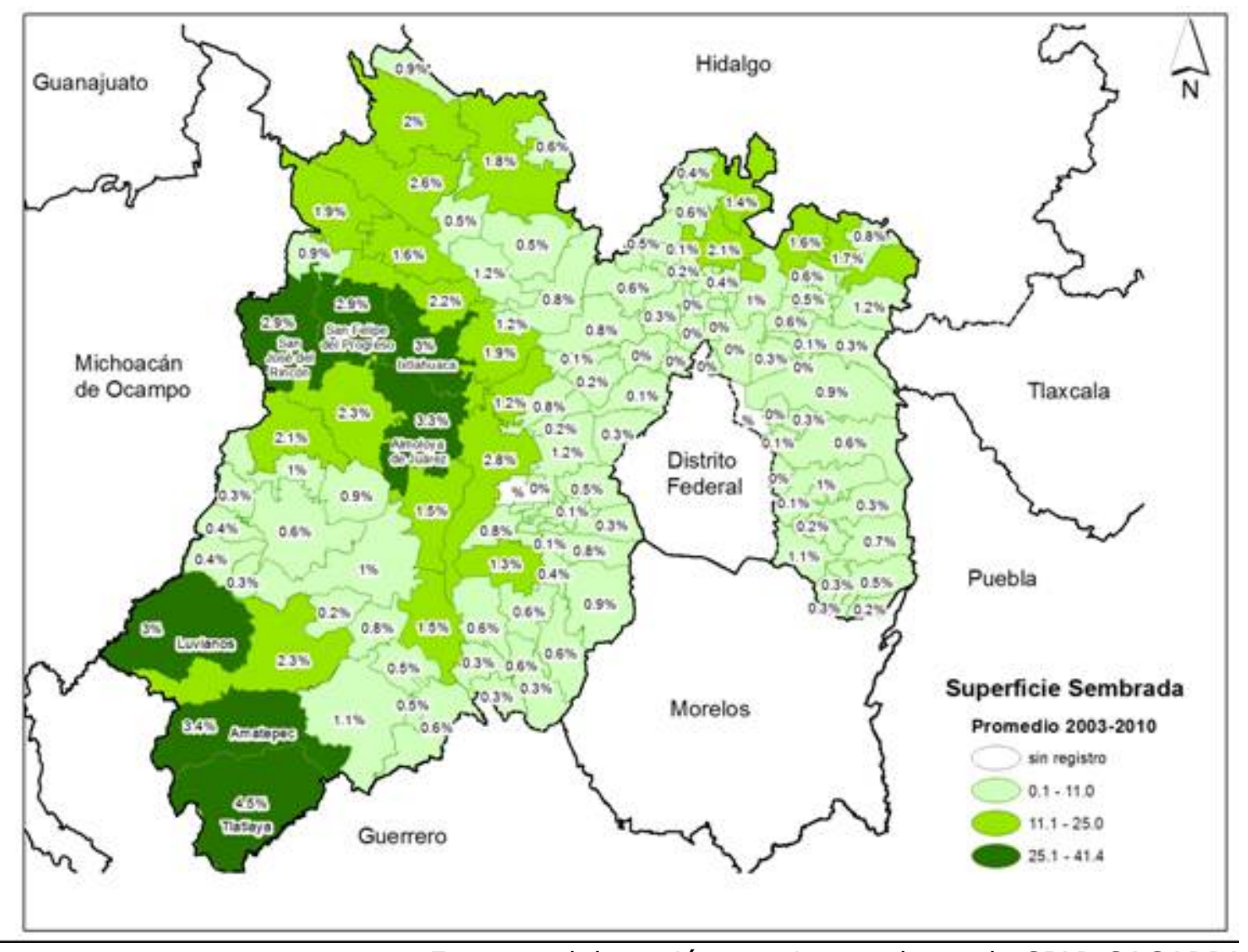

Fuente: elaboración propia con datos de SIAP-SAGARPA. 
5.3 Comportamiento histórico de los precios pagados al productor de los principales cultivos agrícolas en el Estado de México

Las variaciones en los índices de precios pagados al productor en el Estado de México, comparados con el comportamiento de los mismos a nivel nacional, permiten observar si la entidad cuenta con ventajas, desventajas o si, en términos generales, se encuentra en posición similar respecto al resto del país. La gráfica siguiente es un referente único que permite observar la evolución en la variación anual de los precios recibidos por el productor en la agricultura nacional, comparados con los recibidos por los agricultores de la entidad bajo estudio para sus 40 principales cultivos.

Es importante señalar que los índices de precios que no refieren al INEGI son estimaciones propias a partir de obtener los valores corrientes y relacionarlos con la estimación de los valores constantes; nótese en la siguiente gráfica la estrecha relación de los índices de precios, a pesar de la diferencia en los años base, pues el cálculo de INEGI refiere a diciembre de 2003 como base y la estimación propia considera al año 2007. Nuevamente vale la pena comentar el fin de los periodos hiperinflacionarios a principios de la década de los noventa, además de hacer notar que:

- Los precios de los cultivos del Estado de México se encuentran determinados por el comportamiento del mercado, de modo que reflejan las variaciones estacionales propias del subsector agrícola.

- El hecho de identificar precios más bajos a principios del año 2000 no se relaciona necesariamente con la intención de castigar los ingresos del productor del campo, pues ya se indicó que la inflación a nivel nacional a partir de la pasada década se ubica en menos de dos dígitos de variación anual y obedece, más bien, a medidas de política económica ya referidas. 
- La alta estacionalidad, así como las afectaciones, sobre todo climáticas, dan lugar a altibajos en los precios de las cosechas, lo cual ocasiona que, a diferencia de productos con oferta estable durante el año, los cultivos tengan variaciones anuales en sus precios por arriba de los dos dígitos tanto de manera positiva como negativa.

\section{Gráfica 5.12 Variación porcentual anual de los Índices de Precios al Productor} para los principales cultivos del Estado de México (1981-2010)

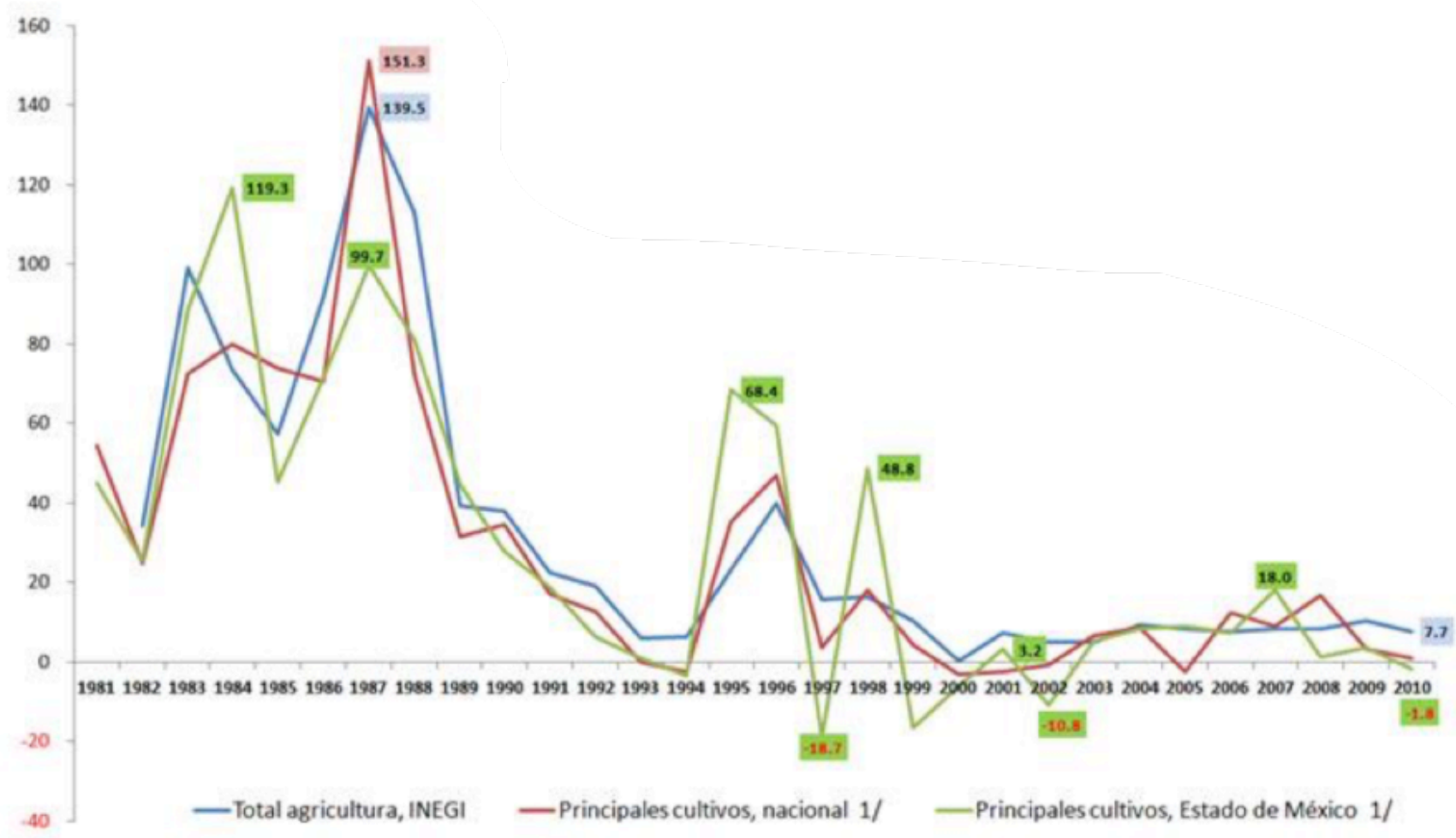

Fuente: elaboración propia con datos de los 40 cultivos que mayor valor aportaron en el Estado de México de 1981 a 2010 con datos del INEGI. 
5.3.1 Comportamiento histórico de los precios de los principales cereales en el Estado de México

Los precios más altos a los cereales registrados en la última década se tienen en 2008, no sólo en México, sino a nivel mundial (Arámbula Reyes, Alma 2008:08). Esa situación podría explicarse por a través de lo siguiente:

- Aumentos en los precios internacionales del petróleo. En la tercera decena del mes de septiembre de 2008, la cotización del barril de petróleo tipo Brent del Mar del Norte, para entrega en noviembre, se mantenía en 103.88 dólares en el mercado electrónico Intercontinental Exchange (ICE), y se cotizaba en 107.15 dólares por barril el crudo estadunidense West Texas Intermediate (WTI) para entrega en el noviembre, después de haberse acercado a los 150 dólares americanos.

- Impacto de los aumentos en el precio del petróleo respecto a insumos agrícolas.

- Recomendaciones de la FAO y el Banco Mundial en el sentido de aprovechar las oportunidades respectivas que se abren en torno a la producción de energéticos renovables de origen vegetal. Se refuerza la tendencia mundial al cultivo de plantas que se puedan transformar en los relativamente novedosos bioenergéticos. Pero la mayoría de estos cultivos compiten directamente con los cultivos de alimentos y con los bosques.

- Restricción que varios países impusieron a las exportaciones de granos cerealeros, como Vietnam y Tailandia en arroz y Argentina en trigo.

- La crisis hipotecaria en Estados Unidos impactó en buena medida a la crisis alimentaria.

- Aunque con efectos menores sobre la crisis alimentaria, es más notorio el aumento en la demanda de cultivos debido a la mejora en los ingresos per-cápita de países como China e India, a pesar de ser buenos productores de cereales. 
En la gráfica mostrada a continuación se tiene el respaldo relacionado con el elevado aumento de precios en 2008, aunque llama la atención el hecho de que el indicador del INEGI se mantenga, más bien, estable en tal año y prácticamente desde 2004 hasta 2010.

Al considerar la necesidad de diversificarse dentro de un mismo grupo, en este caso el de los cereales, también es importante identificar aquellos cultivos que generan mayores ingresos por contar con un mejor precio, sin olvidar la necesaria relación con los costos de producción, de los cuales no se cuenta con estudios actualizados a nivel nacional. Así, en el caso de los precios de los cereales a nivel nacional se tiene que sus precios llegan a encontrarse por arriba de los correspondientes a los principales cereales del Estado de México.

\section{Gráfica 5.13 Variación porcentual anual de los Índices de Precios al Productor para cereales a nivel nacional y en el Estado de México (1981-2010)}

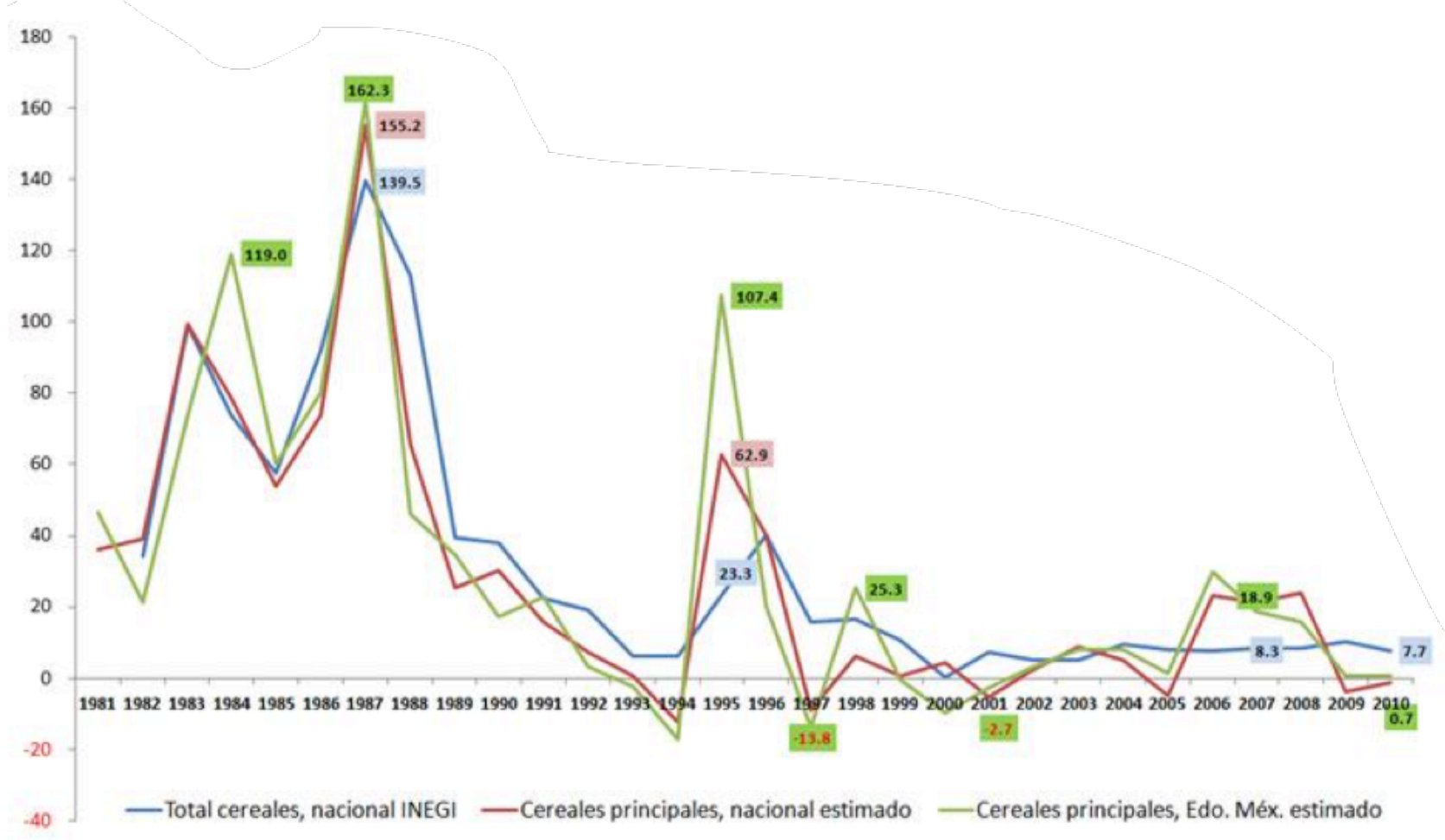

Fuente: elaboración propia con datos del INEGI. 
Al identificar de manera desglosada la evolución de los precios de los cereales a nivel nacional, así como los más importantes de la entidad mexiquense, se tiene que la cebada grano representa una alternativa viable al buscar diversificarse, pues en el periodo 2000-2010 el incremento anual del precio fue de $8.1 \%$ a nivel nacional y de $7.8 \%$ en la demarcación bajo estudio, superado sólo por el precio del trigo grano nacional. Es importante observar que aunque el estado no se orienta hacia la producción de sorgo, el precio del mismo se incrementa de manera similar al maíz grano, lo cual refleja el uso de este último como referente para determinar el precio del primero.

\section{Tabla 5.6 Variación porcentual anual de los Índices de Precios al Productor} para cereales en el Estado de México (2000-2010)

\begin{tabular}{|c|c|c|c|c|c|c|c|c|c|c|c|c|c|c|}
\hline & & & & & & & & & & & & \multicolumn{3}{|c|}{ Promedio de var $\%$ anual } \\
\hline Cultivo & 2000 & 2001 & 2002 & 2003 & 2004 & 2005 & 2006 & 2007 & 2008 & 2009 & 2010 & $1982-1990$ & $1990-2000$ & $2000-2010$ \\
\hline Total agrieultura, INEG| & 0.3 & 7.2 & 4.9 & 4.9 & 9.5 & 8.2 & 7.5 & 8.3 & 8.3 & 10.2 & 7.7 & 76.2 & 18.0 & 7.0 \\
\hline Principales cultivos, nacional 1/ & -3.0 & -2.4 & 0.7 & 6.6 & 8.8 & -2.4 & 12.3 & 9.1 & 16.9 & 3.3 & 1.1 & 68.0 & 15.2 & 4.5 \\
\hline Principales cultivos, Edo. Méx, 1/ & -6.1 & 3.2 & -10.8 & 5.3 & 8.5 & 9.2 & 7.3 & 18.0 & 1.4 & 3.7 & -1.8 & 67.1 & 16.9 & 3.4 \\
\hline Total cereales, nacional INEGI & 1.4 & 3.4 & 5.5 & 8.0 & 9.5 & -1.9 & 9.8 & 29.0 & 12.0 & 5.0 & .2 .6 & 69.6 & 15.8 & 7.2 \\
\hline Cereales principales, nacional estimado & 4.4 & -5.3 & 2.6 & 8.9 & 4.9 & -4.8 & 23.3 & 21.3 & 23.9 & -3.8 & -1.2 & 69.0 & 13.4 & 6.7 \\
\hline Cereales principales, Edo. Méx. estimado & -9.8 & -2.7 & 3.2 & 7.9 & 8.1 & 1.4 & 29.8 & 18.9 & 15.8 & 0.5 & 0.7 & 68.3 & 13.9 & 6.7 \\
\hline Avena Grano, nacional & 19.2 & -15.3 & 10.5 & -2.0 & 20.1 & -1.6 & -4.1 & -1.6 & 3.0 & 51.7 & -11.8 & 75.1 & 17.1 & 6.2 \\
\hline Avena Grano, Estado de México & -2.8 & -7.1 & -8.3 & 1.0 & 35.5 & 9.5 & 8.6 & 4.8 & 23.8 & -7.7 & -8.7 & 84.5 & 28.0 & 4.4 \\
\hline Cebada, nacional INEGI & -6.8 & -2.6 & 5.2 & 5.8 & 9.9 & 8.8 & 6.8 & 19.7 & 30.8 & 4.1 & -5.7 & 69.5 & 15.7 & 6.9 \\
\hline Cebada Grano, nacional & 3.0 & 9.6 & -3.4 & 5.1 & 8.4 & -0.4 & 7.2 & 13.4 & 50.4 & -1.9 & -2.6 & 70.1 & 12.8 & 8.1 \\
\hline Cebada Grano, Estado de México & 2.7 & -2.5 & 6.1 & 4.4 & 16.5 & -16.3 & 27.9 & 22.6 & 46.2 & -15.3 & $-6,8$ & 77.1 & 16,1 & 7.8 \\
\hline Maiz, nacional INEGI & 1.9 & 4.4 & 6.4 & 10.7 & 5.2 & -4.8 & 14.3 & 32.3 & 4.9 & 4.8 & -0.8 & 69.0 & 16.8 & 7.2 \\
\hline Maiz Grano, nacional & 3.7 & -3.8 & 3.4 & 7,8 & 3.7 & .6 .0 & 27.4 & 21.5 & 15.4 & -0.5 & 0.5 & 68.9 & 13.0 & 6.6 \\
\hline Maiz Grano, Estado de México & -10.1 & -2.8 & 3.1 & 8.0 & 7.5 & 1.7 & 30.8 & 19.1 & 15.1 & 1.3 & 0.8 & 68.4 & 13.8 & 6.8 \\
\hline Trigo, nacional INEG| & 3.9 & 4.1 & 4.5 & 3.4 & 11.7 & 5.2 & 5.0 & 35.6 & 19.3 & -13.6 & -8.8 & 71.5 & 14.3 & 6.4 \\
\hline Trigo Grano, nacional & 7.2 & -16.5 & -0.8 & 16.8 & 17.0 & -2.2 & 3.3 & 23.7 & 77.5 & -21.4 & -6.8 & 72.1 & 16.4 & 8.9 \\
\hline Trigo Grano, Estado de México & -15.0 & -1.4 & 22.0 & -2.6 & 8.9 & -0.7 & 29.4 & 9.9 & -10.2 & 18.8 & 9.3 & 81.9 & 17.8 & 6.2 \\
\hline Sorgo, nacional & -1.3 & 1.4 & 3.5 & -1.4 & 16.1 & -2.3 & 4.1 & 17.6 & 21.4 & 22.7 & -1.2 & 71.3 & 15.2 & 7.3 \\
\hline
\end{tabular}

Fuente: elaboración propia con datos del SIAP-SAGARPA e INEGI.

La entrada de México al TLCAN no significa en sentido estricto que los precios pagados al productor agrícola tengan que disminuir, sino más bien que siguen sujetos al comportamiento de los mercados, ahora con mayor influencia por parte de la relación con los socios de dicho acuerdo comercial, sin que ello signifique que tal influencia sólo se deba al intercambio con dichos países, pues al año 2012 México mantiene relaciones de intercambio comercial con prácticamente todos los países del mundo. 


\subsubsection{Precios de los principales cultivos de plantas y flores}

El contar con los índices de precios del INEGI, complementados con la estimación propia, da un marco de referencia que permite analizar el comportamiento de los precios pagados al productor a nivel de la entidad, pero sin dejar de lado la referencia de los precios nacionales.

Una ventaja más es en el sentido de que al analizar precios de plantas y flores es posible evitar las complicaciones que llega a implicar el uso de diferentes unidades de medida para el volumen de producción. La serie mostrada para los precios de plantas y flores es más corta que en el caso de cereales debido a la menor disponibilidad de información, resultado de las menores plantaciones de tales cultivos en el pasado, sin embargo, no puede asociarse la motivación a sembrar plantas y flores sólo a la entrada en vigor del TLCAN, pues tal tendencia se observa desde fines de la década de los años ochenta. Pudiera pensarse que el precio de las plantas y flores es muy estacional y que, por lo mismo, debería de mostrar altibajos recurrentes en sus precios; la gráfica siguiente demuestra lo contrario, pues después de los periodos hiperinflacionarios se observa una tendencia a la baja y, posteriormente, desde inicios de la década de los noventa una estabilidad determinada definitivamente por los precios de los cultivadores del Estado de México que ofertan la mayor cantidad de tales cultivos.

El hecho de que los precios de plantas y flores se mantengan, a final de cuentas, en niveles relativamente bajos y estables también se asocia estrechamente con el hecho de que no se trata de bienes indispensables. 


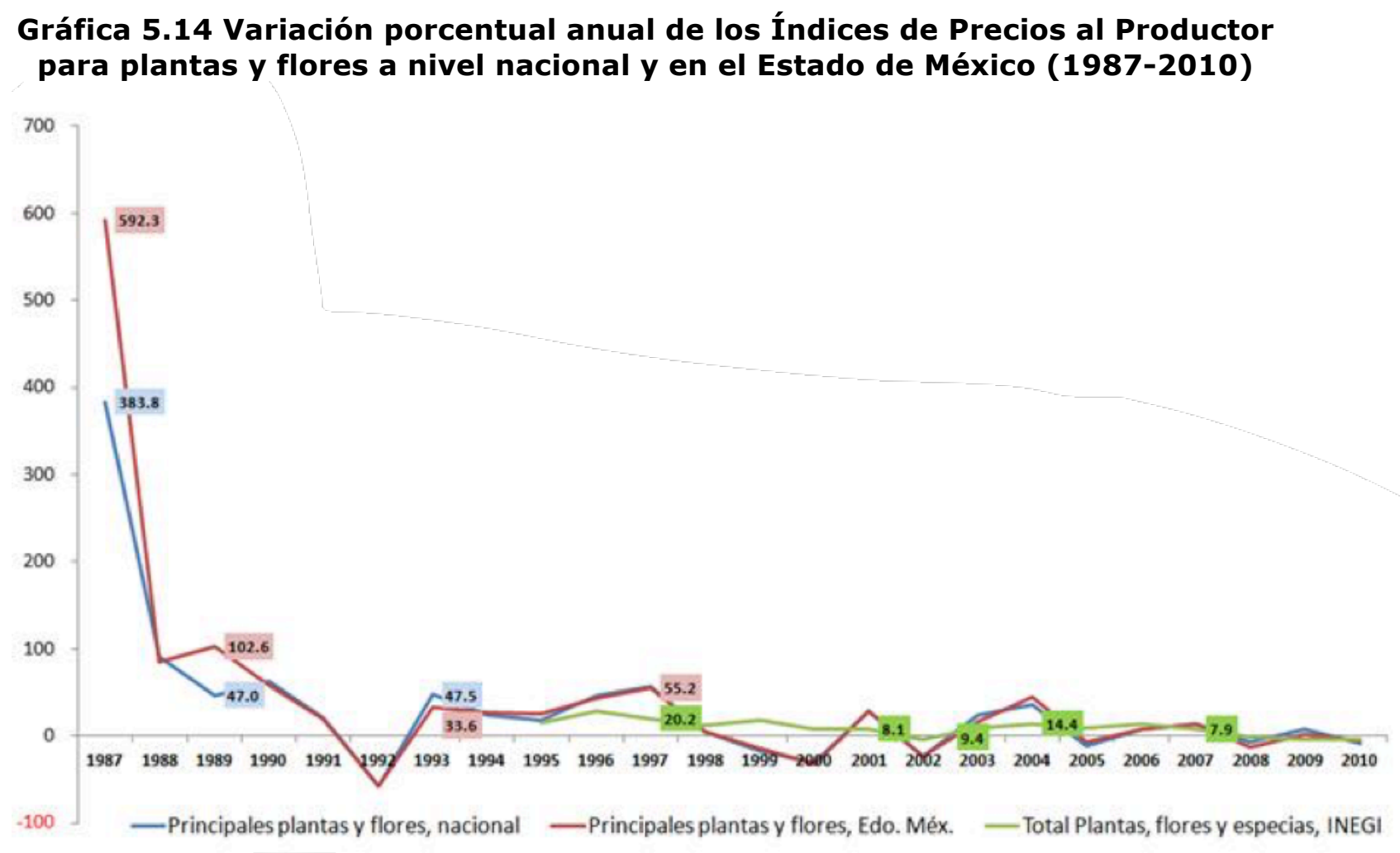

Fuente: elaboración propia con datos del SIAP-SAGARPA e INEGI.

Nuevamente es posible identificar en la gráfica referente a plantas y flores que los índices de precios del INEGI muestran una estabilidad poco común en los cultivos, a pesar de que los registros de los precios de tal institución son mensuales, mientras que la estimación propia parte de datos anuales, pues sólo así se tienen disponibles en el SIAP. La apertura por variedad de plantas y flores permite observar que, en realidad, las variaciones anuales son muy poco estables vistas por separado, de modo que nuevamente las condiciones del mercado resultan determinantes, pues a pesar de que los promedios de los periodos anuales mostrados identifican pocas variaciones negativas en los precios, la realidad anual es opuesta y llega a identificar caídas de hasta el $30 \%$ en 2010 , sin olvidar incrementos de hasta el $37 \%$ en la variedad de gerbera. El productor enfrenta el reto de integrar sus volúmenes de producción en las diferentes cadenas de comercialización, a fin de mejorar sus ingresos. 


\section{Tabla 5.7 Variación porcentual anual de los Índices de Precios al Productor para plantas y flores en el Estado de México (2000-2010)}

\begin{tabular}{|c|c|c|c|c|c|c|c|c|c|c|c|c|c|c|}
\hline & & & & & & & & & & \multicolumn{5}{|c|}{ Promedio de var $\%$ anual } \\
\hline Cultivo & 2000 & 2001 & 2002 & 2003 & 2004 & 2005 & 2006 & 2007 & 2008 & 2009 & 2010 & $1982-1990$ & $1990-2000$ & $2000-2010$ \\
\hline Principales plantas y flores, nacional & .31 .2 & 28.5 & -23.8 & 23.8 & 36.2 & -11.2 & 8.0 & 14.3 & .7 .4 & 7.3 & 8.3 & 168.8 & 15.9 & 3.3 \\
\hline Principales plantas y flores, Edo. Méx. & -31.6 & 28.7 & -23.9 & 17.0 & 45.3 & .7 .5 & 8.2 & 13.4 & -13.3 & 1.8 & .5 .1 & 209.6 & 14.8 & 3.0 \\
\hline Total Plantas, flores y especias, INEGI & 8.4 & 8.1 & -4.7 & 9.4 & 14.4 & 8.6 & 14.3 & 7.9 & -1.5 & -4.4 & -4.3 & nd & 17.2 & 5.1 \\
\hline Alstroemeria (gruesa), nacional. & nd & nd & nd & 50.0 & 99.1 & -29.7 & 84.5 & 16.2 & -4.5 & -13.1 & -29.5 & nd & nd & 21.6 \\
\hline Alstroemeria (grvesa), Edo. Méx. & nd & nd & nd & 50.0 & 99.1 & -29.7 & 84.5 & 16.1 & -4.5 & -13.1 & -29.5 & nd & nd & 21.6 \\
\hline Aster (manojo), nacional & nd & nd & nd & -26.2 & 133,8 & -93.8 & 69.9 & 0.4 & -14.7 & -37.5 & 9.4 & nd & nd & 5.2 \\
\hline Aster (manojo), Edo. Mbx. & nd & nd & nd & -26.2 & 133.8 & -93.8 & 69.9 & 0.4 & -18.0 & -35.2 & 9.6 & nd & nd & 5.1 \\
\hline Clavel (gruesa), nacional & 0.6 & 22.7 & -30.6 & 33.3 & 85.9 & -16.1 & 20.2 & 25.9 & 19.4 & 6.6 & -17.9 & 9.0 & 8.5 & 13.6 \\
\hline Clavel (gruesa), Edo. Méx. & 0.6 & 22.7 & $-30,6$ & 33.3 & 85.9 & -16.1 & 20.2 & 25.9 & 19.4 & 6.6 & -17.9 & 63.2 & 8.5 & 13.6 \\
\hline Crisantemo (gruesa), nacional & .26 .8 & 38.4 & -20.7 & 17.4 & 22.7 & 3.8 & 9.0 & 15.0 & -18.1 & 14.1 & -18.7 & 96.0 & 14.0 & 3.3 \\
\hline Crisantemo (gruesa), Edo. Méx. & -26.8 & 38.4 & -20.5 & 17.7 & 22.5 & 4.1 & 8.9 & 14.8 & -21.1 & -4.0 & -1.5 & 96.0 & 13.9 & 3.0 \\
\hline Cyclamen (planta), nacional & 0.0 & 0.0 & 114.3 & -6.7 & 7.1 & 0.0 & 0.0 & 13.9 & -1.5 & -7.6 & 23.2 & nd & 12.9 & 13.0 \\
\hline Cyclamen (planta), Edo. Méx. & 0.0 & 0.0 & 114.3 & -6.7 & 7.1 & 0.0 & 0.0 & 20.0 & 0.0 & -11.1 & 25.0 & nd & 12.9 & 13.5 \\
\hline Geranio (planta), nacional & nd & nd & -3.0 & -1.8 & 23.6 & -11.7 & 2.7 & 12.3 & -8.1 & 10.9 & 19.2 & nd & nd & 4.9 \\
\hline Geranio (planta), Edo. Méx. & nd & nd & 0.0 & 0.0 & 30.0 & -7.7 & 0.0 & 33.3 & -12.5 & 14.3 & 25.0 & nd & nd & 9.2 \\
\hline Gerbera (gruesa), nacional & -11.5 & 7.2 & -26.0 & 77.3 & -15.3 & -18.3 & -10.0 & 17.4 & -21.6 & -13.1 & 37.2 & nd & 70.3 & 2.1 \\
\hline Gerbera (gruesa), Edo, Méx. & -11.5 & 7.2 & -26.0 & 77.3 & -15.3 & -18.3 & -10.0 & 17,4 & -21.6 & -13.1 & 37.2 & nd & 70.3 & 2.1 \\
\hline Gladiola (gruesa), Nacional & -33.1 & $\$ 5.8$ & -30.0 & $\$ 7.8$ & -4.3 & -6.3 & -0.3 & 31.7 & 3.7 & 0.2 & -8.3 & 204.4 & 13.9 & 6.4 \\
\hline Gladiola (gruesa), Edo. Méx. & -33.1 & 55.9 & -36.3 & 23.6 & 13.7 & 13.8 & -8.8 & 31.7 & .6 .6 & 1.6 & -13.9 & 159.9 & 13.9 & 3.8 \\
\hline Lilium (gruesa), nacional & nd & nd & nd & $\$ 2.1$ & $1,250.5$ & -11.0 & .25 .5 & 69.0 & 8.3 & 10.6 & 2.8 & nd & nd & 167.5 \\
\hline Lilium (gruesa), Edo. Méx. & nd & nd & nd & 52.1 & $1,250.5$ & -11.3 & -25.9 & 70.0 & 8.2 & 10.6 & 2.9 & nd & nd & 167.6 \\
\hline Noche Buena (planta), nacional & 27.5 & -6.4 & -10.0 & 29.4 & -40.5 & 26.0 & 16.1 & -4.2 & 15.5 & -7.0 & 11.6 & nd & 16.9 & 5.3 \\
\hline Noche Buena (planta), Edo. Méx. & nd & nd & 20.0 & -16.7 & 14.5 & 16.4 & 36.4 & 1.1 & 13.5 & 0.1 & 13.0 & nd & nd & 10.9 \\
\hline Rosa (grvesa), nacional & -51.3 & 0.3 & -38.9 & 24.2 & 10.9 & -36.9 & -3.8 & 20.1 & 13.9 & 17.9 & 31.9 & 214.4 & 18.6 & -1.1 \\
\hline Rosa (gruesa), Edo. Méx. & -51.9 & -0.1 & -26.1 & 21.3 & 5.1 & -38.6 & 18.4 & 29.2 & nd & nd & nd & 83.4 & 18.9 & -5.3 \\
\hline Rosa De Invernadero (gruesa), nacional & nd & nd & nd & nd & nd & nd & 12.1 & .6 .8 & -15.5 & 11.0 & -13.8 & nd & nd & -2.6 \\
\hline Rosa De Invernadero (gruesa), Edo, Méx. & nd & nd & nd & nd & nd & nd & 10.2 & -8.2 & -15.4 & 11.1 & -15.3 & nd & nd & -3.5 \\
\hline Rosa De Invernadero (planta), nacional & nd & nd & nd & nd & nd & nd & 14.3 & 0.0 & 0.0 & 12.5 & 3.3 & nd & nd & 6.0 \\
\hline Rosa De Invernadero (planta), Edo. Méx. & nd & nd & nd & nd & nd & nd & 14.3 & 0.0 & 0.0 & 12.5 & 3.3 & nd & nd & 6.0 \\
\hline
\end{tabular}

Fuente: elaboración propia con datos del SIAP-SAGARPA e INEGI.

5.3.3 Precios de los principales cultivos de hortalizas

El mercado de hortalizas a nivel nacional y del estado objeto de análisis, es un ejemplo ideal del comportamiento estacional de la producción y demuestra, en buena medida, que las decisiones de oferta no están determinadas por algún grupo de productores fuertes, sino más bien por las iniciativas consideradas por separado de muchos productores dispersos y de diferentes tamaños. Por tal razón los precios se comportan con aumentos y disminuciones influenciadas por la saturación o no del mercado, con sus respectivas implicaciones por la diferencia en calidades, tamaño de la zona de consumo, ingresos, gustos del consumidor y necesidades cubiertas por el bien, principalmente. 


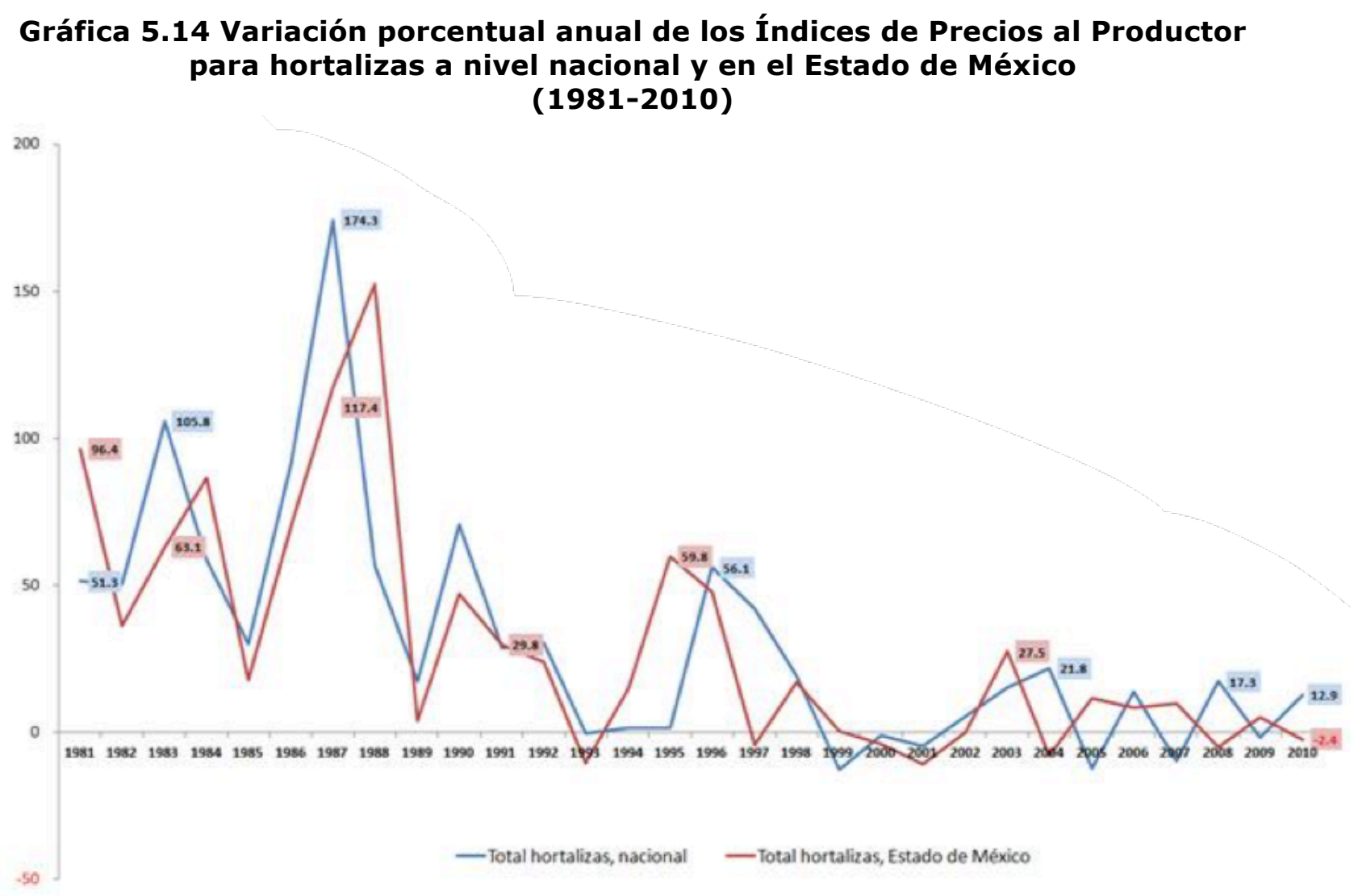

Fuente: elaboración propia con datos del SIAP-SAGARPA e INEGI.

El gráfico anterior nos muestra cómo los precios de ciertos cultivos llegan a tener variaciones, mayores a las observadas en los precios pagados por el consumidor pues, como se ha comentado, en la última década los precios pagados por los demandantes finales no son mayores a dos dígitos. En cambio, el grupo de hortalizas tiene variaciones mayores a dos dígitos en 2008 y 2010, sin olvidar el papel determinante de los diferentes productos.

Aun con todos sus altibajos en los precios de las hortalizas, los comparativos por series de años permiten identificar cultivos que podrían ser las mejores alternativas, sin olvidar relacionar con otros factores que también influyen. Así, resulta que en el Estado de México los desgloses por tipos de productos permiten apreciar que los precios pagados al productor de cebolla en el Estado de México tuvieron variaciones anuales de más de dos dígitos 
(30.4\%) en el periodo 2000-2010, con lechuga y papa en segundo y tercer lugar.

Tabla 5.8 Variación porcentual anual de los Índices de Precios al Productor para hortalizas en el Estado de México (2000-2010)

\begin{tabular}{|c|c|c|c|c|c|c|c|c|c|c|c|c|c|c|}
\hline & & & & & & & & & & \multicolumn{5}{|c|}{ Promedio de var $\%$ anual } \\
\hline Cultivo & 2000 & 2001 & 2002 & 2003 & 2004 & 2005 & 2006 & 2007 & 2008 & 2009 & 2010 & $1982-1990$ & $1990-2000$ & $2000-2010$ \\
\hline Total hortalizas, nacional & 0.9 & -4.6 & 5.4 & 15.4 & 21.8 & -12.3 & 13.9 & -9.8 & 17.3 & -1.6 & 12.9 & 72.9 & 21.6 & 5.2 \\
\hline Total hortalizas, Estado de Mborico & -4.1 & .10 .8 & 0.2 & 27.5 & -7.8 & 11.6 & 8.2 & 10.0 & 5.1 & 5.1 & .2 .4 & 66.1 & 20.2 & 3.0 \\
\hline Papa, nacional INEGI & -9.2 & -12.5 & 43.4 & 15.3 & -10.7 & 13.9 & 12.4 & -21.3 & 12.0 & 48.8 & -5.7 & 79.4 & 19.9 & 7.8 \\
\hline Papa, nacional & 8.9 & 0.9 & 33.9 & -0.6 & 0.9 & 6.5 & 3.5 & -7.2 & 5.9 & 60.8 & 0.1 & 76.3 & 18.2 & 8.4 \\
\hline Papa, Estado de México & -12.6 & 7.6 & 32.3 & -4.5 & -15.1 & 58.3 & -36.2 & 15.5 & 1.5 & 85.5 & $-9,7$ & 101.8 & 17.7 & 11.1 \\
\hline Calabacita, nacional INEGI & -20.4 & 51.6 & 11.5 & 8.2 & 36.5 & -3.9 & 6.2 & 7.1 & 5.8 & 3.9 & 31.5 & 54.8 & 14.5 & 11.0 \\
\hline Calabacita, nacional & -9.4 & 20.1 & -10.7 & 9.7 & 12.4 & -7.5 & 7.4 & 4.3 & 5.6 & -0.9 & 7.0 & 80.3 & 16.3 & 3.4 \\
\hline Calabacita, Estado de México & -22.5 & -33.2 & 79.2 & 12.6 & 2.6 & 11.9 & 15.6 & 3.8 & -18.3 & 17.3 & 22.5 & 65.6 & 26.3 & 8.3 \\
\hline Cebolla, nacional INEGI & -6.1 & 9.5 & 14.4 & 16.4 & -1.5 & 19.9 & -6.1 & 63.8 & -14.9 & -26.8 & 81.7 & 105.8 & 27.6 & 13.7 \\
\hline Cebolla, nacional & -4.5 & 27.6 & 19.2 & 2.6 & -9.7 & 17.3 & -6.3 & 6.4 & 21.4 & -17.8 & 36.1 & 71.5 & 23.1 & 8.4 \\
\hline Cebolla, Estado de México & 150.0 & -46.6 & 79.3 & 50.0 & -43.4 & 40.7 & 12.7 & 38.3 & -20.9 & 7.6 & 67.0 & 100.2 & 56.0 & 30.4 \\
\hline Chicharo, nacional & -25.9 & 14.7 & 0.1 & 4.7 & 23.7 & -2.1 & 10.4 & 5.0 & 31.7 & -14.1 & 4.3 & 75.3 & 12.2 & 3.9 \\
\hline Chicharo, Estado de México & .29 .4 & 36.1 & -24.7 & 38.9 & 5.4 & -11.7 & 23.3 & -11.9 & 15.4 & 11.8 & 1.5 & 71.3 & 15.7 & 5.0 \\
\hline Elote, nacional INEGI & -12.4 & 6.6 & 4.9 & 1.6 & 11.4 & 6.2 & 4.4 & 13.8 & 20.9 & -5.3 & -7.7 & 70.2 & 10.7 & 4.0 \\
\hline Elote, nacional & 11.9 & 5.8 & 10.1 & 4.9 & 4.8 & 8.4 & 6.5 & 3.1 & 12.2 & 1.4 & 4.7 & 73.7 & 12.8 & 6.7 \\
\hline Elote, Estado de México & -19.9 & 5.1 & 38.1 & 9.0 & 18.7 & 3.9 & -4.3 & 0.2 & .29 .5 & 44.5 & -23.0 & 102.0 & 18.4 & 3.0 \\
\hline Haba Verde, nacional & -17.5 & -17.0 & 15.0 & 21.6 & -22.7 & 9.4 & 4.0 & 8.8 & 21.1 & -7.6 & 14.0 & 93.5 & 24.4 & 2.6 \\
\hline Haba Verde, Estado de México & -22.3 & -10.4 & 3.0 & 29.7 & -8.2 & 3.8 & 8.9 & 2.4 & 4.9 & 3.4 & 27.0 & 79.8 & 19.9 & 3.8 \\
\hline Lechuga y col, nacional INEGI & 7.4 & -1.7 & 6.4 & 2.1 & -0.9 & 7.3 & -2.0 & 16.6 & -5.8 & 11.6 & 5.2 & nd & 26.7 & 4.2 \\
\hline Lechuga, nacional & -6.8 & -0.9 & -5.5 & -1.0 & 2.6 & 4.6 & 7.0 & 15.0 & 10.2 & 5.8 & 11.9 & 76.9 & 16.1 & 2.6 \\
\hline Lechuga, Estado de México & -21.6 & 34.8 & -24.2 & 66.2 & -8.3 & 24.9 & 31.6 & -3.9 & -21.4 & 61.1 & -7.6 & 64.0 & 25.8 & 12.0 \\
\hline Nopales, nacional INEGI & -9.3 & 18.0 & 21.3 & -1.3 & 7.4 & -4.7 & 16.9 & -2.2 & 10.5 & -3.8 & 41.8 & nd & 23.8 & 8.6 \\
\hline Nopalitos, nacional & -12.9 & 31.6 & 7.2 & -10.1 & -13.2 & -6.1 & 19.1 & -6.4 & 9.8 & -14.6 & 19.9 & 89.8 & 24.5 & 2.2 \\
\hline Nopalitos, Estado de Mécico & -11.5 & 7.0 & 10.5 & 87.4 & 9.2 & 19.9 & -7.0 & 19.2 & 12.4 & .30 .5 & -24.1 & 120.4 & 12.2 & 6.7 \\
\hline Jitomates, nacional INEGI & 0.4 & 0.5 & 9.3 & 18.5 & 19.8 & -7.9 & 31.2 & -17.4 & 5.8 & 11.7 & -1.6 & 84.0 & 26.0 & 6.4 \\
\hline Tomate Rojo (ijomate), nacional & 3.0 & .20 .6 & 2.5 & 35.3 & 47.0 & .28 .9 & 33.3 & -19.2 & 18.1 & 6.7 & 9.2 & 73.6 & 25.3 & 7.8 \\
\hline Tomate Rojo (ijtomate), Estado de México & 3.5 & -19.5 & -24.8 & 34.7 & 19.3 & -11.0 & 29.1 & 30.0 & -11.9 & 4.8 & -16.7 & 67.6 & 38.5 & 3.4 \\
\hline Tomate verde, nacional INEGI & 14.1 & -2.6 & -2.0 & 15.7 & 15.6 & 31.8 & .26 .9 & -23.2 & 67.1 & -26.4 & 21.1 & 95.0 & 22.5 & 7.7 \\
\hline Tomate Verde, nacional & -10.4 & -5.8 & 5.5 & -6.2 & 22.3 & 25.7 & -18.6 & -14.8 & 24.2 & -6.3 & -0.0 & 68.8 & 22.6 & 1.4 \\
\hline Tomate Verde, Estado de México & 2.2 & -18.9 & 10.5 & 12.5 & -11.3 & 32.9 & 0.6 & -0.4 & -12.9 & 6.3 & 11.3 & 61.4 & 32.3 & 3.0 \\
\hline Zanahoria, nacional INEG| & -4.9 & 33,4 & -10.9 & 25.9 & 0.1 & 23.3 & -2.6 & 19.2 & 1.4 & 8.9 & 2.5 & 52.7 & 17.6 & 8.7 \\
\hline Zanahoria, nacional & 1.1 & 16.0 & -10.7 & 18.4 & -24.2 & 23.5 & -1.2 & 19.5 & 12.5 & 10.3 & 5.2 & 79.5 & 10.6 & 6.4 \\
\hline Zanahoria, Estado de Mésico & 23.5 & 9.7 & -37.0 & 18.9 & -1.0 & 30.9 & -1.2 & 13.8 & 20.7 & 9.2 & 16.5 & 87.9 & 23.3 & 9.4 \\
\hline Chiles frescos, nacional INEGI & 22.3 & -0.9 & 5.4 & -15.0 & 24.5 & 11.2 & -20.2 & 25.5 & 6.8 & 13.3 & 12.1 & 81.0 & 20.2 & 7.7 \\
\hline Chile seco, nacional INEGI & 3.6 & 23.6 & -2.2 & 8.8 & 28.9 & 8.7 & -20.8 & 0.9 & 22.0 & 22.3 & 4,7 & 97.9 & 32.5 & 9.0 \\
\hline
\end{tabular}

Fuente: elaboración propia con datos del SIAP-SAGARPA e INEGI.

La evolución de los precios de papa en el Estado de México merece una mención por separado, dado que es el tercer cultivo que más ingresos aportó a la entidad en el periodo 2000-2010; el comportamiento es marcadamente estacional (véase la gráfica siguiente), pero no permite, de cualquier manera, anticipar las expectativas de los productores, pues obedece a la toma de decisiones individuales, no sólo en la entidad, sino también a nivel nacional por tratarse de uno de los cultivos más generalizados en su siembra. 


\section{Gráfica 5.15 Variación porcentual anual de los Índices de Precios al Productor para papa a nivel nacional y en el Estado de México \\ (1981-2010)}

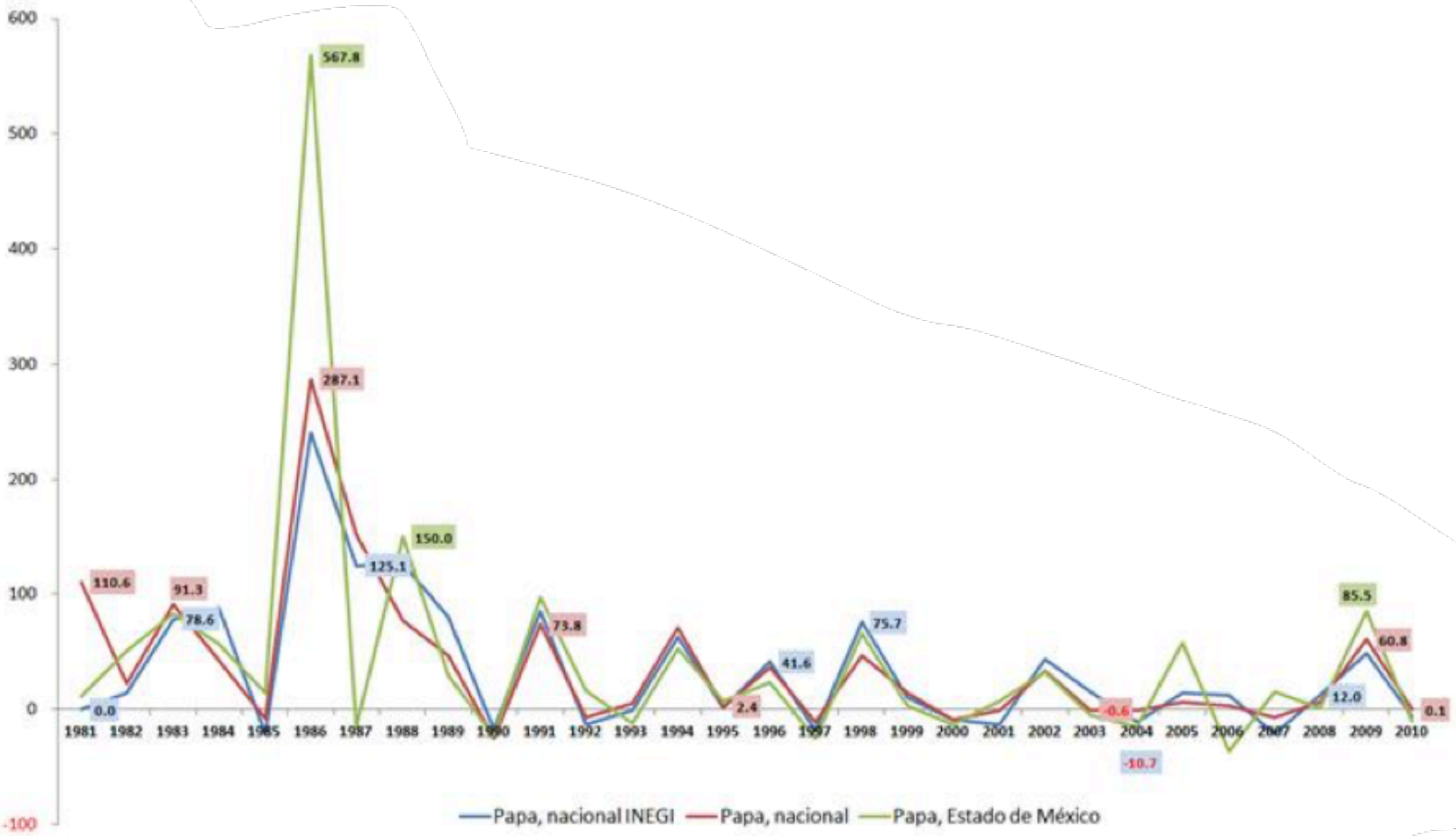

Fuente: elaboración propia con datos del SIAP-SAGARPA e INEGI.

\subsubsection{Precios de los principales cultivos forrajeros}

Las variaciones de los precios pagados a los agricultores (ver cuadro) que siembran forrajes en el Estado de México se tienen para los Rye Grass como parte de los cultivos innovadores, pues sus siembras son recientes en la entidad. El maíz forrajero también cuenta con variaciones aceptables. El incremento en la demanda de carnes a nivel nacional y mundial obliga a cubrir las necesidades alimenticias del ganado, de modo que el mantener el interés en productos forrajeros es una buen alternativa en función de las condiciones requeridas para el cultivo. 
Tabla 5.9 Variación porcentual anual de los Índices de Precios al Productor para forrajes en el Estado de México (2000-2010)

\begin{tabular}{|c|c|c|c|c|c|c|c|c|c|c|c|c|c|c|}
\hline & & & & & & & & & & \multicolumn{5}{|c|}{ Promedio de var $\%$ anual } \\
\hline Cultivo & 2000 & 2001 & 2002 & 2003 & 2004 & 2005 & 2006 & 2007 & 2008 & 2009 & 2010 & $1982-1990$ & $1990-2000$ & $2000-2010$ \\
\hline Total forrajes, nacional INEGI & 11.1 & 0.0 & -0.8 & 5.4 & 0.4 & -2.5 & 11.9 & 5.9 & 4.4 & 10.6 & -1.2 & 97.5 & 14.7 & 4.1 \\
\hline Total forrajes, nacional & 4.2 & -10.1 & -14.1 & -1.5 & 6.9 & .5 .5 & 8.4 & -0.0 & 13.1 & -0.3 & 7.6 & 71.6 & 17.5 & 0.8 \\
\hline Total forrajes, Estado de México & 21.2 & 10.8 & -31.7 & -18.9 & 1.6 & 1.3 & 4.9 & 20.8 & 2.4 & -2.9 & -4.2 & 86.3 & 42.5 & 0.5 \\
\hline Maiz Forrajero, nacional & -3.2 & -7.2 & 0.9 & -8.4 & 0.9 & 20.1 & -2.6 & 5.3 & 9.8 & -2.1 & 8.9 & 90.9 & 49.2 & 1.9 \\
\hline Maiz Forrajero, Estado de México & 26.9 & -47.3 & 29.1 & -7.5 & -2.3 & 18.3 & -8.6 & 37.5 & 3.9 & -2.3 & 4.2 & 103.0 & 240.4 & 4.7 \\
\hline Alfalfa, nacional INEGI & 4.9 & -5.6 & 0.2 & 6.5 & -3.3 & 4.1 & 3.4 & 8.3 & 5.5 & 10.0 & 2.0 & 97.5 & 16.4 & 3.3 \\
\hline Alfalfa Verde, nacional & -6.6 & -9.3 & 5.2 & -6.1 & -2.2 & 3.2 & 8.2 & 4.3 & 7.3 & 2.8 & 5.6 & 76.4 & 17.3 & 1.1 \\
\hline Alfalfa Verde, Estado de México & -20.2 & -5.2 & 6.7 & -1.8 & 14.1 & -23.6 & -0.0 & 90.6 & -38.5 & 5.4 & -2.8 & 79.4 & 42.7 & 2.2 \\
\hline Avena forrajera, nacional INEGI & 9.8 & 12.9 & 5.6 & -7.2 & 2.6 & -1.1 & 9.5 & 3.0 & 9.8 & 11.4 & 0.6 & nd & 13.9 & 5.2 \\
\hline Avena Forrajera, Nnacional & -2.6 & -26.8 & -19.6 & -11.3 & 20.5 & -6.1 & 7.2 & 8.8 & -13 & 4.1 & 7.7 & 103.9 & 16.1 & -1.8 \\
\hline Avena Forrajera, Estado de México & -29.0 & 0.3 & -49.8 & 44.1 & 8.3 & -8.3 & 6.4 & 5.4 & 9.3 & 9.6 & -9.4 & 95.0 & 40.7 & -3.7 \\
\hline Pasto forrajero, nacional INEGI & nd & nd & nd & nd & 2.1 & 8.0 & 20.0 & 2.9 & -1.1 & 11.4 & -4.2 & nd & nd & 3.3 \\
\hline Pastos, nacional & 17.7 & 8.1 & -27.2 & 9.3 & 6.8 & -14.1 & 11.9 & -6.2 & 22.6 & -3.6 & 8.7 & 98.2 & 19.8 & 1.6 \\
\hline Pastos, Estado de México & 57.8 & 34.4 & -39.3 & 40.8 & 6.8 & 6.4 & 11.7 & 9.8 & 13.5 & -11.6 & .5 .7 & 150.8 & 28.6 & 3.9 \\
\hline Otros forrajes, nacional INEGI & 15.4 & 2.0 & -2.1 & 6.3 & 6.8 & 0.7 & 10.8 & 31.4 & 20.7 & 5.7 & -3.1 & nd & 21.6 & 8.6 \\
\hline Rye Grass, nacional & -10.2 & -32.7 & 2.3 & -10.2 & 52.8 & -14.1 & 13.8 & -11.7 & 11.5 & 20.8 & 14.0 & 116.7 & 14.9 & 3.3 \\
\hline Rye Grass, Estado de México & nd & nd & nd & nd & nd & nd & nd & 5.5 & -24.7 & 35.4 & 6.9 & nd & nd & 5.8 \\
\hline
\end{tabular}

Fuente: elaboración propia con datos del SIAP-SAGARPA e INEGI.

\subsubsection{Precios de los principales frutales}

El comportamiento de los precios recibidos por el productor de los principales frutales del Estado de México permite identificar aumentos comúnmente por arriba de los que se tienen a nivel nacional, de modo que la decisión de tomar tales cultivos parece aceptable, independientemente de su representatividad a nivel nacional.

Tabla 5.10 Variación porcentual anual de los Índices de Precios al Productor para frutas en el Estado de México (2000-2010)

\begin{tabular}{|c|c|c|c|c|c|c|c|c|c|c|c|c|c|c|}
\hline & & & & & & & & & & \multicolumn{5}{|c|}{ Promedio de var $\%$ anual } \\
\hline Cultivo & 2000 & 2001 & 2002 & 2003 & 2004 & 2005 & 2006 & 2007 & 2008 & 2009 & 2010 & $1982-1990$ & $1990-2000$ & $2000-2010$ \\
\hline Frutas, nacional INEGI & 80 & 9.8 & 5.7 & 8.6 & 0.1 & 12.4 & 11.5 & 12.3 & 1.4 & 9.9 & 11.2 & 85.7 & 20.5 & 6.8 \\
\hline Aguacate, nacional & -44.5 & 15.2 & 16.2 & 32.4 & 3.8 & 21.0 & 7.9 & 30.8 & 1.9 & 14.2 & 4.5 & 69.3 & 22.1 & 6.4 \\
\hline Aguacate, nacional INEGI & -48.4 & 59.5 & -23.0 & 24.6 & -1.3 & 26.5 & 2.9 & 21.5 & 21.7 & 1.2 & 9.3 & 104.0 & 26.6 & 8.6 \\
\hline Aguacate, Estado de México & -4.8 & 34.0 & -12.7 & 21.0 & -24.7 & 29.3 & 6.6 & 49.5 & .0 .9 & 17.3 & 36.6 & 74.0 & 16.8 & 13.7 \\
\hline Durazno, nacional & -0.0 & -12.1 & -14.6 & 26.6 & 1.0 & 4.0 & 3.1 & 4.0 & 0.5 & 8.8 & -0.3 & 69.4 & 17.9 & 1.9 \\
\hline Durazno, nacional INEGI & 7.9 & 2.1 & 8.1 & -11.0 & -2.8 & 0.0 & 5.3 & 21.0 & 16.3 & -1.4 & -8.1 & 52.0 & 19.2 & 3.4 \\
\hline Durazno, Estado de Mécico & -4.6 & -1.7 & -16.9 & 11.9 & -27.1 & 20.3 & 13.4 & -0.1 & 8.3 & 8,3 & 26.1 & 68.4 & 23.6 & 1.9 \\
\hline Fresa, nacional & 7.8 & 11.9 & 20.1 & -2.6 & -4.2 & 31.3 & 2.1 & -9.7 & -13.7 & 18.1 & 10.7 & 71.6 & 17.0 & 6.5 \\
\hline Fresa, Estado de México & -24.9 & -0.2 & -25.6 & 61.1 & .24 .9 & 7.4 & -11.8 & 15.9 & 20.3 & -22.3 & 24.6 & 69.7 & 30.3 & 1.8 \\
\hline Guayaba, nacional & -27.4 & -1.7 & 0.3 & 9.5 & -6.2 & 6.6 & 24.1 & 16.2 & 2.1 & -19.6 & 14.3 & 79.2 & 21.0 & -0.1 \\
\hline Guayaba, nacional INEGI & -26.0 & -1.4 & -24.2 & -18.2 & 20.6 & -1.3 & 18.4 & 0.8 & 2.5 & 8.6 & 19.0 & 80.4 & 19.1 & 0.2 \\
\hline Guayaba, Estado de México & -15.5 & 41.5 & 0.3 & -1.4 & -20.1 & -5.2 & 33.0 & 0.4 & -12.0 & -9.4 & 47.2 & 108.7 & 17.3 & 5.3 \\
\hline Tuna, nacional & -12.0 & 4.1 & -10.7 & 38.3 & -21.6 & 50.2 & -13.9 & 38.4 & 4.9 & 8.3 & $-4,6$ & 106.3 & 7.4 & 7.4 \\
\hline Tuna, Estado de México & -7.0 & -1.0 & -16.2 & 53.8 & -36.2 & 142.5 & -33.1 & 88.6 & -12.5 & 23.5 & -6.8 & 179.4 & 12.8 & 17.8 \\
\hline
\end{tabular}

Fuente: elaboración propia con datos del SIAP-SAGARPA e INEGI.

El abasto local de gran cantidad de cultivos en la entidad mexiquense le permite contar con ventajas al evitar gastos en transporte en los que podrían incurrir comercializadores que pretendan abastecer desde otros estados. 
5.3.6 Precios de los principales cultivos en el Estado de México por ciclo y modalidad productiva

En las siguientes gráficas se presentan los precios de los principales cultivos sembrados en el Estado de México, por modalidad de riego o de temporal. El chile verde y el frijol son una muestra clara de que los precios mejor pagados se logran comúnmente fuera de la temporada de lluvias, pues aunque se cuente con riego en el ciclo $\mathrm{P}-\mathrm{V}$ los precios recibidos serán muy similares y la ventaja por disponer de agua será al obtener mayores volúmenes.

\section{Gráfico 5.16 Precio medio rural promedio anual 2000-2010 por ciclo productivo en el Estado de México (pesos/toneladas)}

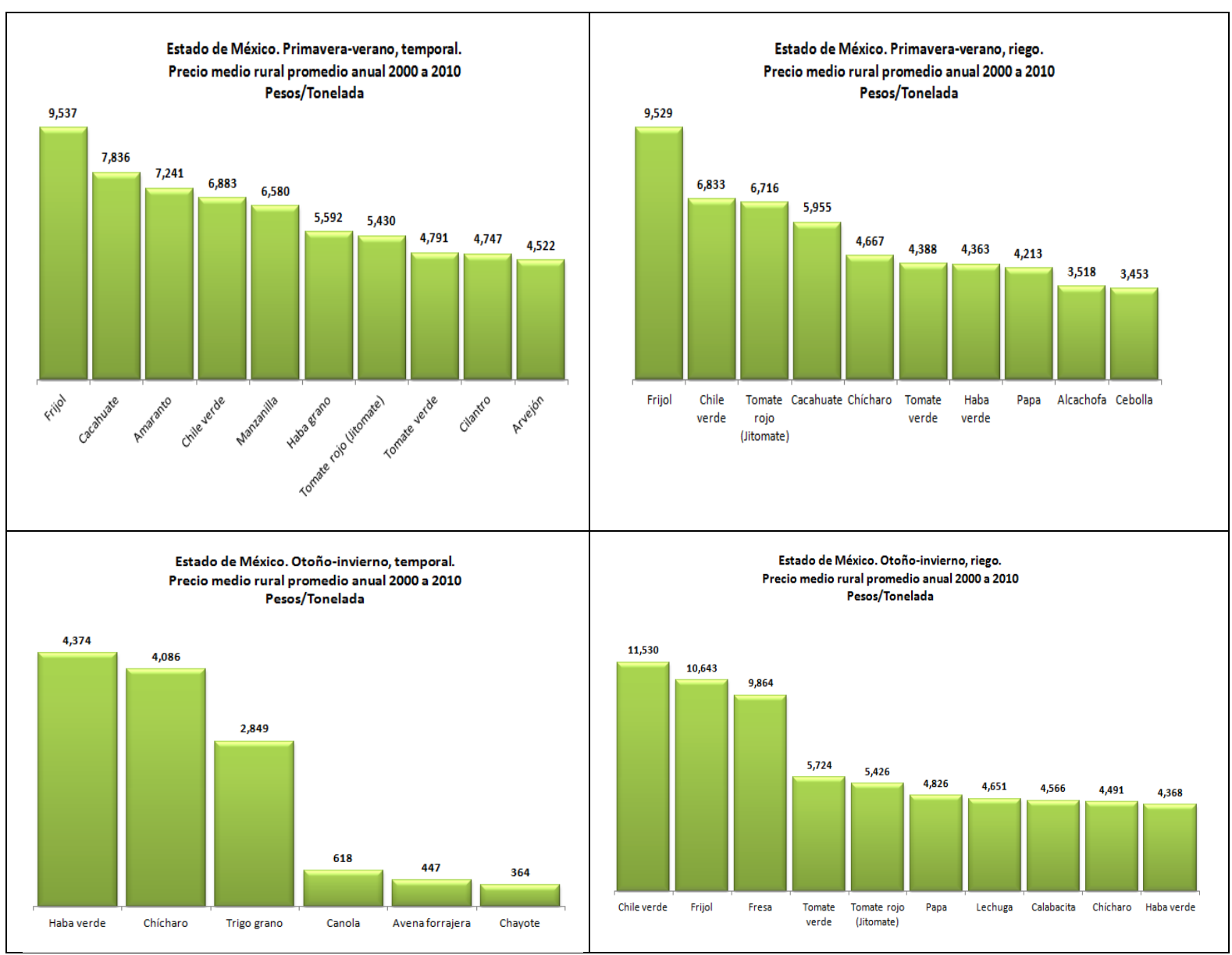

Fuente. Elaboración propia con datos del SIAP-SAGARPA. 


\subsection{Comparativo de los ciclos productivos y sus rendimientos}

Hasta el momento hemos conocido el desempeño y valor de producción agrícola registrado en el Estado de México tomando en consideración los ciclos productivos y los factores superficie sembrada, superficie sinietrada, volumenes cosechados, rendimientos y precios al productor. Con la finalidad de brindar mayor comprensión a las cifras ya descritas, en este apartado nos daremos a la tarea de explicarlas de manera gráfica. Las décadas que se utilizaron para la elaboración de las gráficas son 1980-1990, 1990-2000 y 2000-2010.

Tomando en cuenta los volúmenes de producción agrícola del Estsado de México que representa cada ciclo productivo, se concluye que el ciclo P-V de temporal se ha mantenido como el más productivo.

Tabla 5.11 Volumen de producción (\%) por ciclo productivo en el Estado de México 1980-2010

\begin{tabular}{lrrrr}
\cline { 2 - 4 } & \multicolumn{4}{c}{ Promedios anuales } \\
\hline & $1980-1990$ & $1990-2000$ & $2000-2010$ \\
\hline & 48 & 49 & 53 \\
PV temporal & 47 & 27 & 19 \\
PV riego & 1 & 0.07 & 0.08 \\
OI temporal & 3 & 3 & 3 \\
OI riego & 3 & 2 & 3 \\
Perennes temporal & 28 & 19 & 22 \\
Perennes riego & & & \\
& & &
\end{tabular}

Fuente. Elaboración propia con datos del SIAP-SAGARPA.

Gráfica 5.17 Volumen de producción agrícola (\%) por ciclo productivo en el Estado de México 1980-1990

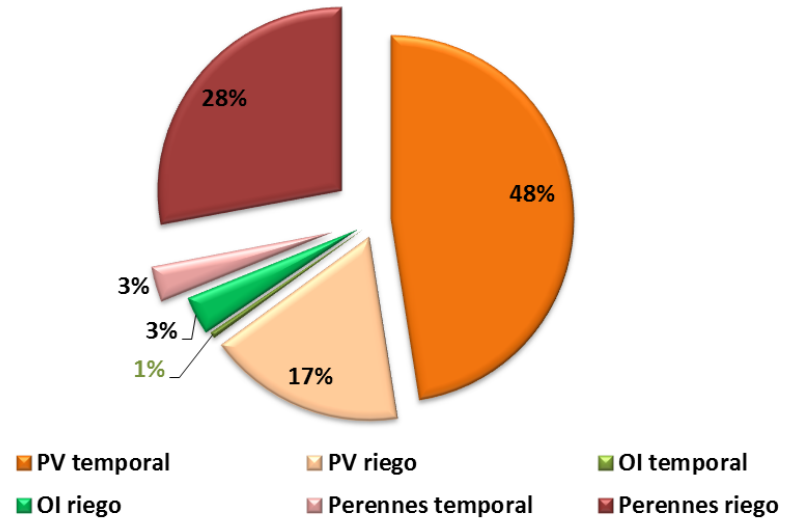

Fuente: Elaboración propia con datos de SIAP-SAGARPA. 
Gráfica 5.18 Volumen de producción agrícola (\%) por ciclo productivo en el Estado de México 1990-2000
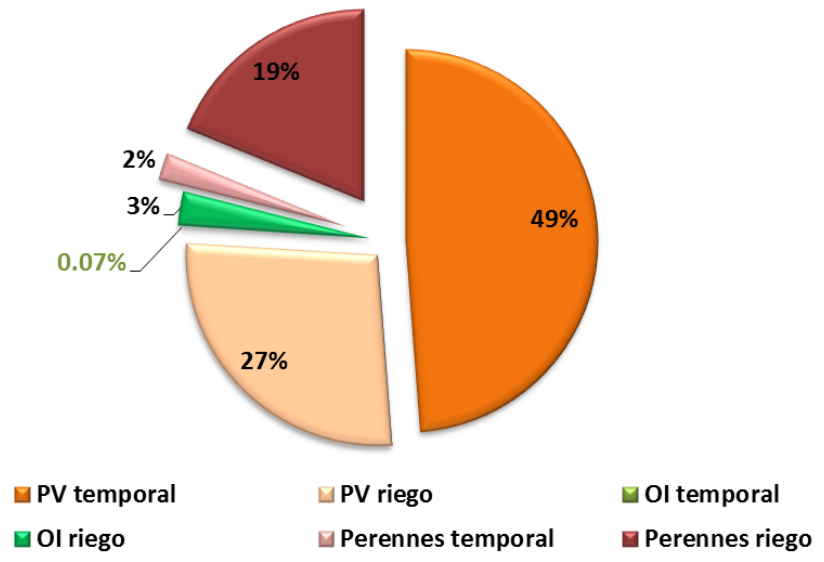

Fuente: Elaboración propia con datos de SIAP-SAGARPA.

Gráfica 5.19 Volumen de producción agrícola (\%) por ciclo productivo en el Estado de México 2000-2010

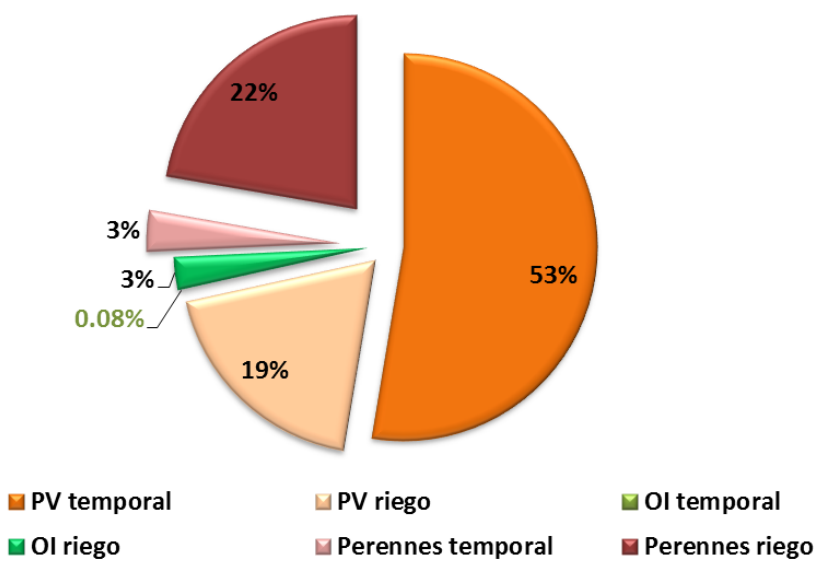

Fuente: Elaboración propia con datos de SIAP-SAGARPA. 
Tomando como referencia el valor de producción de la entidad mexiquense en pesos sucede lo mismo, el ciclo P-V de temporal ocupa el primer lugar.

Tabla 5.12 Valor de producción (pesos) por ciclo productivo en el Estado de México 1980-2010

\begin{tabular}{lrrr}
\cline { 2 - 4 } & \multicolumn{3}{c|}{ Promedios anuales } \\
\hline & $1980-1990$ & \multicolumn{1}{c}{$1990-2000$} & $2000-2010$ \\
\hline PV temporal & $\mathbf{3 0 5 , 8 3 1 , 1 3 6}$ & $\mathbf{2 , 9 1 5 , 2 1 3 , 4 2 4}$ & $\mathbf{4 , 9 6 1 , 2 1 8 , 5 8 0}$ \\
PV riego & $104,577,777$ & $\mathbf{1 , 1 1 6 , 7 4 9 , 5 9 9}$ & $\mathbf{2 , 2 6 0 , 5 7 8 , 1 5 3}$ \\
OI temporal & $\mathbf{1 , 1 1 4 , 6 7 7}$ & $\mathbf{7 , 1 7 6 , 6 8 2}$ & $\mathbf{1 3 , 1 1 7 , 3 6 9}$ \\
Ol riego & $\mathbf{2 6 , 7 2 9 , 6 3 8}$ & $\mathbf{2 4 6 , 5 9 2 , 2 8 9}$ & $\mathbf{6 6 7 , 6 0 1 , 2 4 3}$ \\
Perennes temporal & $\mathbf{5 0 , 0 7 2 , 7 6 4}$ & $\mathbf{7 0 0 , 0 7 7 , 5 8 2}$ & $\mathbf{1 , 7 1 7 , 0 4 6 , 1 2 5}$ \\
Perennes riego & $\mathbf{3 3 , 6 7 5 , 0 8 2}$ & $\mathbf{6 3 3 , 4 6 2 , 3 6 6}$ & $\mathbf{1 , 2 1 8 , 6 0 8 , 0 8 1}$ \\
& & & \\
\hline
\end{tabular}

Fuente: Elaboración propia con datos de SIAP-SAGARPA.

\section{Gráfica 5.20 Valor de producción agrícola (pesos) promedio por ciclo productivo en el Estado de México 1980-1990}

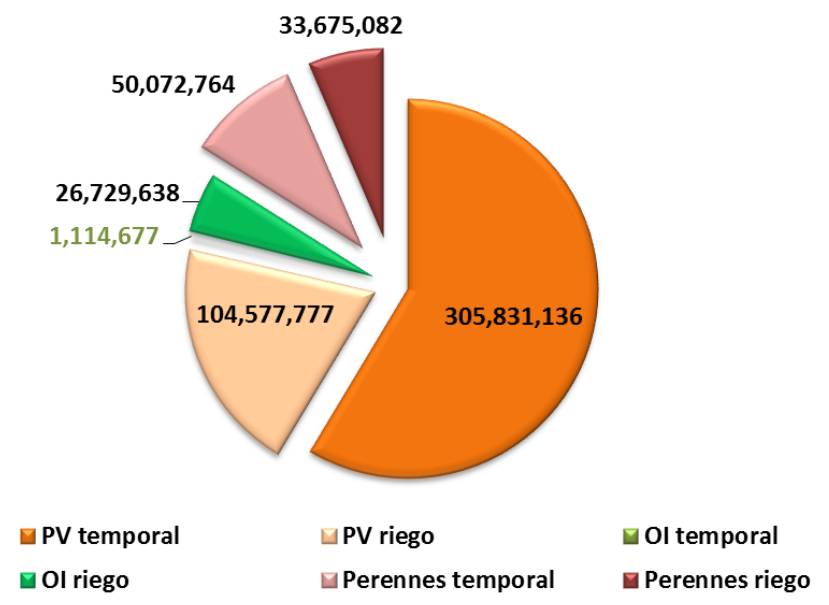

Fuente: Elaboración propia con datos de SIAP-SAGARPA. 
Gráfica 5.21 Valor de producción agrícola (pesos) promedio por ciclo productivo en el Estado de México 1990-2000

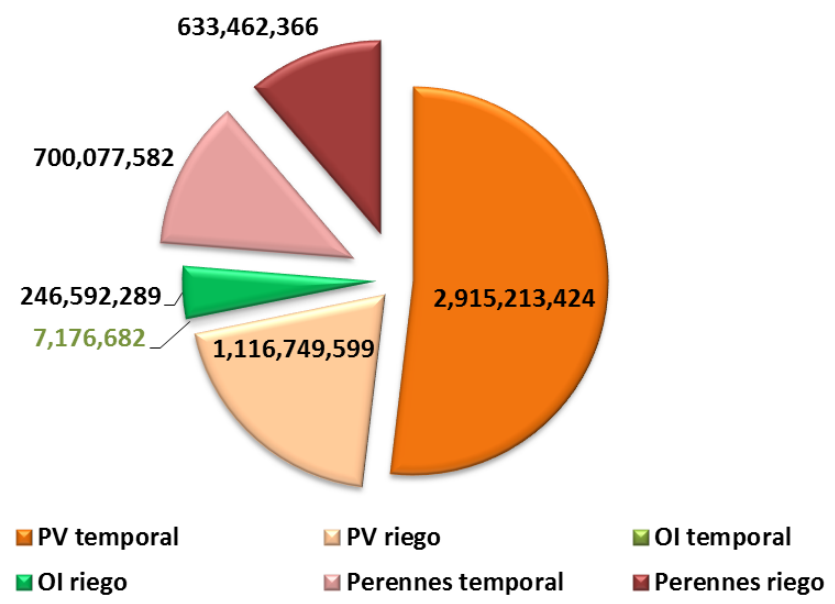

Fuente: Elaboración propia con datos de SIAP-SAGARPA.

Gráfica 5.22 Valor de producción agrícola (pesos) promedio por ciclo productivo en el Estado de México 2000-2010

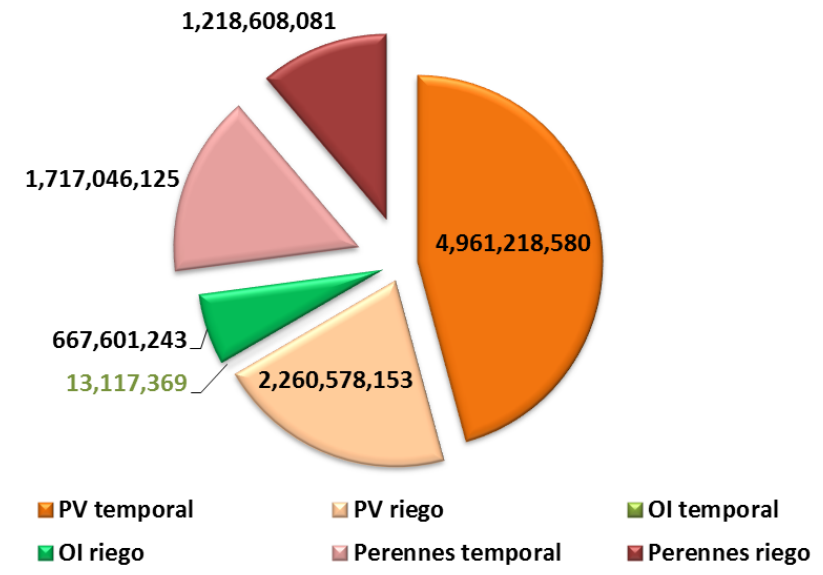

Fuente: Elaboración propia con datos de SIAP-SAGARPA. 
Analizando el volúmen de producción de maíz continuamos con la tendencia de que es el ciclo P-V de temporal el más productivo.

Tabla 5.13 Volumen de producción (toneladas) de maíz grano por ciclo productivo en el Estado de México

\begin{tabular}{lrrr}
\cline { 2 - 4 } & \multicolumn{3}{c|}{ Promedios anuales } \\
\hline & \multicolumn{1}{c}{$1980-1990$} & $1990-2000$ & $2000-2010$ \\
\hline PV temporal & $1,431,043$ & $1,499,304$ & $1,360,913$ \\
PV riego & 393,199 & 417,361 & 401,983 \\
OI riego & 441 & 1,418 & 1,349 \\
& & & \\
\hline
\end{tabular}

Fuente: Elaboración propia con datos de SIAP-SAGARPA.

Gráfica 5.23 Volumen de producción (toneladas y \%) de maíz grano por ciclo productivo en el Estado de México 1980-1990

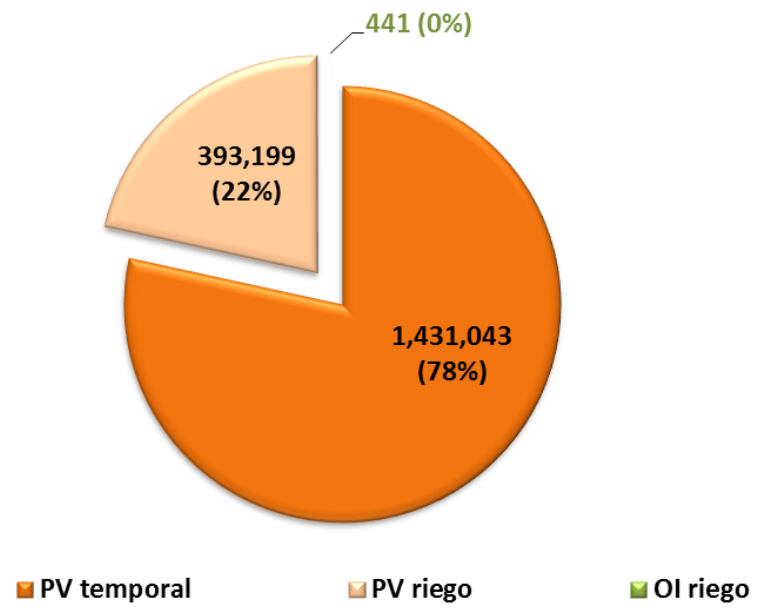

Fuente: Elaboración propia con datos de SIAP-SAGARPA. 
Gráfica 5.24 Volumen de producción (toneladas y \%) de maíz grano por ciclo productivo en el Estado de México 1990-2000

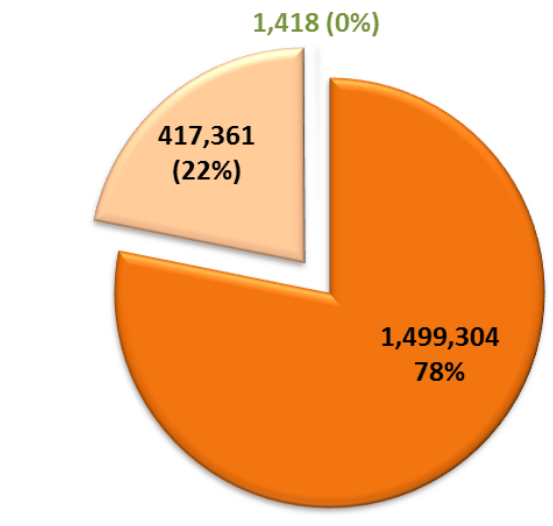

$\square \mathrm{PV}$ temporal $\square \mathrm{PV}$ riego $\square \mathrm{OI}$ riego

Fuente: Elaboración propia con datos de SIAP-SAGARPA.

Gráfica 5.25 Volumen de producción (toneladas y \%) de maíz grano por ciclo productivo en el Estado de México 2000-2010

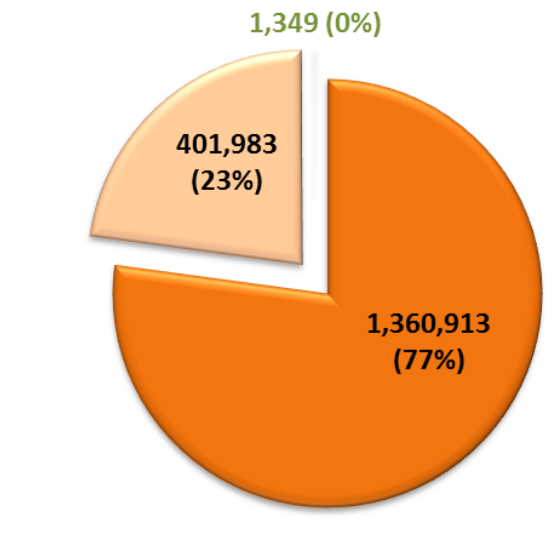

$\square \mathrm{PV}$ temporal $\square \mathrm{PV}$ riego $\square \mathrm{OI}$ riego

Fuente: Elaboración propia con datos de SIAP-SAGARPA. 
No obstante, encontramos un cambio en los resultados obtenidos hasta el momento cuando nos referimos al volúmen de producción del maíz forrajero, el utilizado para alimentar al ganado. En este caso es el ciclo P-V de riego el que arroja las cifras más elevadas de todas las décadas analizadas.

Tabla 5.14 Volumen de producción (toneladas) de maíz forrajero por ciclo productivo en el Estado de México

\begin{tabular}{lrrr} 
& \multicolumn{3}{c}{ Promedios anuales } \\
\cline { 2 - 5 } & $1980-1990$ & $1990-2000$ & $2000-2010$ \\
\hline PV temporal & 73,475 & 316,936 & 501,267 \\
PV riego & 258,339 & 451,482 & 653,405 \\
Ol riego & 5,445 & 1,347 & 1,647 \\
& & & \\
\hline
\end{tabular}

Fuente: Elaboración propia con datos de SIAP-SAGARPA.

Gráfica 5.26 Volumen de producción (toneladas y \%) de maíz forrajero por ciclo productivo en el Estado de México 1980-1990

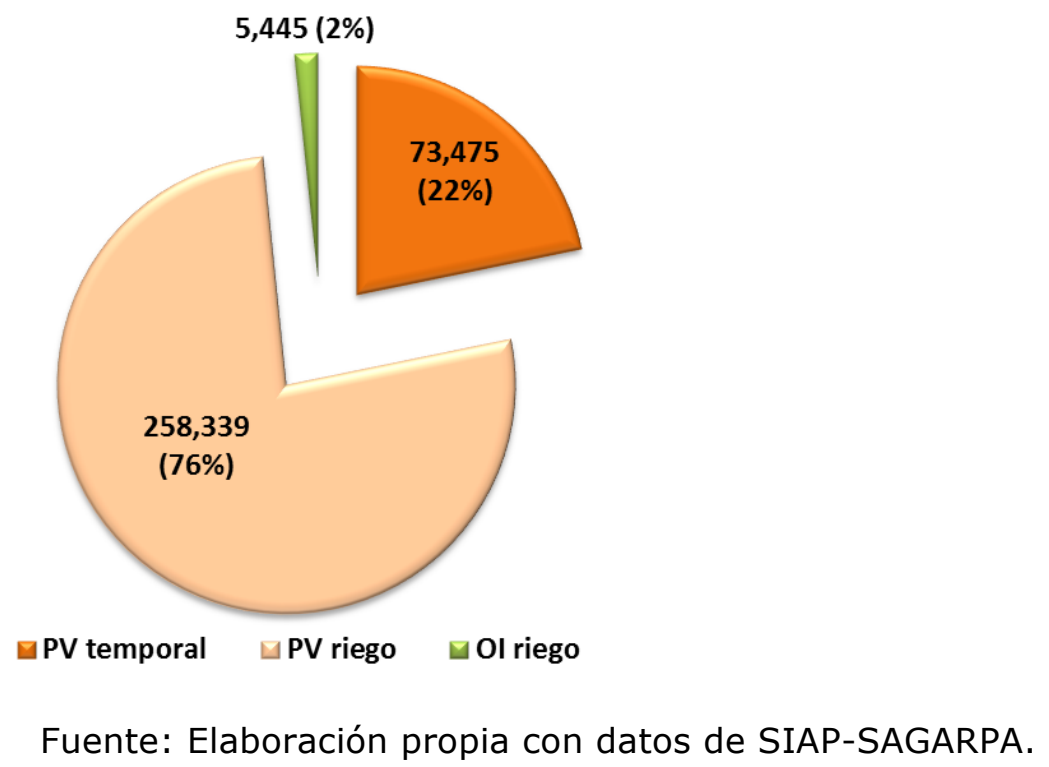


Gráfica 5.27 Volumen de producción (toneladas y \%) de maíz forrajero por ciclo productivo en el Estado de México 1990-2000

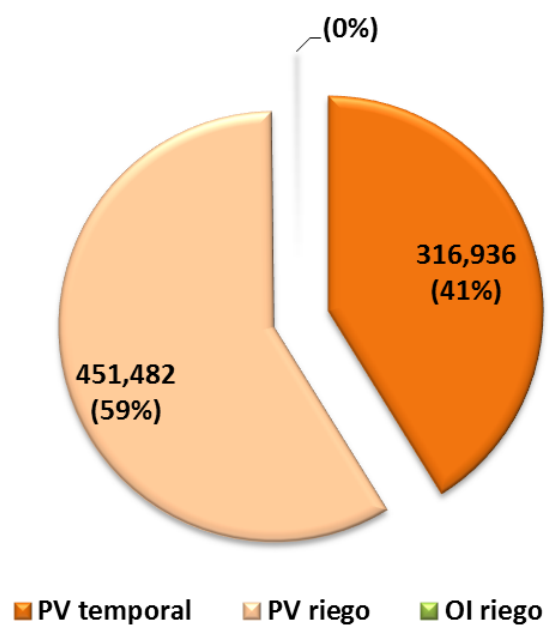

Fuente: Elaboración propia con datos de SIAP-SAGARPA.

Gráfica 5.28 Volumen de producción (toneladas y \%) de maíz forrajero por ciclo productivo en el Estado de México 2000-2010

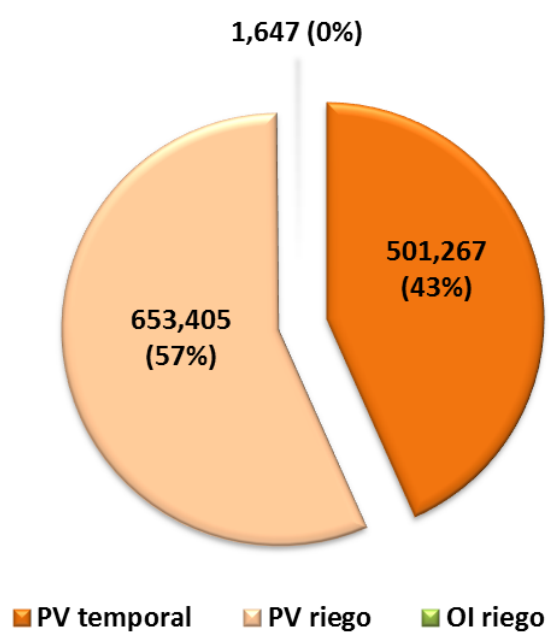

Fuente: Elaboración propia con datos de SIAP-SAGARPA. 
¿Qué ciclo de cultivos resultan menos afectados por cuestiones climáticas? En las gráficas siguientes es posible observar que el ciclo P-V de temporal arroja la mayor cantidad de hectáreas siniestradas. Resulta interesante comparar que el cultivo $\mathrm{P}-\mathrm{V}$ de temporal arroja cifras significativamente menores, aunque la disparidad puede ser explicada por las hectáreas cultivadas de ambas maneras.

Tabla 5.15 Superficie siniestrada (hectáreas) por ciclo productivo en el Estado de México

\begin{tabular}{lrrrr} 
& \multicolumn{4}{c|}{ Promedios anuales } \\
\cline { 2 - 5 } & $1980-1990$ & $1990-2000$ & $2000-2010$ \\
\hline PV temporal & 49,778 & 18,224 & 19,674 \\
PV riego & 4,328 & 2,402 & 1,701 \\
Ol temporal & 15 & 11 & 2 \\
Ol riego & 187 & 290 & $\mathbf{7 4}$
\end{tabular}

Fuente: Elaboración propia con información de SIAP-SAGARPA.

Fuente: Elaboración propia con datos de SIAP-SAGARPA.

\section{Gráfica 5.29 Superficie siniestrada (hectáreas) por ciclo productivo en el Estado de México 1980-1990}

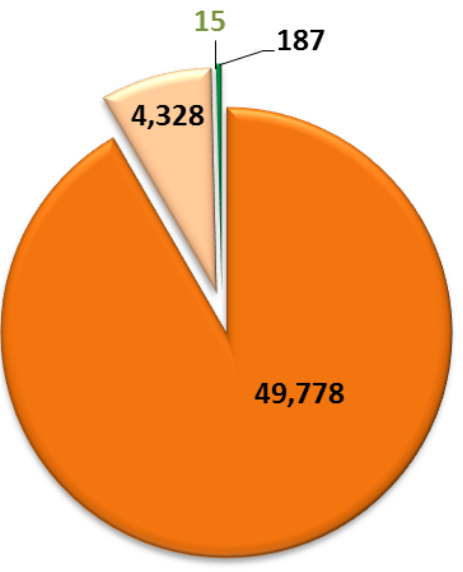

$\square$ PV temporal $\square$ PV riego $\square$ OI temporal $\square$ OI riego

Fuente: Elaboración propia con datos de SIAP-SAGARPA. 
Gráfica 5.30 Superficie siniestrada (hectáreas) por ciclo productivo en el Estado de México 1990-2000

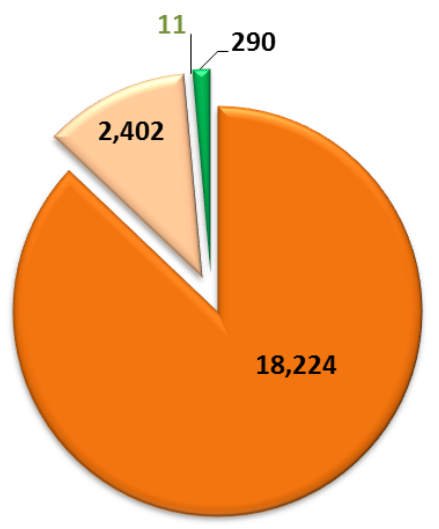

$\square \mathrm{PV}$ temporal $\square \mathrm{PV}$ riego $\square \mathrm{OI}$ temporal $\square \mathrm{OI}$ riego

Fuente: Elaboración propia con datos de SIAP-SAGARPA.

Gráfica 5.31 Superficie siniestrada (hectáreas) por ciclo productivo en el Estado de México 2000-2010

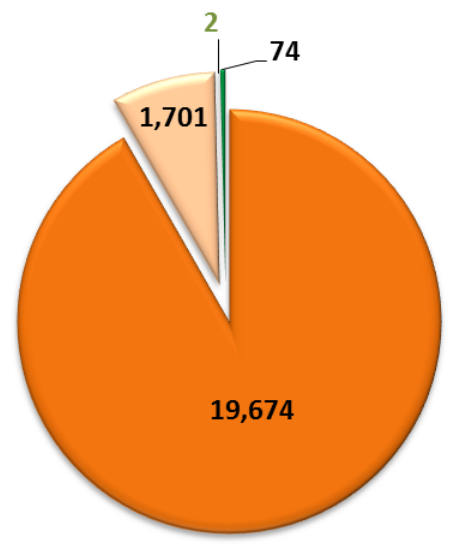

$$
\square \mathrm{PV} \text { temporal } \square \mathrm{PV} \text { riego } \square \mathrm{OI} \text { temporal } \square \mathrm{OI} \text { riego }
$$

Fuente: Elaboración propia con datos de SIAP-SAGARPA. 


\section{CAPITULO 6}

\section{CAMBIOS ESTRUCTURALES EN LOS PRECIOS PARA LOS COMMODITIES SELECCIONADOS}

En este capitulo se aplican un grupo de contrastes de raíz unitaria y estacionariedad para estudiar la hipótesis de cambios estructurales en el precios para 8 commodities seleccionados: avena forrajera, cebada, frijol, maíz grano, papa, pasto, sorgo y trigo. Los precios de los commodities seleccionados resultaron ser no estacionarios, a pesar de que se registraron cambios estructurales significativos con la prueba Lee-Strazicich.

\subsection{Pruebas Estacionarias y de Raíz Unitaria}

Esta sección se ha aplicado tanto en contrastes de estacionariedad como de raíz unitaria a los Índices de Precios al Productor, específicamente los Índices de precios genéricos para producción total, de los commodities seleccionados (avena forrajera, cebada, frijol, maíz grano, papa, pasto, sorgo y trigo). Estados datos se obtuvieron del INEGI. Los datos son mensuales y el periodo varía según el commodity:

Cuadro 6.1 Periodo analizado por commodity

\begin{tabular}{|c|c|}
\hline COMMODITY & PERIODO \\
\hline Avena forrajera & $1994: 1$ al $2012: 6$ \\
\hline Cebada & $1987: 1$ al $2012: 6$ \\
\hline Frijol & $1987: 1$ al $2012: 6$ \\
\hline Maíz grano & $1987: 1$ al $2012: 6$ \\
\hline Papa & $1986: 1$ al $2012: 6$ \\
\hline Pasto & $2004: 1$ al $2012: 6$ \\
\hline Sorgo & $1987: 1$ al $2012: 6$ \\
\hline Trigo & $1988: 1$ al $2012: 6$ \\
\hline
\end{tabular}

Fuente: elaboración propia.

A continuación, se muestra la representación gráfica de las variables. 


\section{Gráfica 6.1 Precios de commodities seleccionados en México}
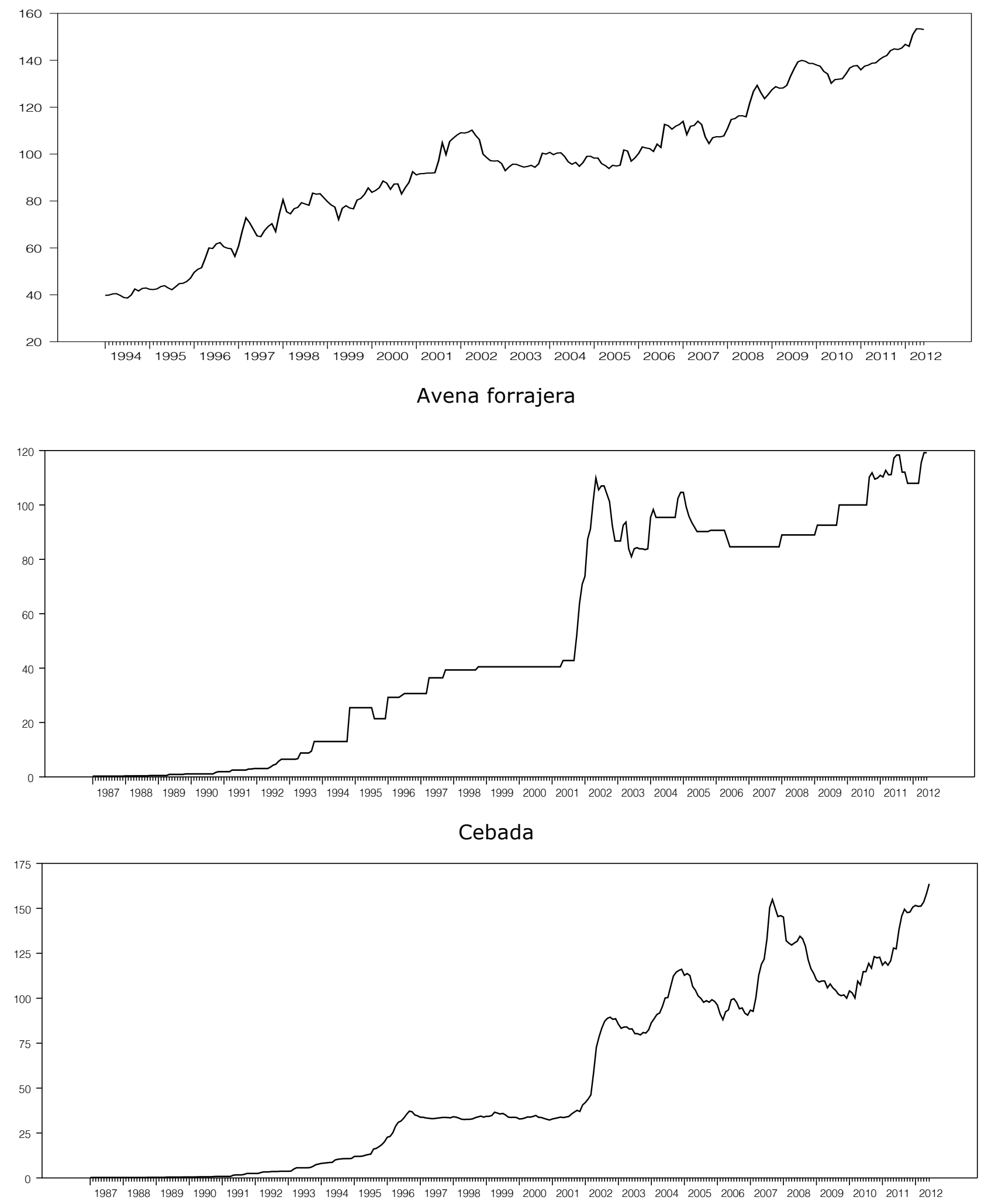

Frijol 


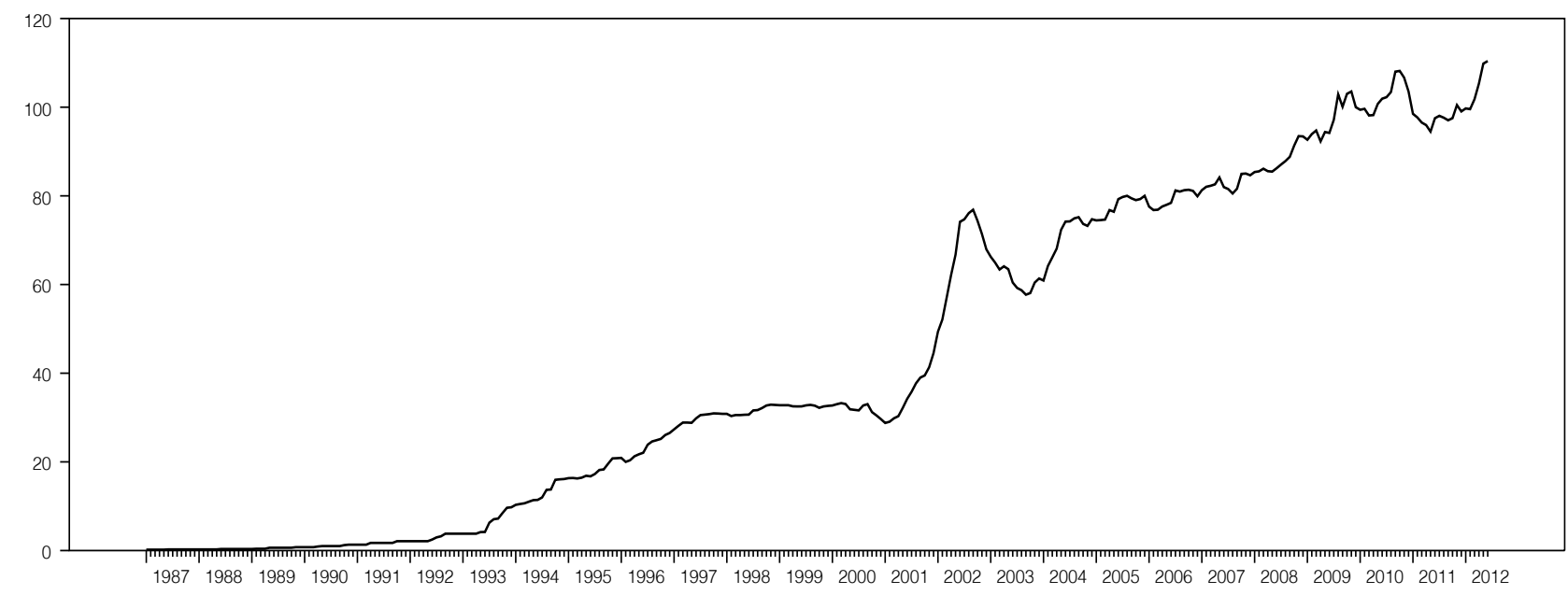

\section{Maíz grano}

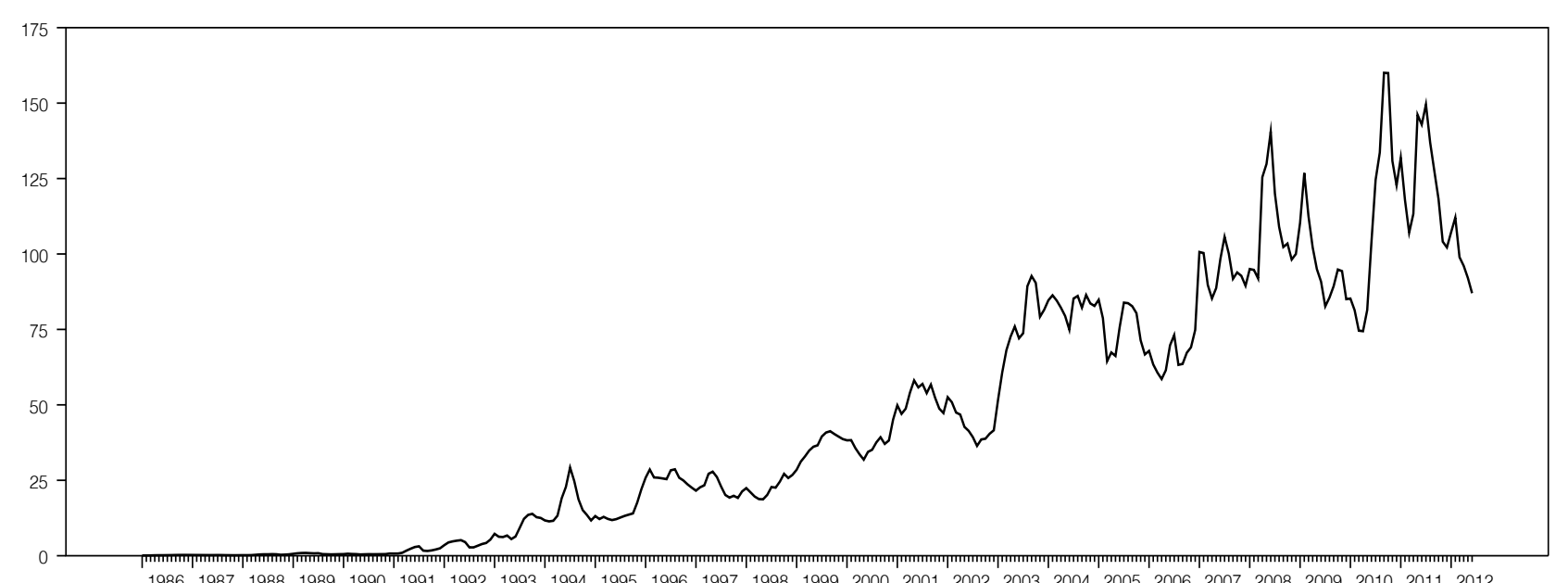
$198619871988198919901991199219931994 \quad 199519961997199819992000200120022003200420052006200720082009201020112012$

Papa

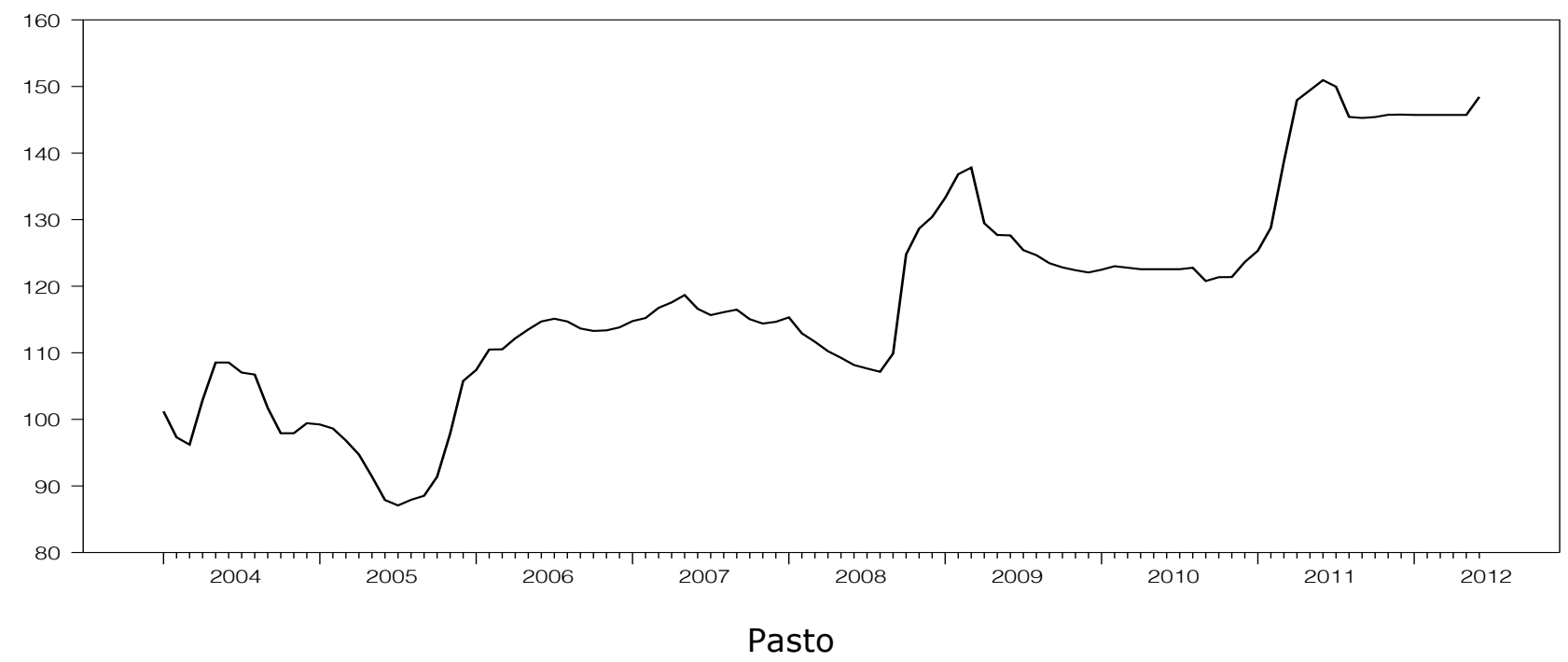



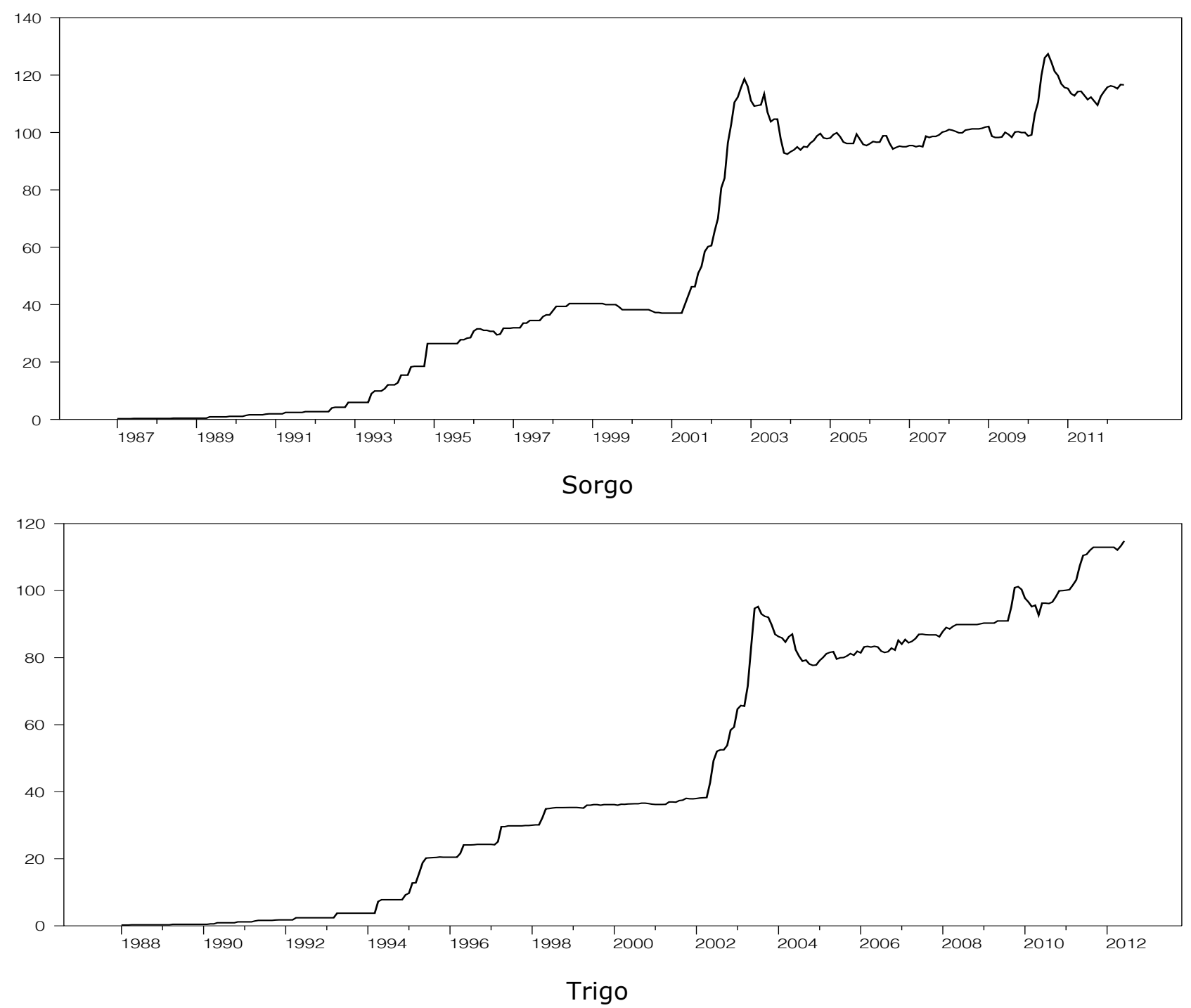

Fuente: elaboración propia utilizando datos del Índice Nacional de Precios al Productor/Índices de Precios Genéricos para producción total (INEGI).

Para realizar los contrastes de raíz unitaria para los precios de los commodities se eligió aplicar dos grupos de estadísticas: la prueba ADF y las pruebas M- propuestas por $\mathrm{Ng}$ y Perron (2001). La elección del retardo es crucial, pues si se eligen demasiado pocos el proceso tendrá errores auto correlacionados que sesgarán el resultado; si, por el contrario, se eligen demasiados retardos, el contraste tendrá baja potencia. Para la selección del truncamiento (k) seguiremos la recomendación de $\mathrm{Ng}$ y Perron (2001). Tal y como señalan estos autores, los criterios de información tradicionales, tales 
como el AIC y el BIC, tienden a seleccionar un truncamiento demasiado bajo. Esto, en su turno, puede provocar un error de Tipo I (es decir, rechazar la hipótesis de nulidad de condición no estacionaria cuando es verdad), sesgando el contraste. Para solucionar este tipo de problemas, Ng y Perron (2001) sugieren usar un AIC (MAIC) modificado con un factor de penalidad que sea dependiente del muestreo.

$\mathrm{Ng}$ y Perron (2001) también definen cuatro pruebas estadísticas basadas en los Mínimos Cuadrados Generalizados (en lo sucesivo, MCG) con datos descartados. Elliot et al. (1996) propuso descartar datos para mejorar el poder de las pruebas $\mathrm{y}$, de acuerdo a $\mathrm{Ng}$ y Perron (2001) deben ser usadas en conjunto con un $\mathrm{k}$ elegido apropiadamente. Las Ilamadas pruebas $\mathrm{M}$ - son las siguientes: MZaGLS y MZt GLS son las versiones modificadas de las pruebas $\mathrm{Za}$ y Zt por Phillips (1987) y Phillips y Perron (1988); la prueba MSB GLS2, una versión modificada de la prueba de Bhargava (1986) R1 y la prueba MP T GLS, que es la versión modificada de la Prueba de Punto Óptimo por Elliott et al. (1996).

La tabla 6.2 presenta los resultados de la prueba ADF, donde la hipótesis nula de no estacionariedad solo puede ser rechazada para el maíz grano y pasto con un nivel de significatividad del 1 y $5 \%$ respectivamente.

La Tabla 6.3 presenta los resultados de la aplicación del contraste de estacionariedad de Kwiatkowski et al. (1992). Para las variables en niveles, en los que el modelo relevante nr, se especifica con tendencia, se rechaza la estacionariedad para todos los commodities en el 1\%, con la excepción del pasto.

La Tabla 6.4 presenta los resultados de las pruebas de raíz unitaria de $\mathrm{Ng}$ y Perron (2001). Para los valores indicados de MZA-OLS se confirma la existencia de raíz unitaria. Para los valores de MSB-OLS se rechaza la hipótesis nula al $1 \%$ de significatividad. Para los valores de MZT-OLS se confirma la existencia de raíz unitaria. Para los valores de MPT-OLS se rechaza la hipótesis nula al $10 \%$ de significatividad.

Por lo tanto, de acuerdo a los dos tipos de prueba (del tipo M- y las pruebas KPSS), el pasto parece ser estacionario. 


\section{Cuadro 6.2. Prueba $A D F^{G L S}$ de raíz unitaria para precios de commodities seleccionados}

\begin{tabular}{lr} 
Commodity & ADF GLS \\
\hline Avena forrajera & -2.2053 \\
Cebada & -1.1742 \\
Frijol & -0.8318 \\
Maíz grano & $-6.2389 * * *$ \\
Papa & -1.1363 \\
Pasto & $-3.5964 * *$ \\
Sorgo & -2.2249 \\
Trigo & -2.6024 \\
\hline Los símbolos *, ** y *** se refieren al rechazo \\
de la hipótesis nula de la raíz unitaria al 10,5 y \\
$1 \%$ respectivamente. Los valores críticos para la \\
prueba ADF son $-3.98(1 \%),-3.42(5 \%)$ y -3.13 \\
$(10 \%)$ y fueron obtenidos de Mackinnon (1996).
\end{tabular}

\section{Cuadro 6.3. Prueba KPSS de estacionariedad para precios de commodities seleccionados}

\begin{tabular}{lr} 
Commodity & $\eta_{T}$ \\
\hline Avena forrajera & $0.687040 *$ \\
Cebada & $1.411206 *$ \\
Frijol & $1.363266 *$ \\
Maíz grano & $0.732449 *$ \\
Papa & $1.376697 *$ \\
Pasto & 0.061201 \\
Sorgo & $1.374477 *$ \\
Trigo & $1.348698 *$ \\
\hline Los símbolos * y $* *$ se refieren al rechazo de la \\
hipótesis nula de estacionariedad al 1 y $5 \%$ \\
respectivamente. Los valores críticos para $\eta_{T}$ son \\
$0.2160(1 \%)$ y 0.1460 (5\%) y fueron obtenidos \\
de RATS.
\end{tabular}




\section{Cuadro 6.4. Prueba Perron-NG de raíz unitaria para precios de commodities seleccionados}

\begin{tabular}{lcccc} 
Commodity & MZA-OLS & MSB-OLS & MZT-OLS & MPT-OLS \\
\hline Avena forrajera & -3.05206 & $0.38836 * * *$ & -1.18529 & $193.00849 *$ \\
Cebada & 0.07790 & $0.75656 * * *$ & 0.05894 & $308.37395 *$ \\
Frijol & 0.27342 & $0.87653 * * *$ & 0.23966 & $312.93135 *$ \\
Maíz grano & -0.30802 & $0.89855 * * *$ & -0.27677 & $286.11973 *$ \\
Papa & -0.65228 & $0.50414 * * *$ & -0.32884 & $209.93722 *$ \\
Pasto & -6.72331 & $0.26938 * * *$ & -1.81112 & $46.59409 *$ \\
Sorgo & 0.35686 & $0.84984 * * *$ & 0.30327 & $335.90717 *$ \\
Trigo & 0.20436 & $0.79376 * * *$ & 0.16221 & $312.77821 *$ \\
\hline \multicolumn{5}{c}{ Valores críticos para el modelo Perron-NG: } \\
\hline $1 \% \quad(* * *)$ & MZA-OLS & MSB-OLS & MZT-OLS & MPT-OLS \\
\hline $5 \% \quad(* *)$ & -23.80 & 0.14 & -3.42 & 4.03 \\
$10 \%(*)$ & -17.30 & 0.16 & -2.91 & 5.48 \\
\hline
\end{tabular}

\subsection{Contrastes de raíz unitaria con cambios estructurales}

La sección previa apuntó a la posible no estacionariedad de los precios de los commodities considerados. Sin embargo, como señaló Perron (1989), es muy probable que las variables sean estacionarias en torno a un proceso con cambios estructurales. De hecho, las pruebas de raíz unitaria tienen un poder bajo cuando las variables analizadas sufren inestabilidades o cambios estructurales. Sin embargo, Perron (1989) trató los cambios como exógenos, una cuestión que fue criticada ya que podía involucrar extracción de datos (data mining). Zivot y Andrews (1992), Banerjee et al. (1992) y Perron (1997) propusieron las pruebas de raíz unitaria con cambios estructurales desconocidos. Además, la literatura también ha considerado la posibilidad de más de un cambio estructural, como lo dicho por Lumsdaine y Papell (1997).

Desde la inspección visual de la gráfica 6.1 , se pueden detectar algunas inestabilidades, generalmente originadas por reformas institucionales o la propia apertura del mercado. Por lo tanto, esta sección aplica pruebas de raíz unitaria que permiten cambios estructurales. Primero, Perron y Rodríguez 
(2003) que es una extensión de las pruebas $M$ - aplicadas antes, permiten contrastar la existencia de un cambio endógeno en la tendencia del proceso. Segundo, hemos aplicado las pruebas de raíz unitaria de Lumsdaine y Papell (1997) para dos cambios estructurales.

Perron y Rodríguez (2003) contribuyen con la literatura de dos maneras. Primero, el uso de las pruebas M GLS, analizadas por Perron y $\mathrm{Ng}$ (1996), debido a sus distorsiones de tamaño menor, y los extienden para permitir un solo cambio en la función de tendencia. Segundo, siguiendo a Elliott et al. (1996), se usa GLS. Usar GLS durante la construcción de las pruebas Mpermite una ganancia sustancial en el poder como se muestran $\mathrm{Ng}$ y Perron (2001), similar a la prueba DF GLS propuesta por Elliott et al. (1996). Perron y Rodríguez (2003) consideran dos especificaciones: una con un cambio en la pendiente de la función de tendencia y otra con un cambio tanto en la intercepción como en la pendiente. El punto de cambio se trata como desconocido y sugiere estimar a g el punto de cambio que conlleva el valor mínimo de las estadísticas. Ellos estimulan los valores críticos asintóticos y recomiendan elegir un truncamiento usando el AIC Modificado.

\section{Cuadro 6.5 Prueba Perron-Rodríguez de raíz unitaria con cambio en tendencia} para precios de commodities seleccionados

\begin{tabular}{lccc} 
Commodity & $M Z_{t}^{G L S}$ & $K$ & $T_{B}$ \\
\hline Avena forrajera & 3.09683 & 2 & $1998: 04$ \\
Cebada & 2.92863 & 0 & $1996: 08$ \\
Frijol & 3.36489 & 8 & $1996: 04$ \\
Maíz grano & 3.75263 & 5 & $1989: 10$ \\
Papa & 3.73210 & 5 & $1995: 07$ \\
Pasto & 3.82363 & 1 & $2006: 04$ \\
Sorgo & 10.44875 & 12 & $1996: 11$ \\
Trigo & 11.68474 & 12 & $1997: 04$ \\
\hline Los símbolos *, ** y *** se refieren al rechazo de la \\
hipótesis nula de la raíz unitaria al 10, 5 y 1\% \\
respectivamente. Los valores críticos para el modelo son \\
1\%(-3.93), 5\%(-3.56) y 10\%(-3.36).
\end{tabular}


Desde la aplicación de la prueba Perron-Rodríguez, no es posible rechazar la hipótesis nula de raíz unitaria a pesar de la existencia de cambios estructurales.

Para evitar el restringir a que las variables tengan solo un cambio estructural, las pruebas propuestas por Lumsdaine y Papell (1997) también fueron aplicadas permitiendo hasta dos cambios estructurales en las variables en tendencia. Estos autores proponen una versión de la prueba de raíz unitaria tipo DF para dos cambios estructurales determinados de modo endógeno.

De las tres especificaciones posibles, Lumsdaine y Papell (1997) sugieren elegir una de las menos favorables para la nulidad de la hipótesis, ya que las pruebas están sesgadas hacia el no-rechazo de la hipótesis nula. Se debe notar, sin embargo, que los modelos de interés del caso presente y aquellos directamente comparables con los resultados de un quiebre son los modelos que permiten cambios en la pendiente.

El cuadro 6.6 permite observar que para los commodities avena forrajera, frijol, maíz grano, papa y pasto, la hipótesis nula de no estacionariedad se confirma. En cambio, para la cebada se rechaza la hipótesis nula indicando la estacionaridad del commodity, cuyos cambios estructurales son significativos para 1994:10 y 2001:09. En el cuadro 2.3 Proceso de liberalización de productos alimentarios seleccionados en el marco del TLCAN (1989-2008) se observa que los aranceles para la cebada fueron liberados hasta el 2003, por tanto, los cambios estructurales no podrían atribuirse en este caso al proceso de liberalización generado en México por la firma del TLCAN. Finalmente, los resultados de esta prueba de raíz unitaria con dos cambios estructurales indican para el caso del sorgo y del trigo el rechazo de la hipótesis nula de no estacionariedad, sin embargo, sus cambios estructurales no son significativos. 


\section{Cuadro 6.6 Prueba Lumsdaine-Papell de raíz unitaria y dos cambios estructurales para precios de commodities seleccionados}

\begin{tabular}{lccc} 
Commodity & Test & Tb1 & Tb2 \\
\hline Avena forrajera & -5.6453 & $1998: 11$ & $2002: 06$ \\
Cebada & $-8.5998 * * *$ & $1994: 10$ & $2001: 09$ \\
Frijol & -6.2862 & $1995: 07$ & $2002: 02$ \\
Maíz grano & -5.0306 & $1990: 05$ & $1995: 10$ \\
Papa & -5.6429 & $1991: 02$ & $2004: 07$ \\
Pasto & -5.7858 & $2005: 09$ & $2011: 02$ \\
Sorgo & $-6.8311 * *$ & $1993: 05$ & $2001: 08$ \\
Trigo & $-7.1212 * *$ & $1995: 01$ & $2002: 10$ \\
\hline Los símbolos *,** y $* * *$ denotan significatividad al 10, 5 y \\
1\% respectivamente. Los valores críticos para el modelo son \\
1\%(-7.19), 5\%(-6.75) y 10\%(-6.48).
\end{tabular}

La prueba endógena de raíz unitaria con dos cambios estructurales de Lumsdaine y Papell se deriva suponiendo que no hay rompimientos estructurales de la hipótesis nula. Empero, el rechazo de dicha hipótesis no implica necesariamente el rechazo de la raíz unitaria per se, pero puede indicar recazo de una raíz unitaria sin cambio estructural. De manera similar, la alternativa no necesariamente implica tendencia estacionaria con cambios, pero puede indicar una raíz unitaria con rompimientos. La prueba Lee-Strazicich permite integrar el multiplicador de Lagrange al análisis, que permite cambios estructurales tanto para la hipótesis nula como para la hipótesis alternativa. Como resultado, el rechazo de la hipótesis nula inequívocamente implica tendencia estacionaria.

El cuadro 6.7 indica los resultados de la prueba Lee-Strazicich de raíz unitaria y dos cambios estructurales para los precios de los commodities seleccionados. A deferencia de los contrastes anteriores, la hipótesis nula es raíz unitaria con cambio estructural frente a la alternativa de estacionariedad con cambio estructural. Resulta interesante observar que en todos los casos se confirma la hipótesis de raíz unitaria y sin cambios estructurales. 


\section{Cuadro 6.7 Prueba Lee-Strazicich de raíz unitaria y dos cambios estructurales para precios de commodities seleccionados}

\begin{tabular}{|c|c|c|c|}
\hline Commodity & Test & $T b 1$ & $T b 2$ \\
\hline Avena forrajera & -4.4753 & 1996:02 & $2002: 12$ \\
\hline Cebada & -4.9722 & $1994: 11$ & 2002:01 \\
\hline Frijol & -2.8133 & $1996: 08$ & 2002:04 \\
\hline Maíz grano & -2.7068 & $1998: 10$ & 2000:08 \\
\hline Papa & -4.2350 & $1990: 10$ & 1994: 11 \\
\hline Pasto & -2.4602 & $2005: 11$ & 2011:01 \\
\hline Sorgo & -4.3039 & 1994:11 & 2002:03 \\
\hline Trigo & -4.4071 & 1995:03 & 2005: 11 \\
\hline \multicolumn{4}{|c|}{ Valores críticos para raíz unitaria: } \\
\hline \multicolumn{2}{|c|}{$1 \%$} & $5 \%$ & $10 \%$ \\
\hline $\mathrm{LM}_{T}$ & $\begin{array}{ccc}-5.823 & -5.286 & -4.989 \\
\text { Valores críticos para cambios estructurales } \text { LM }_{T}\end{array}$ & -5.286 & -4.989 \\
\hline \multicolumn{4}{|c|}{$\begin{array}{l}\text { Valores críticos para cambios estructurales } \text { LM }_{T} \\
\lambda_{2}\end{array}$} \\
\hline \multicolumn{2}{|c|}{0.4} & 0.6 & 0.8 \\
\hline \multicolumn{2}{|l|}{0.2} & $\begin{array}{c}-6.41,-5.74,- \\
5.32\end{array}$ & $\begin{array}{c}-6.33,-5.71,- \\
5.33\end{array}$ \\
\hline 0.4 & - & $\begin{array}{c}-6.45,-5.67,- \\
5.31\end{array}$ & $\begin{array}{c}-6.42,-5.65 \\
5.32\end{array}$ \\
\hline 0.6 & & 一 & $\begin{array}{c}-6.32,-5.73 \\
5.32\end{array}$ \\
\hline
\end{tabular}

\subsection{Conclusiones}

En este capítulo se ha estudiado la condición estacionaria de los precios de 8 alimentos seleccionados para México. Estos commodities, aunque tienen características de producción y procesos de desgravación distintos, son los principales cultivos del país.

Para este propósito se aplicaron una gran variedad de pruebas de raíz unitaria y estacionarias. Sin embargo, cuando se usaron pruebas que no contaban para cambios estructurales, y diseñados para analizar la estacionariedad de los datos, la evidencia fue escasa pues solo se encontró estacionariedad para pasto y posiblemente maíz grano.

Para poder mejorar la especificación determinística de las pruebas de raíz unitaria, se permitieron uno o dos cambios estructurales. Los nuevos resultados arrojaron la confirmación de la hipótesis no estacionaria para la totalidad de los commodities en la prueba Perron-Rodríguez. Posteriormente, 
la prueba Lumsdaine-Papell arroja que únicamente la cebada es estacionaria con cambios estructurales significativos en 1994:10 y 2001:09. Finalmente, aplicando la prueba Lee-Strazicich el sorgo y trigo son no estacionarios pero sus cambios estructurales no son significativos.

Por lo tanto, la hipótesis del impacto del proceso de desgravación originado por el TLCAN sobre los precios de los alimentos en México, en este caso para los 8 commodities seleccionados, específicamente generando cambios estructurales significativos en fechas cercanas a su proceso específico de desgravación puede ser refutada. 


\section{CAPITULO 7 CONCLUSIONES}

Estudiar la relación entre el Tratado de Libre Comercio de América del Norte y el campo mexicano no es tarea sencilla. El campo en México constituye un referente de identidad. A lo largo del siglo XXI muchos fueron los sucesos históricos que determinarían la relación del sector primario con la apertura comercial que viviría el país. El primero de ellos la reforma agraria mediante la cual se dio fin a los latifundios para dar paso a pequeñas unidades de producción. El sistema de sustitución de importaciones que tenía como objetivo fortalecer la industria nacional. Incluso la aparición del Ejército Zapatista de Liberación Nacional el 1ro de enero de 1994, día en el que entró en vigor el TLCAN.

¿Qué se pretendía entonces con esta investigación? Partimos de la hipótesis de que el TLCAN había afectado de manera negativa al sector agrícola mexicano. Los datos a los cuales nos referimos para el desarrollo de la tesis fueron las cifras oficiales de producción, valor de producción, tipos de cultivos y rendimientos tanto a nivel país como referentes al Estado de México, así como los del Índice de Precios al Productor.

En el primer capítulo arrojamos cifras generales referentes a las características generales de población y territorio con la finalidad de arrojar mayor comprensión al tema, pues esta tesis se presenta en una universidad española. De la información detallada rescatamos que el Estado de México tiene una extensión de 22 mil 357 kilómetros cuadrados, representando el $1.1 \%$ de la superficie del país. A pesar de ello, en él vive el $13.5 \%$ de la población total, que equivale a casi 15.2 millones de personas, según cifras el año 2010. Dato importante es que la mitad de su gente es menor de 26 años. Predomina en la mayor parte del estad el clima templado subhúmedo. Su superficie sembrada equivale al $4.1 \%$ del total nacional.

Con respecto al sector primario de la economía la agricultura tiene una tasa de participación del $88 \%$ (cifras de 2010) y la actividad es encabezada por 
varones, quienes promedian 52 años de edad y trabajan alrededor de 37 horas a la semana.

En el segundo capítulo abordamos el contenido del TLCAN, mismo que nos remitió a considerar las reformas previas a la firma de este acuerdo comercial. La intención de este capítulo fue comprender que el TLCAN no fue un instrumento de política económica aislado sino un paso más en la internalización de la economía mexicana. Pudimos observar que las características de la agricultura en México han sido determinadas por las políticas liberales que transformaron la economía mexicana en su conjunto.

Se concluyó que el TLCAN se negoció condiciones de gran asimetría, magnificadas cuando se toman en cuenta las brechas entre la productividad del sector agrícola de México y el de Canadá y EEUU. Este desequilibrio se acentúa al considerar los recursos que estos dos países dedican a estimular el desarrollo sectorial y a apoyar las exportaciones. Los compromisos que se pactaron no reflejan el menor desarrollo de la agricultura mexicana en los plazos de desgravación ni en los montos de mercado para los cuales se acordaron plazos de desgravación más lenta, situación que posiblemente pudo haber sido revertida por una política integral del Estado de mexicano.

Además de las distancias económicas, había brechas en otros aspectos como el marco institucional, la valoración que cada país otorgó a la firma del acuerdo y el marco democrático que cada gobierno enfrentaba en su respectivo país. México, con su economía más intervenida y regulada, y con responsabilidades del Estado en dirección de la economía originadas en principios constitucionales distintos, asumió mayores costos al acoplar su modelo a la normatividad del TLCAN, en el que se plasmaron plenamente los principios que priman en las economías de EEUU y de Canadá.

Así, el TLCAN innovó integrando asimetrías inéditas: aunó la potencia mundial económica, tecnológica, militar y política con un país en desarrollo; incorporó acuerdos sobre la propiedad intelectual, el intercambio de servicios y los compromisos sobre inversión extranjera, que sólo se incluían en mercados comunes o en uniones económicas, en los cuales son centrales la integración política y la cesión de soberanía nacional en el manejo de áreas de política 
económica y social; y, sometió al sector agrícola al proceso de desgravación arancelaria, nunca antes incluido en los acuerdos de integración regional que buscan ganancias en productividad para el sector industrial.

El capítulo tercero nos permitió analizar el desempeño agrícola de México, tomando en consideración las cifras de producción de los principales cultivos, así como la balanza comercial. En este sentido, el sector primario mexicano ha tenido ritmo de crecimiento lento y su participación en el PIB total ha disminuido en los últimos 23 años. La mayor parte de este sector se orienta a la producción de granos básicos y oleaginosas de autoconsumo. Pero en México también se cultivan cereales, legumbres secas, frutales y hortalizas. El maíz resulta el principal cultivo al dedicársele alrededor del $50 \%$ de la tierra cultivable. Los forrajes, por su parte, son los cultivos con mayor volumen de producción en el país.

El último censo agropecuario realizado por el INEGI en 2007, permitió identificar 5.5. millones de unidades de producción con uno o más terrenos, de los cuales 3.7 millones declararon tener actividad agrícola. De éstas, el 10.8\% dispone de sistemas de riego, $83 \%$ es de temporal y $6.2 \%$ combina áreas de riego y áreas de temporal. En promedio, la extensión de la superficie agrícola de las unidades de producción del país es de 8 hectáreas. No obstante, el $57.9 \%$ tiene una superficie de 3 hectáreas o menos, cuestión que dificulta incrementar los volúmenes de producción en México. Resulta importante destacar que el cultivo de riego resulta más productivo que el cultivo de temporal para todos los casos, además de que es siniestrada en menor magnitud.

Con respecto a la balanza comercial de los sectores agropecuario, pesquero y agroindustrial permite observar que la dinámica de las actividades agropecuarias y pesqueras da lugar a mayores exportaciones que las generadas por la agroindustria encargada de procesar alimentos, bebidas y tabaco.

Una vez conocidas las características generales del sector agrícola en México dimos paso al cuarto capítulo, donde se analizaron esas mismas características para el Estado de México, la entidad federativa que constituye 
nuestra unidad de estudio. Por ciclo productivo, en primavera-verano el primer lugar en superficie sembrada lo tiene el maíz grano y en el ciclo otoño-invierno la avena forrajera y el chícharo. Comparando el ciclo primavera-verano de riego contra el de temporal, observamos que el primero presenta menor siniestralidad, pues la principal causa del daño son las sequías. Por su parte, en lo que se refiere al ciclo otoño invierno también es el cultivo de temporal el más siniestrado, sin embargo las cifras de pérdidas son mucho menores que las del ciclo primavera-verano, situación explicada porque en este ciclo la agricultura de la entidad es más activa.

En el capítulo cuarto estudiamos los volúmenes de producción agrícola para el Estado de México. En este sentido, observamos que en el ciclo primavera-verano de temporal, la producción pasó de dos millones de toneladas anuales en promedio en el periodo 1980-1990 a más de tres millones en el lapso 2000-2010. Por su parte, en el mismo ciclo con modalidad de riego se pasó de las 745 mil 900 toneladas de 1980 a 1999 a una producción de un millón 187 mil toneladas de 2000 a 2010.

Con respecto al ciclo otoño invierno de riego las cifras de volúmenes de producción de 1990-2000 a 2000-2010 únicamente incrementaron en 4.7\%. En el mismo ciclo productivo con modalidad de temporal, en los mismos años señalados, se registró una pérdida de 75\% de la superficie cultivada.

En cuanto a los rendimientos del ciclo otoño invierno observamos que aquellos con mayores rendimientos son los que no tienen siembras constantes, como el ejote y el chile verde. Respecto del ciclo primavera-verano los cultivos con mayores rendimientos son las flores polar y terciopelo, así como el jitomate.

En el capitulo cuarto abordamos también la balanza comercial del Estado de México y observamos que para el año 2011 registró un saldo negativo de 15 mil millones de pesos. Los principales productos importados son las oleaginosas y los cereales. Resulta evidente que los productores mexiquenses no están motivados para incursionar en el ámbito de las exportaciones.

Así pues, el seguimiento a las superficies sembradas, cosechadas , siniestradas, así como a los volúmenes de producción, rendimientos, precios y 
colocación en mercados potenciales, deber ser una estrategia para fomentar innovaciones tecnológicas, financiamientos y aprovechamiento de apoyos, sobre todo al investigar cultivos con alta capacidad de mejora en sus rendimientos. Recordando, por supuesto, que el Estado de México se encuentra dentro de los dos mercados con el mayor número de consumidores de todo el país a nivel de entidad federativa.

En el capítulo quinto nos enfocamos a relacionar la actividad agrícola de los municipios del Estado de México en cada uno de sus ciclos y modalidades productivas respecto del valor de producción. Así, el ciclo productivo que tuvo el valor de producción más alto (considerando cifras de 2003 a 2010) fue el de primavera-verano con un promedio de $52.4 \%$. Al igual que a nivel nacional, el maíz grano se coloca como el cultivo con mayor valor de producción. Analizando el valor de producción por municipio Villa Guerrero, Coatepec Harinas y Tenancingo se colocan en los primeros tres lugares. Prevale en el primero y tercero la producción de la flor crisantemo, mientras que el durazno en el segundo.

Otro factor que se abordó en este capítulo fueron los precios al productor de los principales cultivos. En este sentido, se observa que la entrada de México al TLCAN no significa en sentido estricto que los precios pagados al productor agrícola tengan que disminuir, sino más bien que siguen sujetos al comportamiento de los mercados, ahora con mayor influencia por parte de la relación con los socios de dicho acuerdo comercial, sin que ello signifique que tal influencia sólo se deba al intercambio con dichos países, pues a la fecha México mantiene relaciones de intercambio comercial con prácticamente todos los países del mundo.

Las conclusiones a las que se llegan una vez analizada la información en este capitulo quinto son:

1. Tomando en cuenta los volúmenes de producción agrícola del Estsado de México que representa cada ciclo productivo, se concluye que el ciclo $\mathrm{P}-\mathrm{V}$ de temporal se ha mantenido como el más productivo. 
2. Tomando como referencia el valor de producción de la entidad mexiquense en pesos sucede lo mismo, el ciclo P-V de temporal ocupa el primer lugar.

3. Analizando el volúmen de producción de maíz continuamos con la tendencia de que es el ciclo P-V de temporal el más productivo.

4. Tomando como referencia el volúmen de producción del maíz forrajero, el utilizado para alimentar al ganado, es el ciclo P-V de riego el que arroja las cifras más elevadas de todas las décadas analizadas.

5. El ciclo P-V de temporal arroja la mayor cantidad de hectáreas siniestradas (afectadas por cuestiones climáticas).

En suma, en el Estado de México el ciclo P-V de Temporal arroja los mayores volúmenes de producción y es también el que mayor valor de producción representa. Sin embargo, esto se explica porque el número de hectáreas sembradas bajo esta modalidad de producción son significativamente mayores que las cultivadas por riego. Es el cultivo por sistema de riego el que mayores rendimientos genera.

En el capitulo 6 se aplicaron un grupo de contrastes de raíz unitaria y estacionariedad para estudiar la hipótesis de cambios estructurales en el precios para 8 commodities seleccionados: avena forrajera, cebada, frijol, maíz grano, papa, pasto, sorgo y trigo. Los precios de los commodities seleccionados resultaron ser no estacionarios, a pesar de que se registraron cambios estructurales significativos con la prueba Lee-Strazicich.

En este capítulo se estudió la condición estacionaria de los precios de 8 alimentos seleccionados para México. Estos commodities, aunque tienen características de producción y procesos de desgravación distintos, son los principales cultivos del país. Para este propósito se aplicaron una gran variedad de pruebas de raíz unitaria y estacionarias. Sin embargo, cuando se usaron pruebas que no contaban para cambios estructurales, y diseñados para analizar la estacionariedad de los datos, la evidencia fue escasa pues solo se encontró estacionariedad para pasto y posiblemente maíz grano.

Para poder mejorar la especificación determinística de las pruebas de 
raíz unitaria, se permitieron uno o dos cambios estructurales. Los nuevos resultados arrojaron la confirmación de la hipótesis no estacionaria para la totalidad de los commodities en la prueba Perron-Rodríguez. Posteriormente, la prueba Lumsdaine-Papell arroja que únicamente la cebada es estacionaria con cambios estructurales significativos en 1994:10 y 2001:09. Finalmente, aplicando la prueba Lee-Strazicich el sorgo y trigo son no estacionarios pero sus cambios estructurales no son significativos.

Por lo tanto, la hipótesis del impacto del proceso de desgravación originado por el TLCAN sobre los precios de los alimentos en México, en este caso para los 8 commodities seleccionados, específicamente generando cambios estructurales significativos en fechas cercanas a su proceso específico de desgravación puede ser refutada.

Del análisis de la información utilizada para la presente investigación, resultó posible identificar una serie de problemáticas que afectan el desarrollo del sector agrícola tanto en México como en el Estado de México.

Problema 1: Atomización del campo

Las cifras del VIII Censo Agrícola, Pecuario y Forestal del INEGI, revelan que el problema del minifundio ha tendido a agravarse. En 1991 el 66.3\% de las unidades de producción agrícola tenían menos de 5 hectáreas; en contraste, en 2007 se registraron $72.1 \%$ de las unidades de producción con menos de 5 hectáreas.

Tabla 7.1 Estructura de las unidades de producción rural 1991 y 2007

\begin{tabular}{|l|c|c|}
\hline \multirow{2}{*}{$\begin{array}{c}\text { Unidades de } \\
\text { Producción }\end{array}$} & $\mathbf{2}$ Censo Agrícola \\
\cline { 2 - 3 } & $\mathbf{1 9 9 1}$ & $\mathbf{2 0 0 7}$ \\
\hline a 5 Has & $66.3 \%$ & $72.1 \%$ \\
\hline Más de 20 Has & $28.7 \%$ & $22.0 \%$ \\
\hline Total & $5.0 \%$ & $5.9 \%$ \\
\hline
\end{tabular}

Fuente: elaboración propia a partir de las cifras del VIII Censo Agrícola, Pecuario y Forestal del INEGI. 
Con superficies tan pequeñas la mayor parte de los cultivos agrícolas no resultan rentables $y$, por ende, financiables. Estas unidades de producción carecen de economías de escala lo que genera altos costos de producción (semilla, agroquímicos, maquinaria y combustibles) y generalmente no están destinadas a producir cultivos de alto valor; asimismo, una vez que se cosecha se obtienen bajos volúmenes de producción por el tamaño de la superficie cosechada y la falta de acceso a tecnologías.

En la mayoría de los casos, en estas unidades agrícolas minifundistas la producción se utiliza para autoconsumo y solamente una pequeña parte se comercializa en los mercados, observándose también un precio al productor poco competitivo por la falta de economías de escala y diferenciación del producto.

La población del sector rural del Estado de México es una población particularmente vulnerable a riesgos, lo cual dificulta su acceso al crédito y en el mejor de los casos lo encarece: los productores presentan ingresos estacionales, ausencia de salario fijo, no hay un uso generalizado de mecanismos de ahorro y aseguramiento, altos riesgos de salud, envejecimiento y exposición a riesgos naturales.

Problema 2: restricciones y escaso financiamiento

El financiamiento rural en el estado de México es una pieza fundamental en la consolidación de un sistema agroalimentario incluyente, sustentable y eficiente. La penetración financiera en México, no obstante que se han realizado esfuerzos importantes por mejorarla, aún resulta baja y, por lo tanto, existen grandes retos por delante.

En 2008, la SCHP estimaba que a nivel nacional el 52\% de los municipios no tenían acceso a las instituciones financieras, tanto de la banca comercial como del sector de ahorro y crédito popular y de la banca de desarrollo.

Durante los últimos años el financiamiento total al sector agropecuario ha sido cercano a los 100 mil millones de pesos, de los cuales más del 70\% provinieron de la banca comercial, ya sea con recursos propios o a través de 
FIRA. Por su parte Financiera Rural participa aproximadamente con el $17 \%$ del financiamiento al sector y los intermediarios financieros no bancarios que operan con FIRA participan aproximadamente un $11 \%$.

Cabe señalar que si bien el financiamiento total al sector primario muestra una tendencia creciente en el periodo, el nivel de financiamiento es aún muy bajo (20.9 \% del PIB del sector al cierre de 2009) y su ritmo de crecimiento no responde a las necesidades del sector. El financiamiento total como proporción del PIB del sector, decreció 0.7 puntos porcentuales en el mismo periodo.

Como ya se comentó en otra sección de este documento, si lo comparamos con otros países como Chile que registra un nivel de financiamiento del 77\% del PIB y de Brasil del 37\% del PIB, observamos que el nivel de financiamiento en México debe crecer a una tasa más dinámica a la observada recientemente.

Problema 3: falta de competitividad debido a la escala de producción y organización

El $82 \%$ de las organizaciones de productores del estado de México son locales y de escala de producción pequeña, lo que hace compleja su participación en mercados competitivos.

Del total de organizaciones en el padrón de la SAGARPA, solo $18 \%$ corresponde a organizaciones que por su naturaleza rebasan el ámbito local y pueden tener economías de escala.

El porcentaje de productores organizados es sumamente reducido en comparación con el número de productores. Del Censo Ejidal 2007, se observa que de los ejidos contabilizados solo $0.6 \%$ habían constituido sociedades mercantiles, de los cuales pocos son sociedades anónimas.

Se propone constituir a los Sistema Producto como la columna vertebral de las organizaciones de productores, que les permita producir a bajos costos, bajo economías de escala y consolidar ofertas. 
Problema 4: cadena de suministro de alimentos ineficiente

La cadena de suministro del sector alimentario del Estado de México está conformada por productores, proveedores, centros de almacenamiento y negocios con puntos de venta. El buen desempeño de dicha cadena es que los bienes sean producidos y distribuidos en las cantidades adecuadas, a las localidades que corresponde y en el momento justo, para minimizar los costos, satisfaciendo adecuadamente la demanda.

La cadena de suministro representa una serie de restricciones que hacen que su operación sea poco eficiente, lo que genera problemas de competitividad en el sector; entre los que destacan la heterogeneidad en los canales de distribución, reducida infraestructura de almacenamiento y transporte, poco uso de estándares y normas, altos costos de transacción y poco énfasis de la política pública para atender estos problemas.

Problema 5: polarización de los canales de distribución

En el Estado de México (como en el país) existe una polarización de los principales canales de distribución de alimentos, los cuales se dividen en modernos y tradicionales. Los primeros se concentran en los principales puntos de consumo de la entidad, mientras que los segundos se encuentran en regiones con una densidad demográfica inferior.

Lo canales modernos, definidos como las tiendas de autoservicio, departamentales, de membrecía y de conveniencia se encuentran concentrados en localidades de más de 50 mil habitantes; así, su participación en las ventas registradas en las grandes zonas urbanas es hasta cuatro veces mayor que la que registran en localidades con menos de 2,500 habitantes.

Por su parte, los canales de distribución tradicionales, entendidos como los mercados municipales, tianguis y mercados sobre ruedas, tiendas de abarrotes, tiendas específicas y vendedores ambulantes, son preponderantes en el comercio local, particularmente en regiones de baja densidad poblacional. 
Existen marcadas diferencias de eficiencia y de prácticas comerciales entre los canales de distribución tradicionales y modernos, por ejemplo, a diferencia del canal tradicional, el moderno utiliza técnicas de investigación de operaciones con la finalidad de fortalecer la relación entre un centro de acopio y un centro logístico. Lo anterior, entre otros beneficios, le permite a los canales modernos de distribución disminuir costos de manera significativa respecto a las que registran los canales tradicionales.

Resulta evidente la polarización que existe entre los canales de distribución que operan en el Estado de México, por lo que es prioritario promover la modernización de los canales tradicionales con la finalidad de mejorar el abasto equitativo en regiones de la entidad donde la población requiere acceder a alimentos de calidad, vía reducción de costos y una eficiente integración de los agentes que participan en el proceso.

Problema 6: nulo o reducido uso de normas y estándares

El mercado agropecuario en el Estado de México se caracteriza por un gran número de participantes en el sector primario de productores agrícolas y un número reducido de participantes en las actividades de procesamiento y distribución. Los puntos de venta al consumidor final también han tendido a concentrarse a raíz del crecimiento de los supermercados y tiendas de autoservicio, aún cuando la forma tradicional de abastecimiento en los centros de acopio y distribución al por mayor (Centrales de Abasto) sigue siendo importante, principalmente para frutas y hortalizas.

Las asimetrías que caracterizan a la cadena de valor han ocasionado que, por un lado, los agricultores tengan un escaso poder de negociación debido a su pulverización $y$, por otro lado, que los compradores ejerzan poder de mercado, dada su concentración.

El mercado demanda calidad, oportunidad en los suministros y economías de escala, lo cual plantea retos especiales para los agricultores pequeños y medianos, además de la necesidad de desarrollar la infraestructura necesaria, generar información suficiente y establecer grados y estándares de calidad. 
En este sentido, un buen sistema de comercialización agropecuaria puede reducir el costo de los alimentos y mejorar la rentabilidad de los productores. A través de una mejor vinculación de los agricultores con los consumidores, los sistemas de comercialización pueden transmitir señales a los agricultores que guíen sus decisiones de producción y puedan satisfacer las cambiantes preferencias de los consumidores en torno a precio, calidad, variedad e inocuidad de los alimentos.

Cabe señalar que los estándares son instrumentos que solucionan fallas de mercado. De manera específica, los estándares de calidad pueden reducir los costos de transacción entre los diferentes actores, lo que favorece la eficiencia de los mercados.

Asimismo, la tendencia internacional ha sido fijar estándares públicos de calidad y trazabilidad para insertar al sector agropecuario de cada nación en el esquema internacional actual.

En resumen, debe ser prioridad de la política pública, normar, promover e informar sobre estándares de calidad y trazabilidad de los productos agropecuarios, que generen mayores oportunidades para que el sector agropecuario se desarrolle de manera competitiva, y en consecuencia genere un mayor bienestar social.

Problema 7: manejo inadecuado postcosecha eleva mermas y perdidas

Los canales tradicionales de suministro en el Estado de México presentan en promedio mermas y pérdidas de entre 15 y $35 \%$ de sus ventas, mientras que para los canales modernos este indicador se ubica entre 7 y $15 \%$. Una de las principales diferencias entre el canal tradicional y el moderno, es que el primero opera de manera fragmentada, mientras que el canal moderno cuenta con sólidas cadenas de suministro.

Es evidente que uno de los principales problemas de la cadena alimentaria de la entidad es el nivel de mermas que presenta el canal tradicional, ya que en éste se concentran, en promedio, tres cuartas partes de las ventas. 
En el Estado de México persiste una alta incidencia en mermas y pérdidas post-cosecha, las principales causas son infraestructura y medios de transporte deficientes, así como la falta de conocimientos e información entre los productores y distribuidores.

Problema 8: insuficiente infraestructura en almacenamiento, acondicionamiento y transporte

En el Estado de México no existe infraestructura suficiente para almacenar y acondicionar productos agropecuarios, además de que el transporte para moverlos de un lugar a otro es también insuficiente, en general carece de los requerimientos mínimos para transportar este tipo de bienes.

La capacidad de almacenamiento de granos y oleaginosas es asimétrica entre diversas regiones del estado. Este conjunto de factores provoca, por ejemplo, que el costo logístico de abastecer granos a Quintana Roo desde el centro del país, resulte $18.9 \%$ más alto que abastecer a esa entidad con importaciones provenientes de los Estados Unidos.

Asimismo, la capacidad de almacenamiento en los centros de distribución es baja. Por ejemplo, para el caso de almacenamiento de hortalizas en la principal central de abastos (Iztapalapa), solamente $17 \%$ de los mayoristas cuentan con cámara de refrigeración. Un estudio reciente llevado a cabo por la SAGRAPA, identificó que la capacidad de almacenamiento y procesamiento en una de las principales fuentes para abastecer productos hortofrutícolas al centro del país alcanza apenas un $3 \%$ en algunos distritos.

Respecto a la flota vehicular de transporte refrigerado en el Estado de México, representa alrededor del $7 \%$ del total, mientras que los tractocamiones (no refrigerados) representan 35\% y los vehículos de caja cerrada $19 \%$.

En este contexto, más de la mitad de la flota vehicular cuenta con más de 15 años de antigüedad y aproximadamente el $25 \%$ del total rebasan 35 años de uso. Las condiciones de infraestructura carretera, de almacenamiento y transporte, se traducen en incrementos de costos y disminución en la calidad de los productos perecederos. 
Problema 9: precios elevados de los servicios asociados a la distribución

Los precios de los servicios de distribución en el Estado de México son superiores a los registrados de los principales socios comerciales del país. Por ejemplo, el transporte de carga refrigerado resulta en $41 \%$ más alto que en Estados Unidos (considerando rangos en rutas de distancias similares).

De acuerdo a un estudio realizado por el BM (2006), el porcentaje de los costos logísticos como porcentaje del PIB es una medida de la eficiencia de la cadena de distribución. Los costos de distribución de México (20\% del PIB) son mayores que los de nuestros socios comerciales (10\%). Estos costos son aún mayores para los productos alimentarios. México y los países de Latinoamérica presentan costos significativamente mayores que otras regiones más desarrolladas.

De acuerdo con esta información, nuestros principales socios comerciales (Estados Unidos y Canadá) son por lo menos dos veces más eficientes en términos logísticos que nuestras cadenas de distribución. Esto limita la competitividad de las exportaciones de los productos mexicanos.

La diferencia en costos logísticos puede deberse a la falta de infraestructura de carreteras y puertos, a los altos costos de los operadores logísticos de las terminales multimodales y a la falta de una integración de la cadena logística. Uno de los principales componentes es el movimiento de cargas, que es elevado cuando no se utilizan los medios de transporte óptimos para cada tipo de producto; otro componente lo integran los costos de inventarios, que se incrementan con los tiempos de transporte y la falta de confiabilidad en todos los eslabones de la cadena logística.

Otra medida de competitividad, en donde México presenta diferencias significativas con otros países de la región, tiene que ver con las regulaciones y costos en el comercio internacional. Por ejemplo, podemos observar que los costos promedio para exportar contenedores desde México son mayores que los de Brasil en $17 \%$ y que los de Chile en $106 \%$. 
Dentro de los países de la región con ingresos medios, México está entre los que tienen un desarrollo más limitado en logística, por lo que es necesario renovar el esfuerzo en estas áreas para no perder la competitividad del país. Se identifican a las aduanas y a la infraestructura como las principales áreas de oportunidad en materia de competencia logística.

Problema 10: sistema sanitario y fitosanitario desarticulado

Una de las funciones más elementales de un gobierno es asegurar y proteger la provisión de alimentos. Esto es, que a lo largo de la cadena de suministro (producción, transportación, preparación y almacenamiento) se prevengan enfermedades de transmisión a través de los alimentos (seguridad) y que se garantice que existe suficiente provisión para las necesidades humanas (protección). En el Estado de México (y en el país), las responsabilidades sanitarias y fitosanitarias para cumplir con dicha función competen tanto a la SAGARPA, a través del SENASICA, como a la Secretaría de Salud del Estado de México.

Uno de los objetivos de la Secretaria de Salud es la provisión de alimentos seguros, lo cual se busca alcanzar mediante la investigación de casos de enfermedades ocasionados por alimentos y determinar su origen. Asimismo, vigila que se cumplan con los estándares para la importación y exportación de alimentos procesados, función que realiza la instancia federal: Comisión Federal para la Protección de Riesgos Sanitarios (COFEPRIS). Por otro lado, SENASICA agrupa las principales divisiones involucradas en programas sanitarios, fitosanitarios y de seguridad alimentaria.

La falta de claridad en las responsabilidades del sistema sanitario puede ocasionar costos importantes. Por ejemplo, SENASICA a través de la Dirección General de Inocuidad Agroalimentaria se encarga de inspeccionar productos para exportación en rastros que tienen operaciones de exportación. Sin embargo, los rastros municipales son responsabilidad de la Secretaria de Salud. Pero las inspecciones a rastros municipales son generalmente insuficientes, no existen o se realizan una vez que se ha desarrollado alguna 
enfermedad. De esta forma, los consumidores son más vulnerables a contagios por consumo de alimentos contaminados, lo que ocasiona un costo extra para la entidad.

Problema 11: fallas de información

A pesar de que se han multiplicado las fuentes de información económica y los medios electrónicos para acceder a las oportunidades de mercado para productos agropecuarios, persiste la información incompleta o incomparable para la toma de decisiones.

La información sobre oferta, demanda, precios, competidores y mercados potenciales, se encuentra en distintas fuentes, algunas de acceso restringido, obstaculizando la planeación de las actividades agropecuarias.

Las fallas que se presentan en la difusión de datos de demanda y precios, genera incertidumbre en los participantes en la cadena agropecuaria. El posicionamiento estratégico de los productos agropecuarios depende en gran medida de su capacidad de acceder y usar oportunamente información e inteligencia de mercado.

Se propone dotar al SIAP de la infraestructura, equipamiento y recursos humanos y presupuestales multianuales para llevar a cabo esta función.

Problema 12: oportunidades de arbitraje no aprovechadas

La formación de precios es ineficiente cuando existen fallas de información. Esto origina que existan importantes deferencias de precios de un mismo producto, en el mismo tiempo, pero en diferentes regiones (descontando costos de transacción). Ejemplo de ello es el precio del maíz grano en México, cuyo precio varía de un estado productor a otro.

Estas diferencias de precios, según las zonas de consumo final, no son consistentes considerando únicamente los costos logísticos de zona productora a zona consumidora, mostrando incluso variaciones de precios opuestas. Por ejemplo, se ha observado que el precio del plátano es tres veces más caro en 
La Paz (Baja California) que en la central de abastos de Iztapalapa (Distrito Federal).

Problema 13: falta de coordinación interinstitucional y multiplicidad de programas de apoyo

Mientras no exista una línea clara de separación entre lo que es una transferencia y lo que es un apoyo a una estructura de financiamiento, este tipo de programas no necesariamente contribuirán en la medida requerida al desarrollo de un mejor sistema financiero rural.

Existe la multiplicidad en los programas, pues en algunas ocasiones van dirigidos a la misma población, con el mismo objetivo y con un bajo nivel de coordinación interinstitucional, lo cual genera distorsiones, duplicidades e incentivos inadecuados a los beneficiarios. Derivado de lo anterior, los gobiernos deberían:

a. Asumir un rol promotor de la oferta privada de servicios financieros.

b. Promover la oferta de intermediarios financieros sustentables para que brinden una amplia gama de servicios financieros a la población y a las empresas.

c. Establecer un marco jurídico y normativo adecuado que brinde certeza a todas las operaciones.

d. Fomentar un mecanismo para la gestión de los riesgos de precio y producción característicos de la producción agropecuaria.

Problema 14: ingresos de poblaciones vulnerables

El 25\% de los ingresos de las poblaciones de menos de 2,500 habitantes son las transferencias. La mayor parte de las transferencias que reciben provienen principalmente de remesas $(17 \%)$, transferencias en especie de otros hogares $(28 \%)$ y programas gubernamentales (34\%). Dentro de este 
último, la mayor parte la aporta el Programa Oportunidades (66\%), seguido del Programa de Adultos Mayores (16\%) y PROCAMPO (15\%).

Se observa que el decil más alto dentro de las poblaciones de menos de 2,500 habitantes es el que más se beneficia del PROCAMPO.

\section{Consideraciones generales}

Una vez identificadas las características del sector agrícola mexicano y mexiquense, y después de identificados los principales problemas que imposibilitan el pleno desarrollo del campo, podemos elaborar algunas propuestas de solución.

El deficiente diseño y desempeño de las políticas públicas para atender los grandes retos que enfrentará el sistema agroalimentario pone de manifiesto que en los próximos 30 años seguir actuando de la misma forma significaría atentar con el bienestar de las generaciones futuras y presentes en el bien más valioso que es la alimentación.

Al mismo tiempo, se identifican dos aspectos que constituyen una gran oportunidad para que el Estado de México haga frente a los retos presentes y futuros de la alimentación, a saber:

- La vasta disponibilidad y diversidad de recursos naturales que usados responsablemente pueden constituir una fuente significativa de ingresos para la población rural y generar niveles de producción suficientes para atender la demanda creciente de productos del sector primario.

- La amplia disponibilidad de recursos públicos que, bien aprovechados, puede detonar un elevado dinamismo del sistema agroalimentario en beneficio de toda la población del país.

A pesar de la envergadura de estos retos, la entidad tiene la oportunidad no sólo de reaccionar ante las tendencias mundiales, sino que puede ser líder en la producción y distribución de alimentos saludables y seguros. Las ventajas 
del estado son muchas, se cuenta con una gran biodiversidad y variedad de climas. El Estado de México cuenta con la mayor cantidad de población joven del país y con una industria con bajos costos de producción. Otras ventajas son la posición geográfica privilegiada, bajos costos logísticos para exportar a los mercados del TLCAN y un ambiente sanitario favorable en muchas de las principales zonas productoras.

El Estado de México debe aprovechar estas ventajas para consolidar su posición como un proveedor confiable de alimentos de alta calidad. Esto sólo se logrará mediante la integración de la industria, los productores, las universidades, los investigadores y el gobierno en una visión común.

En lo que se refiere a la evolución del sector agroalimentario a nivel regional, Jalisco es el que más aporta al PIB primario nacional, aproximadamente $12 \%$, seguido por Veracruz (7.3\%), Sinaloa (7\%), Michoacán (6.7\%), Sonora (5.5\%) y Chihuahua (5\%). Por otra parte, los estados que menos aportan al PIB primario son: Campeche, Tlaxcala, Distrito Federal y Quintana Roo. Los Estados que muestran un mayor enfoque hacia la producción primaria (es decir, el PIB primario estatal es mayor al PIB agroindustrial) son Sinaloa, Chihuahua, Durango, Baja California Sur, Zacatecas, Chiapas y Campeche. Las entidades que muestran mayor enfoque en el PIB agroindustrial son el Distrito Federal, Estado de México, Jalisco, Nuevo León, Coahuila, Oaxaca, Yucatán y Quintana Roo.

En muchos casos las oportunidades de arbitraje en el Sector Primario no son aprovechadas. Así, en los últimos años el $10 \%$ la superficie cosechada aportó $40 \%$ del valor de la producción agrícola, mientras que $68 \%$ de la superficie lo hizo en sólo 39\%.

Con respecto al consumo agropecuario, en los últimos años se han observado cambios importantes. Productos como el mango, el maíz, el limón mexicano y el huevo han experimentado tasas de crecimiento promedio anual superiores al 4\% por año; en otro segmento, el pollo, el ajonjolí, la carne de res, el melón, el aguacate y la naranja presentan tasas del 2 al $4 \%$. 
Inversamente, los productos que presentan tasas negativas de crecimiento en su consumo aparente son cártamo con $-8 \%$, uva con $-7.6 \%$, fresa $-5.3 \%$, frijol $-4.2 \%$, soya $-3.2 \%$ y miel $-2.9 \%$.

Dando paso a la situación en el Sector Agroindustrial, podemos mencionar que ha tenido un dinamismo superior que el sector primario. La industria alimentaria representó en 2008 el $69 \%$ del valor del sector agroalimentario. En el periodo correspondiente de 2003 a 2010, el subsector que mostró mayor dinamismo fue la industria de bebidas y tabaco, al presentar una TMCA de $5.6 \%$, seguido por la ganadería, $(2.5 \%)$; agricultura $(2.4 \%)$; industria de alimentos $(2.3 \%)$ y la pesca $(-0.3 \%)$.

En 2008 el valor de la producción de la industria manufacturera ascendió a más de $\$ 6.6$ billones de pesos. La industria alimentaria aportó aproximadamente el $18 \%$ del valor total, al producir $\$ 1.18$ miles de millones.

Las importaciones agropecuarias y agroindustriales del país ascendieron a 18.9 mil millones de dólares en 2009, de 2006 a 2010 ese rubro registró una TMAC de $4.4 \%$. En el periodo mencionado se ha registrado una elevada variabilidad en esa cifra, derivada de la volatilidad de los precios de los productos agropecuarios y agroindustriales observada en ese lapso.

Las importaciones agropecuarias se concentran básicamente en granos y oleaginosas, las cuales representan un $64 \%$ de este tipo de compras al exterior. Es importante señalar que en ambos casos las importaciones complementan la oferta nacional y se utilizan como insumo de cadenas productivas nacionales.

Así, una parte significativa de los granos importados se utiliza como insumo para el sector pecuario nacional, principalmente en las regiones alejadas de las zonas de producción y/o en aquellos periodos donde la cosecha nacional es reducida. Lo anterior es consecuencia de que en los últimos 16 años, el PIB del sector ganadero duplicó el PIB agrícola: el primero creció $72.1 \%$, mientras que esa cifra pare el segundo fue de $33.6 \%$. Esa diferencia en el dinamismo de ambos sectores ha implicado que los requerimientos de insumos agrícolas importados del sector ganadero resulten crecientes. 
En este sentido, el acceso a insumos importados ha sido un factor determinante para lograr que el sector ganadero nacional abastezca preponderadamente el consumo nacional de cárnicos, mismo que de otra manera habría sido abastecido por importaciones.

En el caso de las oleaginosas las importaciones se destinan de manera preponderante a la industria aceitera, las cuales agregan valor procesando la semilla y elaborando aceites para consumo final así como pastas oleaginosas que se utilizan en la elaboración de alimentos balanceados en el sector pecuario.

En lo referente a las exportaciones, en el año 2008 las exportaciones totales de productos agroalimentarios de México sumaron 16,670 mdd y su destino principal fue la región del TLCAN (79\%), en menor medida su destino fue la Unión Europea (6\%) y Asia (5\%).

Los rubros que generaron las mayores exportaciones fueron frutas $y$ hortalizas $(6,226 \mathrm{mdd})$; los agroindustriales (4,349 $\mathrm{mdd})$ y los pecuarios, pesqueros y mariscos (1,840 mdd). La concentración en los mercados, es aún mayor para frutas y hortalizas con el $95 \%$ de las exportaciones en la región TLCAN.

El dinamismo del crecimiento en las exportaciones se ha dado en primer lugar en los granos, con una tasa de crecimiento media anual (TCMA) de $21.8 \%$, esto sin embargo, sobre una base pequeña donde el café representa más del $50 \%$ de total. En segundo lugar en crecimiento están los frutales, con TCMA del $16 \%$ aproximadamente, lo que revela la competitividad del sector en México.

Finalmente el sector de verduras y hortalizas, el cual genera la mayor parte de las exportaciones ( $3,733 \mathrm{mdd})$, sólo creció con una TCMA de 5.3\%. La evolución favorable de sus precios influyó positivamente.

Así, en México existe potencial para incrementar la exportación de frutales, pescados y mariscos. También es posible consolidar el liderazgo de México en hortalizas y verduras; y finalmente, se puede seguir creciendo gradualmente en productos pecuarios y café. Para ello, es necesario diversificar las exportaciones a otras regiones fuera del TLCAN, sin que ello 
implique descuidar el principal mercado del mundo (Estados Unidos), con el que se tienen ventajas comparativas que favorecen a los productores e industriales nacionales.

Estados Unidos sigue siendo el principal destino de las exportaciones agroalimentarias de México, por su cercanía y la complementariedad que existe en las estaciones y climas. Aunque es necesario comentar que en el caso de hortalizas y verduras existe el riesgo de saturar el mercado, por lo que una estrategia adecuada para continuar consolidándolo sería el desarrollo de nuevos productos, así como la exploración de productos nicho (como el caso de los orgánicos).

Las exportaciones agroalimentarias de productos mexicanos tienen barreras de entrada a los mercados de mayor valor, constituidos por los países desarrollados. Entre los principales retos para acceder a estos mercados se pueden mencionar:

- Estándares públicos y privados de calidad, sanidad e inocuidad.

- Requerimientos de compradores centralizados.

- Diferenciación de productos y agregación de valor.

A pesar del supuesto retiro de apoyos en la firma de tratados comerciales, los programas de apoyo gubernamentales deben enfocarse a ayudar a los productores a reestructurarse y enfrentar la competencia internacional.

México cuenta con un potencial de mejora de casi medio millón de hectáreas de maíz que pueden ser convertidas a riego; es necesario identificar con precisión los municipios y localidades en los que se cuenta con tales superficies, a fin de canalizar los apoyos adicionales que permitan convertir dichas áreas. Lo anterior implica considerar las condiciones hidrográficas y de infraestructura prevalecientes, sin dejar de tomar en cuenta que, dependiendo de la región, lo más conveniente podría ser una reconversión a otros cultivos.

Ya se mencionó que desde antes de la firma del TLCAN se recomendó convertir superficies de forrajes a hortalizas o frutales, lo cual no se ha visto 
reflejado en las superficies sembradas por grupos de cultivos. La explicación de lo anterior también se encuentra en que las superficies y volúmenes de cultivos alternativos para alimentar ganado no se han incrementado y se hace constar en el hecho de que la superficie de oleaginosas es menor en la década de 2000 a 2010 respecto a la de la década de los ochentas, con una disminución del $64 \%$ al comparar tales decenios. Dentro de las oleaginosas se encuentra la soya, la cual tiene un uso muy generalizado para alimento de animales en el extranjero. A pesar de la menor área dedicada al cultivo de oleaginosas, el promedio anual de producción obtenido en la década de 2000 a 2010 es mayor en $9.7 \%$ respecto al promedio de 1980 a 1990 , lo cual refleja la mejora en los rendimientos de tales cultivos $y$, en consecuencia, su potencial al incrementar su superficie.

El enfoque del programa Pro-Oleaginosas parece muy aceptable y, en efecto, se ha logrado la reconversión a oleaginosas en zonas del sureste mexicano. Sin embargo, queda mucho por hacer, pues aunque se tengan resultados favorables lo cierto es que los aumentos logrados en la producción no logran recuperar los niveles que se tenían en la década de los ochenta y, en consecuencia, se encuentran muy lejos de cubrir las necesidades internas del país.

Se tiene conocimiento de que en México los costos de producción del sorgo son menores a los del maíz; sin embargo, no se cuenta con estudios recientes sobre costos de producción de cultivos a nivel nacional, por ciclo y métodos de producción, de modo que se requiere actualizar $y$, más bien, redefinir la elaboración de tales estudios, de modo que sean verdaderamente representativos de las condiciones en las que se llevan a cabo los procesos de producción en los diferentes modos de producción en México.

En el Estado de México se requiere motivar la producción bajo las diferentes modalidades de agricultura protegida, además de asegurar su registro de manera oficial.

Es evidente que más de uno de los programas operados por la SAGARPA se enfocan a beneficiar a los grandes productores y comercializadores, mientras que los pequeños y medianos se encuentran al margen. Sin embargo, 
es importante señalar que debe buscarse una mejor difusión de los programas entre los agricultores, a fin de que conozcan todos y cada uno de ellos, de modo que puedan decidir por aquellos que más les convengan además de poder evaluarlos en función de los diferentes cultivos con potencial en sus tierras.

La revisión de los cultivos que mayor valor agrícola aportan a la entidad mexiquense permite deducir, sin mayores complicaciones, que la tendencia en las decisiones sobre qué producir, cuánto producir, cómo producir, dónde producir y por qué producir, no tiene un parámetro definido ni obedece a aspectos relacionados con la apertura comercial, pues se carece de una orientación pública en tal sentido.

Evidentemente los programas de la SAGARPA, como lo es el caso de los apoyos a la comercialización de productos agropecuarios y las compras por contrato, tratan de encauzar la producción, pero lo cierto es que esos mismos programas alientan todavía la siembra de cultivos como el maíz y el frijol, sin haber motivado mejores diversificaciones hacia otros cultivos ni, mucho menos, la generación de mayor valor agregado al pretender la transformación de los productos por parte de los mismos campesinos.

Al considerar la necesidad de diversificarse dentro de un mismo grupo, como el de los cereales, también es importante identificar aquellos cultivos que generan mayores ingresos por contar con un mejor precio, sin olvidar la necesaria relación con los costos de producción, de los cuales no se cuenta con estudios actualizados a nivel nacional. Así, en el caso de los precios de los cereales a nivel nacional se tiene que sus precios llegan a encontrarse por arriba de los correspondientes a los principales cereales del Estado de México.

No hay que olvidar la necesidad de vincular, en la medida de lo posible, la explotación de pastos con apoyos a los campesinos, a fin de contribuir a la protección del medio ambiente. Es importante recordar, de igual forma, la siembra de cultivos forrajeros alternativos como se ha indicado, por señalar un ejemplo, en el caso del sorgo; nuevamente las evaluaciones de viabilidad resultan determinantes. 
El seguimiento a las superficies sembradas, cosechadas, siniestradas, así como a los volúmenes de producción, rendimientos, precios y colocación en mercados potenciales, debe de ser una estrategia para fomentar innovaciones tecnológicas, financiamientos y aprovechamiento de apoyos, sobre todo al investigar cultivos con alta capacidad de mejora en sus rendimientos. Resulta significativo recordar la ventaja de estar dentro de los dos mercados a nivel de entidad federativa (Estado de México y Distrito Federal) con el mayor número de consumidores de todo el país.

Tomando en consideración nuestra hipótesis de que el TLCAN impactó de manera negativa al sector agrícola mexicano, y después del análisis de los datos contenidos en esta investigación, observamos que el estado mexicano nunca articuló una política pública agraria que incentivara la producción para términos de exportación. Los apoyos gubernamentales al campo mexicano se reducen a aislados esfuerzos para que la agricultura de autoconsumo no desaparezca. En este sentido, la política estatal en términos agrícolas ha fallado por completo. Nuestra hipótesis no es acertada pero nos muestra que hasta que no exista un verdadero compromiso del gobierno federal para articular una política de largo plazo con respecto al sector agrícola mexicano, los agricultores nunca tendrán una oportunidad real de competir en mercados internacionales, a pesar de que México cuenta con todos los elementos naturales para convertirse en uno de los principales productores de alimentos del mundo.

Tanto en el sector agrícola como en temas como la seguridad nacional y el combate a la delincuencia, la variable determinante es la voluntad política de establecer políticas de largo plazo. 


\section{APÉNDICE ESTADÍSTICO}

La estadística utilizada en la presente tesis proviene de distintas fuentes, todas ellas mexicanas: SAGARPA, INEGI, Centro de Estudios para el Desarrollo Rural Sustentable y la Soberanía Alimentaria (CDRESSA), entre otras. No obstante, para efecto de integrar los datos duros de la parte agrícola se utilizaron fundamentalmente los registros estadísticos del SIAP, órgano desconcentrado de la SAGARPA, el cual es responsable de la integración, análisis y publicación de los datos oficiales relacionados con las actividades productivas agropecuarias y pesqueras de México.

Entre las funciones del SIAP se encuentra el diseño y coordinación de la operación del Sistema Nacional de Información del Sector Agroalimentario y Pesquero, así como promover la concurrencia y coordinación de la implementación del Sistema Nacional de Información para el Desarrollo Rural Sustentable. La información estadística la capta a través de un sistema informático instalado y en operación en los 712 Centros de Apoyo al Desarrollo Rural (CADER), 190 Distritos de Desarrollo Rural (DDR) y las 33 Delegaciones de la SAGARPA. Por medio de éste se lleva el seguimiento mensual de las principales variables de la producción agropecuaria del país. 


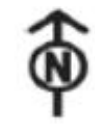

\section{Infraestructura de la SAGARPA}

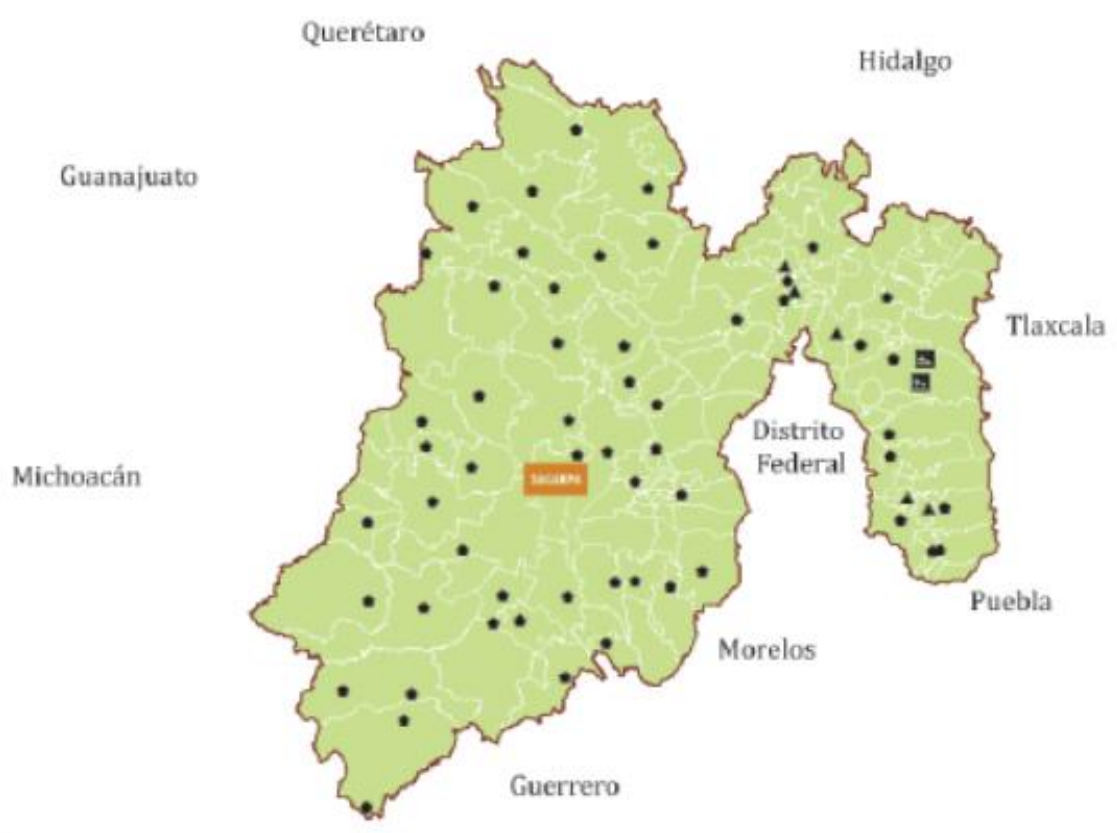

- CADERy DDR

- Establecimientos tipo inspección federal

. Laboratorios fitosanitarios aprobado

welegación de la SAGARPA

La información estadística que recibe el SIAP se somete a un proceso de validación y análisis de consistencia y congruencia con parámetros previamente establecidos a efecto de fortalecer la confiabilidad de los datos que se integran. Esta información es empleada para atender los compromisos que tiene la SAGARPA con diversas dependencias del Ejecutivo Federal tales como el Banxico, la Secretaría de Hacienda y Crédito Público (SHCP), la Secretaría de Economía (SE), la Secretaría de la Función Pública (SFP), usuarios como organizaciones de productores del sector agropecuario, público en general; así como dar respuesta a los requerimientos y compromisos establecidos con organismos internacionales, como la FAO, la Comisión Económica para América Latina y el Caribe (CEPAL), la Organización para la Cooperación y el Desarrollo Económicos (OCDE), el USDA, el Banco Mundial (BM), la OMC, entre otros (SIAP-SAGARPA 2007: 5-6). 
En la parte agrícola el SIAP clasifica la información que genera de la siguiente manera:

- Subsector agrícola: Cifras sobre producción de la agricultura mexicana en forma anualizada para más de 500 cultivos, y sobre el avance mensual de siembras y cosechas para 50 cultivos estratégicos (30 cíclicos y 20 perennes que contribuyen con el $80 \%$ del valor de la producción agrícola nacional).

- Subsector pecuario: cifras sobre producción pecuaria nacional en forma anualizada y mensual para de 12 productos (carne en canal de bovinos, porcinos, pollo, guajolote, ovinos y caprinos; leche de bovino, leche de caprino, huevo, miel, cera en greña y lana sucia).

- Subsector pesquero: cifras sobre captura nacional en forma anualizada para más de 115 productos.

En lo referente a las actividades agrícolas la información disponible de manera digital data de 1980 y las variables anuales identificadas son:

- Superficie sembrada

- Superficie siniestrada

- Superficie cosechada

- Volumen de producción

- Precio medio rural

- Valor de producción

Para los 50 cultivos de seguimiento mensual, indicados en la Tabla 8.1, los informes datan de 2004 aunque no se publican los precios medios rurales ni el valor de producción. Los datos anuales se pueden consultar también por municipio, lo que no es posible para los avances mensuales. 
Tabla 8.1. Cultivos de seguimiento mensual

\begin{tabular}{|l|l|}
\hline \multicolumn{1}{|c|}{ Cíclicos } & \multicolumn{1}{|c|}{ Perennes } \\
\hline Ajo & Aguacate \\
Ajonjolí & Alfalfa verde \\
Algodón hueso & Cacao \\
Arroz palay & Café cereza \\
Avena forrajera en verde & Caña de azúcar \\
Avena grano & Copra \\
Brócoli & Durazno \\
Calabacita & Esparrago \\
Cártamo & Guayaba \\
Cebada grano & Limón \\
Cebolla & Mango \\
Chile verde & Manzana \\
Coliflor & Naranja \\
Fresa & Nopalitos \\
Frijol & Nuez \\
Lechuga & Papaya \\
Maíz forrajero en verde & Piña \\
Maíz grano & Plátano \\
Melón & Toronja (pomelo) \\
Papa & Uva \\
Pepino & \\
Sandia & \\
Sorgo forrajero en verde & \\
Sorgo grano & \\
Soya & \\
Tabaco & \\
Tomate rojo (jitomate) & \\
Tomate verde & \\
Trigo grano & \\
Zanahoria & \\
\hline
\end{tabular}

Fuente: elaboración propia con información de SIAP-SAGARPA.

Es importante señalar que en México por cultivos cíclicos se conoce a aquellos cuya fase de producción corresponde al ciclo "Otoño-Invierno (OI)" o "Primavera-Verano (PV)", de modo que el primer ciclo inicia con la siembra en el mes de septiembre de un año calendario y termina con la cosecha en septiembre del año siguiente; en tanto que el ciclo PV inicia siembras en abril de un año calendario y termina sus cosechas en marzo del año siguiente; así, el año agrícola (ciclo Otoño-Invierno más ciclo Primavera-Verano) tiene una duración de 18 meses. Y como se podrá apreciar en el diagrama hay un momento en el año calendario en el que las siembras de un ciclo se traslapan 
con el periodo de cosechas de otro. En la siguiente tabla se muestra el calendario agrícola.

Tabla 8.2 Calendario agrícola

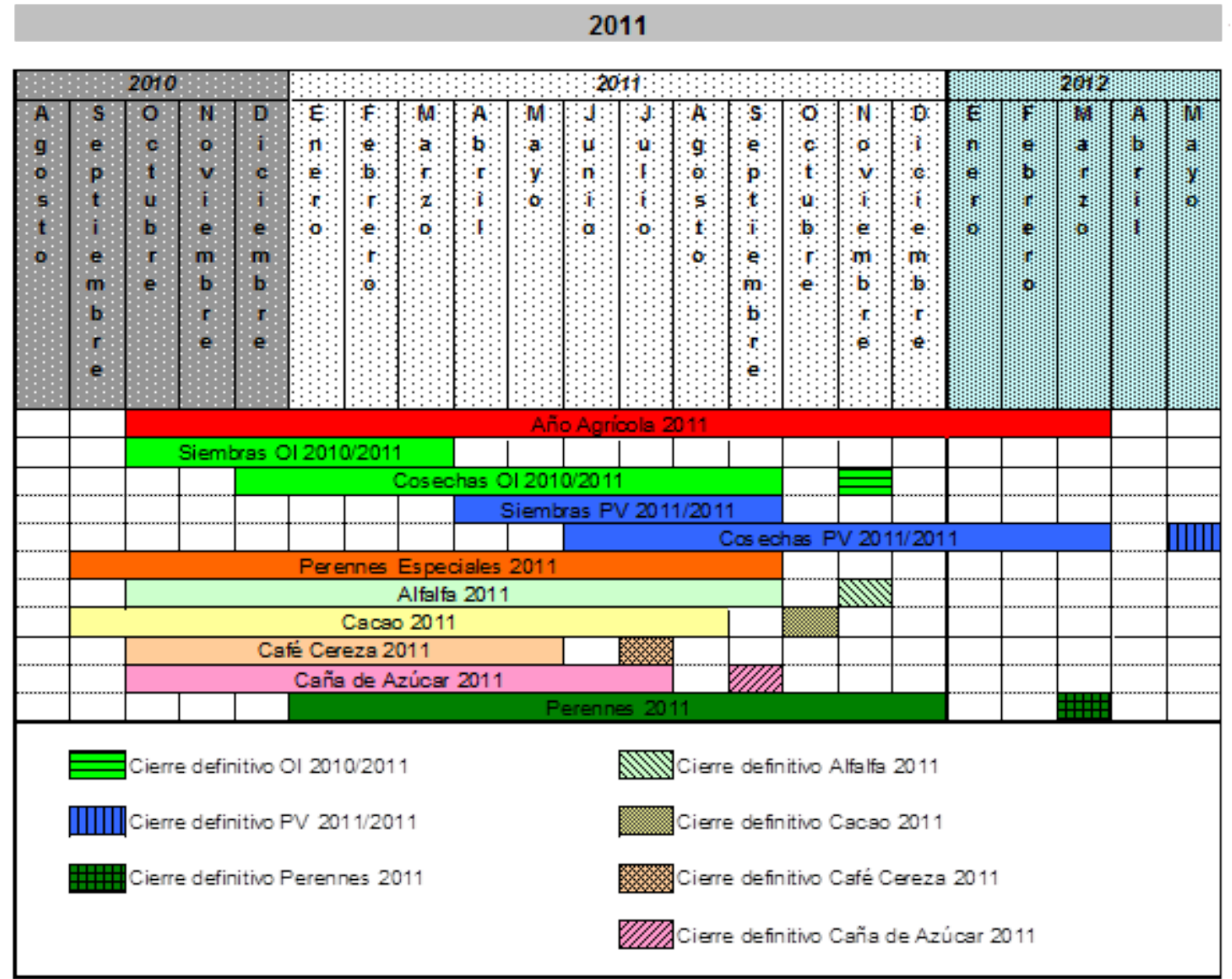

Fuente: elaboración propia con información de SIAP-SAGARPA.

Los productos estacionales son aquellos que no están disponibles en ciertas estaciones del año o bien están disponibles todo el año, pero sus precios o producciones se ven sujetos a fluctuaciones regulares que están sincronizadas con la estación o la época del año.

Existen dos fuentes principales de fluctuaciones estacionales: el clima y los hábitos de consumo de los habitantes.

Al observar los datos de producción de algunos cultivos durante los doce meses del año, a partir del avance de siembras y cosechas del SIAP, se tienen 
algunos comportamientos donde las cifras de la producción de los cultivos aumentan y las cotizaciones promedio de precios de mercado al mayoreo en las principales centrales de abasto del país fluctúan ligeramente a la baja.

Por su parte, los cultivos perennes comúnmente tienen cosechas en el transcurso de los doce meses del año calendario, salvo casos especiales, como el de la caña de azúcar, cacao y café, que comúnmente terminan cosechas antes de llegar a diciembre.

EI SIAP también se encarga de recibir, integrar, procesar y difundir estadísticas relacionadas con el comercio exterior de las actividades agroalimentarias y pesqueras, para lo cual dispone de bases de datos integradas a partir de la estadística que el Servicio de Administración Tributaria (SAT), dependiente de la SHCP, le proporciona diariamente. Las principales variables que publica, de manera mensual, y que se relacionan con las importaciones y exportaciones son: volumen y valor, tanto en pesos como en dólares; país de origen y destino; medio de transporte; y, aduana de entrada y de salida.

Vale la pena señalar que toda la información publicada por el SIAP es gratuita y de acceso para el público en general.

Notas metodológicas sobre precios de principales cultivos comercializados internacionalmente

Se consideran precios internacionales de los principales cultivos comercializados internacionalmente: maíz (amarillo y blanco), trigo, café, soya, frijol (negro y pinto), algodón y azúcar.

Referencia temporal: se consideró una actualización mensual tanto de precios físicos como futuros. Para los precios físicos se consideraron fuentes de información como el BM, para maíz amarillo; el USDA, para maíz blanco; la Bolsa de Chicago (Chicago Mercantile Exchange) para precios de futuros ${ }^{1}$; la Organización Internacional del Café (ICO, por sus siglas en inglés), para precio físico de café; y el mercado para manejo de riesgos, opciones y futuros Intercontinental Exchange (ICE, por sus siglas en inglés). En el caso de 
algunos precios fue necesario emplear factores de conversión, a fin de expresarlos en las mismas unidades de medida.

Notas metodológicas sobre índices de precios pagados al productor en el Estado de México y en el país

Dado que el INEGI, institución encargada de elaborar los índices de precios al productor, sólo los registra a nivel nacional, fue necesario estimar de manera propia los índices estatales para los principales cultivos de la demarcación bajo estudio, los cuales también se obtuvieron a nivel nacional, de modo que la comparación con los índices del INEGI es un referente de la certeza de dicho cálculo personal.

La estimación propia consideró las observaciones metodológicas señaladas por el sistema de cuentas nacionales, en particular:

- Integración de valores corrientes para los cultivos de interés, con sus correspondientes agregaciones.

- Cálculo propio de los valores constantes, a partir de definir como año base a 2007, a pesar de que difiere del año base de INEGI que toma a diciembre de 2003, lo anterior porque la fuente disponible en SIAPSAGARPA no cuenta con información mensual, además de que para los cultivos de interés no se cuenta con información suficiente en 2003.

- Estimación propia de los índices de precios implícitos pagados al productor, a través de relacionar los valores corrientes con los constantes.

El contar con los índices de precios del INEGI, complementados con la estimación propia, da un marco de referencia que permite analizar el comportamiento de los precios pagados al productor a nivel de la entidad, pero sin dejar de lado la referencia de los precios nacionales. Adicionalmente, al analizar precios de plantas y flores es posible evitar las complicaciones que implica hacer uso de distintas unidades de medida para el volumen de producción. La serie mostrada para los precios de plantas y flores es más corta 
que en el caso de otros cultivos, como los cereales, debido a la menor disponibilidad de información, resultado de las menores plantaciones de tales cultivos en el pasado; sin embargo, no puede asociarse la motivación a sembrar plantas y flores sólo a la entrada en vigor del TLCAN, pues tal tendencia se observa desde fines de la década de los años ochenta.

Notas metodológicas sobre el valor de los principales cultivos comercializados por el Estado de México con el resto del mundo

A partir de información preliminar proporcionada por el SAT al SIAPSAGARPA, fue posible efectuar una aproximación del comercio exterior agropecuario y pesquero realizado por entidad federativa en México en el año 2011, registrados en los capítulos uno al catorce catalogados de acuerdo con la clasificación de la Tarifa de los Impuestos Generales de Importación y de Exportación (TIGIE). 


\section{NOTAS}

\section{Capítulo 1}

1 "El Producto Interno Bruto por entidad federativa es un rubro del Sistema de Cuentas Nacionales de México (SCNM). Presenta datos en valores corrientes y constantes, por división industrial y gran división de actividad económica [...] Para evitar confusiones se considerarán como sinónimos el Valor Agregado Bruto y el Producto Interno Bruto, en valores básicos, tal y como sucede en otros países" (Sistema de Cuentas Nacionales del Instituto Nacional de Estadística y Geografía).

\section{Capítulo 2}

1 El Patrón Oro fue un sistema monetario que fijaba el valor de la unidad monetaria en términos de una determinada cantidad de oro. En otras palabras, el emisor de la divisa garantizaba que tenía la capacidad de dar al poseedor de sus billetes, la cantidad de oro estipulada en ellos.

$\underline{2}$ Tratado multilateral creado durante la Conferencia de La Habana celebrada en 1947 y formado al año siguiente. Este acuerdo era parte del plan de regulación de la economía después de la Segunda Guerra Mundial y surgió de la necesidad de establecer normas comerciales y concesiones arancelarias (principalmente la reducción de aranceles según el principio de reciprocidad entre los Estados miembros).

3 La prohibición de importación de alimentos establecida por Rusia se refiere a los siguientes productos: fruta, verdura, carne, pescado, leche y productos lácteos. El Ministerio de Agricultura de España estimó una pérdida de 337 millones de euros durante el veto, que representan el $1.8 \%$ del valor de sus exportaciones agroalimentarias y de los cuales 158 millones son de frutas. Las sanciones impuestas a Rusia por parte de la UE comprenden: la prohibición de la compra-venta de nueva deuda emitida por bancos rusos propiedad del Estado, bancos de desarrollo y sus filiales; un embargo sobre 
armamento o cualquier tecnología que se susceptible de tener uso militar; y, la denegación de licencias de exportación de equipamiento o tecnología para la exploración, o extracción de gas y petróleo.

4 Las barreras no arancelarias son regulaciones políticas de los países que no son precisamente aranceles pero que restringen el comercio. Algunos ejemplos son las medidas sanitarias y fitosanitarias, los obstáculos técnicos al comercio, las medidas en materia de inversiones relacionadas con el comercio, las valoraciones e inspecciones en aduana, las normas de origen y el trámite de licencias de importación. Para mayor información consultar los textos jurídicos de la OMC.

5 Por Decreto Presidencial del 3 de enero de 1992, publicado en el Diario Oficial de la Federación el día 6 del mismo mes y año, se declara reformado el párrafo tercero y las fracciones IV; VI, Primer Párrafo; VII; XV y XVII; adicionados los párrafos Segundo y Tercero de la fracción XIX; y derogadas las fracciones X a XIV y XVI, del articulo 27 de la Constitución Política de los Estados Unidos Mexicanos. Esta reforma eleva a rango constitucional la propiedad ejidal y comunal de la tierra, regulando su aprovechamiento y permitiendo la participación de las sociedades civiles y mercantiles en el campo. (DOF 1992)

6 Las desventajas del sistema de pagos directos serían observadas y analizadas posteriormente. Las familias cuyos ingresos dependen de la agricultura difícilmente tienen sus necesidades básicas cubiertas. Como consecuencia de la ubicación de sus hogares será complicado que accedan a los servicios públicos elementales. Ante esta situación, los apoyos directos no se recomiendan debido a que las cantidades monetarias entregadas por el gobierno no son utilizadas en la producción de sus tierras, sino en garantizarles casa, comida y sustento. Por tanto, se considera un sistema de apoyo al campo ineficiente porque no contribuye a aumentar la productividad del mismo. 


\section{Apéndice estadístico}

1 Los precios futuros se refieren al recio por unidad de activo subyacente acordado en un contrato de futuro en la fecha de celebración. Este se ajustará diariamente para efecto de reflejar las pérdidas y ganancias que registre el precio del subyacente. Las operaciones de los precios futuros se realizan a través de una Sociedad Anónima denominada MexDer, mercado Mexicano de Derivados, S.A. de C.V., que tiene por objeto proveer las instalaciones y demás servicios necesarios para la cotización y negociación de los contratos de futuros y contratos de opciones. Por su parte, un subyacente es un bien o índice de referencia, objeto de un Contrato de Futuro o de un Contrato de Opción, concertado en la Bolsa de Derivados. Los precios de los productos derivados son una función de los precios del valor de referencia. Estos pueden ser: títulos representativos de capital o deuda, índices, tasas y otros instrumentos financieros. También se denomina valor de referencia (Bolsa Mexicana de Valores 2007). 


\section{BIBLIOGRAFÍA}

- Acosta Martínez, Ana Isabel y Carlos Álvarez Aledo (2005) "Integración comercial de la agroindustria mexicana en el marco del Tratado de Libre Comercio de América del Norte". Disponible en línea en: http://www.uabc.mx/iis/ref/REFvol6num11/EFVOL6N11-4.pdf (Consultado el 6 de agosto de 2014).

- Amin, Samir (2002), El capitalismo en la era de la globalización. Barcelona: Paidós.

- Arámbula Reyes, Alma y Gabriel Mario Santos Villareal (2008) La crisis alimentaria mundial. México: Cámara de Diputados, LX Legislatura, Centro de Documentación, información y análisis.

- Balassa, Béla. (1961) The Theory of Economic Integration. Homewood, IL: R.D. Irwin.

-Barros, Magdalena (2000) From Maize to Melons: Struggles and Strategies of Small Mexican Farmers. Ámsterdam: Center for Latin American Research and Documentation (CEDLA).

-Banerjee, A., Dolado, J. J. and Galbraith, J. W. (1990) Recursive and sequential tests for unit roots and struc- tural breaks in long annual GNP series, Discussion Paper 9010, Banco de España.

- Bhargava, A. (1986) On the theory of testing for unit roots in observed time series, Review of Economic Studies 53, 369-84.

- BM (Banco de México) (2008) Informe anual. México: BM.

- BM (Banco de México) (2009), Informe anual. México: BM.

-BM (Banco de México) (2010), Informe anual. México: BM.

- BM (Banco de México) (2011), Informe anual. México: BM.

- BM (Banco de México) (2012), Informe anual. México: BM.

- BM (Banco de México) (2013), Informe anual. México: BM.

-Bovin, Philippe (1996), El campo mexicano: una modernización a marchas forzadas. México: Centro Francés de Estudios Mexicanos y Centroamericanos, Institut Française de Recherche Scientifique pour le Développement en Coopération (ORSTOM). 
- Cámara de Diputados, LVII Legislatura, Comisión de Agricultura (2000) ¿Cuánta liberalización aguanta la agricultura? Impacto del TLCAN en el sector agroalimentario. México: Universidad Autónoma de Chapingo, Centro de Estudios para el Cambio en el Campo Mexicano (CIESTAAM).

- Cámara de Diputados (2008) Distribución del ingreso y desigualdad en México: un análisis sobre la ENIGH 2000-2006. Disponible en línea en: http://www.cefp.gob.mx/intr/edocumentos/pdf/cefp/2008/cefp0092008.pdf (Consultado el 4 de mayo de 2009). México: Centro de Estudios de las Finanzas Públicas.

- Cárdenas, Enrique (2003) La política económica en México, 1950-1994. México: FCE.

- Centro de Estadística Agropecuaria (1997) Programas y Proyectos en apoyo al Campo 1996. México: Secretaria de Agricultura, Ganadería y Desarrollo Rural. - Centro de Estudios de las Finanzas Públicas (CEFP) (2007) El Proceso de Desgravación Arancelaria del Maíz y el Frijol en el Marco del TLCAN, 19942008. Disponible en línea en: www.cefp.gob.mx/intr/edocumentos/pdf/cefp/cefp0592007.pdf (Consultado el 17 de novimebre de 2008).

- Centro de Estudios Económicos del Sector Privado (CEESP) (2003) La apertura comercial en el sector agropecuario. Disponible en línea en: www.fidamerica.org/admin/docdescargas/centrodoc/ centrodoc_990.pdf (Consultado el 17 de noviembre de 2008).

- Centro de Estudios para el Desarrollo Rural Sostenible y la Soberanía Alimentaria (SEDRSSA) (2008) Reporte Rural de Coyuntura: Tratado de Libre Comercio de América del Norte (TLCAN). Disponible en línea en: www.cedrssa.gob.mx/includes/asp/

download. asp?iddocumento=1633\&idurl=2165 (Consultado el 17 de novimebre de 2008).

- Clavijo, Fernando (2000) Reformas Económicas en México: 1982-1999. México: FCE.

- Contreras Castillo, José María (2005) La eliminación de los subsidios a las exportaciones agrícolas: implicaciones para México. Comercio exterior 55 (2). 
- De Albuquerque David, Maria Beatriz (2000) The Impact of the New Economic Model on Latin America's Agriculture. London: World Development 28 (9).

- De Janvry, Alain (et. all.) (1995) NAFTA and Mexico's Maize Producers. London: World Development 23 (8).

- De la Calle Pardo, Luis Fernando (2008) Política Agropecuaria a 15 años del TLCAN. México: Revista Mundo Rural 8.

- De la Reza, Germán y Raúl Conde (coord.) (1999) Nuevas dimensiones de la integración. Del TLCAN al regionalismo hemisférico. México: Plaza y Valdés Editores.

- De Janvry, Alain (et all.) (1997) Agricultural and Rural Development Policy in Latin America: New Directions and New Challenges. California Agricultural Experiment Station, Documento de Trabajo núm. 815 de la Fundación Gianni de Economía Agrícola, Departamento de Economía Agrícola y de los Recursos. Berkeley: Universidad de California.

- DOF (Diario Oficial de la Federación) (1992,6 de enero) Decreto por el que se reforma el artículo 27 de la Constitución Política de los Estados Unidos Mexicanos. Disponible en línea en: http://dof.gob.mx/nota_detalle.php?codigo $=4643312 \&$ fecha $=06 / 01 / 1992$ (Consultado el 9 de agosto de 2014).

- DOF (Diario Oficial de la Federación) (2001, 7 de diciembre) Ley de Desarrollo Rural Sustentable. Disponible en línea en: http://www.ordenjuridico.gob.mx/Federal/Combo/L-25.pdf (Consultado el 2 de mayo de 2009).

• "EEUU y la UE endurecen sanciones a Rusia", Elpaís.com. Disponible en línea en:http://internacional.elpais.com/internacional/2014/07/29/actualidad/1406 647337_984548.html (Consultado del 13 e agosto de 2014).

- Elliott, G., Rothenberg, T. J. and Stock, J. H. (1996) Efficient tests for an autoregressive unit root, Econometrica 64, 813-36.

- "España perderá 337 millones por las restricciones rusas a la importación", ABC.es. Disponible en línea en: http://www.abc.es/economia/20140808/abcirestricciones-rusas-importacion-supondran-201408081349.html (Consultado el 13 de agosto de 2014). 
- FAO (Organización de las Naciones Unidas para la Agricultura y la Alimentación) (2008) Crop Prospects and Food Situation, No. 5. Disponible en línea en: http://www.fao.org/docrep/ 011/ai476e/ai476e04.htm (Consultado el 2 de marzo de 2009).

- FAO (Organización de las Naciones Unidas para la Agricultura y la Alimentación) (2008a), Soaring food prices: Facts, perspectives, impacts and actions required, HLC/08/INF/1. Disponible en línea en: http://www.fao.org/foodclimate (Consultado el 2 de marzo de 2009).

- FAO (Organización de las Naciones Unidas para la Agricultura y la Alimentación) (2011) Volatilidad de os precios y seguridad alimentaria. Disponible en línea en: http://www.fao.org/fileadmin/user_upload/hlpe/hlpe_documents/HLPEInforme-1-volatilidad-de-los-precios-Julio-2011.pdf (Consultado el 1 de septiembre de 2014).

- FAO (Organización de las Naciones Unidas para la Agricultura y la Alimentación) (2011a) Food Outlook. Global Market Analysis.

- Farooki, Masuma y Raphael Kaplinsky (2012) The Impact of China on Global Commodity Prices: The global reshaping of the resource sector. Reino Unido: Routledge.

- FMI (Fondo Monetario Internacional) (2009) Manual de la balanza de pagos y posición de inversión internacional. Washington DC: FMI.

-Fox, Vicente (2005a) IV Informe de Gobierno. México: Presidencia de la República.

- Fox, Vicente (2005b) IV Informe de Gobierno. Anexo Estadístico. México: Presidencia de la República.

- Ghoshray, Atanau (2011) A reexamination of trends in primary commodity prices, Journal of Development Economics 95.

- Gómez Cruz, Manuel Ángel y Rita Schwentesius Rindermann (2004) "Impacto del TLCAN en el sector agroalimentario: evaluación a 10 años". En Schwentesius Rindermann, Rita (et.all.) (2004) ¿El campo aguanta más?, México: CIESTAAM y La Jornada. 
- González García, Juan (1998) La difícil integración de América Latina con el Pacífico Asiático, Comercio Exterior 48 (11).

- Hull, John C. (2009) Introducción a los mercados de futuros y opciones, México: Pearson Education Inc.

- Hussain, Imtiaz (ed.) (2008) Community, Diffusion and North American Expansiveness: The political economy of flux. México: Universidad Iberoamericana.

- INEGI (Instituto Nacional de Estadística y Geografía) (2009) Resultados del VII Censo Agrícola, Ganadero y Forestal. México: INEGI.

- INEGI (Instituto Nacional de Estadística y Geografía) (2010) Agenda estadística de los Estados Unidos Mexicanos 2010. México: INEGI.

- INEGI (Instituto Nacional de Estadística y Geografía) (2011a) Documento Metodológico del Índice Nacional de Precios al Consumidor. México: INEGI.

- INEGI (Instituto Nacional de Estadística y Geografía) (2011b) Documento Metodológico del Índice Nacional de Precios al Productor. México: INEGI.

- INEGI (Instituto Nacional de Estadística y Geografía) (2013) Anuario estadístico y geográfico del Estado de México 2013. México: INEGI.

- INEGI (Instituto Nacional de Estadística y Geografía) Índices Nacionales de Precios. Disponible en línea en: http://www.inegi.org.mx/est/contenidos/proyectos/inp/Presentacion.aspx (Consultado el 1 de septimebre de 2014).

- Jager, Henk y Catrinus Jepma (2011) Introduction to International Economics. Reino Unido: Palgrave Macmillan.

- Krugman, Pau R. y Maurice Obstfeld (2008) Economía Internacional. Teoría y política. Madrod: Pearson.

- Lasa, Alcides José (1992) Tres años de política de estabilización concertada en México, 1988-1990. Revista Investigación Económica, 201.

- Lawrence, Robert Zachary (1996) Regionalism, Multilateralism and Deeper Integration. Washington, DC: Brookings Institution.

- Lechuga Montenegro, Jesús (2006) La Estructura Agraria de México. Un análisis de largo plazo. México: Universidad Autónoma Metropolitana. 
- Lumsdaine, R. L. and Papell, D. H. (1997) Multiple trend breaks and the unitroot hypothesis, The Review of Economics and Statistics 79, 212-18.

- Mackinnon, J. G. (1996) Numerical distribution functions for a unit root and cointegration test. Journal of Applied Econometrics, 11.

- Maydon Garza, Marín y Luis H. Villalpando (1982) Estructura Económica y los Índices de Precio Productor. México: Banco de México.

- Muñoz de Bustillo, Rafael y Rafael Bonete (2009) Introducción a la Unión Europea: un análisis desde la economía. Madrid: Alianza Editorial.

- Ng, S. and Perron, P. (2001) Lag selection and the construction of unit root tests with good size and power, Econometrica 69, 1519-54.

-Norton, Roger D. (2004) Política de Desarrollo Agrícola. Conceptos y principios. Roma: FAO.

- OMC (Organización Mundial del Comercio) (1994) Acuerdo relativo a la aplicación del artículo VI del Acuerdo General sobre Aranceles Aduaneros y Comercio de 1994. Disponible en línea en: http://www.wto.org/spanish/docs_s/legal_s/19-adp.pdf (Consultado el 9 de agosto de 2014).

- OMC (Organización Mundial del Comercio) (1994b) Acuerdo sobre salvaguardias. Disponible en línea http://www.wto.org/spanish/docs_s/legal_s/25-safeg.pdf (Consultado el 9 de agosto de 2014).

- OMC (Organización Mundial del Comercio) (1994c) Acuerdo sobre subvenciones y medidas compensatorias. Disponible en línea en: http://www.wto.org/spanish/docs_s/legal_s/24-scm.pdf (Consultado el 9 de agosto de 2014).

- OMC (Organización Mundial del Comercio) Textos Jurídicos. Disponible en línea

en:

http://www.wto.org/spanish/docs_s/legal_s/legal_s.htm \#wtoagreement (Consultado el 9 de agosto de 2014).

- Perron, P. (1989) The great crash, the oil price shock and the unit root hypothesis, Econometrica 57, 1361-401. 
- Perron, P. (1997) Further evidence from breaking trend functions in macroeconomic variables, Journal of Econometrics 80, 355-85.

- Perron, P. and Ng, S. (1996) Useful modifications to some unit root test with dependent errors and their local asymptotic properties, Review of Economics Studies 63, 435-65.

- Perron, P. and Rodrıguez, G. (2003) GLS detrending, efficient unit root tests and structural change, Journal of Econometrics, 115, 1-27.

-Phillips, P. C. B. (1987) Time series regression with a unit root, Econometrica 55, 311-40.

-Phillips, P. C. B. and Perron, P. (1988) Testing for a unit root in time series regresions, Biometrika 75, 335-46.

- Puyana, Alicia y José Romero (2004) Diez años con el TLCAN. Las experiencias del sector agropecuario mexicano. México: Colegio de México.

- Ramos Francia, Manuel y Daniel Chiquiar Cikurel (2004) La transformación del patrón del comercio exterior mexicano en la segunda mitad del siglo XX, Comercio Exterior 54 (6).

- Robles Berlanga, Héctor Manuel (2007) El Sector Rural en el siglo XXI. Un mundo de Realidades y Posibilidades. México: Cámara de Diputados, LX Legislatura.

- Romero Polanco, Emilio (2002) Un siglo de agricultura en México. México: Universidad Nacional Autónoma de México.

- Rubio, Blanca (2004) La fase agroalimentaria global y su repercusión en el campo mexicano. Comercio exterior 54 (11).

- Salama, Pierre y Jacques Valier (1992) Políticas liberales y fin de los procesos hiperinflacionarios. Revista Investigación Económica 201.

- SAGARPA (Secretaria de Agricultura, Ganadería, Desarrollo Rural, Pesca y Alimentación) (2005) Sistema de Información Agropecuaria de Consulta. México: SIACON.

- SAgARPA (Secretaria de Agricultura, Ganadería, Desarrollo Rural, Pesca y Alimentación) (2007) Normatividad para integrar, validar, analizar y enviar estadísticas agrícolas mediante el módulo agrícola. 
- SAgARPA (Secretaria de Agricultura, Ganadería, Desarrollo Rural, Pesca y Alimentación) (2011), Quinto Informe de Labores.

- SAGARPA (Secretaria de Agricultura, Ganadería, Desarrollo Rural, Pesca y Alimentación) (2011a), Convocatoria Pro-Oleaginosas, Yucatán.

-Sain, Gustavo y Miguel A. López Pereira (1999) Maize Production and Agricultural Policies in Central America and Mexico. México: Centro Internacional de Mejoramiento de Maíz y Trigo (CIMMYT).

- Salinas de Gortari, Carlos (1987) Producción y participación política en el campo. México: Fondo de Cultura Económica.

-Schiff, Maurice y Alberto Valdés (1998) Agriculture and the Macroeconomy. Disponible en línea en: http://elibrary.worldbank.org/doi/pdf/10.1596/18139450-1967 (Consultado el 4 de agosto de 2014).

-Schwentesius Rindermann, Rita (et. al.) (coord) (1996) TLC y agricultura: ¿Funciona el experimento?. México: Universidad Autónoma de Chapingo.

- SEMARNAT (Secretaria de Medio Ambiente y Recursos Naturales) (2003) Informe de la Situación del Medio Ambiente en México. México.

- Servicio de Información Agroalimentaria y Pesquera (2008) Comercio exterior de granos forrajeros. Disponbile en línea en: http://www.siap.sagarpa.gob.mx/ventana.php?idLiga $=1346 \&$ tipo $=1$ (Consultado el 1 de mayo de 2009).

- Suárez Carrera, Víctor (2008) Políticas Públicas para la agricultura mexicana con base en el consenso y la certidumbre: el caso de la Ley de Planeación para la Soberanía y la Seguridad Agroalimentaria y Nutricional. México: ANEC-ITACA.

- Tinbergen, Jan. (1954) International Economic Integration. Amsterdam: Elsevier.

- USDA (Departamento de Agricultura de los Estados Unidos) (2012) Agricultural Projections. February.

- Viner, Jacob (1950) The Customs Union Issue. New York: The Carnegie Endowment for International Peace.

- Von Bertrab, Alejandro (2004) El efecto de la liberalización económica en los pequeños productores de maíz en México. Disponible en línea en: 
http://revistas.bancomext.gob.mx/rce/magazines/70/2/von_Bertrab-NOV.pdf (Consultado el 15 de abirl de 2009).

-Warman, Arturo (2001) El campo mexicano en el siglo XX. México: Fondo de Cultura Económica.

- Ysusi Carla (2010) Comportamiento de los Precios al Consumidor en México bajo un Esquema de Objetivos de Inflación: un enfoque usando micro datos, México: Banco de México.

-Zivot, E. and Andrews, D. W. K. (1992) Further evidence on the Great crash, the oil price shock and the unit root hypothesis, Journal of Business and Economic Statistics 10, 251-70.

\section{SITIOS WEB}

- Sistema de Cuentas Nacionales del Instituto Nacional de Estadística y Geografía (INEGI):

http://www.inegi.org.mx/est/contenidos/proyectos/scn/default.aspx 


\section{GLOSARIO}

- Acuerdo General sobre Aranceles Aduaneros y Comercio (GATT, por sus siglas en inglés)

- Acuerdo General sobre el Comercio de Servicios (GATS por sus siglas en inglés)

- Acuerdo sobre los Aspectos de los Derechos de Propiedad Intelectual relacionados con el Comercio (TRIPS por sus siglas en inglés)

- Acuerdos de Intercambio Comercial (RTAs por sus siglas en inglés)

- Aseguradora Nacional Agrícola y Ganadera, S.A. (ANAGSA)

- Asociación de Naciones del Sudeste Asiático (ASEAN por sus siglas en inglés)

- Asociación Latinoamericana de Integración (ALADI)

- Asociación Latinoamericana de Libre Comercio (ALALC)

- Banco de México (Banxico)

- Banco Mundial (BM)

- Banco Nacional de Crédito Rural (Banrural)

- Bolsa de Chicago (Chicago Mercantile Exchange) (CME)

- Bolsa de Nueva York (New York Mercantile Exchange) (NYMEX)

- Centro de Estudios para el Desarrollo Rural Sustentable y la Soberanía Alimentaria (CDRESSA)

- Central de Equipo y Maquinaria Mexiquense (CEMMEX)

- Centros de Apoyo al Desarrollo Rural (CADER)

- Comisión Coordinadora para el Desarrollo Agrícola y Ganadero del Estado de México (CODAGEM)

- Comisión de Apoyos y Servicios a la Comercialización Agropecuaria del Estado de México (CASERCAMEX)

- Comisión Económica para América Latina y el Caribe (CEPAL)

- Comisión Federal para la Protección de Riesgos Sanitarios (COFEPRIS)

- Compañía Nacional de Subsistencias Populares (CONASUPO)

- Consejo de Cooperación Económica del Pacífico (PECC)

- Consejo Económico de la Cuenca del Pacífico (PBEC) 
- Departamento de Agricultura de los Estados Unidos (USDA, por sus siglas en inglés)

- Distritos de Desarrollo Rural (DDR)

- Encuesta Nacional de Ingresos y Gastos de los hogares (ENIGH)

- Fideicomiso para el Desarrollo Agroindustrial del Estado de México (FAIDEM)

- Fideicomisos Instituidos en Relación con la Agricultura (FIRA)

- Fondo de Fomento Económico (FOMEC)

- Foro de Cooperación Económica Asia-Pacífico (APEC)

- Índices Nacionales de Precios (INP)

- Índice Nacional de Precios al Consumidor (INPC)

- Índice Nacional de Precios al Productor (INPP)

- Instituto de Desarrollo Agrícola y Ganadero del Estado de México (DAGEM)

- Instituto de Investigación y Capacitación Agropecuaria, Acuícola y Forestal del Estado de México (ICAMEX)

- Instituto Nacional de Estadística y Geografía (INEGI)

- Instituto Nacional de Investigaciones Agropecuarias (INIFAP)

- Intercontinental Exchange (ICE, por sus siglas en inglés)

- Mercado Común de África Oriental y Austral (COMESA por sus siglas en inglés)

- Mercado Común del Sur (MERCOSUR)

- Modernización Sustentable de la Agricultura Tradicional (MasAgro)

- Nación más Favorecida (MFN por sus siglas en inglés)

- Organización de las Naciones Unidas para la Alimentación y la Agricultura (FAO, por sus siglas en inglés)

- Organización Internacional del Café (ICO, por sus siglas en inglés)

- Organización Mundial del Comercio (OMC)

- Organización para la Cooperación y el Desarrollo Económicos (OCDE)

- Pacto de Solidaridad Económica (PSE)

- Política Agrícola Común (PAC)

- Producto Interno Bruto (PIB) 
- Programa de Apoyos Directos al Campo (Procampo)

- Programa Nacional de Desarrollo Rural Integral (PRONADRI)

- Protectora de Bosques del Estado de México (PROBOSQUE)

- Protectora e Industrializadora de Bosques (PROTINBOS)

- Ronda de Uruguay (RU)

- Secretaría de Agricultura, Ganadería, Desarrollo Rural, Pesca y Alimentación (SAGARPA)

- Secretaría de Economía (SE)

- Secretaría de la Función Pública (SFP)

- Secretaría de Hacienda y Crédito Público (SHCP)

- Servicio de Administración Tributaria (SAT)

- Servicio de Información Agroalimentaria y Pesquera (SIAP)

- Servicio Nacional de Sanidad, Inocuidad y Calidad Agroalimentaria (SENASICA)

- Tarifa de los Impuestos Generales de Importación y de Exportación (TIGIE)

- Tasas Medidas Anuales de Crecimiento (TMAC)

- Tipo de Cambio Real (TCR)

- Tratado de Libre Comercio de América del Norte (TLCAN)

- Unión Europea (EU por sus siglas en inglés)

- Zona de libre comercio (FTA por sus siglas en inglés) 